\title{
Archaeological Survey of Huntsville State Park and Excavations in 41WA47 Walker County, Texas
}

Russell D. Greaves

Follow this and additional works at: https://scholarworks.sfasu.edu/ita

Part of the American Material Culture Commons, Archaeological Anthropology Commons, Environmental Studies Commons, Other American Studies Commons, Other Arts and Humanities Commons, Other History of Art, Architecture, and Archaeology Commons, and the United States History Commons

Tell us how this article helped you.

This Article is brought to you for free and open access by the Center for Regional Heritage Research at SFA ScholarWorks. It has been accepted for inclusion in Index of Texas Archaeology: Open Access Gray Literature from the Lone Star State by an authorized editor of SFA ScholarWorks. For more information, please contact cdsscholarworks@sfasu.edu. 


\section{Archaeological Survey of Huntsville State Park and Excavations in 41WA47 Walker County, Texas \\ Creative Commons License \\ (c) (1) (8)}

This work is licensed under a Creative Commons Attribution-NonCommercial 4.0 International License 


\title{
Archaeological SURVEY:
}

\author{
of \\ HUNTSVILLE STATE PARK \\ and \\ EXCAVATIONS IN 41 WA47
}

Walker County, Texas

\author{
by \\ Russell D. Greaves
}

with Contributions by

J. Philip Dering, Richard B. Mahoney,

Barbara A. Meissner, Raymond P. Mauldin, Susan C. Mulholland, Steve A. Tomka, Marybeth S. F. Tomka, and Jason D. Weston

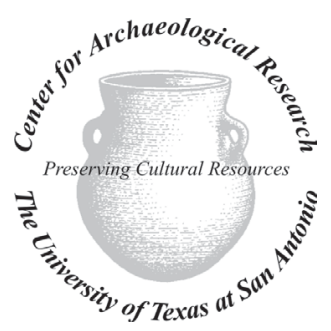

Center for Archaeological Research The University of Texas at San Antonio Archaeological Survey Report, No. 327 

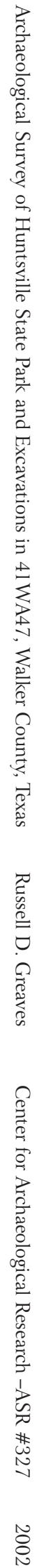


\title{
Archaeological Survey of Huntsville State Park and Excavations in 41WA47, Walker County, Texas
}

\author{
by \\ Russell D. Greaves
}

with Contributions by

\begin{abstract}
J. Philip Dering, Richard B. Mahoney,
Barbara A. Meissner, Raymond P. Mauldin, Susan C. Mulholland, Steve A. Tomka, Marybeth S. F. Tomka, and Jason D. Weston
\end{abstract}

Texas Antiquities Committee Permit No. 2610

Russell D. Greaves and Raymond P. Mauldin

Principal Investigators

Prepared for:

Texas Parks and Wildlife Department

4200 Smith School Road

Austin, Texas
Prepared by:

Center for Archaeological Research

The University of Texas at San Antonio

Archaeological Survey Report, No. 327 
The following information is provided in accordance with the General Rules of Practice and Procedure, Chapter 41.11 (Investigative Reports), Texas Antiquities Committee:

1. Type of investigation: Survey and mitigation

2. Project name: Huntsville State Park (41WA47)

3. County: Walker

4. Principal investigators: Russell D. Greaves and Raymond P. Mauldin

5. Name and location of sponsoring agency: Texas Parks and Wildlife Department, 4200 Smith School Rd., Austin, Texas, 78744-3292

6. Texas Antiquities Permit No.: 2610

7. Published by the Center for Archaeological Research, The University of Texas at San Antonio, 6900 N. Loop 1604 W., San Antonio, Texas 78249-0658, 2002

A list of publications offered by the Center for Archaeological Research is available. Call (210) 458-4378; write to the Center for Archaeological Research, The University of Texas at San Antonio, 6900 N. Loop 1604 W., San Antonio, Texas 78249-0658; e-mail to car@ lonestar.utsa.edu; or visit CAR's web site at http://car.utsa.edu. 


\section{Abstract:}

Two archaeological field efforts were performed at Huntsville State Park, Walker County, Texas in May and July 2001. An archaeological survey examined the areas to be impacted by rehabilitation and expansion of roads, parking areas, campground pullouts, and utilities (160 acres/65 ha). Additional testing and limited mitigation was performed at 41WA47, a previously identified archaeological site. This work was conducted by the Center for Archaeological Research, The University of Texas at San Antonio in contractual agreement with Texas Parks and Wildlife Department (TPW) under Texas Antiquities Permit No. 2610.

During the archaeological survey, three previously unidentified sites (41WA264, 41WA265, and 41WA266) were recorded. None of these appear to merit designation as official State Archeological Landmarks (SAL) or listing in the National Register of Historic Places (NRHP). No additional archaeological testing is recommended for these sites.

Shovel testing conducted in the vicinity of a previously recorded site, 41WA228, identified a significantly larger site extent. Archaeological materials from shovel tests here were moderately abundant and extended to the basal depths of testing ( $\sim 60 \mathrm{~cm}$ below ground surface) in several of the units. However, at least a portion of the existing cultural material on-site has been severely impacted by previous road construction and park facilities improvements. Given the increased site size, the SAL and NRHP eligibility of the site remains unknown. While the proposed road improvements will impact the cultural deposits falling in the immediate vicinity of the road, it is recommended that TPW Cultural Resource Coordinator, Art Black, monitor construction within the impact area and halt work if and/or when cultural deposits and features are encountered -to evaluate the nature and significance of the deposits in consultation with the Texas Historical Commission.

The second portion of archaeological field efforts, the examination of site 41WA47, involved three work efforts: 1) shovel testing was performed to assess the previously identified boundaries of the site, locate deep deposits that have not been subject to extensive erosion, and produce additional information about spatial variation in the archaeological deposit; 2) a 28-m (92-ft) long backhoe trench was excavated to provide geomorphic and stratigraphic information about site formation and cultural deposition; and, 3) controlled excavation of nineteen 1 x 1-m units was performed in four areas of the site as a limited mitigation effort. Charcoal samples from one block excavation produced a chronosequence of six AMS dates, indicating multiple occupations between 1900-1500 BP (AD 50-450) and 500400 вр (АD 1450-1550). Abundant lithics ( $\mathrm{n}=3,717)$ included a large number of diagnostic projectile points $(\mathrm{n}=36)$. Ceramics $(\mathrm{n}=471)$ and highly fractured bone $(\mathrm{n}=1,264)$ also were relatively abundant. Excavation data strongly suggest good to high integrity of these deposits. Paleobotanical recovery identified charcoal, carbonized hickory nutshells, and abundant but heavily weathered phytoliths. The site has already been designated a SAL. Results of this investigation indicate 41 WA 47 possesses a very significant potential for research on site formation, multiple occupation dynamics, technology, and subsistence.

The proposed road construction will affect several portions of 41WA47. Erosion caused by park facility construction and maintenance has impacted parts of the site. Heavy park visitation has also initiated significant erosion around camping facilities located within the site. Because of the scientific value of 41 WA47 and the ongoing degradation, the following actions are recommended to protect the significant cultural deposits of the site: 1) Remove campground pullouts 63, 64, and 65 from camping use and return those areas to a natural state; 2) Prevent the digging of temporary barbecue/roasting pits by park visitors restricting fires to designated fire rings and barbecue stands, and restrict ash and charcoal disposal to designated areas; and, 3) Identify erosion control measures for the site to stabilize the ground surface preventing further erosion and impact to the buried deposits. 


\section{Table of Contents:}

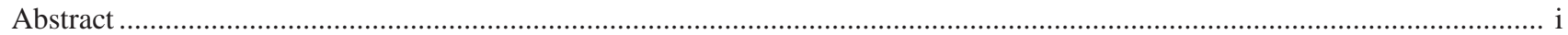

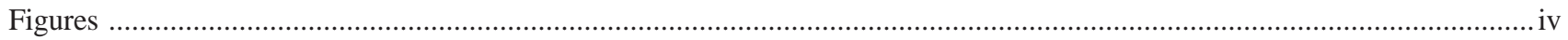

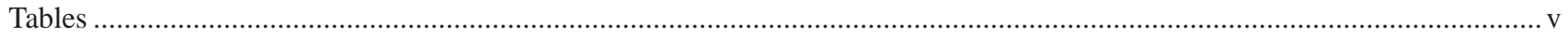

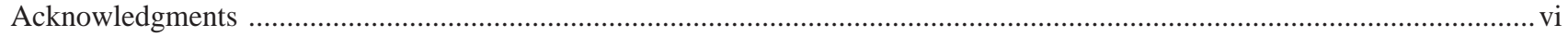

Chapter I: Introduction by Russell D. Greaves

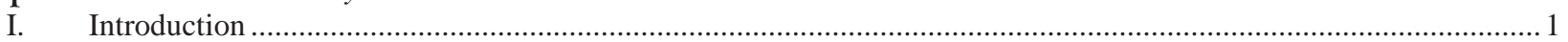

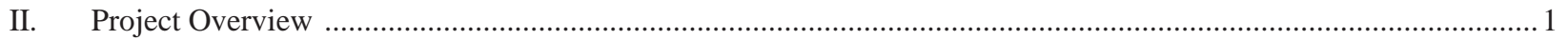

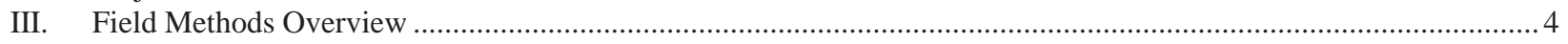

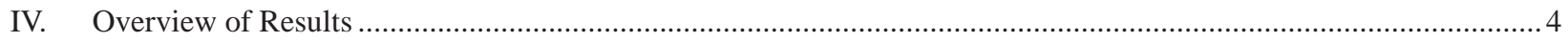

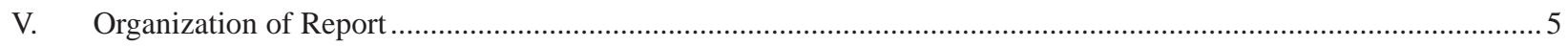

Chapter 2: Scope of Work \& Research Design by Russell D. Greaves

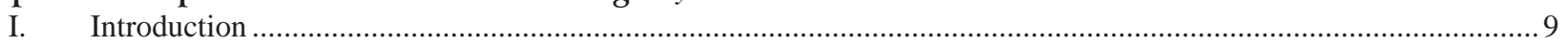

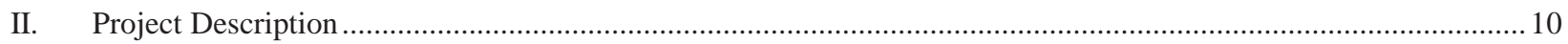

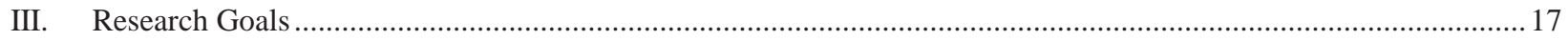

Chapter 3: Archaeological Background by Richard B. Mahoney

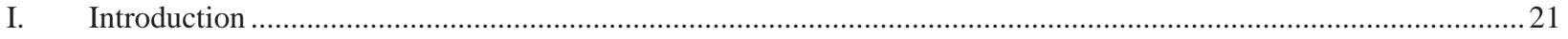

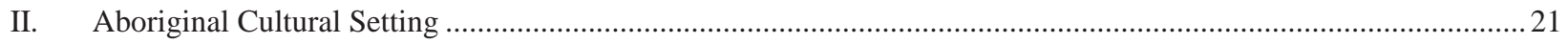

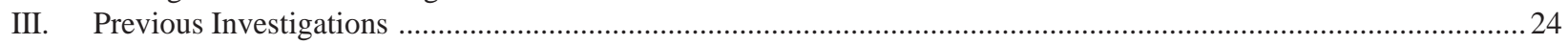

Chapter 4: Archaeological Survey by Russell D. Greaves

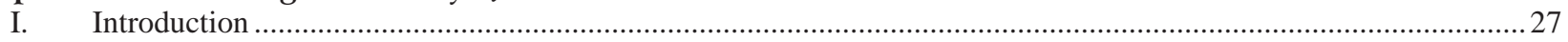

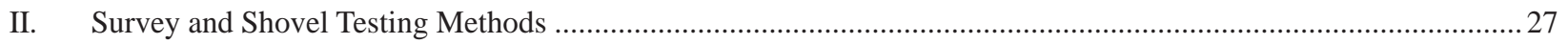

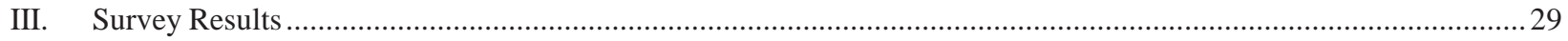

IV. Recommendations Regarding Archaeological Sites within the Survey Parcels .................................................34

Chapter 5: Excavations in 41WA47 by Russell D. Greaves, Marybeth S. F. Tomka, Steve A. Tomka \& Jason D. Weston

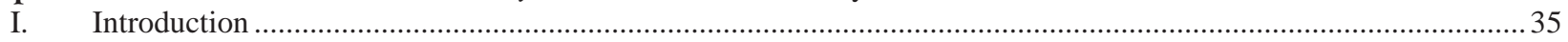

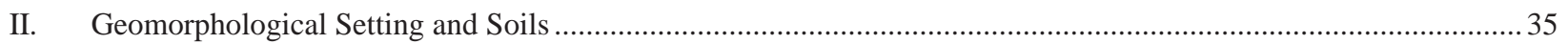

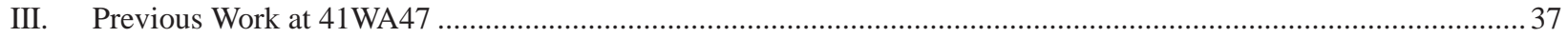

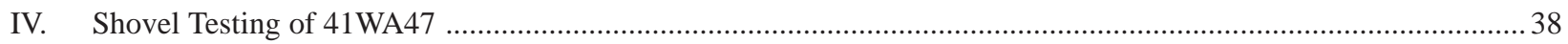

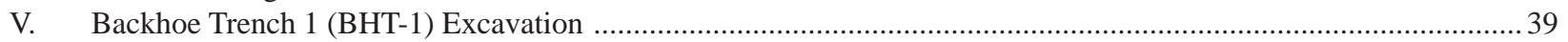

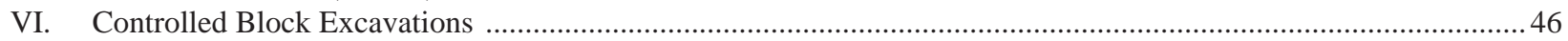

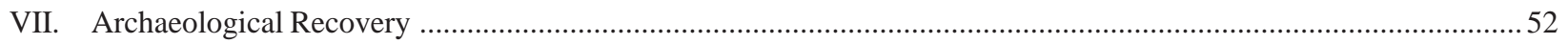

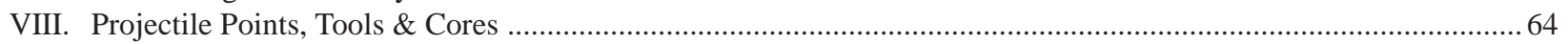

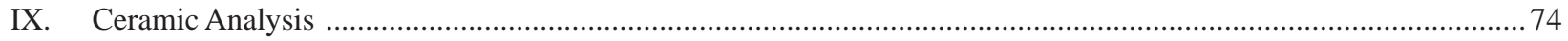

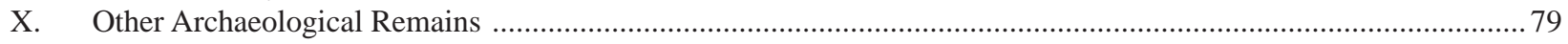

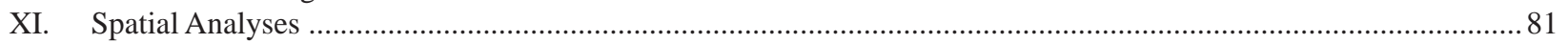

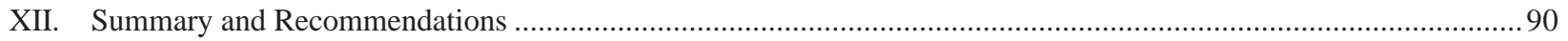

Chapter 6: Summary \& Recommendations by Russell D. Greaves

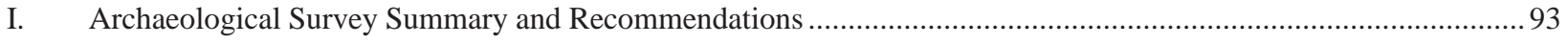

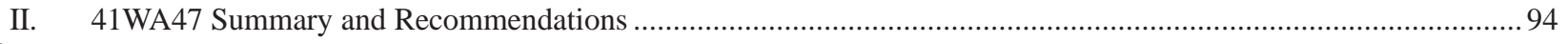

\section{References}

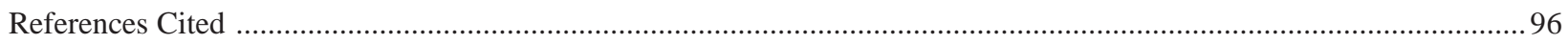

Appendix A: Plant Remains from 41 WA47 by J. Philip Dering

Plant Remains from 41WA47.

Appendix B: Scan of Phytoliths from 41WA47 by Susan C. Mulholland

Scan of Phytoliths from 41WA47.....

Appendix C: Vertebrate Faunal Remains by Barbara A. Meissner 
Appendix D: Radiocarbon Laboratory Analysis by Russell D. Greaves Radiocarbon Laboratory Analysis 136

Appendix E: Shovel Test Data: Areas A, B, C, \& D

Shovel Test Data: Areas, A, B, C, \& D 146

Appendix F: Shovel Test Data: Area E

Shovel Test Data: Area E

Appendix G: Shovel Test Data: Area F

Shovel Test Data: Area F ... 154

Appendix H: 41WA47 Shovel Test Results

Shovel Test Results: 41WA47

Appendix I: Excavation Data: Blocks Y47 \& M59

Excavation Data: Blocks Y47 \& M59

Appendix J: Excavation Data: Block NN/OO

Excavation Data: Block NN/OO 166

Appendix K: Excavation Data: Block PP/QQ

Excavation Data: Block PP/QQ. 


\section{Figures:}

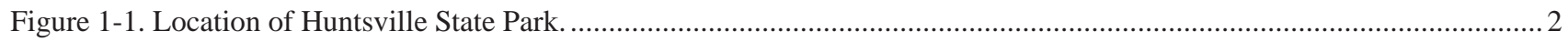

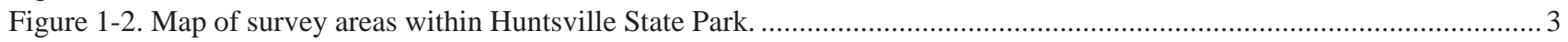

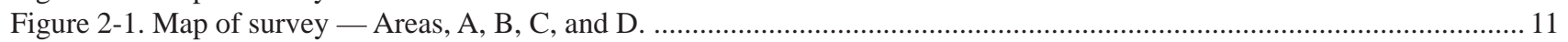

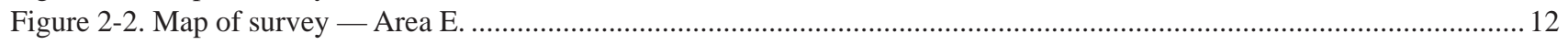

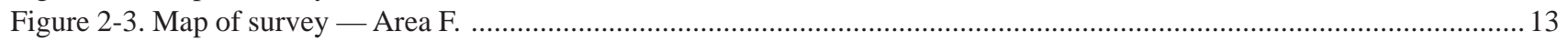

Figure 2-4. General location of shovel tests, backhoe trench, and controlled excavations at 41WA47.............................. 16

Figure 5-1. Depth of Bt horizon below ground surface as revealed by shovel tests - Area E. ...........................................36

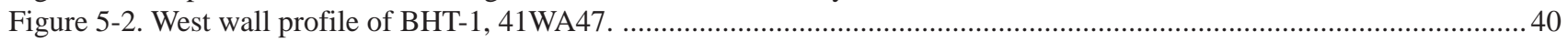

Figure 5-3. Series of roughly parallel lamellae present throughout the bottom half of BHT-1 profile. ....................................41

Figure 5-4. North wall profile of M59 Block Excavation (N940, E960-962), 41WA47.................................................53

Figure 5-5. South wall profile of Y47 Block Excavation (N999, E1020-1022), 41WA47. ..............................................54

Figure 5-6. North and east wall profiles of NN51-OO51 Block Excavation (N975-978, E1098-1101), 41WA47..................55

Figure 5-7. West wall profile of QQ48-49 Block Excavation (N989-992, E1111), 41WA47............................................56

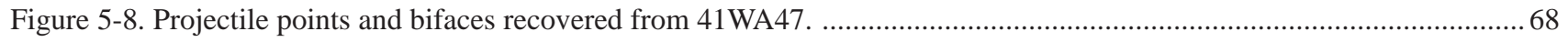

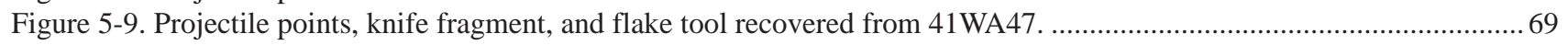

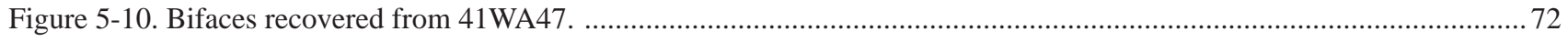

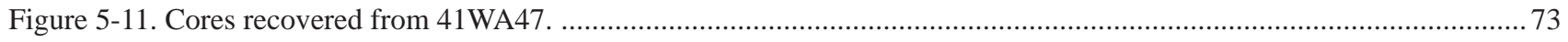

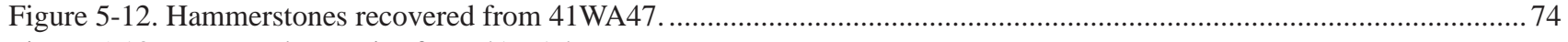

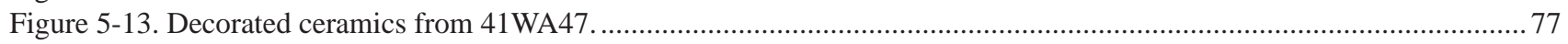

Figure 5-14. Vertical distribution of debitage from M59 Excavation Block, 41WA47...........................................................82

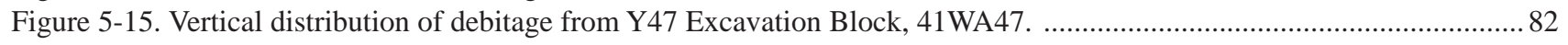

Figure 5-16. Vertical distribution of debitage from NN-OO51 Excavation Block, 41WA47. ..................................................8. 83

Figure 5-17. Vertical distribution of debitage from PP49/QQ48-49 Excavation Block, 41WA47....................................... 83

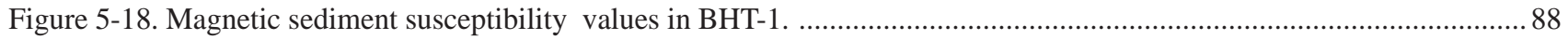

Figure 5-19. Standardized magnetic susceptibility scores and debitage count scores in Unit N989-E1111. ...........................89

Figure 5-20. Distribution of standardized values for ceramic sherds and lithic debitage, combined. ......................................90

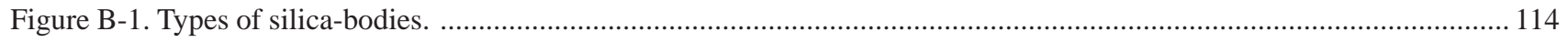




\section{Tables:}

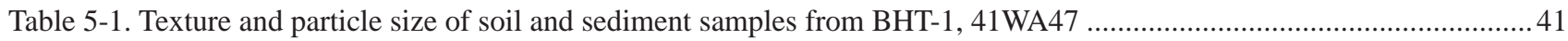

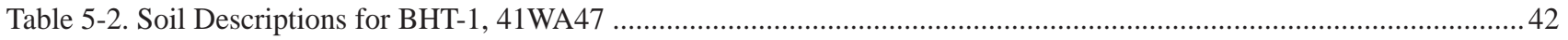

Table 5-3. Soil Descriptions for West Wall Profile of QQ48-49 Block Excavation, 41WA47 ..............................................57

Table 5-4. Equivalence of Soil Horizons - BHT-1 and QQ48-49, N989-992 E1111, West Wall Profiles, 41 WA47 ..................59

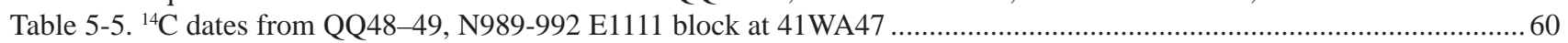

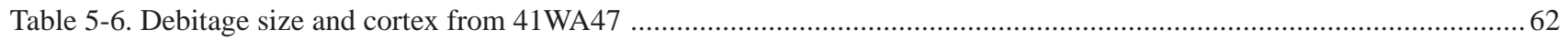

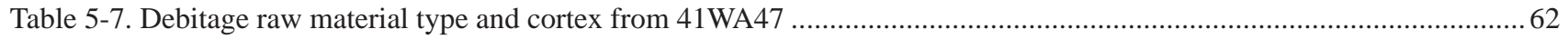

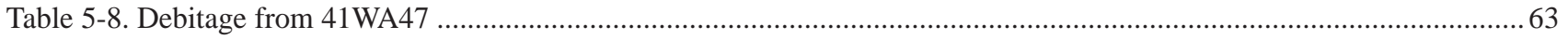

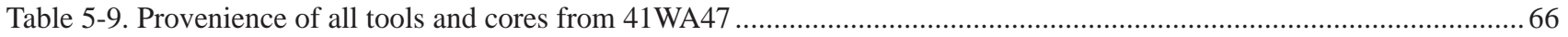

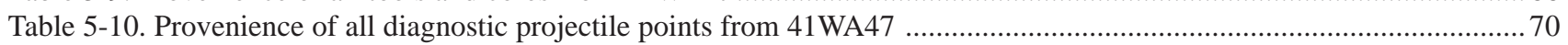

Table 5-11. Vertical distribution of projectile points from the NN-OO and PP-QQ blocks from 41 WA47 ............................71

Table 5-12. Distribution of tempered and decorated sherds by unit and level ............................................................... 78

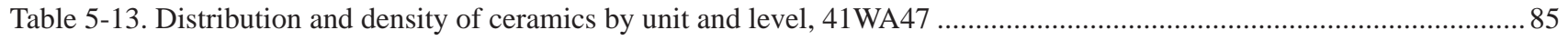

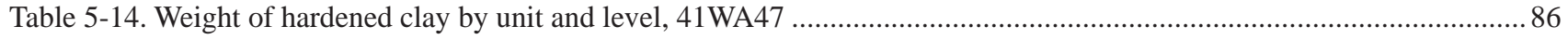

Table 5-15. Count of ceramic sherds and unmodified debitage by level, 41 WA47 ......................................................... 91

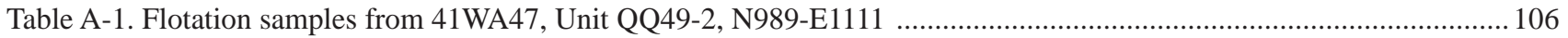

Table A-2. Macrobotanical (charcoal) samples from 41WA47, Unit QQ49-2, N989-E1111 ............................................... 106

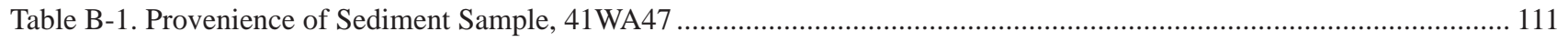

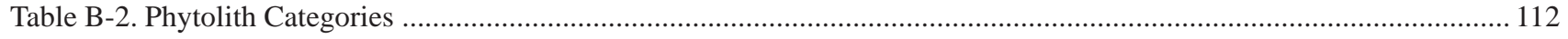

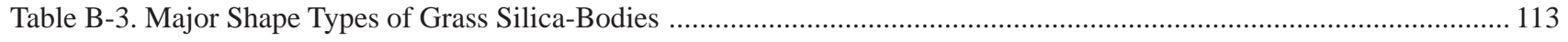

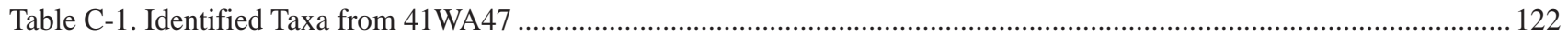

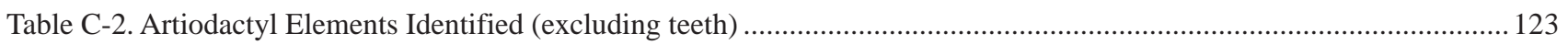

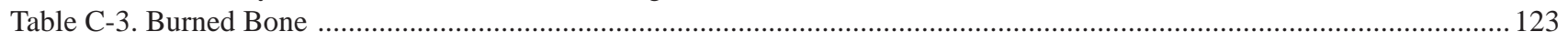

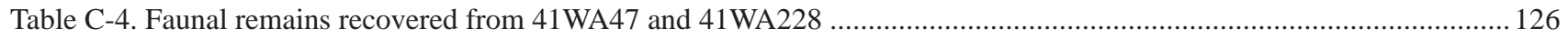

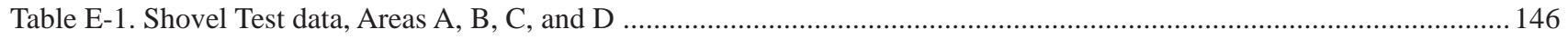

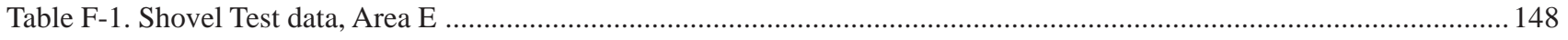

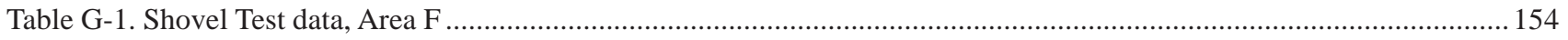

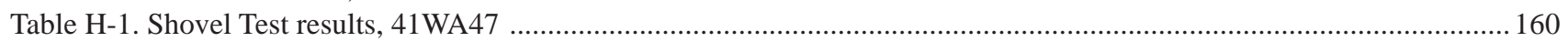

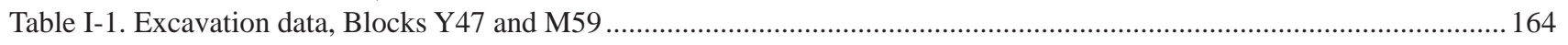

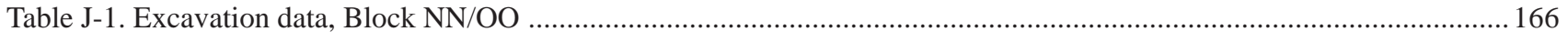

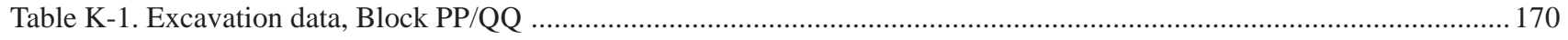




\section{Acknowledgments:}

Many people have contributed significant assistance to this archaeological study of Huntsville State Park. Several staff members at Texas Parks and Wildlife have offered critical help and solid editorial advice. I am especially grateful to Art Black for his guidance, enthusiasm, and support throughout this project. Margaret Howard read a rather rough draft of the report and conscientiously advised on where the gaps were and how to fill them. Logan McNatt and Amy Ringstaff provided advice and unpublished or difficult to obtain information vital to creating the research design and the final document. Other individuals from Texas Parks \& Wildlife who have aided our efforts are Dr. Karen Harry and Aina Dodge. Huntsville State Park personnel who assisted with the logistics of our field effort include Alan Fulenwider and Dennis Smith. During fieldwork, Ron Patel of the Econo Lodge in Huntsville was a gracious host accommodating our eccentric schedule.

The archaeological field crew consisted of Cory Broehm, Leonard Kemp, Ruth Mathews, Raymond Mauldin, Bruce Moses, Emily Olsen, Rick Robinson, Steve Tomka, and Jason Weston. Their dedicated work is deeply appreciated. Emily Olsen kindly volunteered her time during fieldwork. Bruce Moses provided impressively efficient surveying skills critical to the mapping and vertical control necessary for this project. Jason Weston served as crew chief and field equipment manger. I am especially grateful to Leonard, Ruth, Emily, and Jason who worked during the hottest part of the fieldwork and under the effects of tropical storm Allison. Edward Mathews and John Roy both volunteered several days to assist with fieldwork.

At the Center for Archaeological Research, the efforts of many staff members has been critical to the completion of this project. Bruce Moses cheerfully handled a plethora of critical tasks. He helped create the site grid system, calculated spatial data, expertly drafted field maps, and produced the final report figures. Marybeth Tomka directed laboratory efforts, made certain that materials were processed in a timely fashion, performed many laboratory tasks, and efficiently produced databases. Marybeth also performed the ceramic analysis and wrote the section in Chapter 5 on the Huntsville ceramics. CAR staff who processed materials in the laboratory included Laura Burgess, Rebecca Galeando, Shanti Morrell-Hart, Sylvia Reyna, Carol Villalobos, and Jason Weston. Jason also described and analyzed all of the lithics. Steve Tomka identified all of the diagnostic projectile points. Raymond Mauldin performed sediment susceptibility analysis and interpretation. Richard Mahoney wrote Chapter 3 on background archaeological research. Barbara Meissner analyzed all of the faunal remains and wrote Appendix C. Rick Young prepared the artifact figures. Johanna Hunziker and Maryanne King ungrudgingly edited the document to the final layout and production phase. Sherri Suñaz and Tammy Hosek made administrative procedures operate with apparent ease and impressive organization. Mike Wright made wonderful things happen with money and accommodated baroque procedures with tremendous humor. José Zapata made certain that our field equipment was in excellent condition and that we had wheels. Dr. Phil Dering, of the Archaeobotanical Laboratory in The Center for Ecological Archaeology at Texas A\&M University, offered advice on macrobotanical processing, analyzed the samples, and wrote Appendix A. Dr. Susan Mulholland, from the Interdisciplinary Archaeology Studies laboratory at the University of Minnesota Duluth, undertook analysis of the phytolith sample, wrote Appendix B, and offered suggestions about recovery procedures. I am especially grateful to Dr. Steve Tomka and Dr. Raymond Mauldin. Both have dedicated tremendous efforts to all aspects of project planning, budget preparation, research design, fieldwork, laboratory tasks, analyses, and draft editing. Their input and advice has greatly improved the quality of the project and the research accomplished. 


\title{
Chapter 1:
}

\section{Introduction}

\author{
Russell D. Greaves
}

\section{INTRODUCTION}

Two archaeological field efforts were performed between May 30 and July 6, 2001 at Huntsville State Park, Walker County, Texas (Figure 1-1). An archeological survey was performed on approximately 160 acres (65 ha), representing six separate areas of projected park improvements. Additional testing and limited mitigation was undertaken at a previously identified archeological site, 41WA47. This work was conducted by the Center for Archaeological Research (CAR) at The University of Texas at San Antonio in response to a contractual agreement with Texas Parks and Wildlife Department (TPW) under Texas Antiquities Permit No. 2610. This report presents the findings from the archeological survey of the six separate areas slated for park improvements and the mitigation efforts conducted at 41WA47.

\section{Project Overview}

Walker County is situated within the Interior Gulf Coastal Plain physiographic region of Texas. Soils within this area are recent deep sands overlying an older sandy loam or sandy clay loam soil. Soil units mapped within the survey areas (McClintock et al. 1979:Map 53) are primarily the Depcor series and Gunter series deep sands (McClintock et al. 1979:38, 43). Some areas may contain expressions of Landman association soils (McClintock et al. 1979:43). Most of the subsurface investigations encountered deep sands that most closely resemble Gunter soils. Ecologically, this area is transitional between the Piney Woods, Prairies and Lakes, and Gulf Coast regions. Walker County is at the western margin of the Austroriparian biotic zone defined by Blair (1950:98-100). The local vegetation is a Piney Woods forest dominated by loblolly pine (Pinus taeda), blackjack oak (Quercus marilandica), post oak $(Q$. stellata), hickory (Carya sp.), and sweetgum (Liquidambar styractiflua) (Blair 1950:99). Average annual precipitation in the Huntsville area is 44.18-44.96 inches (112-114 cm) (Bomar 1995:Table C-2; McClintock et al. 1979:Table 1) and average annual temperature is $77.8^{\circ} \mathrm{F}\left(30^{\circ} \mathrm{C}\right.$ ) (Bomar 1995:Table B-7; McClintock et al. 1979:Table 1).

The project area is located on the northern shore of Lake Raven (Figure 1-2). The survey units and site 41 WA47 are situated on both banks of Big Chinquapin Creek and areas adjacent the creek drainage. The southeastern portion of the survey project (Area E) is located near the mouth of Little Chinquapin Creek. Survey and site discovery was performed within six parcels that total approximately 160 acres (65 ha). These areas have all been subject to previous ground modification efforts associated with timber harvesting during the early-twentieth century (McNatt et al. 2001: 8-9), construction of Lake Raven, roads, parking areas, improved campsites, and restroom facilities. Additionally, normal visitational use of these areas, lake effects, and surface water runoff has eroded many portions of the epipedon soils and sediments.

The largest survey blocks are located where Big Chinquapin Creek flows into Lake Raven. An area of approximately 100 acres (40 ha) on the western bank (Area F) and 50 acres (20 ha) on the eastern bank (Area E) represent the largest of the survey units. The large survey block of Area F, at the western mouth of Big Chinquapin Creek, is representative of a complete geomorphic unit extending as a peninsula into Lake Raven. One previously recorded site, 41WA228, was identified within Area F.

Smaller survey parcels are situated along access roads to the proposed parking facilities. Two very small, rectangular areas, 0.1 acre $(0.04 \mathrm{ha})$ and 0.25 acre $(0.1$ ha; Areas C and D, respectively), are adjacent to roadways leading to separate facilities on both banks of the mouth of Big Chinquapin Creek. The remaining two survey areas encompass approximately nine acres (3.6 ha) of Huntsville State Park. Area A consists of approximately 5 acres ( 2 ha), while Area B is comprised of four acres (1.6 ha). Area A is the location of a proposed new parking facility situated on currently undisturbed 


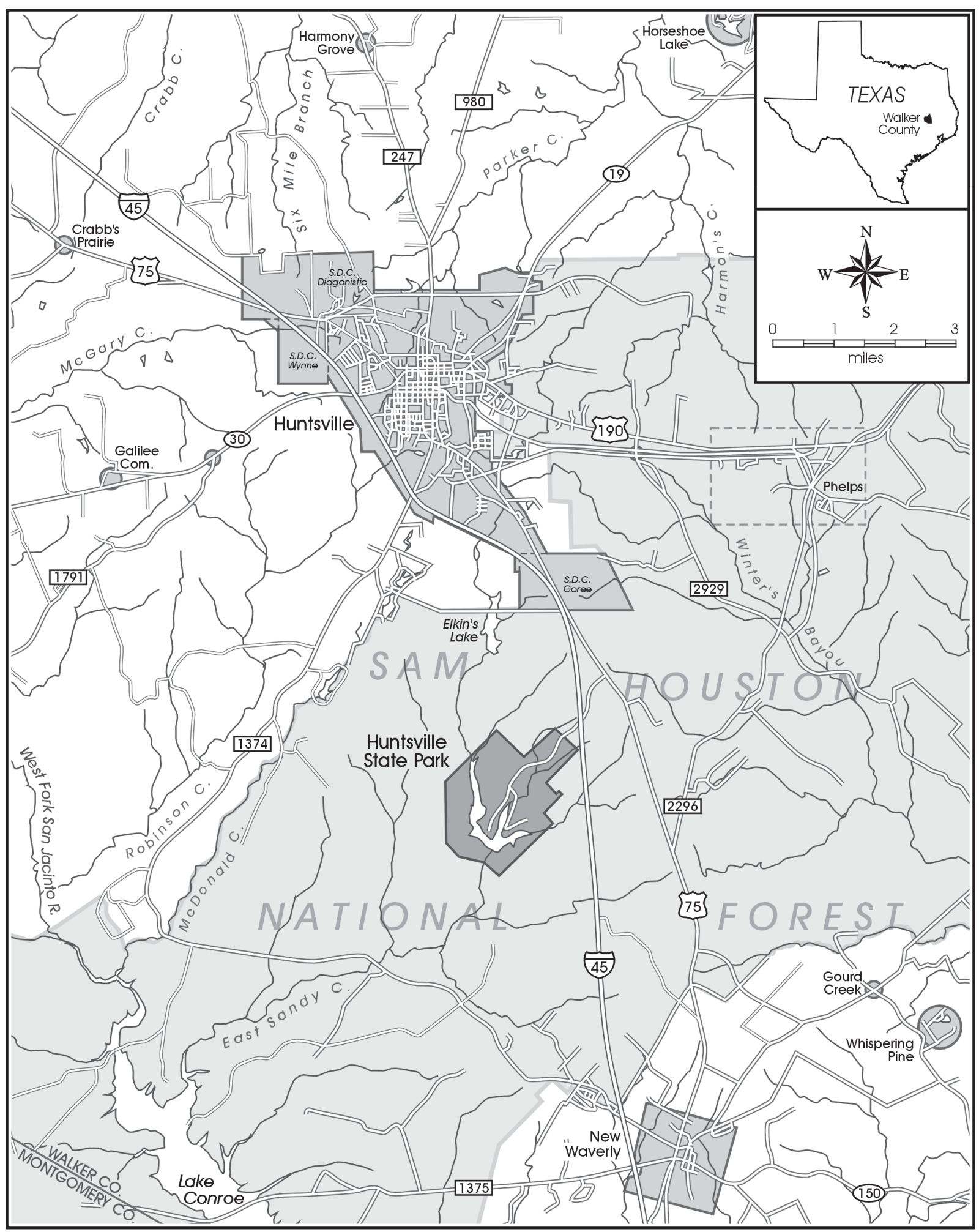

Figure 1-1. Location of Huntsville State Park. 


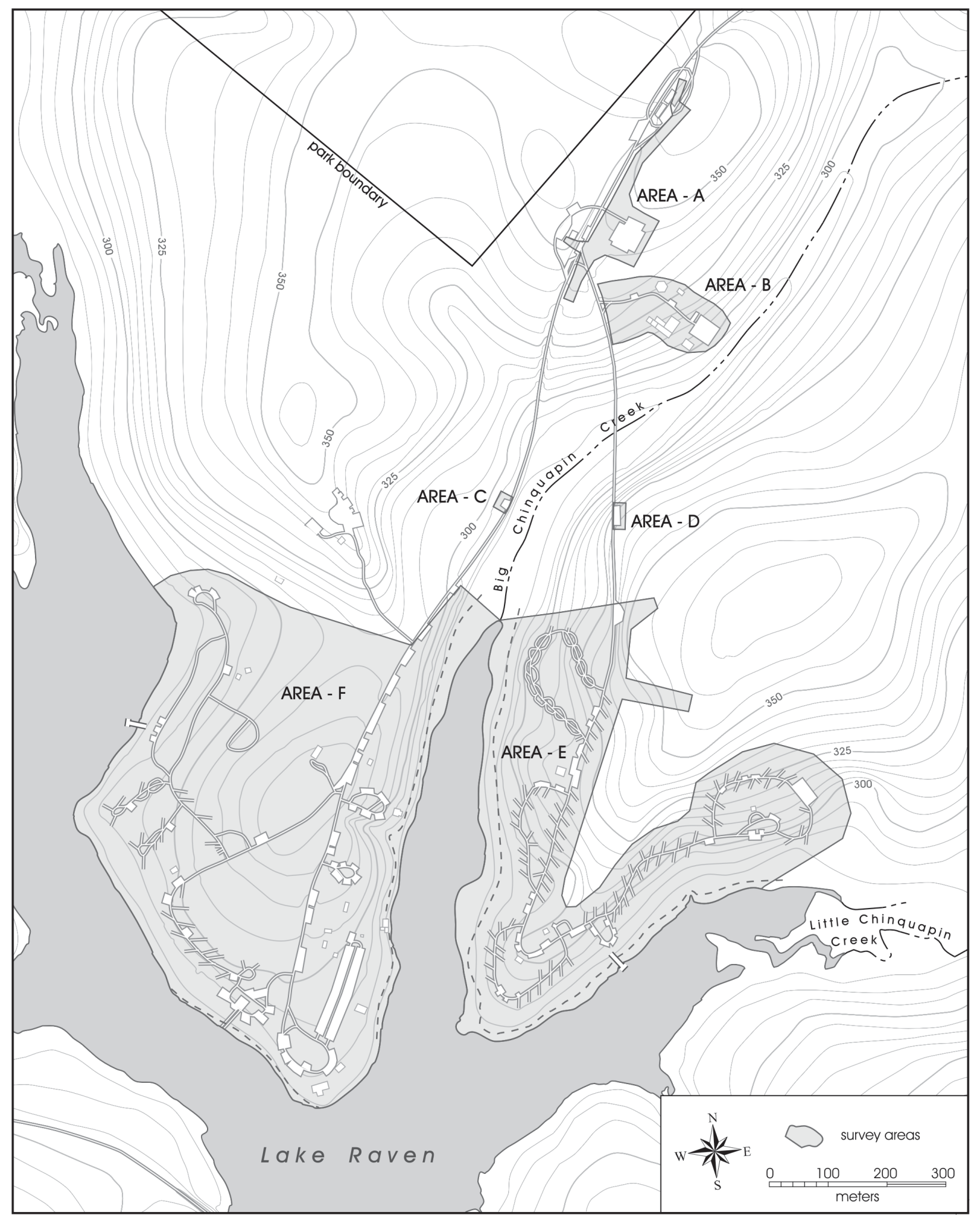

Figure 1-2. Map of survey areas within Huntsville State Park. 
ground. Area B, an existing caliche parking lot and access road, is scheduled for paving and improvements.

\section{Field Methods Overview}

This project was conducted in compliance with the Antiquities Code of Texas (Title 9, Chapter 191 of the Texas Natural Resources Code of 1977, as amended), its attendant Rules of Practice and Procedure (Texas Administrative Code, Title 13, Part II, Chapter 26), and the Council of Texas Archeologists Guidelines (1992). Work was performed under permit from the State of Texas, Texas Antiquities Committee, No. 2610, issued by the Texas Historical Commission on May 24, 2001. Raymond P. Mauldin and Russell D. Greaves served as co-principal investigators.

CAR performed the archaeological survey of the six areas slated for improvements, and the testing of the previously identified site 41WA47 during May 30-July 6, 2001. Standard archaeological field methods were used for the survey, cultural resources characterization, site identification, and mitigation during this project. Specific methods employed during the archaeological survey and mitigation are described in the following sections detailing each of those field efforts. All collected artifacts from the survey were processed and analyzed at the laboratory facilities at CAR. Macrobotanical, phytolith, and charcoal samples from the mitigation effort were analyzed by specialists at other research facilities. The archivally stable materials used in processing and storing artifacts comply with the Texas Archeological Research Laboratory (TARL) and TPW standards. All artifacts, unanalyzed samples, paleoethnobotanical sample residues, original field forms, field notes, maps, photographs, photograph logs, and laboratory records amassed over the course of the current project will be curated by TPW.

\section{Overview of Results of Survey and Limited Mitigation of 4IWA47}

A 100 percent pedestrian survey was required to identify archaeological sites that had not been previously located within the current survey areas and to evaluate the potential significance of site 41WA47. This survey involved shovel testing, preliminary evaluation of cultural resources, and site identification within the six survey parcels. This survey was performed to identify archaeological sites and determine their potential merits for official designation as Texas State Archeological Landmarks (SAL), and for listing in the National Register of Historic Places (NRHP). The survey also served to provide additional information about a previously identified archaeological site (41WA228) located within the bounds of Huntsville State Park. The second field effort, limited mitigation of 41WA47, was conducted to recover site information and to mitigate possible impact caused by the proposed campground road resurfacing. It is felt that the information gathered from both the archaeological survey and the mitigation efforts will prove to be relevant in developing public interpretive information about the archaeological resources and prehistoric use of the Huntsville State Park area.

The archaeological survey involved shovel test examination of a total of 160 acres (65 ha) within six parcels (Figure 1-2). These six areas were selected by TPW for archaeological survey prior to the scheduling of construction of new, or significantly improved, roadways and paved parking areas. Areas A, B, C, and $\mathrm{D}$ were small plots that did not contain any significant evidence of prehistoric occupation. The two larger parcels, Areas E and F, contained both archaeological sites and isolated artifact scatters.

In the northern portion of Huntsville State Park, two parking lots and associated access roads will be constructed and paved. One of these locations, Area A, has been only minimally disturbed along the right-ofway for the existing park entry road. The other improvements will be constructed in Area B which has been significantly modified and currently contains equestrian corrals, maintenance facilities, concessionaire's quarters, and a gravel parking lot. Two very small parcels (Areas C and D) adjacent to trails will be subject to minimal parking area improvements. Area C is located on the western road to the larger campground facility and Area D is along the eastern roadway to a less improved campground. Both of these areas have been affected only along the existing roadway, and minimally disturbed outside of this right-of-way.

The largest areas surveyed represent existing campground facilities within the park. The easternmost 
campground is designated as Area E (50 acres) and the larger, western campground is Area F (100 acres). Many portions of these campgrounds have been significantly modified through construction of picnic table pads, camping platforms, enclosed shelters, bathroom facilities, parking areas, post fencing, water line placement, and electrical utility line burial. Historic logging of the area was extensive prior to the creation of Huntsville State Park (McNatt et al. 2001:8-9). Despite these improvements, there are still many areas that have been minimally affected by twentieth-century construction and maintenance activities. It is anticipated that road construction will involve widening of portions of the existing roadbed and movement of some segments of the road. Two previously unrecorded low-density archaeological sites were identified in Area E (41WA264 and 41WA265). One previously unrecorded archaeological site (41WA266) was identified in Area F. None of these newly identified sites appear to contain significant remains and no additional characterization is considered necessary at these locations. A previously recorded site, 41WA228, is located in Area F. Survey results indicate that this site is larger than its former designation and portions are within the roadways scheduled for improvement. While the areas of site 41WA228 that will be impacted by the proposed improvements have previously been disturbed by construction, Cultural Resource Coordinator Art Black will monitor construction within that site, and if prehistoric cultural features are noted, will halt work so that the nature and significance of those deposits can be evaluated, in consultation with the Texas Historical Commission.

Campground road improvements also may affect site 41WA47, which is a State Archeological Landmark site. Survey and controlled excavations at this site indicated the presence of significant deposits in some areas of the identified site. Recovery efforts encountered deeply stratified deposits with abundant archaeological artifacts. The following actions are recommended to protect the significant cultural deposits of the site: 1) remove campground pullouts 63,64 , and 65 from camping use and return those areas to a natural state; 2) prevent the digging of temporary barbecue pits by park visitors and restrict ash and charcoal disposal to designated areas; and, 3) identify erosion control measures for the site in order to stabilize the ground surface and prevent impact to buried deposits.

The three newly identified archaeological sites do not appear to warrant additional archaeological characterization. Two of these sites (41WA264 and 41WA266) are very low-density manifestations in highly disturbed areas. Site 41WA265 may have some subsurface integrity, but within the project area, artifacts were identified from only two shovel tests. This could be a portion of a larger site that is outside of the current survey project boundaries. If future improvements are planned for this area, then additional shovel testing is recommended to the north and east of these two shovel tests to determine whether they are part of a more pronounced archaeological presence.

Shovel testing in the vicinity of 41WA228 identified a much larger extent to this site than was previously recorded. At least a portion of the existing cultural materials on this site have been severely impacted by previous road construction and improvements to park facilities. While the proposed road improvements will impact the cultural deposits falling in the immediate vicinity of the road, Cultural Resource Coordinator Art Black will monitor construction within the impact area and will halt work, if and when, cultural deposits and features are encountered, in order to evaluate the significance of the deposits in consultation with the Texas Historical Commission.

\section{Organization of Report}

The following material briefly describes the remaining five chapters of this report and summarizes the content of the 11 appendices.

Chapter 2 presents the scope of work and the research design for survey and excavations at Huntsville State Park. It provides an introduction to the project and a brief overview of previous archaeological work at the park. A project description presents the rationale for the requested archaeological survey and the limited data collection for 41WA47. Separate discussions are provided for the survey, and testing and mitigation of 41WA47 components of this work. Each section includes 
the pertinent aspect of TPW's scope of work, a brief summary of the field methods, and a synopsis of the results and recommendations regarding any need for additional characterization of these sites. The section on archaeological testing and mitigation at 41WA47 contains specific discussions on the shovel testing, backhoe trench excavation, controlled $1 \times 1-\mathrm{m}$ excavations, and public outreach requirements and realized activities. Detailed presentation of field methods are not included in this section but are in the chapters addressing the systematic archaeological survey (Chapter 4) and the mitigation efforts at 41WA47 (Chapter 5). A final section on the research goals of this project includes discussion of the investigations of site formation, local chronology, subsistence adaptations, and technology. Other significant research implications of this work are also presented.

Chapter 3 reviews the currently understood cultural chronology, inferred behavioral activities, major archaeological investigations, and some ongoing research issues within the general vicinity of Huntsville State Park. Specific discussions are presented for recognized Paleoindian, Early Archaic, Middle Archaic, Late Archaic, Early Ceramic, and Late Ceramic periods. A more detailed presentation of Late Archaic through Late Ceramic chronology, cultural adaptations, and research as appropriate to the documented temporal periods represented through the dating of deposits at $41 \mathrm{WA} 47$ is included in this section. A segment on previous investigations in the area specifically addresses archaeological research performed within Walker County or significant research from nearby portions of adjacent counties.

Chapter 4 details the archaeological survey of six areas of Huntsville State Park. An introduction reviews the reason for the survey and briefly presents the results. A detailed presentation of the survey and shovel testing methods is included in this chapter. Methods and rationale for use are detailed in this chapter due to the two different investigative efforts carried out in Huntsville State Park. The results of archaeological shovel test survey are presented in sections detailing the work accomplished within each of the six survey parcels (Areas A, B, C, D, E, and F). Areas E and F are the two largest survey parcels, and are the only areas containing identified archaeological sites. Both of these areas are very heavily visited campground facilities. Detailed presentation of the sites identified as 41WA264 and
41WA265 are included with the discussion of the results of survey within Area E. Survey results from Area F include assessment of 41WA228 and one previously unidentified archaeological site, 41WA266. A final section reiterates the recommendations that 41WA264, 41WA265, and 41WA266 do not appear to merit additional archaeological investigations. Results of shovel testing indicate that 41WA228 is significantly larger than previously identified and may possess subsurface integrity. Given previous site disturbances along the proposed road improvement's right-of-way, only construction monitoring is recommended.

Chapter 5 presents the context, research goals, methods, and results of survey testing and limited mitigation of 41WA47. The introduction summarizes the fieldwork accomplished at this site. A preliminary discussion of the general geomorphology, soils, and sediments of the site follows. A summary of previous archaeological work performed prior to this project establishes some of the research questions about site formation that dictated the methods and analytic goals of this investigation. Section IV details the shovel testing methods employed to identify the extent, depth, and artifact densities across the site. The results of shovel testing are included in this discussion. Section V presents the profiling work performed within a single backhoe trench excavated in the deepest deposits at 41WA47. This backhoe trench provided critical geoarchaeological and site formation information which was used to assist selection of areas and methods utilized during controlled excavation. Detailed discussions of the geomorphic interpretations and archaeological recovery of artifacts from this trench are also presented. Section VI documents the methods employed in the excavation of controlled $1 \times 1$-m units on the site. Several aspects of this recovery are discussed in relation to their significance to the overall research design. Separate sections on paleobotanical sampling, charcoal recovery for dating, piece-plotting of larger artifacts, faunal recovery, profiling, and magnetic sediment susceptibility are included.

The remaining sections of Chapter 5 detail the results of archaeological recovery and laboratory analyses, including separate discussions on the results of recovery and analyses of ${ }^{14} \mathrm{C}$ dating, lithic, ceramic, and paleobotanical analyses. AMS dating of a chronosequence from one of the block excavation areas is 
discussed. Lithic analysis includes presentation of the debitage, and each recognized class of stone tools recovered. Ceramic analysis is followed by brief mention of other recovered archaeological materials. A short summary of the macrobotanical analysis (presented in detail in Appendix A) and the phytolith investigation (in detail in Appendix B) incorporate results from specialist reports. A discussion of the faunal remains (in detail in Appendix C) is presented in relation to their taphonomic implications. The following sections of Chapter 5 contain information on spatial analyses of lithics, and site formation implications from the piece-plotted sample, while the final section reviews recommendations and concerns about future impacts to 41WA47.

Chapter 6 is a summary of the cultural resource management recommendations based on both the survey portion and the limited mitigation of $41 \mathrm{WA} 47$ with separate discussions included for each of these field efforts.

Eleven appendices accompany this report. Appendix A is the full text of analysis results on macrobotanical remains from a chronosequence in the controlled excavations of 41 WA47 performed by Dr. J. Philip Dering. Appendix B, by Dr. Susan C. Mulholland, provides a quick-scan analysis of one phytolith sample from 41WA47. The third appendix presents the faunal analysis by Barbara A. Meissner for the survey and mitigation efforts at Huntsville State Park. Appendix D presents the complete laboratory results from Beta Analytic, Inc., along with a brief description of the sample environment and specific contexts for each sample submitted for AMS dating. Appendices $\mathrm{E}$ through $\mathrm{K}$ are summary data tables listing excavation details and artifact recovery for all shovel test survey areas, shovel test results from 41WA47, and the results of controlled excavation for each of the block area excavations. 



\title{
Chapter 2: $\quad$ Scope of Work \& Research Design
}

\author{
Russell D. Greaves
}

\section{INTRODUCTION}

The archaeological survey of six determined areas, and the limited mitigation of one previously identified prehistoric site were performed in response to Texas Parks and Wildlife Department's (TPW) proposal to improve access roads, parking pullouts, and other aspects of camping facilities at Huntsville State Park, Walker County, Texas. The park is situated on the western side of Interstate Highway 45, seven miles south of the city of Huntsville. The work was deemed necessary because of the dramatic increase in park visitation over the last two decades. Normal park use has affected the existing roadways and parking areas and significant rehabilitation is required to deal with the current situation. Anticipated future use also necessitates alterations and upgrades in the roads and existing configuration of park facilities. Planned improvements will include resurfacing and minor rerouting of Park Roads 40 and 40A, the installation of new utility lines, repaving of existing parking areas, and paving of some currently unimproved roadways, parking, and pullout locations.

Prior to initiation of these improvements, TPW wished to determine whether any additional significant archaeological sites were located within the proposed right-of-way. TPW also wanted to mitigate damage to 41WA47, a previously recorded prehistoric site located within the bounds of Huntsville State Park and officially designated as a State Archeological Landmark (SAL). TPW contracted with the Center for Archaeological Research (CAR) to undertake these two fieldwork efforts. CAR performed a 100 percent pedestrian archaeological survey of the six identified project parcels and also undertook the testing and limited data recovery effort at site $41 \mathrm{WA} 47$.

Prior to these investigations, several small archaeological surveys had been performed within or adjacent to the current project area. Systematic surveys of both the motor vehicle camping areas (Areas E and F), a proposed parking area near the park entrance (Area A), the existing unpaved road and parking lot associated with equestrian rental facilities (Area B), and two proposed pullout locations (Areas $\mathrm{C}$ and D) had not previously been conducted (see Figure 1-2). Therefore, six survey parcels were designated by TPW for archaeological survey by CAR, and the investigational effort of 41WA47 was also scheduled upon determination that a portion of the roadway improvements in the Area E campground will occur within the previously identified boundary of site $41 \mathrm{WA} 47$.

\section{Previous Archaeological Investigations}

Archaeological investigations have been performed within Huntsville State Park by TPW since 1978. At that time, human bone was identified in lowered lakeshore deposits by a group of Boy Scouts. An archaeological survey initiated by the discovery resulted in the recording of that area as site 41WA47 (Ralph 1978). Site 41WA47 was designated as a SAL in 1983.

In response to other small park improvement projects, several archaeological surveys have been performed. One, the archaeological monitoring and testing carried out by Boes (1992) in the Coloneh Camping Area (in survey Area E) of the park was conducted in the vicinity of 41WA47 and within and outside of the boundary of 41WA264 (new site recorded during current investigations, see Chapter 4). Since 1978, the various archaeological surveys have documented eight archaeological sites within the boundaries of Huntsville State Park (41WA47, 41WA48, 41WA202, 41WA203, 41WA204, 41WA205, 41WA206, and 41WA228). All of these sites are located adjacent creek channels draining into Lake Raven. Archaeological investigations in 1996 included shovel testing of 41WA47 (McNatt et al. 2001; Ward and McNatt 1996). Results of 13 shovel tests indicated the presence of deep and relatively dense archaeological deposits that included lithics, ceramics, bone, and carbonized nutshells. It was considered possible that midden deposits had been encountered in 
some of the shovel tests. Within the six areas designated for survey in these 2001 investigations, only one other previously identified archaeological site is present -site 41WA228. This site was originally encountered during shovel testing of a utility corridor in the western campground area in 1998 (McNatt et al. 2000). In the 1998 investigations, 14 lithics were recovered from two shovel tests.

Although Huntsville State Park is located in an upland area, TPW considers it retains a strong likelihood of having been utilized for prehistoric habitation due to its location at the confluence of three perennial streams in the area (McNatt et al. 2001:18). Its location, $11 \mathrm{~km} \mathrm{(7}$ mi) upstream of the nearest major drainage, the West Fork of the San Jacinto River, is anticipated to have resulted in a relatively low density of prehistoric occupation. Archaeological site density is probably much lower in the Huntsville State Park area compared with the dense evidence of prehistoric use of the San Jacinto and Trinity River drainages. However, the confluence of the three perennial streams -Prairie Branch of East Sandy Creek, Big Chinquapin Creek, and Little Chinquapin Creek- is clearly associated with archaeological evidence of prehistoric use, although it is not felt that historic settlement was significant within the park area. The only recorded events likely to have any potential archaeological signature related to early Euroamerican use of the area are the recorded logging and camp construction activities conducted in ca. 1937 by the Civilian Conservation Corps (TPW 2002). Because five of the survey parcels (Areas B, C, D, E, and F) are in proximity to these drainages the proposed improvements to roadway and pullout facilities have a high probability of disturbing archaeological sites within the park.

\section{Project Description}

The scope of work identified the two tasks necessary for the investigation of cultural resources that may be affected by the proposed park improvements at Huntsville State Park. The tasks were:

1) A pedestrian archaeological survey of the six designated areas to identify any archaeological remains not previously encountered within the park; and

2) Limited data recovery at $41 \mathrm{WA} 47$.

\section{Archaeological Survey}

Pedestrian survey was required to identify the potential presence of any archaeological sites within the right-ofway areas of the proposed improvements. This investigation was designed to determine whether any sites discovered during survey contained significant research potential. The use of standard $30 \times 30-\mathrm{cm}$ shovel tests was the specified means to identify site boundaries and evaluate the research potential of any identified sites. TPW specifications indicated that if shovel testing could not unambiguously determine site significance, CAR should make additional recommendations regarding the anticipated investigations necessary to make such a determination. Those recommendations were provided to TPW in an interim report submitted by CAR on August 1, 2001 (Greaves and Weston 2001).

The survey consisted of pedestrian survey and systematic subsurface shovel test investigations. Specific methods employed in the placement of shovel test and hand excavation units are specified in Chapter 4 , Section II of this report. The methods utilized meet or exceed the specified precision required by TPW. The six survey parcels amount to approximately 160 acres (65 ha) of land. Shovel testing was performed systematically in all of these areas (Figures 2-1, 2-2, and 2-3). Shovel test units were placed approximately $30 \mathrm{~m}$ apart and either excavated to $60 \mathrm{~cm}$ below the modern ground surface or to the contact with the distinctive Pleistocene Bt soil horizon that contained no archaeological materials. During fieldwork, a modification to the survey shovel testing strategy in Area F was employed with the approval of TPW staff. The amount of disturbance combined with the project schedule necessitated the use of greater intervals between shovel tests in the eastern portion of Area F. Transect spacing of $30 \mathrm{~m}$ was retained in this portion, but shovel tests were placed at $60 \mathrm{~m}$ intervals along those transects. All other portions of survey parcels $\mathrm{A}, \mathrm{B}, \mathrm{E}$, and $\mathrm{F}$ (excluding the eastern portion) were investigated using $30 \mathrm{~m}$ spacing between shovel tests. Areas C and D were small and only two shovel test units were placed within both of these survey blocks. The initial scope of work included provisions to survey all of the roadway segments within Huntsville State Park. That portion of the work effort was removed from the final requested archaeological investigation prior to fieldwork. 


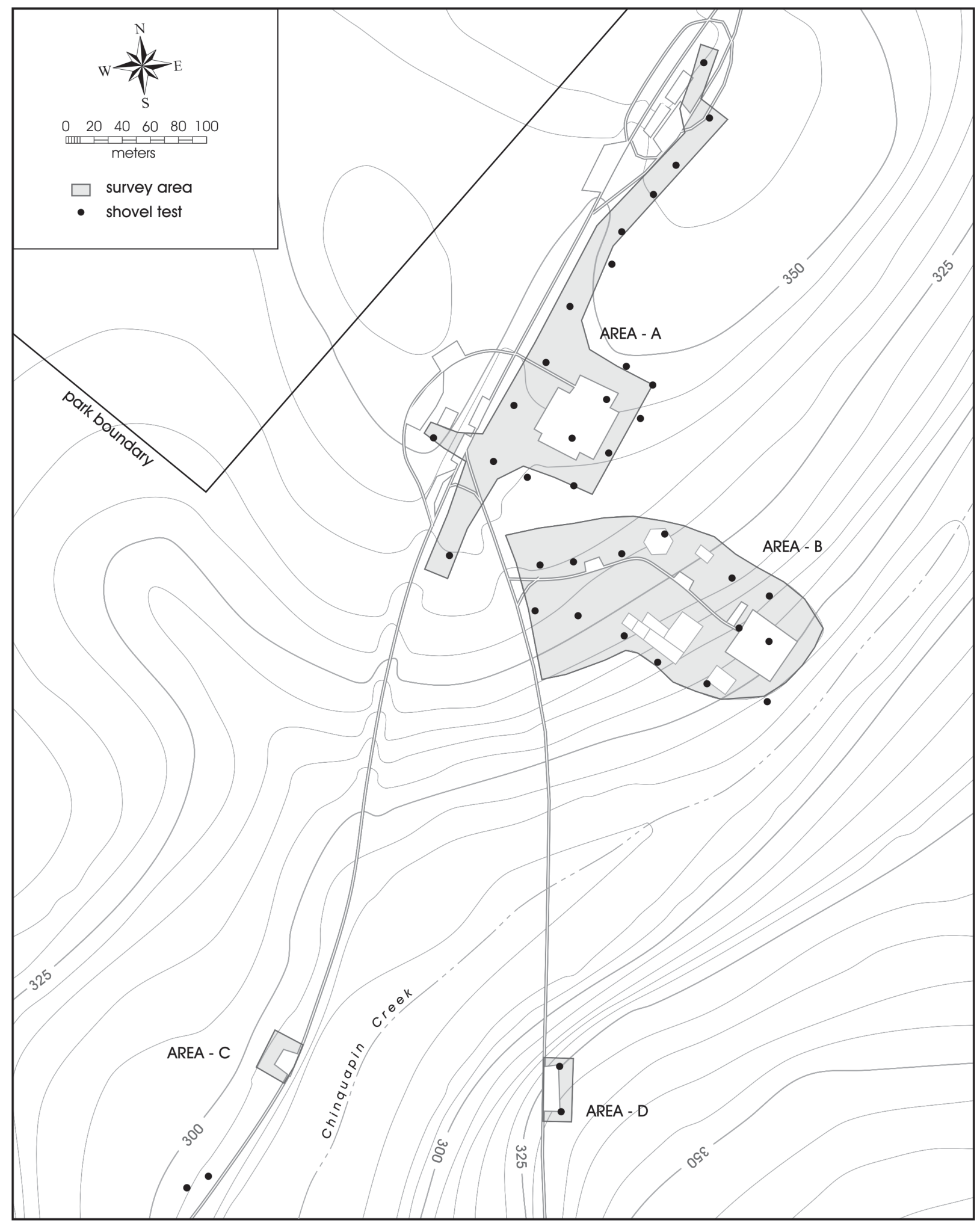

Figure 2-1. Map of survey - Areas, $A, B, C$, and D. 


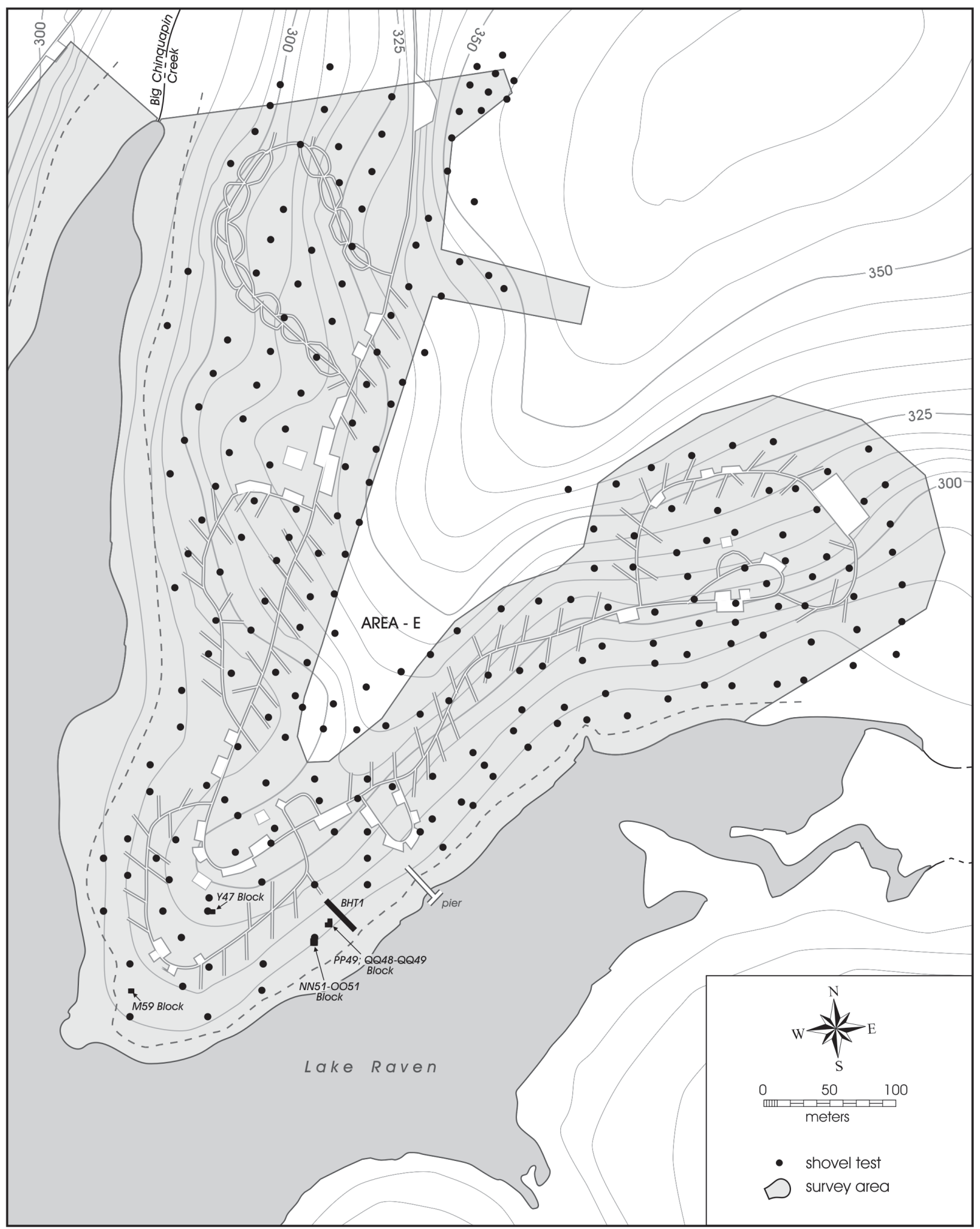

Figure 2-2. Map of survey - Area E. 


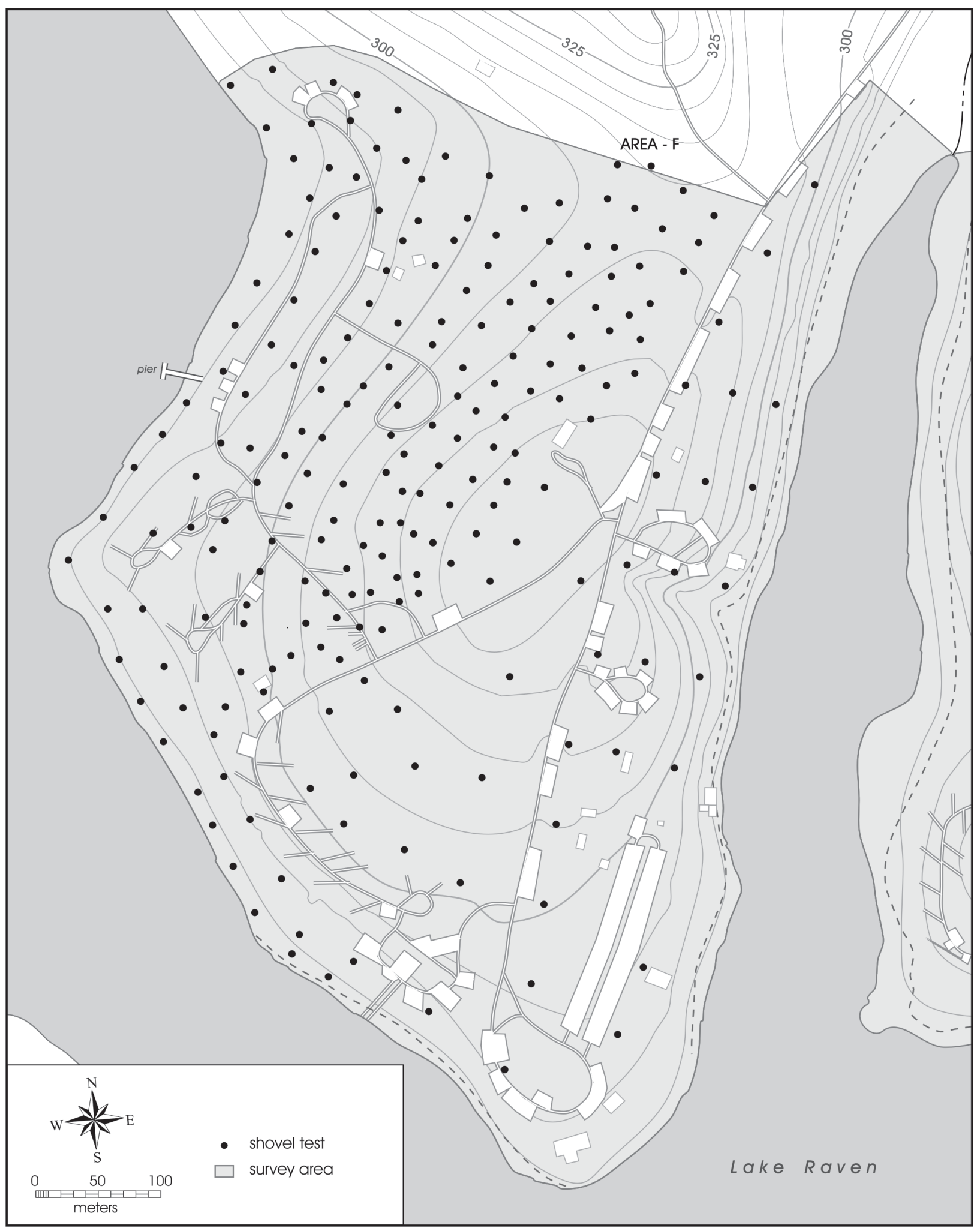

Figure 2-3. Map of survey - Area F. 
Systematic survey also included reevaluation of 41WA228 within Area F (Figure 2-3). This site was previously identified in 1998 from two shovel test units excavated on a utility corridor (McNatt et al. 2000). The current survey shovel tests significantly increased the area of site 41WA228 beyond its initial identified boundaries. This archaeological survey also examined the eastern and northern boundary portions of $41 \mathrm{WA} 47$. Shovel testing confirmed the previous approximate boundaries with slight modifications. Systematic shovel testing of all of 41WA47 was included as part of the limited mitigation effort at that site.

All sites were evaluated for their research potential and suitability for official designation as SAL properties. Criteria employed for these determinations are given in Section 26.8 of the Rules of Practice and Procedure for the Antiquities Code of Texas. Within the survey parcels, three previously unidentified archaeological sites were recorded. Two of these sites (41WA264 [Area E] and 41WA266 [Area F], Figures 2-2 and 2-3) have been extensively impacted by campground construction activities and are not considered to have significant research potential. The other site (41WA265 [Area E], Figure 2-2) was identified through artifacts present in only two of eight adjacent shovel tests. The currently identified manifestation is not considered significant, but could be indicative of an undiscovered site outside of the survey parcel. The reevaluation of site 41WA228 indicated that the site's size was significantly larger than previously identified. Shovel testing revealed the presence of moderately dense subsurface artifacts suggesting that the site has the potential to contain an intact archaeological deposit that may include features. To determine the significance and potential eligibility as a SAL, additional investigation is recommended for this site through 1 x 1 -m test excavations.

\section{Archaeological Testing and Limited Mitigation of 4 IWA47}

Preliminary investigations of 41WA47 by TPW in 1996 identified the subsurface presence of artifacts to a depth in excess of $110 \mathrm{~cm}$ in some portions the site (McNatt et al. 2000). The relatively diverse artifact assemblage included 58 pieces of debitage, one biface fragment, four ceramic sherds, nine pieces of bone, carbonized nutshells, and charcoal. The possible association with the previously recovered human remains also suggested that 41WA47 was a significant archaeological resource with the potential to possess deeply stratified deposits.

Because proposed road improvements will impact portions of the identified site area, TPW requested additional survey and data recovery efforts here. The requested work was designed to accomplish three goals:

1) To provide additional information about the nature of the subsurface deposits at 41WA47 through systematic shovel testing of the entire site area;

2) To obtain finer scale data about the site and to mitigate the effects of the proposed roadway improvements on the portion of 41WA47 within the right-of-way by means of controlled recovery employing 1 x 1-m excavation units; and,

3) To use the information generated from this work to form the basis of a public outreach interpretation of prehistoric use of Huntsville State Park and TPW's commitment to archaeological research.

CAR requested additionally to excavate one backhoe trench to resolve questions about the stratigraphy, geomorphic history, and archaeological implications of site formation. TPW approved the excavation of this trench prior to controlled excavations on the site. The shovel testing, backhoe trenching, and controlled excavations are described briefly below in relation to the scope of work and research design. Detailed presentation of the shovel testing and $1 \times 1-\mathrm{m}$ excavations are provided in Chapter 5. The public outreach efforts performed to date are further discussed at the end of this section.

\section{Shovel Testing}

Systematic shovel testing was required to determine the horizontal extent of 41WA47, the depth of deposits in different areas of the site, and whether midden deposits and their spatial extent could be identified. The original scope of work called for shovel test intervals of $20 \mathrm{~m}$ on site. This was modified to $40 \mathrm{~m}$ because the originally specified intervals would have required 88 shovel tests. Given the project schedule, such a sampling strategy would have permitted much less effort committed to controlled excavation and the other survey tasks. A modification of the shovel testing interval and strategy 
was approved by TPW. Shovel tests were placed at $40 \mathrm{~m}$ intervals and additional units were selected on a judgment basis (Figure 2-4). This provided sufficient areal coverage to characterize the site and help determine the locations of the controlled block excavations.

Soils and sediments from each shovel test were briefly characterized. Several units were drawn and described as witness profiles to compare with the more detailed soil descriptions conducted on the backhoe trench and controlled excavation areas. A total of 26 shovel test units were excavated within the area identified as the site's boundary. Additional shovel tests that did not contain artifacts, or that suggested materials not in situ, were excavated systematically around the site margin. Shovel test data permitted more precise identification of the boundary of site 41WA47, although it was not changed significantly from that identified by TPW in 1996 on the basis of 13 shovel tests (McNatt et al. 2000).

\section{Backhoe Trenching}

The excavation of a single backhoe trench was performed to provide key information about the sedimentary history of this location. A trench $28 \mathrm{~m}$ ( $92 \mathrm{ft}$ ) long was excavated NW-SE from an intact high point on the site towards the lower margin close to the current water level of Lake Raven (Figure 2-4). This trench was excavated to

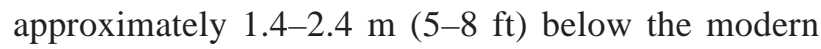
ground surface. Profiling, soil descriptions, mapping and collection of in situ artifacts, and the collection of charcoal, soil, and sediment samples provided critical site formation data. This information aided in the selection of areas slated for controlled excavation. Chapter 5 contains a detailed discussion on the backhoe trench data.

\section{Controlled I x I-m Excavation}

Following completion of systematic shovel testing of the site and examination of the backhoe trench, controlled excavations were performed at 41WA47. Recovery was directed towards evaluating the contexts of the archaeological deposits, obtaining well-provenienced artifacts, examining any potential buried features, and collecting specialized samples for laboratory analyses. A minimum of 15 standard 1 x 1-m excavation units were to be placed in high-potential areas of the site to maximize the recovery of artifacts, stratigraphic information, and permit evaluation of potential features.
Placement of the standard $1 \times 1-\mathrm{m}$ units at $41 \mathrm{WA} 47$ was determined judgmentally, on the basis of the results of shovel testing and geomorphic interpretation of the landform derived from the backhoe trench. The limited data recovery program at the site targeted areas with deep deposits containing a high diversity of artifacts. Nineteen $1 \times 1-m$ excavation units were placed in four areas of 41WA47 (Figure 2-4). Of the nineteen units, seventeen terminated at contact with the older, Pleistocene Bt soil horizon.

Excavation employed standard 10-cm levels and screening of all material through $1 / 4$-inch mesh screens. All material retained in the screen was returned to the laboratory at CAR for analyses. Materials were separated in the field to provide a preliminary count of recovered artifacts. Natural clasts were counted, weighed, and measured, but not retained for curation. Several additional data recovery methods were employed to assist in the analyses and interpretation of 41WA47. Sediment samples were collected from each excavation level in seven of the nineteen units, providing specimens for soil and sediment characteristics, as well as macrobotanical, pollen, and phytolith analyses.

Although the original scope of work requested placement of excavations to maximize areal coverage, contiguous block excavations were employed rather than scattered individual units. The four areas of excavation sampled several contexts within the site. Often, comparisons between isolated units are hampered by their separation, therefore, logically, dispersed units are very likely to represent unrelated past activities in different parts of a site. Analytic comparisons provide low confidence that there could be behavioral relationships between dispersed artifact samples. Although there is no assurance that activities represented by artifacts and their spatial patterning are necessarily related, contiguous units do, at least, offer control over spatial distribution of artifacts. Even if the sample is too small for meaningful horizontal spatial analyses, or if patterning is not demonstrably cultural, artifacts can be assumed to have some relationship because they have some unspecified association through proximity.

\section{Public Outreach}

During the survey and excavations at Huntsville State Park, the field crew was afforded several opportunities 
This page has been

redacted because it

contains restricted

information. 
for interaction with the public. As part of our work, the crew undertook to answer questions and discuss the goals, methods, and results of the field investigations. These informal interactions allowed the crew to practice the important skills of presenting archaeology to the public, and show visitors using the campgrounds that prehistory is a critical cultural resource of Huntsville State Park. Several avocational archaeologists spoke with the crew and offered useful information about local archaeology. Especially during the excavations at 41WA47, several families, groups of children, and adults took advantage of the investigations taking place to ask about the methods, interpretations, and need for publicly funded archaeology. Following completion of the fieldwork, Russell Greaves, project archaeologist, presented a paper on site formation at 41WA47 during the 72nd Annual Meeting of the Texas Archeological Society, in Corpus Christi, Texas (Greaves 2001). Preparation of educational materials based on the archaeological investigations by CAR at Huntsville State Park is anticipated following completion of this final report. Additionally, a summary of the fieldwork at 41WA47 will be prepared and presented on the CAR Web site (http://car.utsa.edu).

The excavations in $41 \mathrm{WA} 47$ offer TPW the opportunity to showcase the research possible within their stewardship. The integration of archaeological research about past environments, site formation, spatial distribution of artifacts, and characterization of those artifacts all offer exciting views of the Native American adaptations to this region. Additionally, the implementation of the careful and detailed archaeological methods utilized in the current limited data recovery effort at 41WA47, and possible future mitigation efforts can contribute to public programs developed from this work to illustrate how scientific archaeological inquiry develops new knowledge about the past and generates additional research questions.

\section{ReseARCH GoAls}

Both components of the archaeological investigations at Huntsville State Park offer opportunities to improve the understanding of this region. The archaeological survey, through shovel testing, provides additional data on regional patterns of use. However, the identification of remains through shovel testing does not provide significantly more sophisticated information beyond site location and possible depth of archaeological deposits. The degraded condition of three of the sites identified during survey (41WA264, 41WA265, and 41WA266) suggest that only limited information may be recoverable from these sites. Investigations at 41WA228 may offer some additional research data if testing is performed. Investigations at $41 \mathrm{WA} 47$ may provide more significant research information.

The testing and limited mitigation at $41 \mathrm{WA} 47$ represents the first detailed excavation of this site beyond the initial shovel testing performed in 1996. The known density, diversity, and depth of deposits clearly indicate that this site is a significant cultural resource within Huntsville State Park. Investigations at 41WA47 were designed to provide data that can improve understanding of this site, variation in occupational history of the project area, and potentially address larger issues of anthropological interest. In addition to the descriptive goals for recovered classes of relational and material remains, important research issues addressed by this investigation include site formation, local chronology, subsistence activities, and technology. These goals do not imply that unambiguous results are expected from this investigation. The advancement of archaeological knowledge requires rigorous approaches to expected research opportunities and appreciation of the potential complexities in evaluating archaeological data. It also demands vigilance for unanticipated results that may broaden understanding of the gaps in our learning and awareness of new dimensions to archaeological problems.

\section{Site Formation}

The emphasis on vertical excavation control is designed to address the nature of the deep deposits at 41WA47. Site formation may represent an accumulation of minimally disturbed deposits on an accreting land surface. Sediments also may have been deposited through agencies that dramatically obscure behavioral implications of the archaeological materials or suggest complete lack of contextual integrity. Field recovery and laboratory analyses in this research design offer opportunities to address some of these ambiguities. Geoarchaeological descriptions and analyses provide a first order understanding of the sedimentological 
dynamics of this location. Profiling is designed to provide a framework for interpretation of site formation history and the potential integrity of the archaeological deposits. Collection of all materials from screening allows the examination of archaeological materials and natural clasts to identify whether cultural artifacts do appear to have been deposited in a different manner than alluvial or colluvial clasts. Piece-plotting of artifacts provides a sample of fine-grained vertical and horizontal spatial information that can be critical to understanding taphonomy and site formation. Dating of well-controlled charcoal samples provides a temporal framework for understanding site formation and the integrity of the archaeological materials. Paleobotanical samples also provide information about past environment, sediment formation, and post-depositional modification of sediments and soils. Sediment susceptibility samples are an additional means of checking the apparent formation events that can be identified through geoarchaeological analysis, vertical distribution of artifacts, dating, and paleobotanical analyses. Taphonomic understanding of an archaeological site is the first critical stage to address the research implications of the different physical remains and their interrelationships (Waters 1992:11).

\section{Local Chronology}

Site $41 \mathrm{WA} 47$ appears to represent a multiple occupation site spanning the Late Archaic through Late Prehistoric periods. Dating of charcoal from this site can provide secure chronometric control of the temporal range of human activities in this location. 41 WA47 offers the opportunity to examine local chronology and changes in human behaviors at a single location. Although multiple occupation open sites are often thought to be a disadvantage to archaeological research, they can provide important controls on temporal variation in human behavior. The reoccupation of a particular location does not necessarily result only from repeated use for identical activities. The apparent time span represented at 41WA47 makes it unlikely that all revisitation events represent the same activities, organizational events, or archaeological preservation dynamics. The opportunity to control potentially variable behavior at a single site offers tremendous analytic advantage to understanding diachronic changes in past adaptive strategies. The recovery of a relatively large number of diagnostic projectile points affords critical comparisons between absolute dating of charcoal and well-provenienced artifacts. The implications of temporal analyses at 41WA47 can be significant at the regional level and address important archaeological questions of the use of diagnostic artifacts in relative dating, changes in the intensity of occupation through time, environmental and subsistence changes, and archaeological visibility of behavior.

\section{Subsistence Adaptations}

Archaeological recovery is strongly directed toward classes of residues that inform about past environments and possible subsistence activities. Paleobotanical sampling and analyses can permit reconstruction of past environment and changes that may have had an influence on human adaptations. An understanding of the prehistoric vegetation is a critical component of addressing past climate and complements the geoarchaeological interpretations of the local geomorphology. These data also provide valuable controls for interpreting faunal remains and the subsistence implications of particular tool classes. The apparent evidence of multiple occupations at 41WA47 is expected to relate to use of this area for similar or varying subsistence activities. Identification of the resource options in this setting is an important frame of reference for understanding potential seasonal behaviors. Archaeological identification of subsistence activities is one of the most well-developed and secure areas of archaeological investigations. The importance of environmental opportunities and subsistence adaptations to understanding a broad array of human organizational behaviors is well demonstrated (Binford 2001).

\section{Lithic and Ceramic Technology}

A relatively abundant amount of artifacts are present at 41WA47. Lithics and ceramics are present throughout the deep deposits at the site. They are complemented by the presence of faunal remains, charcoal, and paleobotanical residues. Lithic raw material sources were not identified in the immediate vicinity of Huntsville State Park. Much of the recovered debitage and formal implements have been made of materials with 
problematic fracturing qualities. This offers opportunities to examine lithic manufacture, use, and discard with controls on some of the parameters of lithic raw material budgets. For example, it may be possible to make inferences about parts of the technological behavioral system not strictly represented at this site. Activities that may be minor components of technological behaviors at 41WA47 are likely to include significant amounts of provisioning, early stage reduction, or significant curation efforts for some of the tools manufactured at this site. These expectations can guide inquiry about the lithic assemblage to address characteristics of the recovered sample, suggest behaviors related to larger scale landscape use, and contrast 41WA47 with other sites located in proximity to more abundant raw materials. The abundance of ceramics in the excavations offers complementary views of an alternate system of material production, use, and discard. The presence of many large sherds offers good opportunities for analyses of vessel forms represented at 41WA47. Ceramic vessels are domestic implements that frequently have very different use dynamics than lithic tools. Their coassociation strongly suggests that 41WA47 represents a habitation site containing a potentially wide range of behaviors preserved in patterns of material association and discard. The evidence of multiple occupations offers additional opportunities to evaluate significant trends in technological stability and change.

All of the research goals contain multiple implications for a variety of other significant anthropological problems. The temporal span of site occupations may provide information about changes from hunting and gathering to horticultural behaviors. Site formation data may contribute to geoarchaeological debates regarding the nature of sandy mantle deposits in eastern Texas. Site 41 WA47 can provide important views of research comparisons possible on multiple occupation sites. The research from this investigation should provide suggestions for productive future inquiry that could be performed at this significant site.

Mitigation efforts at 41WA47 have been designed to produce a variety of data that have broad scientific interest. This archaeological research is designed for interdisciplinary study of past environments, community ecology, and the dynamics of human adaptations. The depth of detail provided by this project will be used to produce a database that can be of use to other scientific investigations in the area and will also lead to the development of public information outreach material about the cultural resources of Huntsville State Park. 



\title{
Chapter 3: $\quad$ Archaeological Background
}

\author{
Richard B. Mahoney
}

\section{INTRODUCTION}

Huntsville State Park is situated in the Pineywoods of East Texas just south of the juncture of the Post Oak Savannah and Blackland Prairie vegetation subregions. The general region of the project area is bordered to the west by the Post Oak Savannah, to the north by the Ouachita province, to the east by the Southeastern Evergreen Forest of the Lower Mississippi River Valley, and to the south by the Gulf Coast Prairies and Marshes. This chapter presents a brief overview of the aboriginal cultural setting of the project area, along with a concise review of previous archaeological endeavors within the region.

\section{Aboriginal Cultural Setting}

\section{Paleoindian}

The Paleoindian period, the time when humans first entered the New World, occurs during the latter part of the Pleistocene geologic epoch. Due to the frequent location of isolated finds of Paleoindian-era projectile points and the infrequent encounter of dense occupational features, it is inferred that these peoples were highly mobile, nomadic hunters and opportunistic gatherers. Without certainty, it is possible that the cultures of this era were specialized exploiters of the dwindling population of the now extinct megafauna that once roamed the North American continent.

With some variation, the Paleoindian period for this region is generally agreed to have begun approximately 12,000 years ago and terminated roughly 8,000 years ago, sometime during the Early Holocene climatic interval (Ensor and Carlson 1988; Johnson and Goode 1994; Perttula 1999; Schambach 1998). However, Girard (2000:7) argues that the Paleoindian period for Northwest Louisiana occurs from 12,000 BP until 10,000 вP. The termination for this period, relative to conventional Texas chronologies (however slightly varied they may be) is quite premature, and Girard qualifies this discrepancy due to the fact that "archaeologists in Texas do not routinely calibrate radiocarbon dates" (2000:8). Granted, the primary reference Girard cites (Collins 1995) does not use calibrated dates; however, the periods of Collin's chronology do not differ markedly from those espoused by Johnson and Goode (1994), which are based upon calibrated dates utilizing the methodology of Stuvier and Reimer (1993).

Regardless the chronology of choice, the Paleoindian period is divided technologically into early and late phases. The early phase is characterized by the presence of primarily fluted projectile points (i.e., Clovis and Folsom) produced of non-local materials. The exotic stone tools recovered from these early sites further suggest a high-mobility culture. The late phase of the Paleoindian period is regionally characterized by dart points, such as San Patrice and Dalton, made primarily of local materials (Ensor and Carlson 1988:18; Schambach 1998). The presence of woodworking tools, such as the Dalton adze, in association with these new variant dart points suggests a slightly more sedentary culture than its predecessor.

\section{Early Archaic}

The Archaic Era represents the following ca. 6,000 to 6,500 years of prehistory for this region and is subdivided into three separate periods: Early, Middle, and Late. These three subdivisions (Early, Middle, and Late Lithic periods) correspond to those outlined in Shafer et al. (1975:13). Environmentally, this era commences just before the onset of the Middle Holocene geologic epoch, a time of "oscillating" conditions beginning at a moderate climate, trending toward a dry extreme, and returning to moderate conditions throughout the entirety of the era (Collins 1995:383; Johnson 1995). Culturally, the development of the Archaic within this region may have been attributable to late Paleoindian plainsmen exploiting the woodland-prairie margin and interacting with woodland cultures during times of drought (Johnson 1989). 
Early Archaic manifestations within the region include the apparent onset of sedentary subsistence indicated by the diversity of recovered artifact assemblages at numerous sites (e.g., Girard 2000; Wyckoff 1984). Specifically, woodworking tools, such as adzes and wedges, become more common, as well as abraders and scrapers. The Conly site in northwestern Louisiana exhibited excellent preservation of faunal remains including mussel shell, bone, snail, and crawfish exoskeletons (Girard 2000:63). Additionally, Girard (2000:63) cites the presence of burned rock, grinding stones, pounding tools, an axe, various bifaces, and bone tools as further indicators of a more diversified pattern of subsistence.

\section{Middle Archaic}

The relatively brief Middle Archaic period represents the final years of the Middle Holocene and can be viewed as a transitional time for the prehistoric peoples of the region. During the early part of this period, bison are present along the bordering plains and prairie regions after a nearly three millennia hiatus (Dillehay 1974). However, their appearance is short-lived, and by approximately 5200 BP bison once again disappear from the faunal assemblage of the Southern Plains and adjoining prairie margin. The continuance and massive proliferation of relative sedentism and/or specific exploitation of localized natural resources is evidenced by the continued occupation and reoccupation of preferred landforms (e.g., Girard 2000:8). These adaptations, in response to an increasingly drier environment (c.f. Bousman 1998; Johnson 1995), would form the basis for the transformation in the overall stylistic tradition to that of the Late Archaic.

\section{Late Archaic}

The Late Archaic period represents the final three millennia of the Archaic Era, from approximately 4200 BP to 1200 вP (Johnson and Goode 1994:29), and roughly coincides with the commencement of the Late Holocene. Within northeast Texas, the Woodland, pre-Caddoan culture introduces a new aspect to this generally accepted time of pre-ceramic, dart and atlatl using inhabitants of the state. Crude ceramics alongside smaller dart points typical of the Late Archaic period are diagnostic of this Woodland period.

Adaptation to a relatively dry climate with low precipitation and high temperatures appears to mark the beginning of the period (Bousman 1998), with bison reappearing in the faunal assemblage following over a one thousand year hiatus (Dillehay 1974). Despite these xeric conditions, human population seems to have increased within the region (Prewitt 1985; Shafer et al. 1975:17). Adaptation to this changing environment is best shown in Shafer's (1974) discussion of the Lake Conroe Reservoir project. During this time, burned rock accumulations are noted inland, with similar burned clay "ball" accumulations occurring in lithic poor environments toward the Gulf Coast. Floodplain-focused adaptation during this time is evident in various sites adjacent to the region (e.g., Girard 2000:9; Mahoney and Tomka 2001). Environmental changes can be cited as determinant factors in settlement patterns during this time. Specifically, temporary stabilization of stream bank terraces influenced settlement locations.

As evidenced in recovered artifact assemblages in the region, processing of plant resources appears to increase during this period (Story 1990). Palynological evidence from the Boriak Bog (Lee County, Texas) and the Weakly Bog (Leon County, Texas) reveals relatively low arboreal canopy cover, indicating a predominant grassland environment for these adjoining regions (Bousman 1998:Figure 7). Johnson and Goode (1994:34-35) propose for Central Texas that, due to the xeric conditions experienced by the peoples of the Late Archaic I period, burned rock middens proliferate for the processing of semi-succulents. Typical eastern Texas projectile-point styles of this period include Dawson, Gary, Kent, and Morrill (Fields 1995:305).

Johnson (1995) suggests Eastern (United States) religious influences, manifested in the form of various burial practices, as one of the primary indicators of the Late Archaic II phase in the adjoining Central Texas region. The continuum of the trend toward a mesic environment can also be attributable to this period change. While a definitive date cannot be placed upon the abandonment of burned rock middens, Johnson and Goode (1994) note that these feature types are generally associated with the Late Archaic I phase, and the 
diminishing numbers thereof denotes the beginning of the Late Archaic II phase.

\section{Early Ceramic}

Unique to eastern Texas cultures, the Early Ceramic period encompasses the latter roughly 700 years of the traditionally accepted Late Archaic period and the initial 200 years of the traditionally accepted Late Prehistoric period in other Texas temporal chronologies. Within the Southeast Texas area, this period basically subsumes the Late Archaic II phase of Central Texas, referenced above. Artifact assemblages consist primarily of later, smaller Gary and Kent dart points and early arrow points such as Scallorn with early, sandy paste ware ceramics. As stated above, most ceramic cultures within Texas are associated with the Late Prehistoric. Here, Archaic-era dart points are encountered alongside similar ceramic vessels and associated sherds. This coincidence provides strong evidence for a suggested continuum of aboriginal technology within this region. While the advent of ceramics in concert with the occurrence of the bow and arrow in the majority of the remainder of the state signifies the onset of the Late Prehistoric period, the advent of ceramics alone indicates the Early Ceramic period of Southeast Texas.

For the Upper Texas Coast, Aten (1983) further subdivides this period into the Clear Lake, Mayes Island, and Turtle Bay periods. Aten utilized graphic seriation of aboriginal ceramic types to define his more detailed regional chronology. The Clear Lake period (1900-1650 BP) introduces ceramic technology to the archaeological record with temporal diagnostics of early sandy paste wares. The intermediate period, Mayes Island (16501350 вр), is marked by a predominance of Goose Creek Plain, var. Goose Creek ceramics. The final subdivision of the Early Ceramic period, Turtle Bay (1350-1000 BP), reveals an increase in Goose Creek Red Filmed and, more importantly, introduces the arrow point to the archaeological record of Southeast Texas.

The introduction of these early ceramics into the region has primarily been attributed to influence from the Tchefuncte culture (Weinstein et al. 1989:18) of the Tchula period of the adjoining Lower Mississippi River Valley region to the east (Hahn et al. 1994:14). Key markers of this ceramic technology are sandy paste wares of introduced varieties such as Tchefuncte Plain, Mandeville Plain, and O'Neal Plain (Weinstein 1986), and various local varieties of Goose Creek Plain (Aten 1983:287).

In the Central Texas region, bordering the western edge of the Southeast Texas area, Prewitt (1981:Figure 3) identifies the initial succeeding Late Prehistoric phase as the Austin Phase, occurring from the termination of the Late Archaic II until approximately $650 \mathrm{BP}$. This phase would generally be coeval with the final 200 years of the Early Ceramic cultures. Aside from the aforementioned changes in technology, Prewitt (1981:74) ascribes only a slight increase in the dependence upon hunting as a means of subsistence and a marked increase in the occurrence of "true cemeteries" as an indicator of period change.

In the Caddoan area adjoining to the north, transition from the Late Archaic, and more specifically from the Woodland (2500-1200 BP), to the Formative Caddoan (1200-1000 BP) period is arguably accepted to occur with the advancement in technology from hunting techniques utilizing the atlatl and dart to utilization of the bow and arrow, alongside the beginning of horticultural groups (Kenmotsu and Perttula 1993). Thus, the Woodland and Formative Caddoan periods would generally be coeval with the Early Ceramic cultures of Southeast Texas.

\section{Late Ceramic}

The subsequent Late Ceramic period is marked by the addition of the bow and arrow to the technological repertoire. Shafer et al. (1975:21) suggests that the bow and arrow may have been introduced by the Caddo to the north during the preceding Turtle Bay sub-period of the Early Ceramic period. However, rather than leading to the complete conversion of hunting practices, lithic assemblages from a number of East Texas sites (Fields 1995:314; Story 1990:275) suggest that dart points such as Gary and Dawson and atlatls may have continued in use throughout at least the first part of this period.

Continuing with the seriation of aboriginal ceramics, Aten (1983) again subdivides this more general period into two prehistoric periods, Round Lake and Old River. 
The Round Lake period (1000-650 вP) is discernible with the introduction of grog-tempered ceramics, although sandy paste wares are still in use during the early part of the period. The final prehistoric period for the upper Texas coast, Old River (650 BP to European contact), witnesses a variance of grog-tempered predominance, followed by a return to sandy paste wares, and concludes with the proliferation of bone tempering.

As opposed to eastern ceramic technology influences experienced during the Early Ceramic period, the archaeological assemblage of the Late Ceramic period is indicative of more of a northern, or Caddoan, technological influence. Specifically, Weinstein et al. (1989:20) cite the decorative motif of excising, a Caddoan marker, in combination with the increase in bone-tempered wares as strongly influenced by Caddoan culture.

To the west, the continuing Austin phase and the succeeding Toyah phase, as defined by Prewitt (1981), is characterized by the "dramatic" shift in subsistence from hunter-gatherer to that of an economy based primarily upon hunting. The majority of the Austin phase would generally be coeval with the Round Lake period, and the Toyah phase would generally be coeval with the Old River period. Based upon data from Dillehay (1974), bison once again appear in the faunal assemblage of archaeological sites within Central Texas. An intermediate shift to a generally dry, mesic environment is attributed to this influx of ungulate dependence (Johnson 1995). The material culture of this time period appears to reflect subsistence based upon the procurement of bison in the form of various stone tools utilized for both bison procurement and processing, such as Perdiz arrow points, along with "tear-drop-shaped" scrapers and beveled knives.

In the Caddoan area adjoining to the north, formal horticulture proliferates and agriculture begins with the Early Caddoan period (1000-800 BP); agriculture intensifies through the Middle Caddoan period (800$600 \mathrm{BP})$; and culminates during the Late Caddoan period (600 BP to European contact) with intensive agriculture, primarily of maize (Kenmotsu and Perttula 1993). Accordingly, the suite of Early, Middle, and Late Caddoan periods would generally be coeval with the Late Ceramic cultures of Southeast Texas.

\section{Previous Investigations}

The bulk of previously recorded archaeological sites in the Walker County region are centered about work on the Honea Reservoir (now, Lake Conroe) and the associated San Jacinto River, and the Lake Livingston Reservoir and the associated Trinity River: the ConroeLivingston Area per Aten (1983). These reservoirs are located at, and form the boundary of, Walker County in the northeast and the southwest. The balance of the previously recorded prehistoric sites in Walker County, similar to the remainder of inland Southeast Texas, is comprised of earthen midden deposits in riverine settings (c.f. Perttula 1993:210) and on interfluves overlooking major drainages (Fields 1995:307, 314).

Professional archaeological investigations begin in the region with the 1933 University of Texas excavations at the C. W. Ellis and Carl Matthews sites (41PK1 and 41PK2, respectively) in nearby Polk County (Barnard 1939). Excavations at the multicomponent Ellis site revealed cultural material spanning the Late Paleoindian through the Late Archaic periods. The Matthews site produced artifacts ranging from the Late Archaic through the Historic periods, including two Protohistoric burials.

Save for a single East Texas regional effort by Arnold of the University of Texas during 1939-1941 (Duffen et al. 1940), apparently no professional archaeological investigations were conducted in the region until the Texas Archeological Salvage Project (TASP) reservoir projects of the 1960s. The Arnold regional study focused primarily on the location of historic Alabama-Coushatta Indian sites in East Texas, apparently to little avail (Davis et al. 1994:22).

The impending construction of the Honea and Livingston Reservoirs necessitated archaeological surveys that resulted in the recordation of over 230 sites in Walker and, primarily, in the surrounding counties. During the 1965 survey of the proposed Honea Reservoir, Shafer (1965) recorded a total of 34 archaeological sites. Only one site (41WA51), a prehistoric site of unknown temporal affiliation, was recorded in Walker County, though. The Livingston Reservoir survey was initially begun by TASP during the 1961-1962 investigations (Nunley 1963). The Houston Archaeological Society 
(HAS) continued survey efforts from 1964 through 1969. In total, over 200 sites were recorded by TASP and HAS, with only seven occurring in Walker County (41WA1 through 41WA7). From 1965 through 1967, TASP conducted more intensive cultural resource investigations at six sites surrounding the Livingston Reservoir (McClurkan 1968) and three sites surrounding the Honea Reservoir (Shafer 1968). It is interesting to note that none of the sites identified in Walker County were judged to warrant further investigation.

Intensive work at prehistoric sites did not resume until the mid-1970s, with a survey of areas to be impacted by United States Forest Services development adjacent Lake Conroe (Shafer and Baxter 1975). Two sites (41WA81 and 41WA82) were located in the Kaygal Recreation Area in Walker County and four were located along Scott's Ridge in Montgomery County. Subsequent to this survey, 41WA82 was subjected to further testing (McNatt 1978), as was 41MQ41 (Shafer and Stearns 1975). The Kaygal site revealed occupations of the Early and Late Ceramic periods, while the Scott's Ridge site produced artifacts spanning the late Paleoindian through Middle Archaic periods.

Following another decade-long hiatus, intensive work resumed with the 1984-1985 excavations at the Crawford Site (41PK69), in Polk County. The site is located north of Lake Livingston and was discovered by State Department of Highways and Public Transportation archaeologists during survey for a bridge replacement in 1984 (Denton 1984). In total, roughly $114 \mathrm{~m}^{3}$ was excavated, revealing a temporal span from the Early Archaic through Protohistoric periods (Ensor and Carlson 1988).

Most recently, in 1996, Prewitt and Associates, Inc., conducted National Register of Historic Places (NRHP) eligibility testing of 41WA185 in Walker County (Gadus and Fields 1997). Results of the investigations revealed two isolable components covering the Early Ceramic and Late Ceramic periods. Due to the apparent high integrity of the site, 41WA185 was considered eligible for NRHP. 



\title{
Chapter 4: $\quad$ Archaeological Survey
}

\author{
Russell D. Greaves
}

\section{INTRODUCTION}

Archaeological survey investigated six areas that represent approximately 160 acres (65 ha). This survey was performed to identify archaeological sites that may be present within areas that are scheduled for roadway improvements. One previously recorded site (41WA228), consisting of two positive shovel tests, was revisited during this effort. Three new archaeological sites (41WA264, 41WA265, and 41WA266) were encountered. These sites represent small or dispersed, low-density artifact concentrations. One of these sites (41WA265) was identified through the presence of several artifacts in two shovel tests. The two largest distributions are in very disturbed areas with poor subsurface integrity and have been subject to multiple episodes of recontouring with imported sedimentary fill. None of the three new archaeological sites evaluated during this portion of the investigation had any significant surface manifestations. Mapping of these sites was based on the presence or absence of artifacts from shovel testing. The SAL/NRHP eligibility of site 41WA228 remains unknown.

Additional shovel testing, recording, and limited mitigation was performed on one previously identified site, 41WA47. This site dates to the Ceramic period with possibly stratified cultural deposits extending almost two meters below the current ground surface. This site is officially designated as a SAL. Chapter 5 provides the detailed survey and testing investigation information for the archaeological work conducted at 41WA47.

\section{Survey and Shovel Testing Methods}

\section{Shovel Testing}

Survey involved pedestrian traverse and standard shovel testing of six areas identified for reconnaissance by TPW. Shovel tests were identified by the area (i.e., Areas A-F), the transect number (e.g., T01), and the specific unit numbers (e.g., ST04, ST12). For instance, shovel test B-T02-ST04 refers to the fourth shovel test on transect two, in Area B.

Shovel tests consisted of $30 \times 30-\mathrm{cm}$ units excavated in $10-\mathrm{cm}$ arbitrary levels below ground surface. Every shovel test (ST) was excavated to at least $60 \mathrm{~cm}$ below the current ground surface (bgs), unless soil conditions prevented effective excavations to that depth. Some shovel tests were terminated at shallower depths because of the presence of an older subsoil unit, identified disturbance from water or electrical line burial, or perched water tables. Fieldwork was performed during the time of tropical storm Allison. Approximately 14 inches $(36 \mathrm{~cm})$ of rain was recorded within the park during three days, and an additional five inches $(13 \mathrm{~cm})$ of rainfall occurred within two days during the fieldwork. Perched water that supersaturated the massive sands was encountered in many shovel tests at variable depths. Topographic position was not a predictor of soil drainage conditions. It appears that proximity to the highly variable upper boundary of the older Bt soil horizon is responsible for conditions influencing the flow of vadose water in these soils. Most areas of these soils drained within five to ten days of the heavy storm downpours. Although the older Bt soil horizon was not encountered in all shovel tests, this amount of variability in saturation of the upper sandy sediment strongly suggests a very irregular depth to this unit across the park area.

The occurrence of the older, rubified Bt soil horizon below the sand soils was used as a termination point of excavation in much of the survey area. This decision was based on several shovel test units that were excavated into this fine, sandy clay loam soil to determine whether it contained archaeological material. Four shovel test units in Area A, four shovel tests in Area B, one unit in Area D, and 36 shovel tests in Area E were excavated at least $5 \mathrm{~cm}$ into the Bt soil. Most of these extended $\geq 10$ $\mathrm{cm}$ into the Bt horizon and none produced any artifacts. Based on the results of these shovel tests and information from a backhoe trench placed within 41WA47, it was determined that this soil horizon is unlikely to be young enough to contain archaeological materials. These 
Bt horizons underlying the Holocene alluvium are probably no younger than the Late Pleistocene (Crawford and Nordt 2001; Kuehn 1996:33-34; Nordt and Bousman 1998:14), and formed from Late Pliocene-Early Pleistocene Willis formation rocks (Aronow 1979:54; McClintock et al. 1979:Table 21). A total of fourteen shovel tests distributed in all survey parcels was excavated to a depth of $70 \mathrm{~cm}$ below ground surface.

Shovel tests were placed along transects oriented to compass directions (north, south, east, or west), depending on the shape of each area and its geomorphic setting. Intervals between each transect were $30 \mathrm{~m}$. Individual shovel tests were situated along transects at $30 \mathrm{~m}$ from each other in Areas A-E. This interval also provided adequate examination of areas with minimal buried archaeological material. More closely spaced shovel tests were used to examine some areas with subsurface prehistoric remains. Only two shovel tests were excavated within each of Areas C and D, the two smallest parcels. Subsurface artifact densities did not suggest the presence of archaeological deposits within Areas C and D. In the eastern portions of the most heavily disturbed part of the survey area (Area F), the intervals between transects and shovel tests were increased. These areas have a profusion of enclosed cabins, buried water and electrical lines, and parking pullouts, that are more densely spaced than in other portions of this recreational area.

All sediments removed from shovel test units were screened through $1 / 4$-inch mesh. From the survey area, only cultural materials retained within the screen were reserved for laboratory analyses. The approximate frequency of natural clasts was noted for every excavation level in each shovel test. This information is useful in addressing sediment deposition in this area and site formation. A more detailed discussion of the use of data on natural clasts is presented in a section on mitigation methods for site 41WA47 in Chapter 5.

A shovel test form was completed for every excavated shovel test. Data collected from each shovel test include the final excavation depth, a tally of all materials recovered from each $10-\mathrm{cm}$ level, and a brief soil description (texture, consistence, Munsell color, inclusions). A profile sketch was made for a few of the shovel tests. Because the sediment and soil profile was redundant across the entire survey area, these sketches were not made for every shovel test. The location of most shovel tests was identified through the use of Trimble Geo Explorer II GPS units. Because of poor horizon visibility in portions of the survey area and periodic unavailability of satellites, some shovel test units could not be positioned by the GPS. These shovel tests were sketched onto detailed topographic maps that included the park features. A brief, informal description of the location of each shovel test unit relative to adjacent tests or park features was included for those units that could not receive a GPS reading. Most of these units are bracketed by adjacent shovel tests whose positions could be fixed by the GPS data recorders.

The 30-m interval between shovel tests provided adequate coverage to determine the presence of archaeological sites at Huntsville State Park. In some locations, shovel tests were more closely spaced to determine whether the presence of archaeological materials suggested the presence of an archaeological site or isolated artifact occurrences. Isolated occurrences were defined as three or fewer artifacts that are spatially separate from any identified clustering of artifacts that is designated as an archaeological site. An arbitrary distance of $50 \mathrm{~m}$ from such a clustering was applied to the definition of artifacts as isolated occurrences. In two areas additional shovel tests were excavated between the standard intervals -in a judgment sample- to adequately identify the apparent site boundaries, depth of deposits, and provide sufficient information for a preliminary evaluation of site significance. The precise number of additional shovel tests required to accomplish these goals varied in relation to the size of the archaeological site, the apparent integrity of the cultural deposits, and the nature of the artifacts recovered.

\section{Special Samples}

Only one set of specialized samples was collected from shovel tests. No evidence of archaeological features was encountered in any shovel test units. Sediment magnetic susceptibility samples were collected from each $10-\mathrm{cm}$ level in all shovel tests in Areas A, B, C, and D. Samples from every level also were collected from approximately 
one half of all shovel tests excavated in Area E. Because of the redundancy in the soil profile across all of the survey landscape, only single samples were collected from Level 4 (30-40 cm bgs) in the shovel tests on the western side of Area E and in all of Area F. It was determined that the samples from other areas represented sufficient data to examine patterns of soil susceptibility in relation to soils, sediments, and archaeological deposits. Sufficient matrix to approximately fill a $2.5 \times 3$ inch zip-closure sealable bag was taken for each sample.

No other specialized samples were collected because of the difficulty in determining context within $30 \times 30-\mathrm{cm}$ shovel test units. Some wood charcoal and gastropods were collected from shovel testing. These remains have not been submitted for dating, paleoethnobotanical, or paleoenvironmental analyses because the poor contextual control offered by 30 x 30-cm units makes stratigraphic assignment of these samples unreliable. They have been retained for possible species identification or other future research uses.

\section{Survey Results}

Areas A, B, C, and D are each relatively small survey tracts that contained no evidence of archaeological sites. The results of the 38 shovel tests in these areas (see Figure 2-1) are presented in Appendix E. None of the shovel tests produced any undeniably cultural prehistoric materials. Recent debris from park visitors was common in all portions of the survey, but no historic artifacts were encountered in any shovel tests. Some fragments of concrete that may be derived from the early twentiethcentury construction of picnic benches were the only historic materials encountered that did not represent recent refuse.

\section{Area A}

Area A is located at the northern end of the park. It is situated on the eastern side of the park entrance facility and extends southwestward along the eastern side of the road (see Figure 2-1). Area A covers the road margin from the entrance to just south of the intersection of the two main campground roads. Construction of a new, paved parking lot is scheduled for a portion of this survey parcel approximately $100 \mathrm{~m}$ east of the road right-ofway. Most of this area is currently only minimally disturbed. A total of 20 shovel tests was excavated in this area. These shovel tests were almost entirely within the upper, massive sand deposit that can be correlated across the entire park area. The older, underlying Bt soil horizon was encountered in only four shovel tests in this area, between $30-55 \mathrm{~cm}$ bgs. Shovel tests in Area A ranged from $50-70 \mathrm{~cm}$ bgs in completed excavation depth. Recent refuse was common, especially close to the road, but no prehistoric artifacts were recovered from any of the 20 shovel tests in this area (Appendix E). On the basis of these shovel test results, clearance of this area for road improvements and construction of the parking facilities is recommended.

\section{Area B}

Area B is south of Area A in a location currently housing equestrian corral and maintenance facilities (see Figure 2-1). The equestrian compound will be improved with the construction of a paved roadway and parking lot. Fourteen shovel tests were excavated in this area, their depth ranged from 40 to $70 \mathrm{~cm}$ bgs. In shovel test BT02-ST04 the Bt soil horizon was contacted at $40 \mathrm{~cm}$ bgs. The eastern three-quarters of this area have been extensively modified through mechanical leveling and preparation of the existing equestrian facility, gravel parking area, and seasonal housing. There was much evidence of localized disturbance within the survey parcel. Shovel test unit B-T01-ST05 was not excavated because its transect position had extensive evidence of household dumping and surface recontouring. No prehistoric artifacts were encountered in any of the 14 shovel tests excavated in Area B. Only four of these shovel tests encountered the older Bt horizon between 23 and $50 \mathrm{~cm}$ bgs (Appendix E). A fourth unit displayed mottling at the base of the excavation, $60 \mathrm{~cm}$ bgs, that is probably indicative of proximity to the upper boundary of the Bt horizon. Because no evidence of prehistoric or historic resources were encountered during testing and the area has been subject to ongoing impacts, no additional cultural resources characterization is considered necessary in Area B. 


\section{Areas C and D}

These two survey parcels are considered together because they are small and only two shovel tests were excavated in each of these locations (see Figure 2-1). Results of shovel testing in Areas C and D are presented in Appendix E.

Area $\mathrm{C}$ is located on the western park access road leading to the larger, more-developed campground area (Area F). A small area of approximately 0.1 acre (0.04 ha) on the western side of the road was examined in preparation for expansion of parking facilities adjacent to hiking and bicycling trails. Two shovel tests were excavated in this small area. A single piece of angular chert came from Level 3 (20-30 cm bgs) in shovel test C-T01-ST02. No other artifacts were encountered in this unit, excavated to a final depth of $70 \mathrm{~cm}$ bgs. Although this piece was identified as angular debris, in the absence of other associated artifacts, it is considered a non-culturally fractured gravel fragment. The other shovel test in this survey parcel did not contain any artifacts. Recent charcoal was encountered in the upper $10 \mathrm{~cm}$ of shovel test C-T01-ST01 but no other modern debris or historic materials were found in either excavation unit.

There is some spatial incongruity between the placement of this area on the maps provided by TPW and the shovel test locations from GPS readings (see Figure 2-1). TPW personnel provided a map showing the location of Area $\mathrm{C}$ at the intersection of two roughly-north-south running trails with an east-west running trail that intersects the two parallel trails at a nearly right angle. A 0.5 acre $(0.2$ ha) area at this intersection was surveyed and shovel tested by CAR personnel. Following the fieldwork, Texas Department of Transportation maps provided to TPW indicated that Area C was located approximately $152 \mathrm{~m}$ to the north at the intersection of two, rather than three, trails. Contingent on verification whether the area examined during field work is the intended location for survey testing, clearance for construction is recommended. The single piece of angular debris does not indicate the presence of any significant archaeological resources within the area of impact. No additional characterization of this locality is considered necessary and the proposed parking improvements should be allowed to proceed as planned.
Area $\mathrm{D}$ is located on the eastern access road to the lessdeveloped campground (Area E). Two shovel tests were excavated in this 0.25 -acre (0.1-ha) area on the eastern side of the road. As with Area $\mathrm{C}$, this location is scheduled to receive a small parking facility adjacent to hiking and bicycling trails. One of these units had a very thin mantle of sandy sediment overlying the older Bt soil horizon just $10 \mathrm{~cm}$ below the current ground surface. No prehistoric artifacts were recovered in these shovel tests. There were no recent or historic artifacts found within these excavation units. No additional archaeological testing in this area is considered necessary.

\section{Area $\mathrm{E}$}

Area E encompasses the eastern campground area at Huntsville State Park along the shore of Lake Raven (see Figure 2-2). This survey block encompasses approximately 50 acres (20 ha). It consists mostly of minimally improved tent camping areas, picnic tables, and associated roads, parking pullouts, bathroom facilities, and one recontoured recreational field. The northernmost camping loop has been more heavily modified to accommodate recreational vehicle (RV) camping. Although this area may receive lower visitation than the campgrounds in Area F, it is intensively used on weekends and holidays. The charcoal from recent campfires forms extensive midden deposits outside of the cleared use area. In some shovel tests, and in the controlled excavation, it is apparent that some of this charcoal is becoming mixed into the upper pedons to a depth of $30 \mathrm{~cm}$. A recent roasting pit was identified in excavation unit NN51-19 (N976-E1099) on site 41WA47. This pit contained abundant charcoal and sawn bone fragments. The practice by campers of excavating roasting pits has been noted by TPW personnel (Art Black, personal communication 2001).

The designated survey area is restricted to the campgrounds along the margins of Lake Raven, at the former confluence of Big Chinquapin and Little Chinquapin Creeks. The soils and sediments in this location are very uniform. The upper portion of the soil profile is a sand unit of uncertain origin overlying an older, slightly loamy sand (Bt). The upper portion of the sand has weakly developed soil horizons extending 
approximately $40-80 \mathrm{~cm}$ bgs, depending on the depth of this sand deposit. This sand is probably a lower energy alluvial unit, but the presence of siliceous gravels and plinthites suggest that some slope wash colluvial and alluvial deposition also is represented. A few of the units nearest the lakeshore exhibited gleying, but less consistently than seen in Area F. The older Bt soil horizon was encountered in 68 (34\%) of the shovel tests at depths ranging from $6-60 \mathrm{~cm}$ bgs.

A total of 202 shovel tests were excavated within Area E (see Figure 2-2; Appendices $\mathrm{F}$ and $\mathrm{H}$ ). Two new archaeological sites (41WA264 and 42WA265) were recorded and site $41 \mathrm{WA} 47$ was extensively shovel tested. Of the 202 shovel tests, 26 were dug on site 41WA264, eight were excavated on $41 \mathrm{WA} 265$, and $41 \mathrm{WA} 47$ received 46 shovel tests. The remaining 122 shovel tests were excavated in off-site locations. Of the 122 off-site shovel tests, 7 (6\%; E-T04-ST14; E-T11-ST09; E-T12ST15; E-T13-ST04; E-T14-ST18; E-T16-ST01, and ET16-ST03) contained prehistoric artifacts $(n=24)$ consisting of debitage $(n=20)$, cores $(n=2)$, and firecracked rock $(\mathrm{n}=2)$ between 10 and $70 \mathrm{~cm}$ bgs. An additional 26 off-site shovel tests contained modern artifacts $(n=33)$ consisting of plastics, wire, pull tabs, concrete, tent stakes, bottle caps, and glass distributed between $1-40 \mathrm{~cm}$ bgs.

\section{WA264}

Site 41WA264 is located at the extreme eastern end of Area E in a heavily modified campground loop (see Figure 2-2). Boes (1992:Figure 3, Table 1) excavated four shovel tests within the boundaries of the site. Since none of them recovered archaeological materials, he did not identify this location as a site. Shovel Test 9, excavated by Boes (1992:Table 1) encountered a water pipe indicating significant disturbance in the area.

A total of 26 shovel tests were excavated on site by CAR staff. Of these, eight (31\%) shovel tests contained prehistoric artifacts (E-T02-ST02, E-T04-ST02, E-T04ST07, E-T04-ST08, E-T08-ST02, E-T09-ST02, E-T10ST02, and E-T10-ST04) from 11-60 cm bgs. Seven of the eight shovel tests contained lithic artifacts, the eighth (E-T02-ST02) contained carbonized nutshell fragments in Level 6 (50-60 cm bgs). All but two of the seven units contained only a single lithic (Appendix F). Shovel test E-T04-ST07 contained a single recent artifact in Level $1(0-10 \mathrm{~cm} \mathrm{bgs})$. Eight $(80 \%)$ of the ten lithic artifacts recovered are from Level 4 or below. Of the ten chipped lithic artifacts, nine are flakes and one is an early reduction stage biface. Of the nine flakes, six $(67 \%)$ are fine-grained quartzite specimens, and three $(33 \%)$ are chert. Four $(67 \%)$ of the quartzite flakes are corticated and two $(33 \%)$ are decorticate. Two of the chert flakes are decorticate. The early reduction stage biface is a small, poor-quality chert pebble ( $54 \times 35 \times 28 \mathrm{~mm})$ with ten flake scars.

The area identified as 41WA264 covers $20,884 \mathrm{~m}^{2}$. This area is separated from site $41 \mathrm{WA} 47$ by a drainage and landform differences that strongly suggest that these artifacts are not related to the intact archaeological deposits identified at that site.

All of the area of 41WA264 where artifacts were recovered has been heavily disturbed from construction of roadway loops, camping areas, and sanitary facilities. Many of the shovel tests in this area encountered disturbed sediments, high amounts of gravels, and other evidence of construction disturbance. A total of nine flakes, one biface, and carbonized nutshell fragments were recovered from the eight positive shovel tests. Although many of the artifacts encountered were recovered at $30 \mathrm{~cm} \mathrm{bgs}$, this site appears to have poor integrity from the campground construction, improvements, and maintenance activities. Based on the low-density occurrence of artifacts and evidence of significant recent recontouring damage to these sediments, no additional archaeological characterization is recommended for this site.

\section{WA265}

Site 41WA265 is located in the extreme northern portion of Area E (see Figure 2-2). A total of eight shovel tests were excavated on this site. Initial survey efforts on the site produced three flakes (Level $4 ; 30-40 \mathrm{~cm} \mathrm{bgs}$ ) and a dart point stem fragment (Level 6; 50-60 cm bgs) from Shovel Test E-T18-ST01 (Appendix F). Two of the three flakes are fine-grained quartzite, and the third is novaculite. A tertiary quartzite flake and the novaculite specimen are heat-treated. The secondary quartzite flake is not heat-treated. The stem fragment is made of silicified wood and may be a Dawson type, although it is too 
fragmentary to identify with confidence. An additional seven shovel tests were excavated near to this unit at 15$\mathrm{m}$ intervals to determine whether this was a site or isolated occurrence. Two lithics were recovered from Level $3(20-30 \mathrm{~cm} \mathrm{bgs})$ of one of the adjacent shovel tests (E-T18-ST01-N01). Shovel tests that did not contain artifacts completely encircle the two positive units. Minimally, this site covers $790 \mathrm{~m}^{2}$. These two shovel tests were given a site designation because they represent an artifact density above the arbitrary definition of isolated occurrence used in this survey and one unit contains material from $30-60 \mathrm{~cm}$ bgs. It is possible that additional artifacts are present in untested areas to the north and east of 41WA265. In the process of archaeological investigations for a proposed wastewater system at Huntsville State Park, McNatt et al. (2000:64) documented one site, 41WA227, that appears to be situated east of $41 \mathrm{WA} 265$. Since $41 \mathrm{WA} 265$ is potentially down slope of 41WA227, it is possible that the two positive shovel tests in 41WA265 represent artifacts redeposited through slope wash from 41WA227. Given that this possibility cannot be established with certainty, at the present time it is assumed that 41WA265 is a new site. No additional investigation of this site is considered necessary. However, future construction activities in this area should further evaluate whether these shovel tests are part of a larger site (41WA227).

Twelve other shovel tests within Area E contained prehistoric artifacts. None of these units contained more than a single flake and seven were in excess of $60 \mathrm{~m}$ from any other isolated occurrence or identified site boundary. One of the positive shovel tests (E-T14-ST03) is approximately $30 \mathrm{~m}$ north of the northwestern boundary of 41WA47. This shovel test was not included within the site boundary because it is significantly downslope from most of 41WA47. Although this isolated lithic is probably derived from 41 WA47, its position is unlikely to represent an extension of the site boundaries.

Although two low-density sites have been identified in Area $\mathrm{E}$ in addition to $41 \mathrm{WA} 47$, it is very unclear what the more ephemeral sites may represent. The artifacts identified at 41WA264 are related to very extensive disturbance and the use of imported fill in construction of this camping loop and restroom facility. None of the positive shovel tests outside of the vicinity of $41 \mathrm{WA} 47$ appear to represent dense deposits of in situ materials that suggest analogous deposits to those in 41WA47. On the basis of current information, it cannot be determined whether 41WA264 might represent a short-term occupation that is similar to a synchronic portion of the stratified events seen at 41WA47. The presence of 41WA264 at this confluence region does provide important evidence regarding the revisitation of this locale. An additional five previously recorded sites are located along the Little Chinquapin Creek drainage east of this survey area (41WA54, 41WA202, 41WA203, 41WA204, and 41WA206) and several of these sites are small, low-density sites. Improved understanding of the prehistoric use of this area should involve investigation of both large and small archaeological occupations. Site 41WA264 does not appear to contain sufficient integrity to offer a good opportunity for examination of one of these lower-density occupation sites.

\section{Area F}

Area F is the largest survey parcel in this project, covering approximately 100 acres (40 ha; see Figure 2-3). This survey parcel is situated on a peninsula into Lake Raven between the western bank of Big Chinquapin Creek and the eastern bank of the former channel of the Prairie Branch of East Sandy Creek. The camping and recreational facilities in Area $\mathrm{F}$ have been much more developed than those in Area E. Road systems, paved pullout areas, paved parking lots, bathrooms, service facilities, subterranean electrical and water lines are more extensive than in Area E. Many of these improvements were constructed during the early twentieth century. This area accommodates more RV camping than the other campground, and appears to suffer greater impacts from visitation. Other services such as swimming, boat rental, enclosed cabin visitation, and concessions are confined to this portion of Huntsville State Park. Some of the interior of this camping area has been less impacted by development, but is not pristine. Buried power lines, trail clearance, and underbrush management have affected all portions of the survey parcel. Numerous scatters of recent trash are indicative of the frequent visitation of areas away from established campsites.

Sediments and soils in Area F are nearly identical to those in Area E. All of the upper material is weakly developed sandy soils with massive underlying sands that are 
unmodified by pedogenesis. The entirety of this sand unit is underlain unconformably by an older soil remnant represented by a Bt horizon. Only $19(9 \%)$ of the shovel tests in Area F encountered the Bt soil horizon, at depths ranging from $10-56 \mathrm{~cm}$ bgs. Some shovel tests along the lake margin exhibited gleying that obscured the recent soil horizons. Some portions of the southern half of the survey area exhibited what appear to be over-thickened B horizons. These may represent slight differences between the Landman association soils (McClintock et al. 1979:46-47) and the Gunter soils (McClintock et al. 1979:43, Map 53) that were more common in the other survey parcels.

A total of 212 shovel tests were excavated in Area F (see Figure 2-3; Appendix G) One new archaeological site, 41WA266, was discovered and the boundaries of an existing site, 41WA228, were expanded as a result of the shovel testing. Of the 212 shovel tests, ten were dug in 41WA266, and 55 were excavated in 41WA228. The remaining 147 were excavated in off-site locations. Of the 147 off-site shovel tests, 16 contained cultural materials. Of these 16, only six (4\%; F-T08-ST02, FT16-ST13, F-T17-ST05, F-T17-ST07, F-T22-ST03, and F-T26-ST07) contained prehistoric artifacts $(n=6)$ consisting of unmodified debitage $(n=4)$, a core fragment (F-T08-ST02, Level 2), and a biface edge fragment (FT17-ST05, Level 1) distributed between 10-60 cm bgs. The other ten shovel tests contained recent artifacts $(n=11)$ such as unidentified metal, wire fragments, pulltabs, and glass, distributed between $10-40 \mathrm{~cm}$ bgs.

\section{WA228}

Site 41WA228 was previously identified on the basis of 14 flakes recovered from two shovel tests within a buried utility corridor (McNatt et al. 2001). The initial site description identified a site area of 5,104 $\mathrm{m}^{2}$ located southwest of the Huntsville State Park superintendent's residence. A total of 55 shovel tests were excavated at the site during the current project. Of these, 21 (38\%) were positive with materials concentrated primarily between 10-60 cm bgs (see Appendix G). All of the positive shovel tests contained flakes. In addition, one of these positive shovel tests contained a single recent artifact (can lid) in Level $2(10-20 \mathrm{~cm} \mathrm{bgs})$. An unidentified bone fragment was recovered from Level 4 of F-T08-ST04, another of the positive shovel tests. Charcoal samples were recovered from Level 4 and 5 of this same unit. A total of 27 flakes have been recovered from the 21 positive shovel tests. Levels 2 and 3 contained four and five flakes, respectively, while Levels 4-6 (30-60 cm bgs) each contained five or more flakes. Nineteen $(70 \%)$ of the 27 flakes are chert. Only two $(11 \%)$ of these are secondary, all others are tertiary flakes. Eight pieces of petrified wood are also present in the collection, with five $(63 \%)$ of them tertiary and three $(38 \%)$ secondary.

Shovel test results from this survey indicate that this site is significantly larger than the previous designation. No shovel testing was performed within the property boundaries of the superintendent's house. This property is already highly disturbed, artifacts were identified in shovel tests around this location, and avoidance of the lawn at this property was considered desirable. The larger area currently included as 41WA228 represents $39,698 \mathrm{~m}^{2}$. There was a consistent presence of lithics and one ceramic from this area. Although the artifact density is much lower than at $41 \mathrm{WA} 47$, this is clearly a relatively dense concentration of archaeological material.

\section{WA266}

Site 41WA266 was identified based on the recovery of six lithics in five shovel tests (F-T10-ST03, F-T10-ST04, F-T10-ST05, F-T11-ST02, and F-T11-ST03) clustered at the northwestern portion of Area F. This small site covers $7,547 \mathrm{~m}^{2}$. A total of ten shovel tests were dug at the site. All of the lithics were recovered from $10-40 \mathrm{~cm}$ bgs, most from 20-30 cm bgs (Appendix G). They are in a highly disturbed location around a road loop. There is a strong likelihood that some of this material has been redeposited from previous roadwork. This is a welldefined artifact cluster. Unless all of these artifacts have been redeposited, this appears to represent a small site separate from 41WA228. No artifacts were identified in the northernmost shovel tests in this area, creating an apparent boundary to this site just within the survey parcel. There is a chance that these artifacts could extend outside of the improved campground area to the north of the current survey.

There are a total of six additional positive shovel tests with prehistoric artifacts outside of the two sites identified in Area F. Two of the positive shovel tests are on the eastern margin (F-T16-ST13 and F-T26-ST07) of the area, two are along the southern shore (F-T17-ST05 
and F-T17-ST07), and two are south of 41WA228 (FT08-ST02 and F-T22-ST03). The six unmodified debitage recovered from these shovel tests appear to be isolated finds with no additional positive shovel tests in their vicinity. The south-central portion of Area $\mathrm{F}$ and the eastern shoreline were surveyed at greater intervals than the other survey areas. Transects were spaced $30 \mathrm{~m}$ apart, but shovel tests were placed at 60-m intervals.

Finally, ten additional shovel tests contained only recent camping refuse. These units were scattered along the western and southern shores of Area F. The recent artifacts range from $10-40 \mathrm{~cm}$ bgs.

\section{Recommendations Regarding Archaeological Sites Within the Survey Parcels}

Three previously unidentified archaeological sites (41WA264, 41WA265, and 41WA266) were encountered during shovel test survey in Areas A-F at Huntsville State Park. All three are small, low-density archaeological sites containing lithics and provide no indications of archaeological features. No additional archaeological characterization is recommended for these sites. Sites 41WA264 and 41WA266 are in highly disturbed contexts and contain few artifacts. The low density of artifacts is not by itself a reason to exclude these sites from additional testing, but both sites are located within heavily modified camping loops that have experienced significant degradation of their contextual integrity. Both of these sites do not appear to merit official designation as SALs or listing in the NRHP. No additional testing is recommended for these highly disturbed archaeological sites. Site 41WA265 is a very small manifestation confined to two shovel tests. The site is located at the edge of Survey Area E. Subsurface artifact density was higher (four lithics in three levels of E-T18-ST01 and two lithics in E-T18-ST01-N01) than in most shovel tests, and the subsurface integrity may be good. This small site at the periphery of the survey area may be related to archaeological materials that could be present outside of the survey area. On the basis of its currently identified extent, this site is not considered to merit official designation as a SAL or NRHP listing. Future impacts to the site area should further evaluate adjacent areas to the north and east to determine whether 41WA265 might be part of a larger, adjacent archaeological site.

Shovel testing demonstrated that 41WA228 is a much more extensive site than previously identified. Although $30 \times 30-\mathrm{cm}$ shovel testing can be useful in defining site boundaries, these units do not provide sufficient information to evaluate the significance of large and potentially complex archaeological sites. Additional testing using $1 \times 1-\mathrm{m}$ controlled excavation is recommended to ascertain whether this site merits official SAL and NRHP designation. A minimum of four to five controlled 1 x $1-\mathrm{m}$ excavation units is considered necessary to determine the integrity, context, artifact associations, and potential significance of this site. 


\title{
Chapter 5: $\quad$ Excavations in 41WA47
}

\author{
Russell D. Greaves, Marybeth S. F. Tomka, Steve A. Tomka \& Jason D. Weston
}

\section{INTRODUCTION}

Examination of site 41WA47 involved three work efforts:

1) Shovel testing was performed to assess the previously identified boundaries and produce additional information about spatial variation in the archaeological deposit;

2) A 28 m-long backhoe trench (BHT-1) was excavated prior to controlled excavations to provide stratigraphic information about site formation and cultural deposition; and,

3) Controlled excavation of nineteen $1 \times 1$-m units was performed in four areas of the site as a limited mitigation effort prior to road improvement work within the site area.

The locations of the shovel tests, backhoe trench, and controlled excavations are shown in Figure 5-1. The results of each of these efforts are presented in the following sections.

\section{Geomorphological Setting and Solls by Russell D. Greaves}

41WA47 is situated on Depcor-Huntsburg-Gunter association soils (McClintock et al. 1979:10-11, Map 53) along the margins of the former channel of Little Chinquapin Creek, just east of its confluence with Big Chinquapin Creek. Currently, this site is on the northeastern shore of Lake Raven and the bay formed by the dammed mouth of the Big Chinquapin Creek (Figures 2-2 and 5-1). The site is on a terrace. It is uncertain whether this is likely a terrace of the Prairie Branch of East Sandy, Big Chinquapin, or Little Chinquapin Creeks. Soils examined most closely resemble descriptions of the Gunter series (McClintock et al. 1979:43). Because of the emphasis on profiling and determination of site formation, detailed information about soils and geomorphology was collected from the backhoe trench profile, controlled 1 x 1-m block excavation profiles, and observations during excavation.
The site was initially identified through informal reconnaissance by Boy Scouts in January 1978 during a period when the lake level was lowered. The troop recovered bone that was later identified as fragments of a human cranium and unspecified long bone fragments (McNatt et al. 2001:43). There were no associated artifacts, and the precise provenience of the find was not recorded. In October of 1978, TPW archaeologists conducted archaeological survey and recording (Ralph 1978). The site was shovel tested by TPW in October of 1996 (McNatt et al. 2001:43-46). During that effort, site boundaries were assigned on the basis of 13 shovel tests. The initial area identified as site 41WA47 encompassed approximately $34,000 \mathrm{~m}^{2}$. Following shovel testing of the site, the current archaeological survey project has increased the apparent site area to $52,129 \mathrm{~m}^{2}$.

The sediments of site 41 WA47 are dominated by very fine, well-sorted sands. Most have rare inclusions of larger clasts, although some colluvial depositional units contain high proportions of siliceous gravels and plinthites. Gravels identified were $\leq 1 \mathrm{~cm}$ in size. No areas containing sedimentary lenses of alluvially deposited gravels were identified. All of the larger clasts were encountered as isolated inclusions within the well-sorted, very fine sands. This appears to be a relatively rapidly and steadily deposited sedimentary unit. No stratigraphic breaks are apparent within these massive sands overlying an erosional unconformity with an older Bt soil horizon that is probably late Pleistocene in age. These are very acidic soils, pH 4.5-6, (McClintock et al. 1979:Table 18 ) and there is evidence of $\mathrm{E}$ horizon formation in soil profiles on $41 \mathrm{WA} 47$ and in much of the adjacent area. Calcium carbonate is not present in these soils and sediments. Artifacts were common throughout this soil profile. Bone and charcoal also were encountered in the backhoe trench and the controlled excavations.

Minimal evidence of bioturbation was noted during excavation. Root disturbance was evident in many areas of the site, but fossorial animal burrowing and insects appear to have played only a minor role in potential movement and concentration of soil clasts. All samples 
This page has been

redacted because it

contains restricted

information. 
come from sedimentary units below the major root zone. Root bioturbation is only likely to have affected the context of radiocarbon sample \#QQ49-1-10 (Appendix D). Evidence of illuviation of clays is apparent within the lower $\mathrm{C}$ horizon deposits. Lamellae containing small amounts of clay were readily apparent in these horizons. They are thin $(<5 \mathrm{~mm})$ and indicate an aggrading environment in these sediments (Ferring 1992:18; Stein 1992:206). The formation of such deposits is poorly understood. However, the accumulation of organic materials and clay in this portion of the soil profile may be associated with stratigraphic breaks in these sediments. Textural distinctions due to separate depositional events within these massive sands are considered responsible for material hanging up within lower sediments and forming such fibers (Soil Survey Staff 1975:25).

Artifacts were common throughout the entire sedimentary column in this excavation area. This is a ceramic period site with sherds and four projectile point forms present in moderate abundance. Extensive use of this park facility for camping has resulted in dense charcoal deposits on the surface and in occasional subsurface pits. There is evidence of charcoal concentrations in the upper portion of the soil profile that are certainly derived from modern camping. No charcoal was collected for analysis from the upper 30 $\mathrm{cm}$ or any obviously deeply disturbed context.

\section{Previous Work at 41WA47}

\section{by Russell D. Greaves}

Archaeological investigations by TPW within Huntsville State Park began in 1978 with the identification of 41WA47. The first investigations were in response to the discovery of human bone fragments along the lowered lakeshore. Since then, this site remains the most significant cultural resource identified within the park boundary. Minimal characterization was performed during initial recording. Subsequent investigations were not undertaken until 1996. The current field effort represents the most detailed investigation of 41WA47.

TPW staff initially described this site during reconnaissance in 1978 (Ralph 1978). Recording followed recovery of human remains by Boy Scouts along the lake margin. 41WA47 was listed as a SAL in 1983. Although the provenience of this burial has been provisionally assigned to this site, its original context and association are uncertain. Direct association with 41WA47 has never been demonstrated. TPW archaeologists excavated 13 shovel tests in 1996. Those excavations encountered a relatively high artifact diversity, distribution of cultural materials to a depth of at least $1 \mathrm{~m}$, and possible midden deposits. These characteristics, and the unresolved association of the human burial, were important factors in determining that this site has a high potential to provide important information about prehistoric human use of the area. The current mitigation effort is in response to planned resurfacing of existing roadways within the camping, picnicking, and parking facilities within the identified site area. Archaeological information from this site also may provide an excellent opportunity for the development of public interpretation about cultural resources within Huntsville State Park.

Previous work suggested that 41WA47 is a potentially significant site for two sets of reasons. The site's artifact content and the inferred depositional integrity indicated a strong research potential for additional investigations at this site. The shovel testing performed in 1996 (McNatt et al. 2001:43-46) suggested a relatively rich deposit containing lithics, ceramics, bone, and macrobotanical remains. Shovel testing identified areas of the site adjacent the lakeshore that contain artifacts in excess of $1 \mathrm{~m}$ below the current ground surface. Some amount of slope related redeposition is expected in this setting, but preliminary work indicated that there is a strong likelihood that some primary archaeological deposits are present at 41WA47. The available information about the site context suggested a strong likelihood that the archaeological material is contained within significant intact or deep deposits.

Regardless of the particulars of site formation, the varied material content indicates that this site has been the location of many different activities. This suggests that 41WA47 may be a habitation site. The presence of ceramics, lithics, faunal remains, and potentially human introduced plant remains, all indicate a strong potential for research into several aspects of past subsistence, mobility, and technology at 41WA47. This breadth of materials also suggests a good probability that features 
may be present on this site. The research proposed by CAR emphasizes recovery of materials that can address past environmental conditions and human subsistence. Environmental reconstruction and determination of subsistence activities are critical aspects of archaeological research that have strong implications for other aspects of human cultural adaptations.

\section{Shovel Testing of 4IWA47}

\section{by Russell D. Greaves}

\section{Methods}

Shovel testing was performed across the entire area of site 41WA47. Judgmental alterations in the sampling intervals between shovel tests were made so that additional time would be available for the excavation of controlled 1 x 1-m units. Shovel test intervals were not increased to more than $40 \mathrm{~m}$ between shovel tests. The originally specified 20-m interval was retained for some portions of the site, in cases of positive shovel tests. Some adjustments in the placement of shovel tests from strictly systematic placements were necessary because of existing ground conditions. Some areas of 41WA47 were eroded to the Pleistocene Bt soil horizon that contained no artifacts. Additionally, campground roads, parking areas, picnic tables, and other facilities necessitated situational relocation of some units.

Boundary definition appears to match well with the previously identified site margins. Only minor alterations in site definition resulted from the shovel testing. The previous dimensions of $41 \mathrm{WA} 47$ were $34,007 \mathrm{~m}^{2}$. Approximately $3,423 \mathrm{~m}^{2}$ of the area assigned to this site are currently under water. The site dimensions increased to $52,129 \mathrm{~m}^{2}$ as a result of the shovel testing.

A total of 46 shovel tests were excavated within 41 WA47 (Figure 5-1). Of these, 26 (56\%) contained cultural materials. These efforts provide good coverage for subsurface sampling to identify and allow preliminary characterization of the buried archaeological deposits at 41WA47. Artifact recovery, total depth of each shovel test, and the depth to the older Bt soil horizon for each of the 46 shovel tests are presented in Appendix $\mathrm{H}$.

\section{Results}

Shovel testing identified prehistoric cultural materials at $41 \mathrm{WA} 47$ present from approximately $3-4 \mathrm{~cm}$ below the current ground surface (bgs) to $70 \mathrm{~cm} \mathrm{bgs}$, the terminal depth of the shovel tests. Although the first level $(0-10 \mathrm{~cm} \mathrm{bgs})$ of the 26 positive shovel tests did not recover prehistoric artifacts, virtually no sterile overburden was present in many portions of the site. Much of this could be due to the gradual erosion, through sheet wash, of any sterile layer that may have capped the archaeological deposits. Modern materials were encountered in most shovel test units to a depth of $20 \mathrm{~cm}$ bgs.

The current ground surface is variable, but most prehistoric artifacts were recovered from Level 2 (10$20 \mathrm{~cm}$ bgs) through Level 6 (50-60 cm bgs). Of the 62 prehistoric artifacts (debitage $n=54 ; F C R n=5$; ceramics $\mathrm{n}=1$; projectile point $\mathrm{n}=1$; burned nutshell fragment $\mathrm{n}=1$ ) encountered in the shovel tests, the highest number occurs in Level $3(n=15)$, followed by Level $4(n=12)$. Levels 6, 5, and 2 contain the next highest quantities with 11, 10, and 9 artifacts respectively. Level 7 contained only five artifacts.

An examination of Figure 5-1 and the depths of the Bt horizon in Appendix $\mathrm{H}$ indicate that the south-central portion of the site contains the greatest concentration of shovel tests that did not reach clay at $70 \mathrm{~cm}$ bgs. Even there, however, some erosion has taken place as a result of heavy runoff from the RV pullouts in the area. The western and southwestern portions of the site appear to have been relatively severely eroded, given the shallowness of the Bt horizon in some of these shovel tests. Based on the shovel test data alone, it appears that the portion worthy of preservation is located in the southcentral section of the site. This section appears to constitute approximately 15-20 percent of the overall site, or roughly an area of 7,819-10,500 $\mathrm{m}^{2}$. We estimate that the remaining 80-85 percent of the site area has been impacted by either current park usage, construction associated with park improvements, natural forces of erosion, or a combination of the three. Areas devoid of artifacts, at least based on our shovel testing results, appear to be present in the extreme northeastern and 
extreme northwestern portions of the site. The most consistent line of positive shovel tests occurs in a band along the south-southeastern edge of the site.

It is difficult to estimate the potential for site recognition by park visitors. The debitage encountered on surface is small and of relatively low density. Ceramic sherds are somewhat difficult to recognize and could potentially be mistaken for modern pieces, except by artifact collectors. Although prehistoric artifacts are present on surface, especially in the least disturbed portion of the site, the quantities are not great and surface site visibility is not very high. However, the excavation of pits either for hearths or charcoal disposal would increase site visibility as noted from the increase in artifact numbers by depth within the positive shovel tests. Continued erosion of the site surface would also contribute to increased site visibility.

It is difficult to synthesize the archaeological implications of shovel test results beyond presence and absence of materials. This is a relatively large site and shovel testing offers only very small views of subsurface material provided by $30 \times 30-\mathrm{cm}$ shovel tests. Shovel tests that were placed on or adjacent to grid coordinates can be related to surface elevations recorded during establishment of the grid. Subsurface remains for these units can be compared using absolute elevations and data from the controlled 1 x 1-m excavation units. However, the small sample of space and material that they provide, their dispersed positions, and noncontiguous positions, renders sophisticated statements beyond artifact frequency and depth of deposits problematic. Shovel tests do offer information about the depth of sediments above the Bt horizon and may indicate which parts of the site likely contain greater potential for excavation efforts. The shovel test information on artifact presence and depth of sediments above the Bt horizon contact were used to select locations for backhoe trenching and more controlled recovery. Information from the backhoe trench and controlled $1 \times 1-m$ excavations offered significantly more useful information about site content, context, and formation.

\section{Backhoe Trench l (BHT-1) Excavation}

\section{by Russell D. Greaves}

\section{Methods}

On June 4, 2001 a single backhoe trench was placed on site 41WA47 (Figure 5-1). The trench was oriented at $297^{\circ}-117^{\circ}$ from magnetic north and was $28 \mathrm{~m}$ long. The excavation was approximately $1 \mathrm{~m}$ wide. The trench was excavated to a depth of between 1.35-2.35 m below the modern ground surface (Figure 5-2). The northern 16.90 $\mathrm{m}$ of the trench was excavated more deeply to identify the contact between the artifact bearing sands and the older remnant soil underlying the archaeological deposits. Adjacent to the margin of Lake Raven, the southern end of the trench encountered perched water at approximately $1.05 \mathrm{~m}$ below surface. These sediments are extremely loose. A stepped trench wall on the opposite face from the profile wall was required for safe examination of this profile. This action increased trench width to approximately $2 \mathrm{~m}$ along the southern 17 meters of the trench.

\section{Results}

The profile of Backhoe Trench 1 (BHT-1) contains sediments dominated by fine, well-sorted sands with very rare larger clast inclusions. Results of texture and particle size analysis of samples from BHT-1 are presented in Table 5-1. Gravels identified during profiling were $\leq 1$ $\mathrm{cm}$ in size. No areas containing sedimentary lenses of alluvially deposited gravels were identified. All clasts were encountered as isolated inclusions within the very well-sorted, fine sands. Little evidence of bioturbation was noted during examination and recording of the profile. Tree roots, primarily pine, were extensive in the southern $9.5 \mathrm{~m}$ of the trench. During backhoe excavation, many of these coarse roots $(\leq 3 \mathrm{~cm}$ in diameter) caught on the backhoe bucket and loosened the adjacent soft sand sediments. This was problematic only in the southernmost $2.6 \mathrm{~m}$ of the trench, where this disruption obscured visual and textural identification of the sediment and soil horizon distinctions in this profile. 


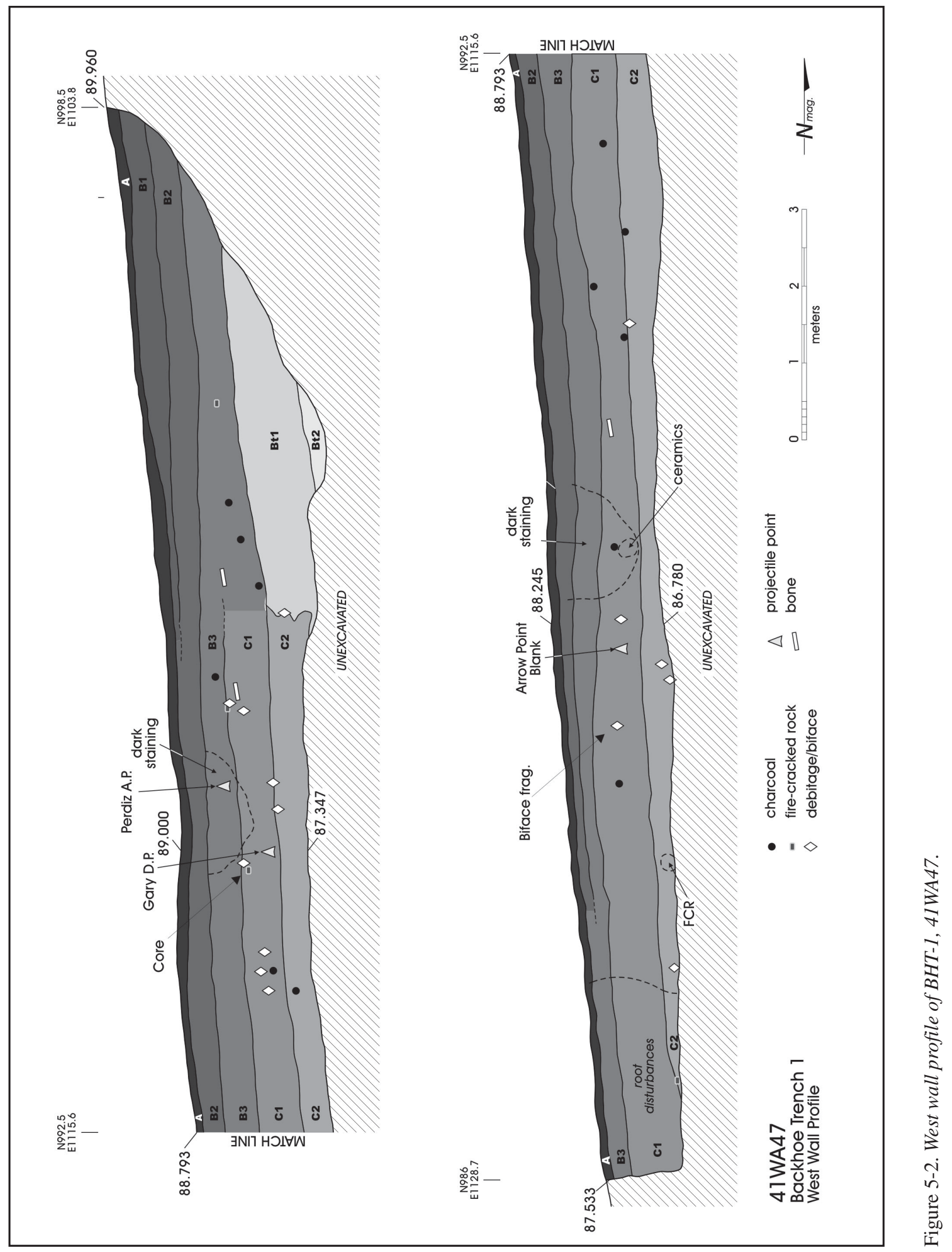


Table 5-1. Texture and particle size of soil and sediment samples from BHT-1, 41WA47

\begin{tabular}{|l|l|c|c|c|l|}
\hline $\begin{array}{l}\text { Soil/Sediment } \\
\text { Horizon }\end{array}$ & Texture & \% Sand & \% Silt & \% Clay & Comments \\
\hline A1 & very fine sand & 93 & 2 & 5 & \\
\hline B1 & loamy very fine sand & 87 & 3 & 10 & \\
\hline B2 & loamy very fine sand & 87 & 3 & 10 & \\
\hline B3 & loamy very fine sand & 87 & 4 & 9 & \\
\hline C1 & very fine sand & 93 & 4 & 3 & \\
\hline C2 & very fine sand & 93 & 4 & 3 & \\
\hline Bt1 & clay loam & 67 & 3 & 30 & $\begin{array}{l}\text { sand is fine-very fine; higher energy deposits } \\
\text { than in other portions of profile }\end{array}$ \\
\hline Bt2 & $\begin{array}{l}\text { very fine sandy } \\
\text { loam/sandy clay loam }\end{array}$ & 53 & 27 & 20 & \\
\hline lamella* & loamy very fine sand & 87 & 5 & 8 & $\begin{array}{l}\text { *= sample of lowest lamella in the north wall } \\
\text { of QQ49-2 (N989-E1111) at the boundary } \\
\text { between the C3 and C4 horizons }\end{array}$ \\
\hline
\end{tabular}

The western wall profile of BHT-1 was drawn (Figure 5-2). Due to the scale of the profile, it was impractical to illustrate a series of roughly parallel lamellae present throughout the bottom half of the profile. These lamellae are shown in Figure 5-3. All artifacts encountered in situ in the trench wall were mapped and collected, sediment samples were collected, and standard soil descriptions performed for each identified horizon (Table 5-2). Artifacts were identified within the sandy sediments designated as the $\mathrm{B} 3, \mathrm{C} 1$, and $\mathrm{C} 2$ horizons. The upper boundary of the $\mathrm{B} 3$ horizon is located approximately 40 $\mathrm{cm}$ below the modern ground surface. Except in the northern $4.75 \mathrm{~m}$ of BHT-1, the artifact bearing C2 horizon extends below the level of excavation. These are well-sorted, very fine sands that appear to have accumulated rapidly. Within the $\mathrm{C} 1$ and $\mathrm{C} 2$ horizons, numerous organic stained lamellae with small amounts of illuvial clay, approximately $5 \mathrm{~mm}$ thick, bracket sedimentary units of these sands. These lamellae and their implications are discussed in greater detail below. They indicate some surface stability to these deposits suggesting a stratified set of archaeological deposits within this massive sand deposit. Numerous artifacts were encountered within this profile and charcoal was apparent throughout the sediments of interest. Archaeological artifacts were encountered from approximately $40 \mathrm{~cm}$ below ground surface to the base of the $\mathrm{C} 2$ sands in the trench $(140-150 \mathrm{~cm})$. Archaeological material is likely to extend to a greater depth than could be safely examined in the profile. Deeper trenching would require stepping of both sides of the trench, and a wider excavation than was performed for this examination. Such destruction of the stratified and relatively dense archaeological deposits is unwarranted for the present needs of this investigation.

The relatively high density of chipped lithic artifacts $(n=16)$ in this trench profile, abundant charcoal, good preservation of organic materials, and evidence of

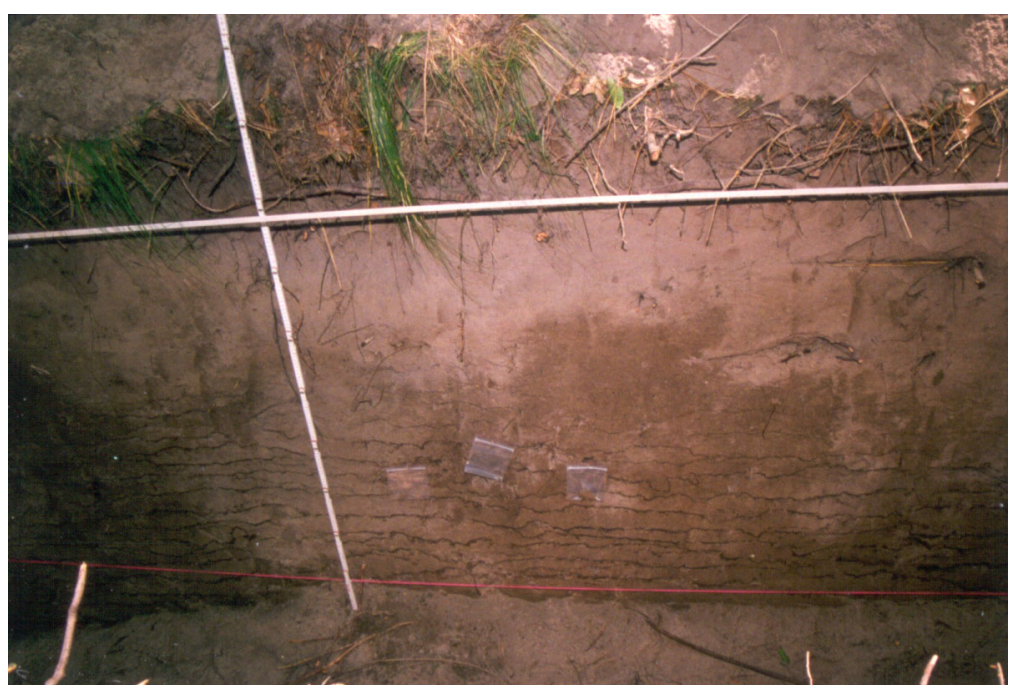

Figure 5-3. Series of roughly parallel lamellae present throughout the bottom half of BHT-1 profile. 


\begin{tabular}{|c|c|c|c|c|c|c|c|c|}
\hline : & 0 & 0 & 0 & 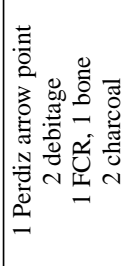 & 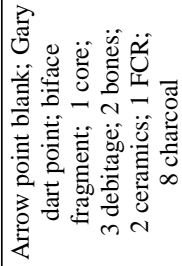 & 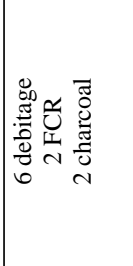 & 0 & 0 \\
\hline 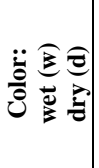 & 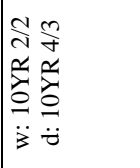 & 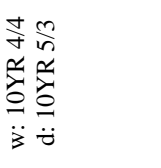 & 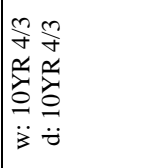 & 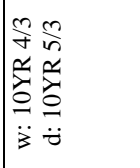 & 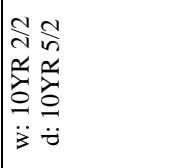 & 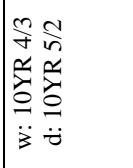 & 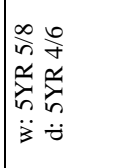 & 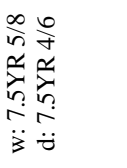 \\
\hline 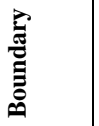 & 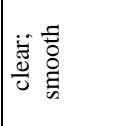 & 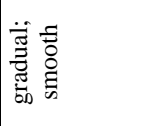 & 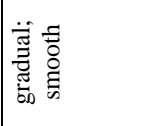 & 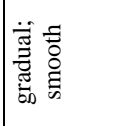 & 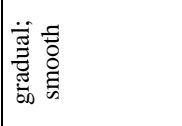 & $\begin{array}{l}\tilde{E} \\
0 \\
0 \\
\text { E } \\
\Xi\end{array}$ & 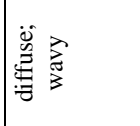 & 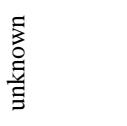 \\
\hline 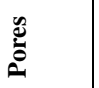 & 0 & 0 & 0 & 0 & 0 & 0 & 窇导 & 节导 \\
\hline 号 & 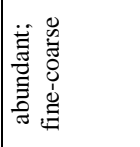 & 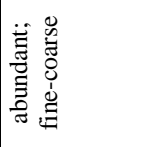 & 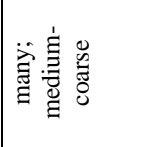 & 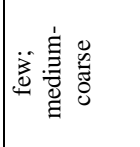 & 泀惫惫 & 童言总 & 竧总 & 竧怘 \\
\hline 产 & 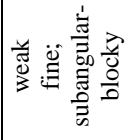 & 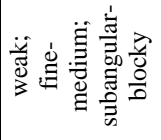 & 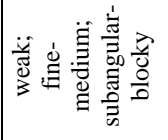 & 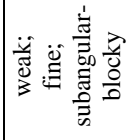 & 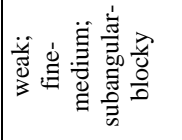 & 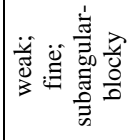 & 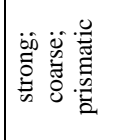 & 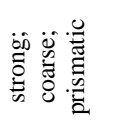 \\
\hline שี & 0 & 0 & 0 & 0 & 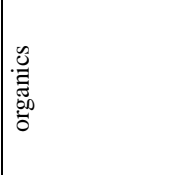 & 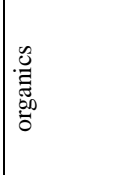 & 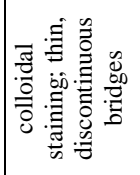 & 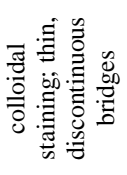 \\
\hline 密 & 0 & 0 & 0 & 0 & 0 & 0 & 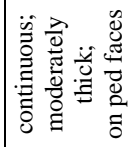 & 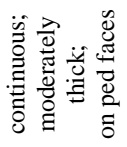 \\
\hline 芦总 & 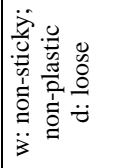 & 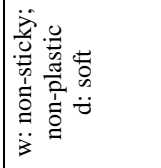 & 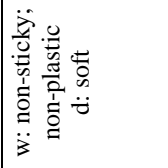 & 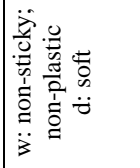 & 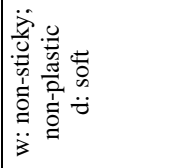 & 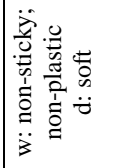 & 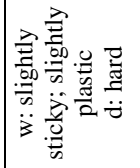 & 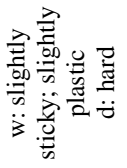 \\
\hline 竧 & 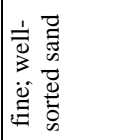 & 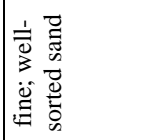 & 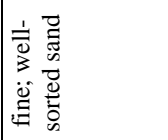 & 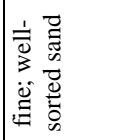 & 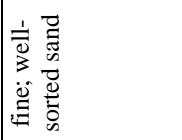 & 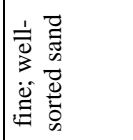 & 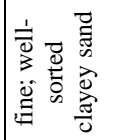 & 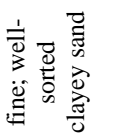 \\
\hline 萢 & ष & $\vec{m}$ & $\cong$ & $\tilde{\varphi}$ & $\bar{U}$ & $\tilde{U}$ & $\bar{\oplus}$ & ๓ี \\
\hline
\end{tabular}


apparent multiple occupations all suggested that $41 \mathrm{WA} 47$ may contain significant, possibly stratified, cultural deposits. The examination of this trench prior to controlled excavation provided vital data about 41WA47. Especially critical was information about the sediment depth, vertical distribution of artifacts, and site formation. Information from the profile of BHT-1 directed several research questions addressed through controlled $1 \times 1$ $\mathrm{m}$ unit excavations. Controlled recovery in $1 \mathrm{x} 1$-m units and contiguous block excavations targeted recovery of piece-plotted artifacts greater than $2 \mathrm{~cm}$, datable charcoal in good contexts, and paleoethnobotanical samples useful in determining site formation and pertinent to understanding associational implications of the artifact assemblage.

\section{Geomorphic Interpretations}

There are two main sedimentary and soil formation regimes evident in BHT-1 (Figure 5-2, Table 5-2). An older sandy loam Bt horizon was encountered at the base of the northern end of the trench. This soil is encountered in shovel tests at different elevations below the modern ground surface. Although it has been characterized as a clay soil in previous investigations (McNatt et al. 2001:44-45), the Bt horizons (Bt1 and Bt2) are primarily sand. There is some translocated clay apparent in this soil. Clay films were identified on all ped faces, as colloidal staining of sand grains, and as thin, discontinuous bridges between grains on ped interiors. The translocated clay may also be responsible for the rubification of this sand. Although the clay content of this soil is 30 percent or less, it may still be characterized as an argillic horizon. This soil is clearly much older than the overlying sands. Strong structure is indicated by coarse $(\sim 15 \mathrm{~cm}$ in maximum dimension) prismatic peds. The upper boundary of this unit with the $\mathrm{C} 1$ and $\mathrm{C} 2$ sediments represents an erosional unconformity. The distinctions between this older soil and the more recent sands are dramatic. The Bt horizon is clearly part of an older regime of pedogenesis compared with the more recent sands above it.

The $\mathrm{C} 1$ and $\mathrm{C} 2$ sediments represent a massive sand unit that probably has accreted relatively rapidly. These sediments are not the remnants of the erosional events that have truncated the older Bt horizon. All of the sand is very fine, well-sorted with very few larger clasts. These sediments have been deposited by lower energy alluvial events subsequent to the erosion of an unknown amount of the soil profile above the extant Bt horizon. Soil structure is weak in these sediments and they show no evidence of significant soil development. With the exception of the lamellae discussed below, there are no stratigraphic separations between the $\mathrm{C} 2$ and $\mathrm{C} 1$ sediments. Distinctions between these two $\mathrm{C}$ horizons are based on textural differences in the profile. The $\mathrm{C} 1$ and $\mathrm{C} 2$ horizons contain evidence of the lamellae that may indicate pulses of surface stability for very short periods of time. The organic enrichment seen in these lamellae has been obscured in the B3 deposit by pedogenesis. Current surface stability has led to soil formation seen in the A and B horizons affecting the uppermost $40-90 \mathrm{~cm}$ of the profile. Comparable surface stability is not apparent in lower portions of this profile. The solum is thinnest at the downslope (southern) end of the trench adjacent to the current lake. There is significant $\mathrm{C}$ horizon material with no evidence of paleosols below the current soil profile. The parent sediments of the A and B horizons are identical to the lower $\mathrm{C}$ horizon sands. They also appear to have been deposited as part of the same sedimentation events represented by the massive sands of the $\mathrm{C}$ horizons. There are no stratigraphic breaks between the epipedon units of the modern soil and the underlying $\mathrm{C}$ materials. A pale, apparently leached horizon was noted in some of the shovel tests in the position of the B1 and B2 horizon seen in the backhoe trench. These likely represent eluvial (E) horizons. These are highly acidic soils. The current forested condition of this setting and the dominance of pine in this portion of the park contribute to the high acidity and formation of an eluvial horizon below the epipedon.

Evidence of bioturbation is apparent within the A, B1, and uppermost B2 horizons. Root casts are the most common manifestation. Some relatively large concentrations of charcoal are apparent within the uppermost $20 \mathrm{~cm}$ of the soil profile. At least one of these appears to represent a burned tree root. Clear indications of krotovina, root casts, or invertebrate presence were not identified within the B3, C1, and C2 horizons. This is consistent with the suggestion that these sediments were laid down rapidly in an accreting environment. Several lines of evidence indicate rapid and continual deposition of the $\mathrm{C} 2$ and $\mathrm{C} 1$ sands, offering little opportunity for surface stability, soil formation, subsurface 
biological activity, and growth of large trees to have occurred. The recent surface stability is associated with soil formation and bioturbation of the upper portion of the soil profile.

Within the $\mathrm{C}$ horizons, there is evidence of organic enriched lamellae (Figure 5-3). These are very similar to those noted at the Huntsville Fish Hatchery (Davis et al. 1994:18, Fig. 4). These soil features suggest an aggrading sedimentary environment with short-term surface stability. Regardless of the etiology of these zones of organic enrichment (see below), they are thin $(<5 \mathrm{~mm})$ and indicate an aggrading environment in these sediments (Ferring 1992:18; Stein 1992:206). The identical morphology of these sediments indicates consistent depositional and, possibly, climatic conditions throughout this portion of the soil profile. Some lamellae are visible within the lower portions of the B3 horizon, but most have apparently been obscured by pedogenesis. The boundaries between units bounded by these darker lamellae are abrupt and wavy-irregular. No sedimentary structure is apparent that indicates whether the sand matrix was deposited through alluvial, lacustrine, or shoreline processes. The fine, well-sorted texture, paucity of larger clasts, and lack of beach sand structure suggest that alluvial deposition is most likely.

The irregular boundaries of these lamellae indicate that they are not paleosols developed on level sediments. At the southern margin of the upper boundary of the $\mathrm{Bt}$ horizon, one thin, stained stratum extends from this eroded boundary southward at the approximate textural boundary between the $\mathrm{C} 1$ and $\mathrm{C} 2$ horizons. It appears to represent a deposition unit extending from the eroded surface of the Bt horizon. The sedimentary structure of these lamellae is wavy and parallel (Davis et al. 1994:Fig. 4; Soil Survey Staff 1975:Plate 4A). Few exhibit wavy, nonparallel orientations.

Currently, three depositional origins seem most likely for these dark-stained interruptions in the massive sand units. They could be thin soils formed on irregular ground surfaces. The lamellae may represent colluvial and alluvial slope wash materials deposited on an uneven sedimentary surface. They are perhaps most likely to represent illuviated materials redeposited within the lower portion of the soil profile.
Irregular ground surfaces may have resulted following alluvial (or other) deposition. Some of this morphology could have been due to surface erosion such as rilling. These surfaces were apparently stable for short periods of time. Under conditions of aggrading deposition, very short duration surface stability could result in minor accumulations of organic material without formation of robust paleosol horizons. Subsequent deposition repeated the same process of an undulating epipedon development. The morphology of these sands and organic staining make it unlikely that these are autochthonous floodplain sediment organics (Brown 1997:80).

The irregular boundary between these repeated units may suggest that the organic staining is due to slope wash. Colluvial and alluvial transport of organics could periodically enrich the stable ground surface and cause the observed staining (Waters 1992:35). Some artifacts recovered from the profile appear to have been lying in non-level orientation. These did not appear to be high angle repose, but a flat orientation is not consistent across all recovered artifacts. Orientation and degrees of dip were not collected from these materials but were measured for artifacts mapped in situ. As noted above, the irregular surface that these lamellae trace, the apparent association of the organic material with the eroded upper surface of the Bt horizon, and nonhorizontal orientation of artifacts may suggest some slope wash effects on this landscape. Particle size of the sediments and larger clasts do not suggest that this was high-energy transport. Site structural integrity of these deposits may still be quite good. Although artifacts can move easily in sand, even documented displacement of items by as much as one meter still does not necessarily obscure meaningful spatial patterns related to past human activity and site formation (Jodry and Stanford 1992:109, 137-141, 154-155).

Other identified examples of similar morphological lamellae are attributed to translocation of clays or other minerals through leaching of upper portions of the soil profile (Waters 1992:41-42). This is the most likely manner in which these thin, irregular secondary horizons were created. The formation of such deposits is poorly understood. However, the accumulation of organic or clay materials in this portion of the soil profile may be associated with stratigraphic breaks in these sediments. 
Textural distinctions due to separate depositional events within these massive sands are considered responsible for material hanging up within lower sediments and forming such fibers (Soil Survey Staff 1975:25).

Although the staining of the lamellae appears to be due to organic material, it is possible that this discoloration is due to the translocation of other minerals downward in the soil profile. Ferric nodules are relatively common in these sediments. Reduced iron compounds may be accumulating in areas with slight textural differences. This still suggests that these textural anomalies may represent interruptions in the deposition of these sands. At least some of these depositional differences are likely to represent short-term stable soil surfaces. Analysis of sediment susceptibility samples, radiocarbon dating, particle size analysis, and paleoethnobotanical investigations may provide complementary information that can resolve some of these questions regarding site formation at $41 \mathrm{WA} 47$. The similarity of this staining to that observed in the nearby Huntsville Fish Hatchery (Davis et al. 1994:18, Fig. 4) and other sites in the region (Margaret Howard, personal communication 2002), indicates a strong likelihood that regional edaphic control and climatic conditions are responsible for the formation of these lamellae.

\section{Materials Recovered}

A total of 25 prehistoric artifacts was collected from the profile of the backhoe trench. The majority of these are lithics $(n=16)$ and include: one Perdiz arrow point, one Gary dart point, one arrow point blank, one biface fragment, one core, and 11 flakes. Two ceramic sherds were collected from the wall. Four FCR and three bones were identified in the profile. Twelve charcoal samples were collected from the profile of BHT-1. Additional charcoal was present in smaller amounts. No charcoal was collected from the uppermost $69 \mathrm{~cm}$ of the soil profile. Large and relatively dense concentrations of near surface charcoal probably represent modern and very recent burning. In addition to natural forest fires, controlled burning has contributed charcoal to these upper horizons. The samples from this profile were derived from horizons $\mathrm{C} 2(\mathrm{n}=2), \mathrm{C} 1(\mathrm{n}=8)$, and $\mathrm{B} 3(\mathrm{n}=2)$. None of the charcoal is directly associated with archaeological materials or unambiguous features and therefore none of these samples have been submitted for dating. Finally, 11 additional debitage pieces, a ceramic sherd, a Dawson preform, and a piece of bone were recovered from the backdirt of BHT-1.

As can be seen in the profile (Figure 5-2) and in Table 52 , most of the cultural material came from the $\mathrm{C} 1$ horizon. It is uncertain whether this suggests that there is a single cultural deposit that has a vertical displacement of $1 \mathrm{~m}$ or greater. The apparent division of these massive sands seen in the presence of the organic and clay enriched lamellae strongly suggests that there are short-term interruptions in the deposition of these sands. If these represent periodically stable surfaces, then the cultural materials may indicate multiple occupational history and stratified deposits present on this site. The sharp condition of lithic edges indicates insignificant postdepositional damage to these flakes and tools. Preservation of the single bone fragment recovered indicates that burial was rapid enough that no surface weathering is evident on this element. Some of the recovered lithics appeared to be resting at high angle and not lying flat. This suggested that some of the artifacts were subject to redeposition, trampling, or were laid down on an irregular surface at the time of deposition. A larger sample of artifacts with recorded orientation, inclination, and other pertinent observations was obtained from the controlled $1 \times 1$-m excavation units to address these questions of site formation.

Two areas within the profile appeared to contain greater amounts of organic staining. These are not well-defined sediments. Although originally they were thought to represent organic enrichment from disposal concentrations of trash, subsequent evaluations of the matrix suggest that the two areas and their organic enrichment are the product of bioturbation. Magnetic susceptibility columns sampled sediments within and adjacent to these areas of apparent staining. Sample column 1 was placed through the southern margin of the northernmost organically enriched zone and sample column 2 was placed approximately $30 \mathrm{~cm}$ south of the southernmost stained area. These column samples represent $5 \mathrm{~cm}$ wide columns sampled continuously from the lowermost deposits upward in $5 \mathrm{~cm}$ increments. Following the reinterpretation of the organically enriched zones, it was decided that these samples would not be processed since they could not contribute to the clarification of the nature of these zones. 
A broken Perdiz arrow point was collected from the B3 horizon within the dark staining. This is the highest chipped lithic artifact in the soil profile of BHT-1. It is missing the distal blade and has apparently broken and reworked barbs. This type is considered a Late Prehistoric diagnostic. A complete dart point was identified in the lower portion of the $\mathrm{C} 1$ horizon just below the area of organic enrichment. This specimen is a Gary dart point. A triangular biface from the $\mathrm{C} 1$ horizon in the southern half of BHT-1 is an arrow point blank. The second biface, a Dawson perform, was recovered in backdirt removed from the trench.

The testing in 1996 suggested that the ceramics from the site are Goose Creek (McNatt et al. 2001:45). The two sandy paste sherds collected from the $\mathrm{C} 1$ horizon are finely made and resemble Goose Creek ware. The ceramics were knocked out of the wall during backhoe excavation. Their exact provenience is uncertain. However, evidence of equipment damage directly above the sherds suggests their original location can only be approximated. This area is associated with the base of the apparent organic staining in the southern half of the profile. Both body sherds provide insufficient amounts of the original vessel to determine whether they represent bowls or jars. One sherd is a reduced black and the other is a redware. One additional sandy paste sherd was collected from the backdirt, it is also likely a Goose Creek ware.

Bone preservation appears to be very good. Two of the three bone fragments collected were unidentifiable. One of these is a portion of a larger bone left in situ, extending westward beyond the profile wall. The single identifiable bone is a deer-sized right calcaneus. The entire proximal end is missing and a single carnivore drag mark is evident on the cranial aspect of the medial side. This calcaneus has been extensively carnivore gnawed but shows no evidence of subaerial weathering. This suggests relatively rapid post-depositional burial.

Two-liter samples of matrix from each defined soil horizon were collected for additional analyses. Soil texture analysis was performed on these samples (Table 5-1). These have not been submitted for other sedimentological, chemical, or paleoethnobotanical analyses. These samples also could be fractionated to permit several complementary examinations of the sediments and soils. All of these samples, including the magnetic susceptibility ones have been reserved for future analyses.

\section{Vi. Controlled Block Excavations}

\section{by Russell D. Greaves}

\section{Methods}

Four areas of 41WA47 were selected for placement of controlled 1 x 1-m excavation units (see Figure 5-1). Location of these units was based on a judgment sample of different portions of the site considered to have good potential to contain subsurface archaeological remains that would sample most areas of the site that were not heavily eroded (see Figure 5-1). This was based on information provided by preliminary shovel testing, the BHT-1 profile, and geomorphic surface assessment of the site area. All of these determinations indicated that the area adjacent to BHT-1 contained the deepest and least disturbed sedimentary deposits. For this reason, the greatest number of excavation units was placed within the less disturbed area west of BHT-1. A perpendicular set of six $1 \times 1-\mathrm{m}$ units was excavated approximately seven meters west of BHT- 1 and a 3 x 3-m block excavation (nine units) was placed $13.5 \mathrm{~m}$ southwest of those six units. These units sampled the portions of 41WA47 that appeared to be least eroded, and contained the deepest sedimentary and cultural deposits. Two other areas of the site were examined through excavation of 1 x 2-m block excavations (see Figure 5-1). Based on shovel testing, both of these areas contained moderately deep sedimentary deposits and abundant cultural remains. These nineteen units represent a very small spatial sample of this site. In a site area of approximately $52,129 \mathrm{~m}^{2}$, the controlled excavation units represent a 0.03 percent sample of the total site area. The portion of 41WA47 considered to contain the most intact deposits represents approximately $15-20$ percent of the overall site, or roughly an area of 7,819-10,500 $\mathrm{m}^{2}$.

Cultural deposits span all of the sediments above the older argillic Bt horizon. The depth of these sediments is highly variable. Shovel testing encountered many eroded contexts across portions of 41WA47 where there was only minimal sandy sediment remaining. The most extensive deposits extended to $190 \mathrm{~cm}$ below the modern ground surface. The deepest sediments encountered 
during excavation all contained artifacts to within a few centimeters of the contact with the rubified Bt horizon.

Excavation methods were similar to those employed for shovel testing. Several modifications permitted greater control of the provenience and context of excavated materials in the $1 \times 1-\mathrm{m}$ units. Excavation levels were standardized across the entire site. Level designations and their $\mathrm{z}$ coordinates were in relation to the main site datum (N1000-E1000) assigned the arbitrary elevation of $100.00 \mathrm{~m}$. An existing brass cap on the site was used as the main site datum. Except for the Pleistocene Bt horizon, no natural stratigraphy was encountered that could be readily identified in the field and used to segment arbitrary excavation levels. Excavation levels were always assigned even $10-\mathrm{cm}$ increments relative to the arbitrary datum, and were always designated by the same level identification number. For example, Level 260 always referred to levels with an elevation of 89.00$88.90 \mathrm{~m}$ relative to the arbitrary datum elevation of $100.00 \mathrm{~m}$ (representing the basal elevation of Level 149). The high numbers of the excavation levels permit future expansion of the site level system to include more upland settings above the site datum. This procedure avoids common analytic problems of comparing artifact-bearing deposits across sites if excavation levels and depths are referenced to varying local ground surface elevations. The necessity to record both the numeric level designation and its elevation on the field forms served as a check that correct level assignments were made for all paperwork, artifact bags, and specialized samples. Grid coordinates and surface elevations of excavation areas were established using a Sokkia Set 6E total station. Subdatum rebar elevation references also were created using the Sokkia total station. These rebar markers were removed at the conclusion of the fieldwork.

Surface elevations were measured for all four corners and the center of each $1 \times 1-\mathrm{m}$ unit. The first excavation level brought the entire unit to the nearest complete arbitrary excavation level relative to datum. In some instances, the first level encompassed more than $10 \mathrm{~cm}$ because of the differences in surface elevation. All of the first levels have volumes different than the succeeding excavation levels. The amount of disturbance apparent within the upper portion of the profile due to campsite use suggested minimal loss of information from initial levels that removed greater than $10 \mathrm{~cm}$ of material. It was decided that removal of slightly more soil within the first level was an acceptable inconsistency. Elevation provenience data for piece-plotted items and excavation level termination elevations were determined using the rebar subdatum with a standard tape measure, string, and line level procedure. All final elevations for each excavation level were determined using the subdatum to check each corner and center of the $1 \times 1-m$ unit. Mapped $\mathrm{x}$ and $\mathrm{y}$ coordinates for each piece-plotted item were measured using tapes from the referent SW corner of each excavation unit. Because of the depth of these units in some areas, there is some error in the $\mathrm{x}$ and $\mathrm{y}$ coordinates. Attempts were made to maintain the full $1 \mathrm{x} 1 \mathrm{~m}$ dimensions for every excavation unit. Elevational $\mathrm{z}$ coordinates are more accurate.

Accurate vertical control is important to understanding a site such as $41 \mathrm{WA} 47$ where cultural deposits were anticipated to exceed $110 \mathrm{~cm}$ in vertical extent and there is not clear stratigraphic separation between artifacts. Site definition and identification of the position of the archaeological deposits is critical to the determination of site formation, identification of individual occupation episodes, and overall site significance. More coarsegrained lumping of archaeological horizons can always be made during analyses. However, at the outset of fieldwork there was no information available that permitted the a priori determination of the appropriate scale of vertical control necessary to characterize the nature of the archaeological deposits encountered during the 1996 testing effort. Piece-plotting also was employed to obtain more fine-grained control over vertical artifact distribution.

Controlled excavation at 41WA47 employed block excavation units to sample four areas of the site. Shovel testing indicated that these locations had the highest probability to contain relatively deep archaeological deposits with a high diversity of artifacts. Contiguous block excavation offers several significant advantages over dispersed 1 x 1-m recovery units. Minimally, all units within a block excavation can be analytically related through proximity and the continuous distributions of archaeological materials, soil horizons of interest, or proximity to any potential features located within the block area. Logically, isolated $1 \times 1$-m units have a much more tenuous inferential relationship to other test units that are not spatially adjacent to them. Comparative 
analyses are tremendously facilitated by the use of block excavation proveniences. Block excavations provide exposures of soil profiles that are directly related to controlled excavation, the recovered artifacts, and samples from the individual $1 \times 1-\mathrm{m}$ units.

Although all shovel tests excavated on 41WA47 were positioned on the same grid system as the hand-excavated units. Shovel tests dug on site during survey were designated by transect and shovel test number. Those shovel tests dug on site, once intensive site-specific work began, were designated by a northing and easting coordinate. All controlled excavation units were designated by an alphanumeric block and unit system combining provenience checks with their grid coordinates relative to an arbitrary datum designated as N1000-E1000. The block/unit provenience system employed divided the entire site area into a series of $5 \mathrm{x}$ 5-m units designated by an alphanumeric series of columns and rows. Each $5 \mathrm{~m}$ north-south column of the grid was designated by a single letter. The origin for the sequence was from the west and extended to the east. The site was large enough that the letters were doubled (i.e., block NN) to designate the middle 5 x 5-m blocks of the site and tripled on the eastern margin. Each east to west row was designated by a number, originating from the north of the site and increasing to the south. These two designators identify a unique 5 x 5 -m block. For example, NN-38 would be directly west of OO-38, and directly south of NN-37. Within each of these $5 \times 5-\mathrm{m}$ blocks, a sequence of numbers $1-25$ is given to each individual $1 \times 1-\mathrm{m}$ unit. The system used at Huntsville employed alternating order to the numbering. The northernmost row (units 1-5) was numbered from west to east, the row immediately south was numbered east to west (6-10). The other three rows in each block alternated the unit numbering order in the same manner so that the southernmost row in each $5 \times$ x 5 -m block was numbered 21-25 from west to east. The northwestern most 1 x 1 within the NN-38 block would be identified as NN-38-1. Every $1 \times 1-\mathrm{m}$ unit also is identified by its grid northing and easting relative to the site datum's designation of N1000-E1000.

Although this system may at first appear cumbersome, it has many advantages over a simple grid system. Each alphanumeric designator is unique and offers opportunities to cross check all provenience data very effectively. A particular grid unit identified by its northing and easting can only represent a single alphanumeric block. Several instances of laboratory confusion because of inadvertent mislabeling of one portion of the unit provenience were easily corrected through comparison of the block/unit and grid position. The most important benefit of a block/unit grid system is its utility in expanding arbitrary site grid systems across large sites and even across large landscapes of archaeological interest. This greatly facilitates multiple season excavation projects, especially where spatial analysis is a desired goal of archaeological recovery and interpretation. This system has been very effectively used in a large number of multi-year excavation projects in the American Great Plains.

The four block excavation areas are of variable size. Greater numbers of units were excavated within the deeper sediments that appear to contain an excellent record of multiple occupations of this site. The M59 block consisted of two adjacent 1 x 1-m units (M59-1/N939E960 and M59-2/N939-E961) and the Y47 also represented a 1 x 2-m block (Y47-1/N999-E1020 and Y47-2/N999-E1021). The NN-OO block was a 3 x 3-m area, selected because shovel testing indicated a high probability of deep deposits with abundant artifacts (Figure 5-1 and Appendix H, ST N980-E1100). The PPQQ block was located near BHT-1 because the trench profile demonstrated the presence of deep archaeological sediments. Block excavations also offer the advantage that they can be readily expanded if they encounter significantly dense artifact concentrations or features. Excavation results indicate that the area encompassing BHT-1, the PP-QQ units, the NN-OO block, and an area approximately 20 m east of the latter block, contains the most intact archaeological deposits at 41WA47 (Figure 5-1).

All block excavation units were shovel skimmed to these standard elevations and were not referenced to ground surface. All sediment was screened through 1/4-inch hardware cloth. All materials remaining within the screens were returned to the laboratory. This included gravel and plinthite clasts. Field sorting into categories of lithics, ceramics, bone, charcoal, daub, and gravels were used to provide preliminary counts of subsurface artifact densities. Natural clasts can offer vital clues about site formation processes. Their quantification involved 
a numeric count and weight for comparability. These data were more efficiently collected in the laboratory than during survey testing. Non-cultural materials recognized in the laboratory were discarded without cataloging.

\section{Paleobotanical Sampling}

Sampling for plant remains is a critical recovery trajectory that provides information about the paleoenvironment and possible past human use of plant resources. Macrobotanical, pollen, and phytolith analyses offer complementary paleobotanical information that can help establish some parameters of the natural environment. These data are critical to archaeological inferences about human activities. Even if not indicative of human behavior, they may offer important information about the past environment in the vicinity of Huntsville State Park. Although carbonized nutshells were observed in the 1996 shovel testing, it is uncertain whether these are referable to human agency. Recovery of plant remains is useful to both environmental studies of the park and archaeological inquiry.

Macrobotanical analyses provide information on natural background plant remains and possible residues of human plant use. Seeds and charcoal may reflect human selection of food, firewood, construction materials, or other carbonized plant tissue indicators of past cultural activities. Pollen and phytolith samples are important because they offer complementary information at different scales about the paleoenvironment. Each records the potential presence of different kinds of plant tissues. The pollen record contains regional information about plant communities. Phytoliths provide a local view of past vegetation on the site. Phytoliths are highly resistant to destruction, so that if pollen preservation is poor samples can still be processed for phytolith recovery.

Carbonized nutshell fragments were recovered from STs 3 and 7 during the 1996 testing effort. They were present in Level 9 (80-90 cm bgs) of ST 3, and Levels 4, 5 (30$50 \mathrm{~cm})$, and $9(80-90 \mathrm{~cm})$ of ST 7. Given the presence of these macrobotanical remains and the suggestion that a midden deposit may exist in proximity to these test units, paleobotanical recovery was considered a potentially critical opportunity to address subsistence at 41WA47. Paleobotanical samples were collected systematically from a randomly selected sample of seven 1 x 1-m units. No soil samples were collected from the
Y47 and M59 blocks. Four excavation units in the NNOO block were sampled for macrobotanical and pollen/ phytolith remains. Soil was collected from NN51-17 (N976-E1098), NN51-16 (N976-E1099), NN51-25 (N975-E1099), and OO51-20 (N976-E1100). Paleobotanical samples were systematically collected from three randomly selected units in the PP-QQ block. Samples were collected from all excavation levels in PP49-5 (N989-E1109), QQ49-1 (N989-E1100), and QQ49-2 (N989-E1111). No prehistoric features were identified during controlled excavations so there is no recovery from hearths, middens, or other identifiable contexts. Only nine samples selected from alternating excavation levels in QQ49-2 were analyzed for macrobotanical contents by Dr. Philip Dering of the Archaeobotanical Laboratory in The Center for Ecological Archaeology of Texas A\&M University (Appendix A). The goal of this study was to identify the potential of macrobotanical studies and subsistence change through time evidenced at the site. A single randomly selected phytolith sample was analyzed by Dr. Susan Mulholland of the Interdisciplinary Archaeology Studies Laboratory of the University of Minnesota, Duluth (Appendix B). These analyses examined only a portion of the samples collected to determine the recovery success from these sediments, the utility of processing additional samples, and potential future recovery needs.

Two sets of samples were collected from the designated sample units. A macrobotanical sample and a combined pollen/phytolith sample were taken from every excavation level in the selected excavation units. For macrobotanical sampling, approximately 1.5-2 liters of sediment was collected from every $10-\mathrm{cm}$ excavation level within each sample unit. Most samples were collected from a consistent area of the excavation unit (the southwestern quadrant), unless roots, presence of piece-plotted artifacts, or other excavation logistics prohibited collection from that quadrant. Attempts were made to take a sample that represented the entire depth of the excavation level. Standardized sample locations assist in spatial analysis of laboratory results of examination for macrobotanical remains, phytoliths, or pollen. Each sample was collected by trowel and placed in a tyvek Hubco soil sample bag. Although it would have been important to clean trowels following the recovery of each sample, these tools were not washed prior to the removal of each soil and sediment sample. 
All samples were allowed to dry in their bags following fieldwork until flotation, or more precisely, decanting, was performed. Flotation of all collected samples was performed at the Center for Archaeological Research laboratory by a standard method. Each entire sample was agitated in a bucket by hand for 30 seconds. The sample was allowed to rest for approximately one minute, and then poured into cheesecloth. Additional water was added to the sample and this process was repeated once more. The materials that were poured off following the two agitation cycles represents the light fraction. The remaining sediment was poured through a $1 / 4$-inch screen and what remained constitutes the heavy fraction from each sample. The light fractions from the two rinses were combined and air-dried prior to submittal for analysis. Prior to submittal for paleobotanical analysis, some light fraction samples were scanned for charcoal for radiocarbon dating. Only small pieces that were light enough to float and be poured off were noted in the light fraction samples. During flotation, it was noted that some larger pieces of charcoal were sufficiently heavy to sink during agitation. These pieces were retained in the heavy fraction from each sample. To recover sufficient charcoal for dating, the charcoal was picked and submitted for analysis from three heavy fraction samples. All equipment was washed between processing of each sample using tap water, not distilled water. It was noted previously that one sample (Level 259) was lost during flotation processing.

The selected samples from QQ49-2, N989-E1111 submitted for macrobotanical analyses represent nine of 18 excavated levels. Alternate $10-\mathrm{cm}$ levels were selected for analysis. The single sample that was lost (Level 259) necessitated the selection of an alternative sample that was from the adjacent level above (Level 258) that sample. The interval between Level 258 and the next lowest sample submitted for analysis is $20 \mathrm{~cm}$. Only half of the collected samples were submitted for analysis because of the very high probability that paleobotanical recovery from such small samples may be poor and translocation of remains through the sands of these soils and sediments may have occurred.

Sampling for phytoliths was performed similarly to macrobotanical soil collection. A standard sediment sample was taken from the southwestern quadrant of each excavation level and placed in a tyvek Hubco bag. Each sample bag holds approximately 0.5 liters of soil or sediment. These were collected as a combined sample for pollen and phytolith analyses. In consultation with paleobotanists, the potential for good pollen preservation within the sandy, highly acidic sediments was considered to be poor. For those reasons, analysis focused on examination of only a single phytolith sample to determine the preservation conditions of those plant remains.

It was uncertain how good the recovery of paleobotanical remains would be at $41 \mathrm{WA} 47$. All macrobotanical samples have been floated and are reserved for possible future analyses. Preliminary phytolith scan analysis indicated that phytoliths might be present in relative abundance, although most have been severely weathered. All sediment samples collected for pollen/phytoliths analyses have been retained and can be submitted $f$ or future analyses. These combined samples can be fractionated for analyses of either or both of these plant residues.

\section{Charcoal Sampling}

Charcoal from the shovel tests was not considered appropriate for dating because of the poor control offered in those units. Only charcoal from the controlled excavation blocks was targeted for sampling as datable material. Charcoal was collected opportunistically. Only charcoal identified in situ that could be piece-plotted was selected as a potential sample for dating. For each sample collected, the northing, easting, and elevation was recorded. A note on the size of the sample and a brief statement about the observed context also was made on the excavation form. This assisted the selection of priority samples from the collected material for submission to Beta Analytic Labs for AMS dating. No charcoal was collected intentionally from the uppermost $30 \mathrm{~cm}$ of the site because of extensive inclusion of charcoal from modern fires within the epipedons. Care was taken not to sample any charcoal from krotovina or any other obvious disturbance.

\section{Piece-Plotting}

Although the majority of sediments were removed using shovel-skimming methods, attempts were made to map in situ artifacts that measured $\geq 2 \mathrm{~cm}$ in maximum dimension. As accomplished, it seems that the majority of the piece-plotted items were slightly larger than this 
target size. The orientation and inclination of each pieceplotted artifact encountered in situ was recorded using a Brunton pocket transit. Some artifacts were moved out of place during shovel skimming or troweling. If their location could be identified from the impression of their position, then minimally their three-dimensional coordinates could be recorded. Many of these slightly out of place artifacts also could still have their orientation and inclination measured. These data are useful to determine site formation processes at 41WA47. Orientation was measured as the direction that the longest axis of each piece followed from its highest to lowest position. Inclination simply measures the angle of repose on an item along the axis of orientation. This procedure has been used extensively to determine whether artifacts have been subject to significant post-depositional movement. Orientation and inclination data can be used to address the most common forms of artifact movement. Clasts that are entrained as alluvial or colluvial sediment load often demonstrate preferred orientation parallel or perpendicular to the direction of flow (Waters 1992:27).

Measuring orientation and inclination from highest to lowest position relies on two sets of assumptions. Neither one assumes a priori that artifacts have not been subject to significant post-depositional movement. Items are most commonly moved into a lower, rather than higher, position from their place of deposition. Significant negative inclination often is an indicator of trampling or sediment movement. If an artifact is moved to a higher position, then the highest end of the artifact represents the farthest point in the artifact's upward movement or subsequent subsidence and is a fair measurement of its position as a sediment clast. For relatively flat lying artifacts, collecting the inclination first allows precise determination of the orientation when that is not initially apparent.

A total of 124 artifacts were piece-plotted in the block excavations. Of that total, $73(\sim 59 \%)$ of these items did have their orientation and inclination measured. Fiftyone pieces did not have orientation or inclination measurements collected. The reasons for non-collection of the orientation data were idiosyncratic and not a systematic exclusion of particular items. Some larger artifacts were moved out of place before the excavator noticed them. Orientation and inclination were still measurable for many of these pieces if their impression was still visible in the sandy sediments. Conservative criteria were employed in determining which artifacts could have their position measurements taken in addition to their northings, eastings, and elevations.

\section{Faunal Material Recovery}

Increasing the samples of recovered faunal remains from 41WA47 was identified as one of the goals of additional work at this site. Because of the tremendous information potential provided by faunal remains, care was taken to recover as many bones as possible in situ with minimal damage. Upon encounter with bone, metal tools were put aside and bamboo excavation implements used to minimize potential damage to cortical surfaces that may preserve evidence of processing activities. Attempts were made to map larger faunal material in place and recover the maximum amount of spatial information possible for this very important class of material.

\section{Treatment of Human Remains}

A single, human burial was discovered in 1978 in an area near the site. 41WA47 has been recorded as the provenience of this burial, although no precise locational information is available for that find. Given the possible association of deposits with potential burials, all precautions were made to conform to the TPW protocol dictating that human bone must be left in situ, protected from additional exposure, and the appropriate responsible parties contacted promptly. The principal investigator is a competent faunal analyst and observed all bone found to assure that potential human remains were not disturbed during the testing or mitigation. No human remains were identified among the 1,255 bones recovered from both the survey and mitigation efforts at Huntsville State Park (see Appendix C).

\section{Profiling Methods}

Profiling involved standard soil profiling methods employed in soil science (Soil Survey Staff 1993:117 $168,172-180,184-193)$. A profile was drawn for one face of the backhoe trench. Soil descriptions were completed for every identified sedimentary and soil horizon from each profile. Sediment samples were collected from each horizon in the backhoe trench profile. Profiles also were drawn for each of the $1 \times 2$-m block excavation areas, M59 (Figure 5-4) and Y47 (Figure 5-5). Abbreviated soil descriptions were made for these two 
profiles. Two perpendicular walls were profiled in the 3 x 3-m NN51-OO51 block (Figure 5-6). Complete soil descriptions were performed for these profiles and sediment samples were collected from the north wall profile of this block. One profile of the deep controlled excavations was drawn for the western wall of the QQ4849 block, N989-992 E1111 (Figure 5-7). The soil description for this profile is presented in Table 5-3. There are slight differences in horizon sequence and nomenclature between this block excavation and BHT-1. This is simply because they are in slightly different positions sampling variation in the sediment and soil profile and because more detailed description was possible for the QQ48-49 profile. A comparison of the equivalent soil horizons between the backhoe trench profile and the QQ48-49 profile is presented in Table 5-4. Charcoal samples were collected from some profiles. Color slide photographs were taken of all profiles. Field observations included Munsell colors (wet and dry), texture, consistence, structure, and horizon boundaries. These attributes permit designation of the soil and sedimentary horizons in standard soil nomenclature (Soil Survey Staff 1993:117-135). The abundance and morphology of roots, pores, and clasts also was recorded.

\section{Magnetic Sediment Susceptibility Sampling}

Magnetic sediment susceptibility samples were collected differently from the controlled 1 x 1-m excavation units. Following completion of excavation to the final depth, samples were taken from one profile wall of each block excavation area. A continuous sample column was collected in $5 \mathrm{~cm}$ increments. Collection procedures were identical to those described for sampling from shovel tests. Two sample columns were collected from the backhoe trench profile (Column 1 and Column 2). In addition, one sample column each was collected from the following two units: N977-E1098 (NN51-14), and N989-E1111 (QQ49-2).

Magnetic susceptibility (MS) of sediments can be a useful analytic tool for identifying past human activity. This method is especially productive in sediments and soils that do not have readily apparent stratigraphy and where the nature of potential palimpsest deposits is ambiguous. Signature values from MS analyses are related to the organic content of sediments (Collins et al. 1994; McClean and Kean 1993; Singer and Fine 1989) and the decay of those materials (Reynolds and King 1995).
Variance in values produced from analysis of samples provides relative information about the comparative differences in past organic content of adjacent sampled areas of a site. This analysis can identify vertical and horizontal areas that have experienced organic enrichment. This is an especially useful technique for examining deposits at 41 WA47. The lack of stratigraphy and the sandy texture of these sediments make definition of sedimentary or cultural horizons difficult. Although large sediment and soil units can be readily distinguished, finer scale divisions in the vertical artifact distribution are problematic.

Comparisons of analysis results from 41WA47 with variability in artifact densities with depth (i.e., in N989E1111, N977-E1098) and correlations in susceptibility value patterns with changes in depositional units within a profile (i.e., the two sample columns from BHT-1) can assist in the assessment of integrity and definition of archaeological deposits.

\section{Archaeological Recovery}

\section{by Russell D. Greaves, Steve A. Tomka \& Jason D. Weston}

Excavation within all of the blocks, except the perpendicular six $1 \times 1-\mathrm{m}$ units, was completed upon contact with the older Bt horizon that does not contain archaeological artifacts. In the area adjacent BHT-1, this older soil was identified in two units at a depth of 180$190 \mathrm{~cm}$ below the current ground surface. Excavation of an additional $1 \times 1-\mathrm{m}$ unit to the contact with the $\mathrm{Bt}$ horizon was terminated following wall collapse of 110 $150 \mathrm{~cm}$ of trench wall. Very high rainfall associated with tropical storm Allison ( 19 inches of rain at Huntsville State Park within a one week period) resulted in supersaturated soil conditions. The high pore pressure in these massive sands was still significant in destabilizing the excavation walls following approximately two weeks of lower rainfall conditions. The materials recovered from the block excavations are presented in Appendices I and $\mathbf{J}$.

Artifact recovery suggests that this is a stratified deposit spanning the full $170-180 \mathrm{~cm}$ of sediments observed within the PP49/QQ48-49 block adjacent to BHT-1. The majority of recovered artifacts are lithics, described 


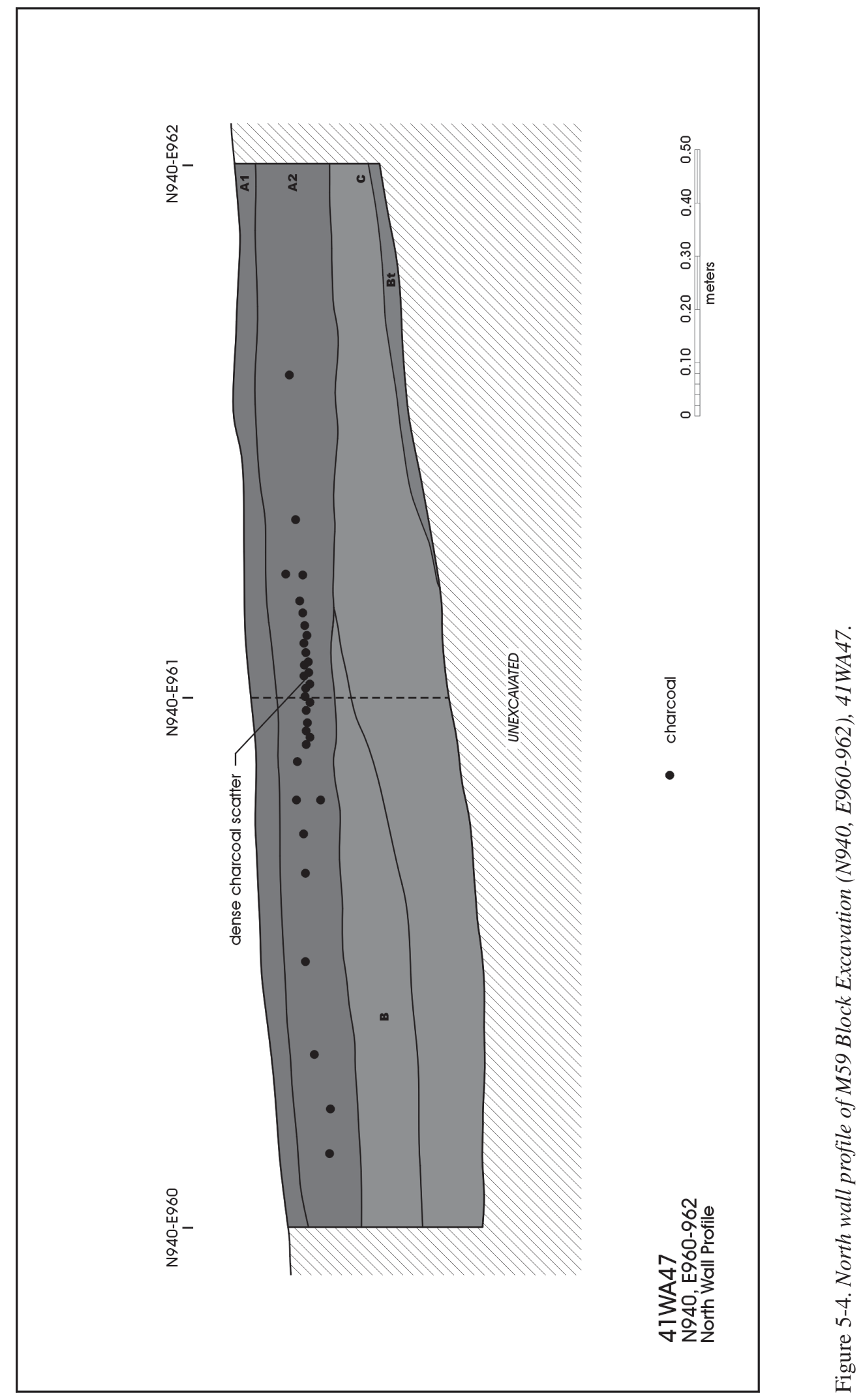




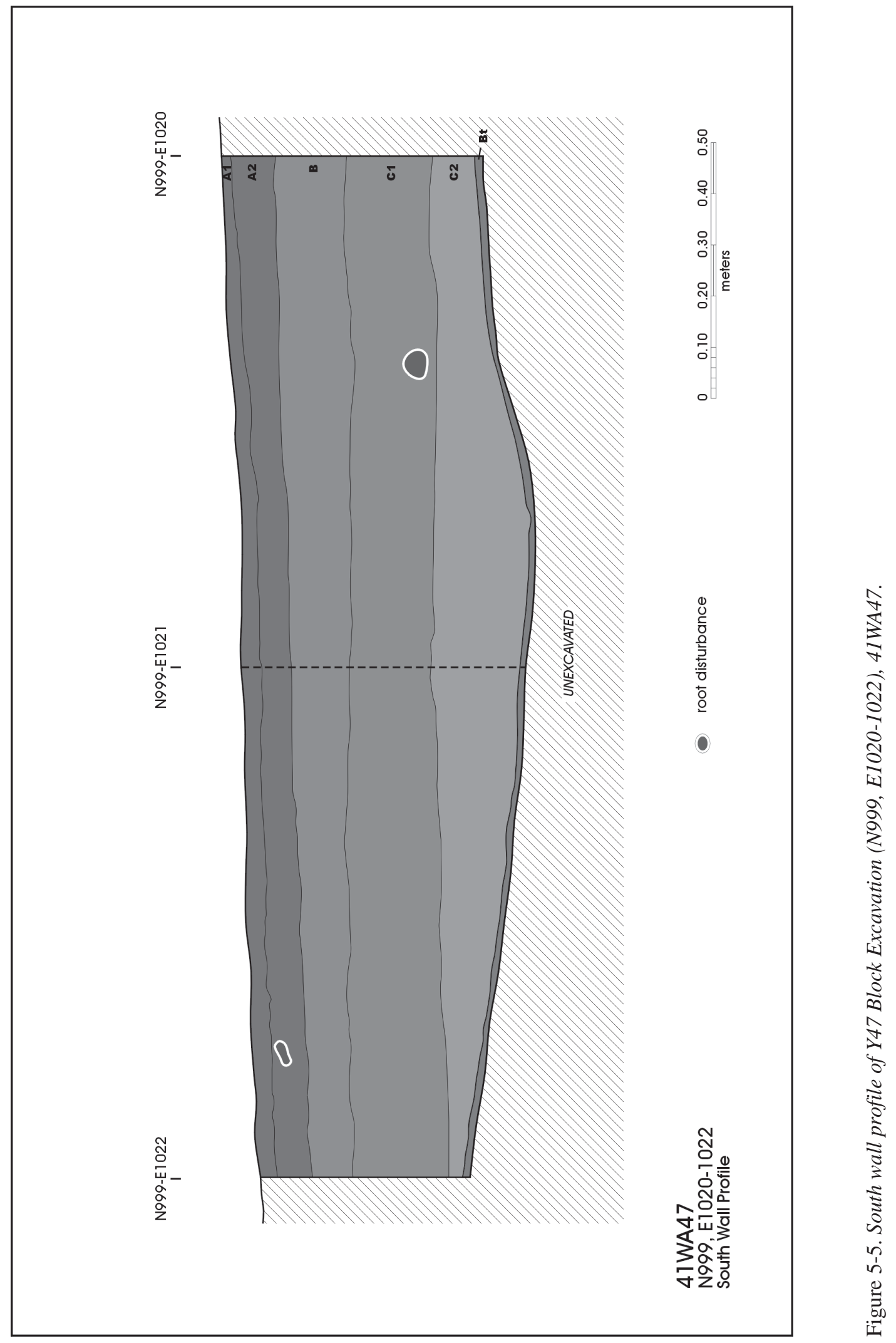




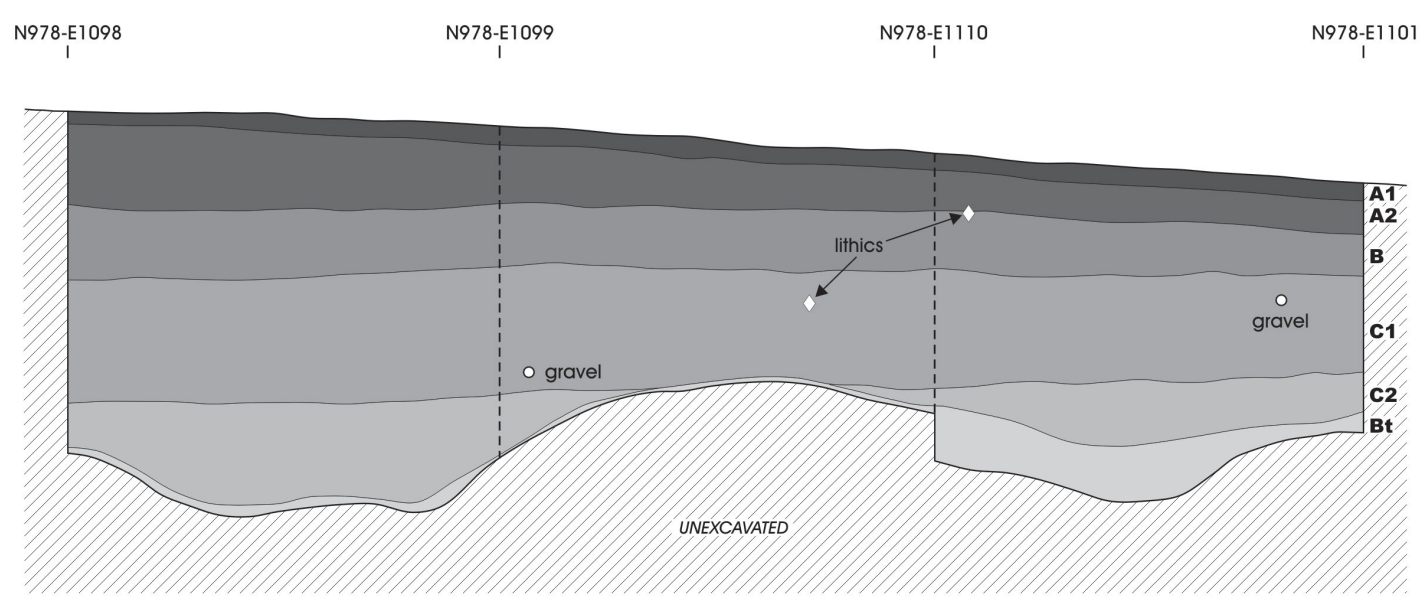

41WA47

N978, E1098-1101

North Wall Profile
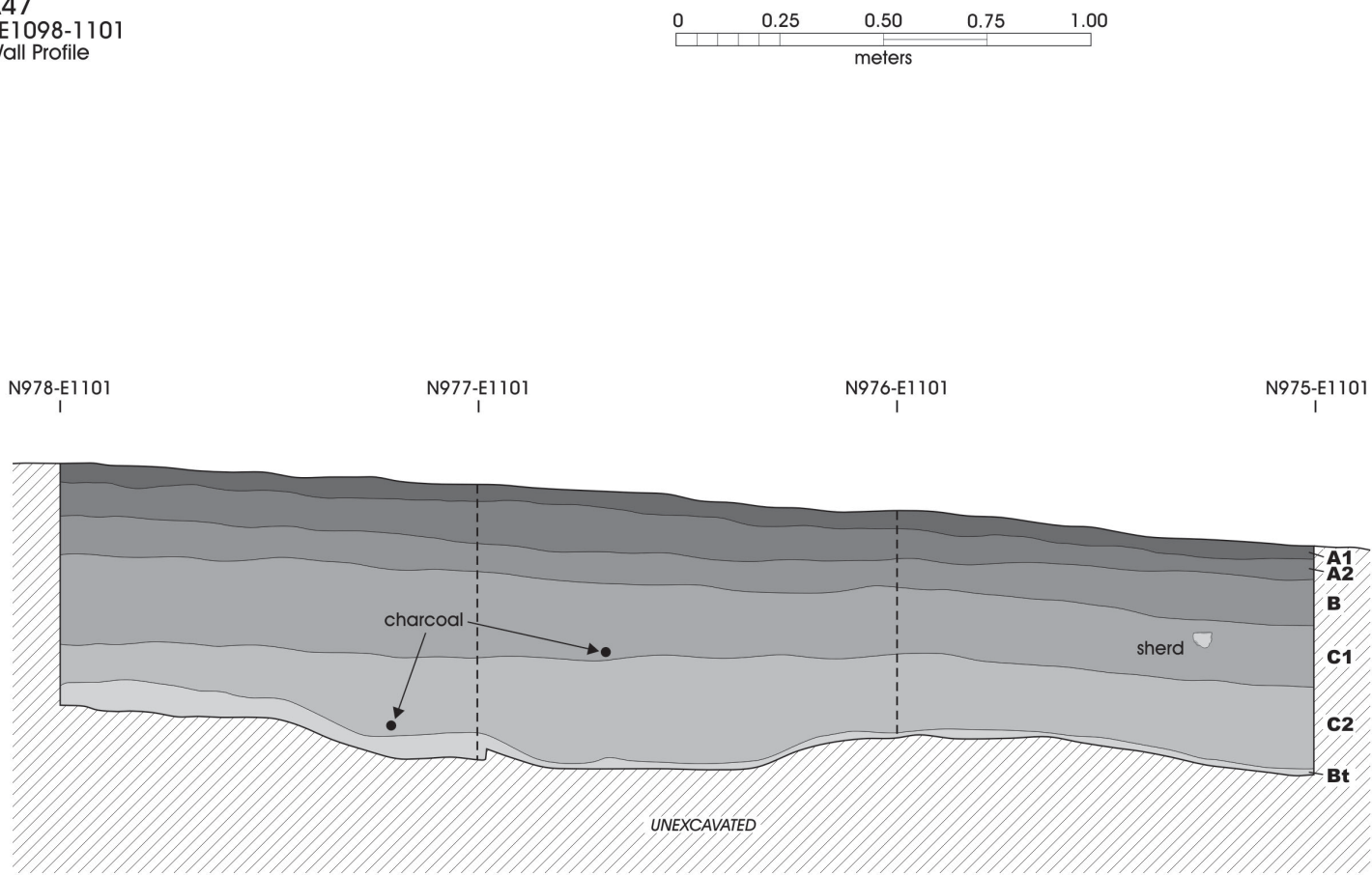

41WA47

N975-978, E1101

East Wall Profile

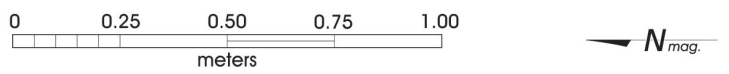

Figure 5-6. North and east wall profiles of NN51-OO51 Block Excavation (N975-978, E1098-1101), 41 WA47. 


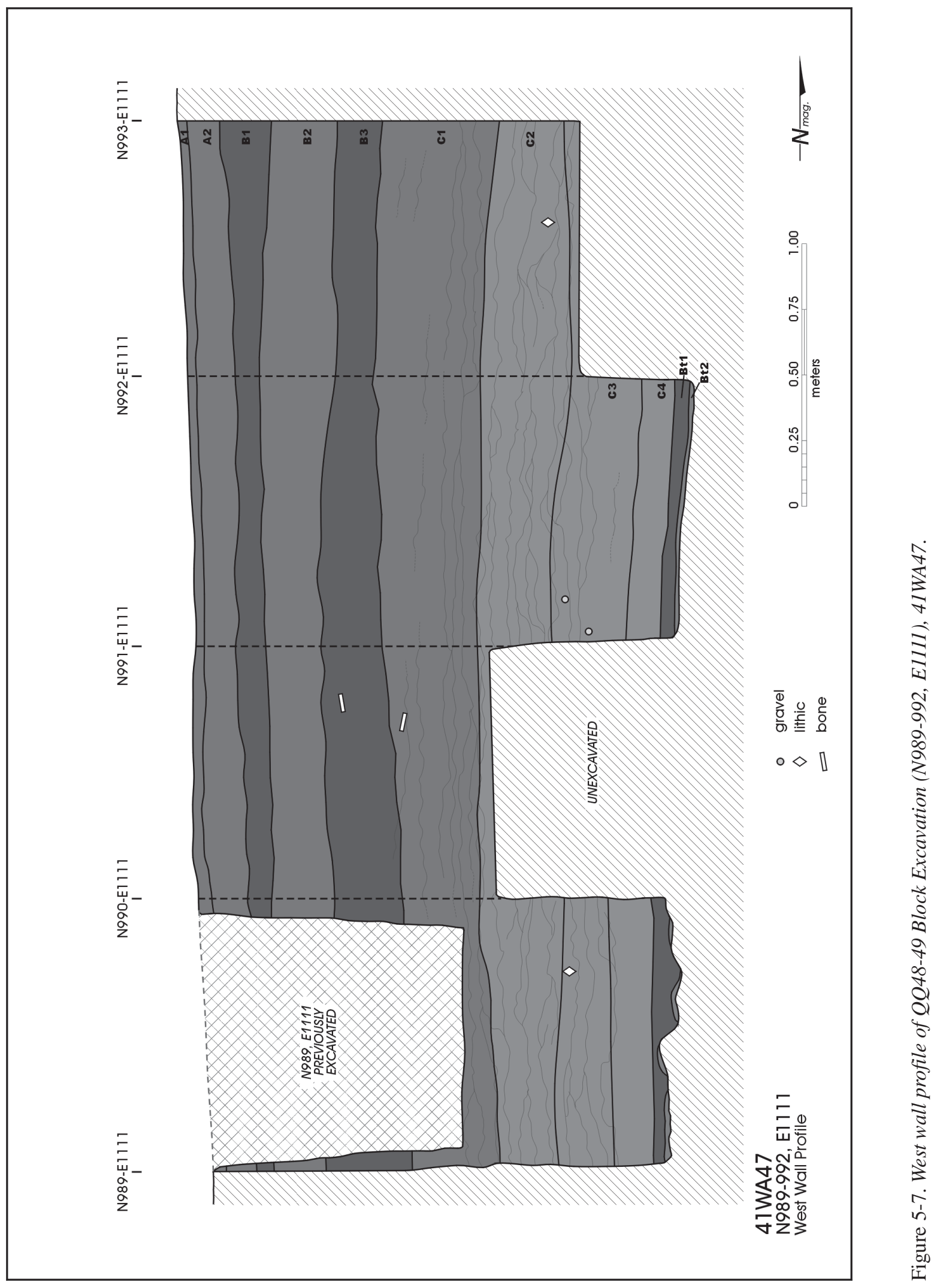




\begin{tabular}{|c|c|c|c|c|c|c|c|}
\hline Uू & 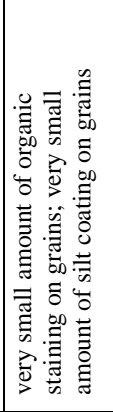 & 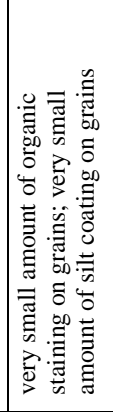 & 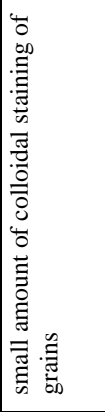 & & 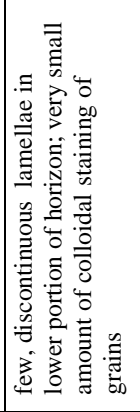 & 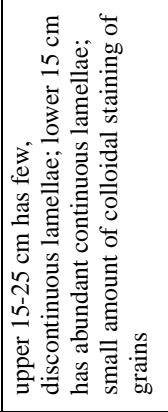 & 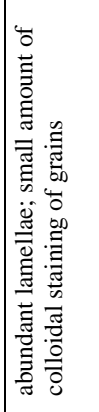 \\
\hline 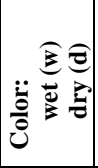 & 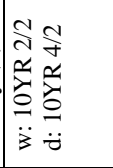 & 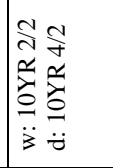 & 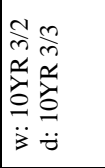 & 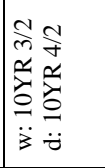 & 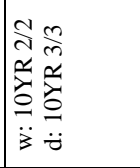 & 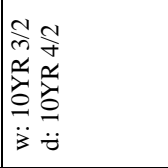 & 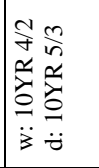 \\
\hline ف해 & 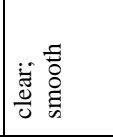 & 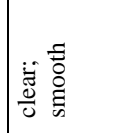 & 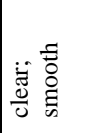 & 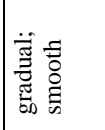 & 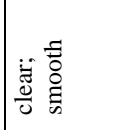 & 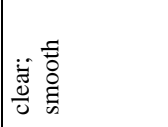 & 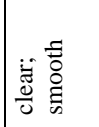 \\
\hline 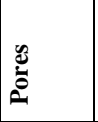 & 0 & 0 & 0 & 0 & 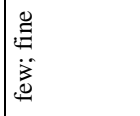 & 0 & 0 \\
\hline 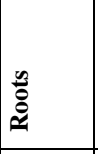 & 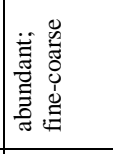 & 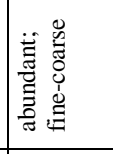 & 总 & 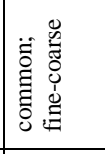 & 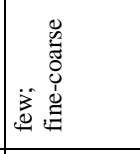 & 吾害 & 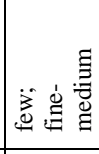 \\
\hline 产 & 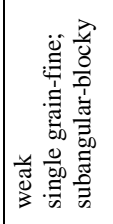 & 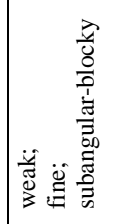 & 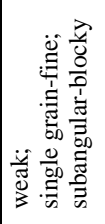 & 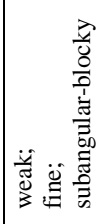 & 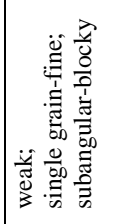 & 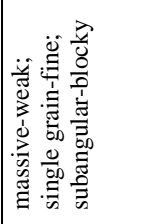 & 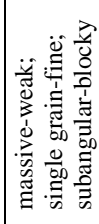 \\
\hline Uू. & 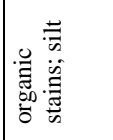 & 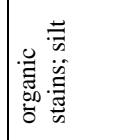 & 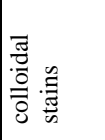 & 0 & 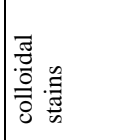 & 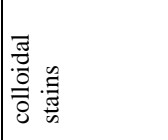 & 烝 \\
\hline 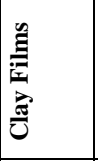 & 0 & 0 & 0 & 0 & 0 & 0 & 0 \\
\hline 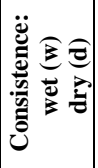 & 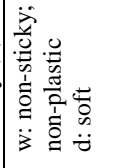 & 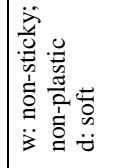 & 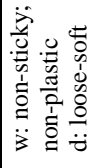 & 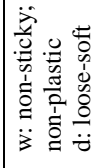 & 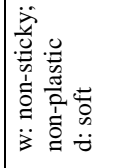 & 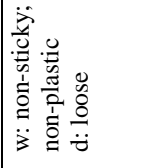 & 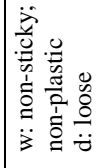 \\
\hline 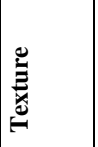 & 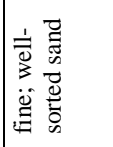 & 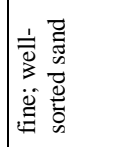 & 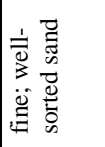 & 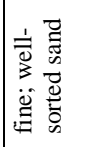 & 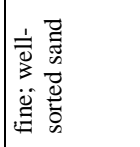 & 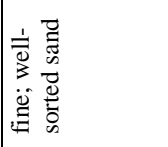 & 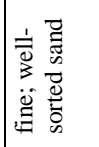 \\
\hline 产 & \& & \& & $\vec{\infty}$ & $\tilde{\infty}$ & 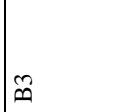 & $\bar{u}$ & $\tilde{U}$ \\
\hline
\end{tabular}




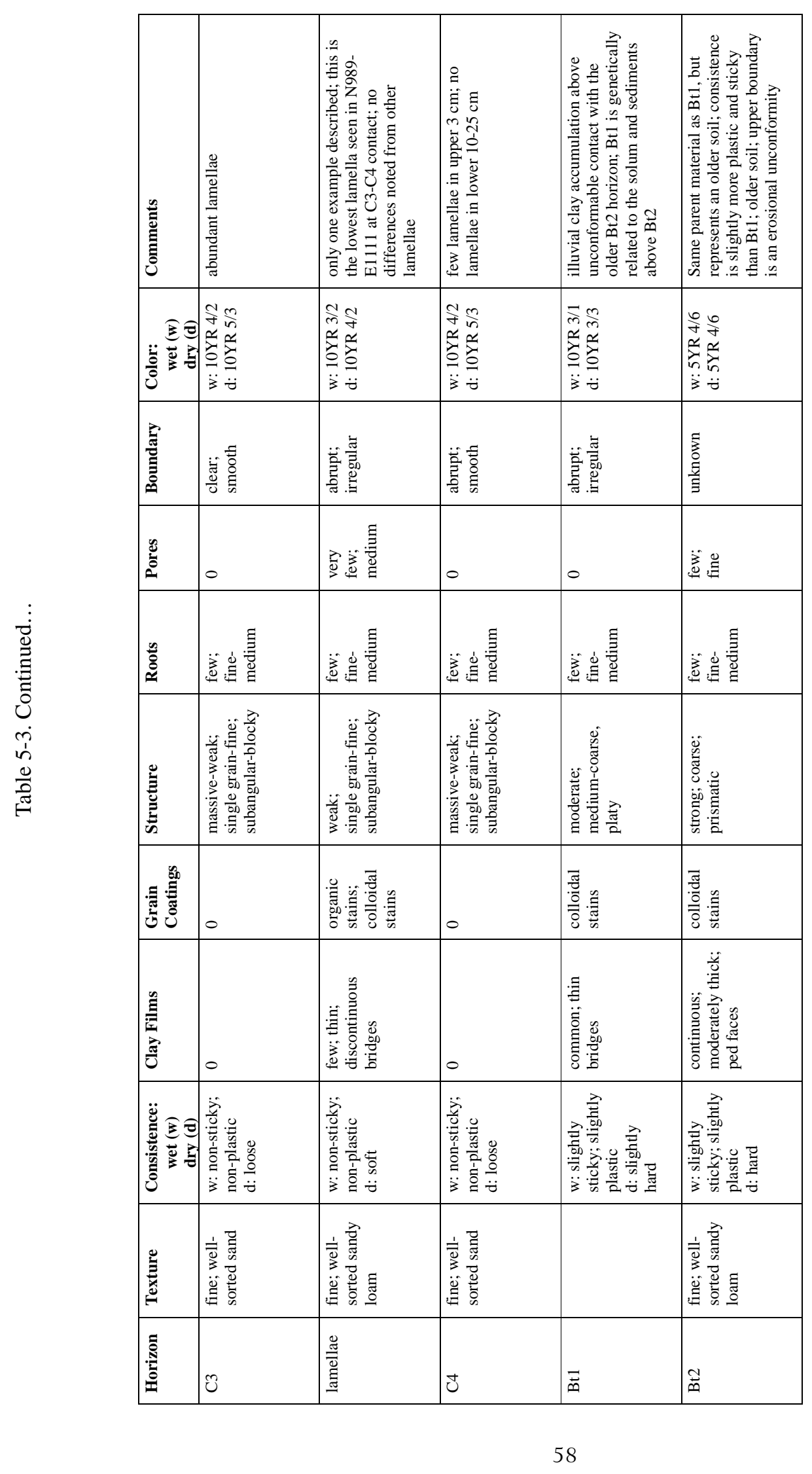


Table 5-4. Equivalence of Soil Horizons between BHT-1 and QQ48-49, N989-992 E1111, West Wall Profiles*, 41WA47

\begin{tabular}{|c|c|c|}
\hline Backhoe Trench-1 & $\begin{array}{l}\text { QQ48-49, } \\
\text { N989-992 E1111 }\end{array}$ & Comments \\
\hline A1 & $\mathrm{A} 1 ; \mathrm{A} 2$ & $\begin{array}{l}\text { uppermost soil less disturbed in the N989-992 E1111 profile than in BHT-1 so } \\
\text { that finer distinctions made between A horizons }\end{array}$ \\
\hline B1 & B1; B2 & $\begin{array}{l}\text { B1 in BHT-1 only apparent in north end of trench; B2 is in an equivalent } \\
\text { position in the southern } 3 / 4 \text { of BHT-1 profile }\end{array}$ \\
\hline B2 & B1; B2 & $\begin{array}{l}\text { B2 in BHT-1 is in an equivalent position to B1 in the southern } 3 / 4 \text { of BHT-1 } \\
\text { (see note above) }\end{array}$ \\
\hline B3 & B3 & \\
\hline $\mathrm{C} 1$ & $\mathrm{C} 1 ; \mathrm{C} 2$ & finer distinctions made between massive sands in the N989-992 E1111 profile \\
\hline $\mathrm{C} 2$ & $\mathrm{C} 3$ & \\
\hline none & $\mathrm{C} 4$ & BHT-1 not as deep as N989-992 E1111 excavation block \\
\hline none & Bt1 & $\begin{array}{l}\text { presence of illuvial clay within sediment overlying the rubified Bt } 2 \text { soil in } \\
\text { N989-992 E1111 excavation block not identified in BHT-1 because older Bt } \\
\text { soil identified at higher position }\end{array}$ \\
\hline Bt1 & Bt2 & $\begin{array}{l}\text { same soil in both profiles, different nomenclature because of presence of Bt1 } \\
\text { containing illuvial clay in N989-992 E1111 excavation block }\end{array}$ \\
\hline Bt2 & none & $\begin{array}{l}\text { QQ48-49 not excavated below upper } 3 \mathrm{~cm} \text { of contact with } \mathrm{Bt} 2 \text { so that no } \\
\text { distinctions identified within this rubified soil as seen in the in the deeper } \\
\text { exposure of BHT-1 }\end{array}$ \\
\hline
\end{tabular}

* = discrepancies due to nonadjacent placement of BHT-1 and the QQ48-49 block excavation, and more fine-grained horizon designations distinguished in the QQ48-49, N989-992 E1111 excavations.

below. The results of the analysis of the relatively large ceramic collection, also is presented following the lithic discussion. Results of macrobotanical, phytolith, and faunal analyses are summarized at the end of this chapter. The reports discussing the details of each respective analysis are presented in Appendices A (macrobotanical analysis), B (phytolith analysis), and C (faunal analysis), respectively. In addition, 124 piece-plotted artifacts provide information about deposit integrity and site formation. The results of this analysis are presented in a section discussing spatial analysis patterns.

\section{Chronometric Dating}

A series of six charcoal samples were submitted to Beta Analytic Laboratories for AMS dating. The results of those analyses are presented in Table 5-5 and complete results from Beta Analytic are provided in Appendix D. All samples are charcoal that was piece-plotted in four of the deepest, controlled $1 \times 1$-m units in the QQ48-49, N989-992 E1110-1111 excavation block. These samples were recovered from Levels 266, 264, 262, and 260 in these excavation units. Four of these samples provide closely spaced dates for the lamellae in horizons C2 and
C1. One of the other two samples is from the top of the $\mathrm{C} 1$ horizon where there are few, discontinuous lamellae. The other sample is from the B3 horizon. No samples were processed from the PP49-5, N989-E1109 block. Six additional samples that have not been submitted for dating were collected from the controlled excavation units (Appendices I and J). Piece-plotted charcoal that has not been dated was recovered from NN51-16, Level 259, PP49-5, Levels 258 and 261, QQ49-1, Levels 260 and 261, and QQ48-19, Level 266. Charcoal was reserved from the screen when encountered below the modern disturbance. Because of the imprecision in the exact provenience of these samples, they were not submitted for dating and have been reserved primarily for potential species identification.

The six samples were submitted for AMS dating and sufficient carbon was present for standard AMS analyses. Samples were collected from artifact bearing deposits ranging from $68-125 \mathrm{~cm}$ below the current ground surface $(88.96-88.32 \mathrm{~m}$ below the arbitrary datum elevation of $100.00 \mathrm{~m})$. The results range from cal $1900 \pm 40$ вР (AD 10-90) to cal $370 \pm 40$ ВР (АD 1540-1620; 


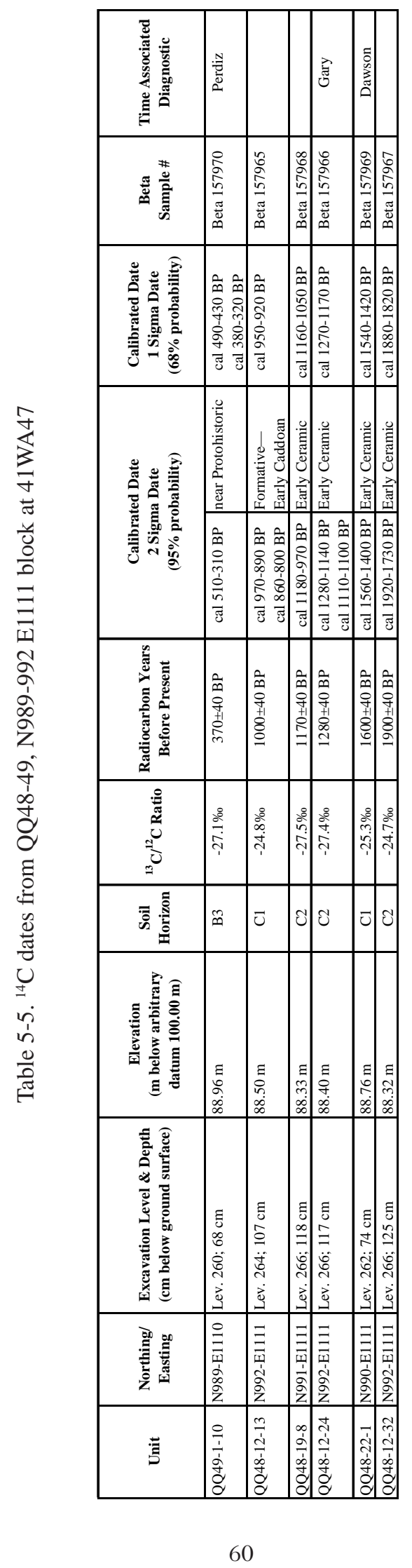


Table 5-5). The sequence of dates has one apparent anomaly. Beta sample 157969 was collected from $74 \mathrm{~cm}$ bgs in N990-E1111 and was dated to cal 1600 $\pm 40 \mathrm{BP}$ (AD 310-390). This appears to be much too old compared with the dates for samples from adjacent sediments. Beta sample 157970 is the most recent date (cal $370 \pm 40 \mathrm{BP}$; AD 1540-1620) and was collected at $68 \mathrm{~cm}$ bgs. Beta sample 157965 was collected at $107 \mathrm{~cm}$ bgs and dated to cal 1000 \pm 40 BP (AD 910-990). All other dates in the sequence other than Beta sample 157969 do appear to be in temporal sequence with their stratigraphic position.

Although this is a small sample of dates for such a deeply stratified site, these results do indicate a strong likelihood that charcoal from $41 \mathrm{WA} 47$ can provide reliable and significant dating information about the human use of this location and the stratigraphic integrity of the deposits. The presence of relatively abundant diagnostic artifacts also offers an opportunity to associate them with absolute dates and compare AMS dating with relative chronological information defined by projectile points (see Projectile Points section).

\section{Lithic Analysis}

A total of 3,717 pieces of debitage were recovered from controlled block excavations at 41WA47. Additionally, 36 complete or nearly complete points were recovered from this site. Six additional fragments of finished or nearly finished bifacial tools that are likely points also were collected from the controlled block excavations. The distal blade of a finished bifacial knife was recovered from the deep controlled excavation area. A single flake tool with use wear and minimal steep retouch was identified from one of the controlled units with shallow sediments (Y47-2, N999-E1021, Level 222, 92.8-92.7 $\mathrm{m})$. Nine bifaces in various stages of reduction, three hammerstones, and six cores or tested cobbles also were collected in the controlled excavation blocks.

\section{Debitage Attributes}

The debitage was sorted into six flake categories and attributes of maximum dimension, percentage of cortex present, incidence of heating, and raw material type was recorded for each piece (Tables 5-6-5-8). The attributes are defined first followed by a description of flake types. The categorization used in these analyses is considered heuristically useful to identifying some trends in lithic manufacture through debitage that may be distinctive of the reduction of different rock forms or removal techniques.

The maximum dimension was measured as the longest dimension of each piece. It is not necessarily oriented along the axis of the flake removal, proximal to distal, but represents a measurement of the lithic's greatest length in any orientation. This measurement serves as an indicator of the size of each piece as a clast in the soil. This is an important variable to address taphonomy of lithics and determine whether assemblages are likely to represent cultural or geomorphic accumulation.

The percentage of cortex present was recorded as a visual ordinal estimate of amount of natural cortex preserved on the dorsal surface of any lithic. Estimates identified pieces with no cortex present, $1-50$ percent cortex, $>50$ and $<100$ percent $(\sim 51-99 \%)$, and coverage of 100 percent of the dorsal surface. Cortex was readily identifiable on lithics at Huntsville. All of the raw materials appear to derive from alluvial gravels and petrified wood with distinctively weathered cortex. This estimate permits determination of the approximate stage of reduction represented at the site from unspecified procurement events of unmodified raw materials from unidentified sources.

The heating of lithics was identified through the presence of pot-lidding, crazing, or apparent heat fractures of the cryptocrystalline material. No attempts were made to specify the relative intensity of heating represented on each piece, or whether thermal modification occurred prior or subsequent to the final knapping events.

Raw materials are identified by rock type but no source has been identified for them. Five raw material types were identified for the lithics from Huntsville State Park (Table 5-7). All debitage was assigned as either chert, quartzite, extremely coarse-grained quartzite, petrified wood, and silicified sandstone. Except for quartzites, no attempts were made to distinguish subgroupings of these materials on the basis of color, texture, or inclusions. The coarse-grained quartzite is dramatically different from the other quartzites, and has much poorer fracture qualities. 
Table 5-6. Debitage size and cortex from 41WA47

\begin{tabular}{|c|c|cccc|}
\hline Size (mm): & $\begin{array}{c}\text { Portion of } \\
\text { the total }\end{array}$ & $\begin{array}{c}\text { Cortex: } \\
\text { decorticate }\end{array}$ & $\mathbf{1 - 5 0 \%}$ & $\mathbf{5 1 - 9 9 \%}$ & $\mathbf{1 0 0 \%}$ \\
\hline $0-10$ & $29.2 \%$ & $66 \%$ & $22 \%$ & $8 \%$ & $4 \%$ \\
count: & 1085 & 721 & 234 & 86 & 44 \\
\hline $11-20$ & $60.2 \%$ & $49.8 \%$ & $32.1 \%$ & $12.1 \%$ & $6 \%$ \\
count: & 2237 & 1114 & 719 & 269 & 135 \\
\hline $21-30$ & $9.1 \%$ & $25.5 \%$ & $40.5 \%$ & $26.3 \%$ & $7.7 \%$ \\
count: & 338 & 86 & 137 & 89 & 26 \\
\hline $31-40$ & $1 \%$ & $5.1 \%$ & $51.2 \%$ & $36 \%$ & $7.7 \%$ \\
count: & 39 & 2 & 20 & 14 & 3 \\
\hline $41-50$ & $.4 \%$ & $12.5 \%$ & $37.5 \%$ & $37.5 \%$ & $12.5 \%$ \\
count: & 16 & 2 & 6 & 6 & 2 \\
\hline $51-60$ & $.1 \%$ & $0 \%$ & $50 \%$ & $50 \%$ & $0 \%$ \\
count: & 2 & 0 & 1 & 1 & 0 \\
\hline & Total: 3717 & \multicolumn{5}{c}{} \\
\cline { 2 - 6 } & \multicolumn{5}{r}{}
\end{tabular}

Classification of flakes into the six identified types is a somewhat subjective procedure combining particular attributes with the relative variation of lithics within the assemblage. No claim is made that these represent completely objective categories that unambiguously identify stages or procedures of lithic reduction. Flakes were identified as angular debris, blades, platform or core preparation flakes, uniface reduction flakes, bifacial reduction flakes, or indeterminate. Identifications were made by the debitage analyst Jason Weston, under the direction of Dr. Steve A. Tomka. Angular debris represents lithics that have no clearly identifiable flake characteristics. These pieces have no ventral surface or platform and do not fall within other morphological categories. It is possible that some of these pieces represent naturally fractured chert. However, natural chert is rare in the Huntsville sediments above the gravel size category $(2-75 \mathrm{~mm})$, and almost all exhibit rounding.

Blades were distinguished morphologically by having relatively few dorsal flake scars (2-3) that indicated previous flake removals in the same direction as the blade flake. They possessed no cortex and had no characteristics distinctive of biface thinning or uniface flakes.

Table 5-7. Debitage raw material type and cortex from 41WA47

\begin{tabular}{|c|c|c|c|c|c|c|c|}
\hline Material Type & $\begin{array}{c}\text { Portion of } \\
\text { the total }\end{array}$ & $\begin{array}{c}\text { Heating: } \\
\text { yes }\end{array}$ & no & $\begin{array}{c}\text { Cortex: } \\
\text { decorticate }\end{array}$ & $1-50 \%$ & $51-99 \%$ & $100 \%$ \\
\hline chert: & $30.2 \%$ & 0.08 & 0.92 & $66.7 \%$ & $23.5 \%$ & $6.8 \%$ & $3 \%$ \\
\hline count: & 1122 & 91 & 1031 & 748 & 264 & 76 & 34 \\
\hline quartzite: & $49 \%$ & 0.02 & 0.98 & $48.8 \%$ & $32.3 \%$ & $12.9 \%$ & $6 \%$ \\
\hline count: & 1819 & 34 & 1785 & 887 & 589 & 234 & 109 \\
\hline coarse & $.7 \%$ & 0 & 1 & $46.4 \%$ & $28.6 \%$ & $25 \%$ & $0 \%$ \\
\hline quartzite: count: & 28 & 0 & 28 & 13 & 8 & 7 & 0 \\
\hline sil wood: & $20 \%$ & 0.02 & 0.98 & $36.8 \%$ & $34.4 \%$ & $19.8 \%$ & $9 \%$ \\
\hline count: & 741 & 8 & 733 & 272 & 255 & 147 & 67 \\
\hline sil sandstone:\%: & $.1 \%$ & 0.14 & 0.86 & $71 \%$ & $29 \%$ & $0 \%$ & $0 \%$ \\
\hline count: & 7 & 1 & 6 & 5 & 2 & 0 & 0 \\
\hline
\end{tabular}


Table 5-8. Debitage from 41WA47

\begin{tabular}{|c|c|c|}
\hline $\begin{array}{r}\text { Flake Type } \\
\end{array}$ & Number of Pieces & $\%$ of Total \\
\hline Angular debris & 104 & $2.9 \%$ \\
\hline Core/platform preparation flakes & 1221 & $32.8 \%$ \\
\hline blades & 4 & $0.1 \%$ \\
\hline Uniface flakes & 12 & $0.3 \%$ \\
\hline Biface thinning flakes & 226 & $6.1 \%$ \\
\hline Indeterminate & 2150 & $57.8 \%$ \\
\hline Total & 3717 & \\
\hline
\end{tabular}

Lithics identified as core or platform preparation flakes were distinguished primarily on the basis of platform morphology. These flakes possessed platforms that were at nearly right angles to the ventral face and usually had only a single facet. Core and platform preparation flakes often had thicker bulbs of percussion, fewer dorsal scars, and often had relatively large amounts of cortex. These represent evidence of relatively early stage reduction.

Uniface flakes possess evidence that they were removed from pieces having some shaping on one face but also exhibit no modification or minimal flaking on the other. These flakes must contain a portion of an unworked face that is identifiable as part of the piece they were removed from in order to be assigned as a uniface flake. Some may have evidence of a retouched or worn edge. Because only a portion of the parent piece is preserved on the dorsal surface, these flakes are suggestive, but not diagnostic of uniface production, modification, or rejuvenation. Some of these flakes are likely to represent reduction of pieces with minimal or broad removals from the less worked face. They also exhibit fewer dorsal scars than biface thinning flakes. Uniface flakes are indicative of reduction that is later than core and platform preparation flakes and potentially earlier than most biface reduction flakes.

Biface thinning flakes were identified on the basis of several characteristics. Most have very acute angle platforms with multiple facets. Frequently, the platform is the margin of the piece with flake scars from bifacial shaping. These flakes usually are lipped, are often thin, slightly convex, have multiple dorsal flake scars, and do not have large bulbs of percussion. They indicate later stage reduction than most other flakes. They are a useful indicator of the amount of tool production or modification occurring on sites.
Flakes that could not be identified according to the five categories described above were categorized as indeterminate.

\section{Debitage Analysis Results}

The majority of the debitage from 41WA47 is small. Table 5-6 presents an ordinal size grouping of the lithic debris. Almost 90 percent of the flakes are $20 \mathrm{~mm}$ or less in maximum dimension. Because $1 / 4$-inch screen was used during excavation, lithics $\leq 7-8 \mathrm{~mm}$ in dimension are not present within the assemblage. Despite this, debitage $\leq 10 \mathrm{~mm}$ represents 29.2 percent of the total assemblage $(n=1,085)$. Lithics between $11-20 \mathrm{~mm}$ constitute 60.2 percent of the sample $(n=2,237)$. Pieces measuring 21-30 $\mathrm{mm}$ are 9.1 percent of the debitage $(\mathrm{n}=338)$, and flakes larger than $31 \mathrm{~mm}$ represent only 1.5 percent of the lithics $(n=57)$. Some of this may be related to the availability of relatively small pebbles as raw material. Most of the tested rocks, possible cores, and incomplete bifaces recovered are small (less than $50 \mathrm{~mm}$ in maximum dimension). The largest pieces in the assemblage, providing some information on the size of available raw material, are the hammerstones and the tested pieces of petrified wood. The three hammerstones in the assemblage are quartzite gravels ranging from 56$77 \mathrm{~mm}$. The tested pieces of petrified wood are the largest lithics recovered. They measure $88-105 \mathrm{~mm}$ in maximum dimension and are not rounded from alluvial transport.

The amount of cortex present on debitage provides an estimate of the prevalence of initial reduction through final shaping events within the sample. As noted previously, the raw materials identified at site 41 WA47 are mostly small pebbles with distinctive, weathered cortex. Although several of the pieces of petrified wood indicate that much of it has been derived from non-gravel 
sources, the cortex also is readily apparent. Tables 5-6 and 5-7 present the ordinal frequency of cortex on debitage by raw material type and the size of flakes. Although the larger flakes do have more cortex, they represent a very small portion of the total assemblage. It is noteworthy that the highest percentage of decorticate debitage is in the chert raw material sample. Nearly 67 percent of the chert debitage is decorticate, while less than 50 percent of the quartzite samples consists of tertiary flakes. These patterns suggest that the chert debitage represents a longer reduction trajectory than the quartzite debitage. That is, entire tool manufacture sequences are represented in the chert debitage while early to middle reduction stage manufacture sequences are represented in the quartzite debitage.

Evidence of heating is uncommon on the lithics from Huntsville State Park. Table 5-7 indicates that only a very small proportion of the assemblage shows heat damage. The frequency of heating by raw material was examined to determine whether attempts were made to improve the knappability of any of the different rock types. There are no statistical differences between the amount of heating present on any raw material class. Given the lack of systematic evidence for heating of lithics, it is most likely that heat modification is a post discard effect. Because excavation did not encounter features or provide extensive horizontal coverage, it cannot be determined whether inadvertent heating is due to accidental inclusion or proximity to cultural thermal features or caused by natural fires.

Quartzite was the most common raw material (Table 5-7). The assemblage contained 1,819 pieces of quartzite, 49 percent of all the debitage. Both coarse- and finegrained quartzites are represented within the raw material classified as quartzite, but excludes the very coarsegrained quartzite that was tallied separately. Cherts are the second most frequently encountered raw material. A variety of chert colors (e.g., pink, red, tan, brown, and gray) are represented in the 1,122 pieces $(30.2 \%$ of the total sample) recovered in the controlled excavations. The gray chert appears to be of exceptional quality and may represent a nonlocal material source. The other colors appear to be of local origin. Petrified wood accounts for 20 percent of the assemblage $(n=741)$. Most of this is poorer quality petrified wood that breaks with planar fractures. Only a small percentage is high quality silicified wood. Twenty-eight flakes of the very coarse quartzite $(0.7 \%)$ and seven pieces silicified sandstone, or quartz arenite, $(0.1 \%)$ also were identified.

It is apparent that much of the raw material discarded at this site exhibits mediocre and poor fracture qualities. Within the areas of Huntsville State Park surveyed, no alluvial gravel deposits were encountered. Lithic materials appear not to be abundant in the immediate vicinity. The dearth of better quality cryptocrystalline rock is at least partly due to low availability, but could suggest retention of better material through modification and recycling of scarce high quality lithics. Because no distinctions were made to measure lithic quality, it is uncertain whether individually more controllable rocks were subject to differential reduction and curation. These data suggest that all raw materials are treated similarly and that no preferential trajectories of use are apparent for the kinds of raw materials distinguished in these analyses.

The flake type analysis indicates that angular debris represented 2.9 percent of the debitage from this site $(n=104$; Table 5-8). Only four blades were identified representing 0.1 percent of the total debitage assemblage from 41WA47. Lithics classified as platform and/or core preparation flakes were the second most common flake types distinguished in this analysis, representing 32.8 percent of the assemblage $(n=1,221)$. Uniface flakes were infrequent as only $12(0.3 \%)$ were identified from the controlled excavations at 41WA47. A total of 226 biface thinning flakes were identified, the third most common flake type identified from this site, representing 6.1 percent of the assemblage. The majority of flakes in this assemblage were classified as indeterminate. A total of 2,150 pieces $(57.8 \%)$ were assigned to this unspecified grouping. Many of these are broken flakes, also known as chips, missing the diagnostic portions.

\section{Projectile Points, Tools \& Cores}

\section{by Russell D. Greaves \& Steve A. Tomka}

Tools recovered in the sample of lithics from 41WA47 include 36 nearly complete or unbroken projectile points, six bifacial fragments that probably represent points, nine bifaces, six cobbles that may be cores or tested cobbles, three hammerstones, one finished bifacial knife blade, 
and a single flake tool. Almost all of these were recovered from the controlled excavation blocks and offer good provenience information. Provenience information for all tools and cores is presented in Table 5-9.

\section{Projectile Points}

Of the 36 lithics identified as points (Figures 5-8 and 59), 31 were assigned diagnostic designations by Steve Tomka. The proveniences of all diagnostic points are presented in Table 5-10. All but two of the diagnostic projectile points were recovered in the controlled excavation blocks. One was a surface find adjacent to the disturbed backhoe trench following backfilling, and one was recovered from a shovel test unit. The majority of the points can be used to examine their vertical distributions and can be compared with AMS dating of charcoal contained in these sediments. The identified points include eleven Perdiz, three Catahoula, nine Gary, seven Dawson, and a single Andice barb fragment. Four of the Dawson points were identified as preforms. Two Gary points also appear to represent preforms. Six pieces were considered identifiable as projectile points but insufficiently complete for classification.

The single Andice barb is of chert. Of the seven Dawson points and performs, five (71\%) are fine-grained quartzite and two are chert. Of the nine Gary points (eight finished and one preform), four are fine-grained quartzite, four are petrified wood, and one is chert. Six of the Perdiz points are made of chert, and surprisingly, five are made of petrified wood. The three Catahoula arrow points are fine-grained quartzite. Finally, of the six untyped and/or untypeable points, three are chert, two are fine-grained quartzite, and one is petrified wood.

A comparison of the vertical position was made between all but four points. The surface find (a Dawson preform, Figure 5-8f) is eliminated because of its unknown provenience within the disturbed BHT-1 surface area. The point recovered in ST N1000-E1140 (a Dawson perform, Figure 5-8g) is not included because this unit is not adjacent to the controlled excavations, and its position is not comparable to the deep materials within the excavation blocks. The two points recovered within the Y47 block (one Dawson and one Perdiz) are not included because the elevations of these two units are significantly higher than the other two block areas with the majority of the recovered points. No points were recovered from the M59 excavation block. Most diagnostic projectile points were recovered from the largest excavation blocks. The sediments above the argillic Bt horizon within the $\mathrm{NN}-\mathrm{OO}$ block are not as deep as those of the PP-QQ block. The projectile points from these blocks are combined to examine the vertical distribution because these units are adjacent and represent nearly equivalent ground surface elevations. Although some geomorphic differences exist between these two blocks, combining the points from both areas permits comparison of a larger sample.

Table 5-11 shows the vertical distribution of projectile points from the NN-OO and PP-QQ block controlled excavations. The six points mentioned above are removed from the comparison. The relative vertical positions of these points within the profile falls within the expected distribution of Woodland, early Ceramic period, and the Late Prehistoric projectile points. Only arrow points are present in the two highest levels (255 and 257) and only dart points are present in the five lowest levels (264 266, 269, and 272) there is less overlap between the Perdiz and Gary points. The distribution of the Dawson and Gary points appears to overlap and the distribution of arrow points and dart points overlap each other between Levels 258-263.

Charcoal samples collected from the same excavation levels as points were dated in units QQ48-12, Level 266, QQ48-22, Level 262, and QQ49-1, Level 260. Two charcoal samples from QQ48-12, Level 266 produced dates centered on cal 1940-1240 ВР (AD 10-710; see Table 5-5). A single Gary point (Figure 5-80) was recovered within this excavation level. One Dawson point from QQ48-22, Level 262 (Figure 5-8d) is associated with a date of cal 1640-1560 BP (AD 310 390). This date does appear to be anomalously old in comparison with the other five AMS dated charcoal samples. A Perdiz point from QQ49-1, Level 260 (Figure $5-9 \mathrm{~g}$ ) is associated with a date of 410-330 вP (AD 1540 1620). This date is consistent with conventional temporal assignment of Perdiz points. The date of 1640-1560 во (AD 310-390) from Level 262 in QQ48-22 would be younger than usually assigned to Dawson points (Fields 1995:314). However, this date is problematic, appearing to be older than its stratigraphic position suggests in 
Table 5-9. Provenience of all tools and cores from 41WA47

\begin{tabular}{|c|c|c|c|c|}
\hline Unit & Northing & Easting & Absolute Depth (m) & Tool Type \\
\hline BHT-1 & 988.60 & 1123.41 & 87.78 & Biface distal fragment \\
\hline BHT-1 & 993.57 & 1113.58 & 88.27 & Core \\
\hline BHT-1 & & & suface & Dawson preform \\
\hline BHT-1 & 989.05 & 1122.55 & 87.69 & Arrow point blank \\
\hline BHT-1 & 994.16 & 1112.39 & 88.19 & Gary dart point \\
\hline BHT-1 & 994.53 & 1111.63 & 88.80 & Perdiz arrow point \\
\hline NN51-14 & 977.85 & 1098.63 & 88.66 & Core \\
\hline NN51-14 & N0977.03 & E1098.42 & 88.78 & Core \\
\hline NN51-14 & N0977.67 & E1098.47 & 88.98 & Point Fragment \\
\hline NN51-16 & \begin{tabular}{|l|} 
N0976.47 \\
\end{tabular} & E1099.65 & 89.08 & Core \\
\hline NN51-16 & N0976 & E1099 & $88.90-88.80$ & Hammerstone \\
\hline NN51-16 & N0976 & E1099 & $89.30-89.20$ & Perdiz arrow point \\
\hline NN51-16 & N0976 & E1099 & $89.10-89.00$ & Perdiz arrow point \\
\hline NN51-17 & N0976 & E1098 & $89.20-89.10$ & Gary dart point \\
\hline NN51-24 & $\mathrm{N} 0975.2$ & E1098.08 & 89.08 & Gary dart point \\
\hline NN51-24 & N0975 & E1098 & $89.10-89.00$ & Perdiz arrow point \\
\hline NN51-24 & $\mathrm{N} 0975.2$ & E1098.08 & 89.08 & Point Fragment \\
\hline NN51-25 & \begin{tabular}{|l|} 
N0975.60 \\
\end{tabular} & E1099.98 & 89.19 & Point Fragment \\
\hline OO51-11 & N0977 & E1100 & $89.00-88.90$ & Biface \\
\hline OO51-11 & N0977 & E1100 & $89.00-88.90$ & Biface \\
\hline OO51-11 & N0977 & E1100 & $88.90-88.80$ & Biface \\
\hline OO51-11 & N0977 & E1100 & $89.00-88.90$ & Hammerstone \\
\hline OO51-20 & N0976 & E1100 & $88.80-88.70$ & Biface \\
\hline OO51-20 & N0976 & E1100 & $88.80-88.70$ & Core \\
\hline OO51-21 & N0975.45 & E1100.16 & $89.00-88.90$ & Catahoula arrow point \\
\hline PP49-5 & N0989 & E1109 & $89.50-89.40$ & Biface \\
\hline PP49-5 & N0989 & E1109 & $89.00-88.90$ & Core \\
\hline $\mathrm{PP} 49-5$ & N0989 & E1109 & $89.00-88.90$ & Core \\
\hline PP49-5 & N0989 & E1109 & $88.60-88.50$ & Dawson preform \\
\hline PP49-5 & N0989.30 & E1109.56 & 88.82 & Gary or Dawson preform \\
\hline $\mathrm{PP} 49-5$ & N0989 & E1109 & $89.50-89.40$ & Perdiz arrow point \\
\hline PP49-5 & N0989 & E1109 & $89.50-89.40$ & Perdiz arrow point \\
\hline PP49-5 & N0989 & E1109 & $89.00-88.90$ & Perdiz arrow point \\
\hline QQ48-12 & N0992 & E1111 & $88.80-88.70$ & Core \\
\hline QQ48-12 & N0992.95 & E1111.30 & 88.77 & Dawson dart point \\
\hline QQ48-12 & N0992 & E1111 & $88.50-88.40$ & Gary dart point \\
\hline QO48-12 & N0992 & E1111 & $88.40-88.30$ & Gary dart point \\
\hline QQ48-12 & N0992.74 & E1111.17 & 88.70 & Gary dart point \\
\hline QQ48-12 & N0992 & E1111 & $88.70-88.60$ & Catahoula arrow point \\
\hline QQ48-12 & N0992 & E1111 & $88.80-88.70$ & Tested Cobble \\
\hline QQ48-12 & N0992 & E1111 & $89.00-88.90$ & untyped point \\
\hline QQ48-19 & N0991 & E1111 & $89.30-89.20$ & Biface \\
\hline QQ48-19 & N0991 & E1111 & $89.30-89.20$ & Biface \\
\hline QQ48-19 & N0991 & E1111 & $88.10-88.00$ & Gary dart point \\
\hline QQ48-19 & N0991 & E1111 & $89.10-89.00$ & Hammerstone \\
\hline QQ48-19 & N0991 & E1111 & $89.10-89.00$ & Perdiz arrow point \\
\hline QQ48-19 & N0991 & E1111 & $89.10-89.00$ & \begin{tabular}{|l} 
untyped poss. \\
Perdiz/Bonham \\
\end{tabular} \\
\hline QO48-19 & N0991 & E1111 & $89.10-89.00$ & Catahoula arrow point \\
\hline
\end{tabular}


Table 5-9. Continued...

\begin{tabular}{|c|c|c|c|c|}
\hline Unit & Northing & Easting & Absolute Depth (m) & Tool Type \\
\hline QO48-22 & N0990 & E1111 & $89.30-89.20$ & Biface \\
\hline $\mathrm{QO} 48-22$ & N0990 & E1111 & $89.10-89.00$ & Biface \\
\hline $\mathrm{OO} 48-22$ & N0990 & E1111 & $88.50-88.40$ & Biface \\
\hline $\mathrm{QQ} 48-22$ & N0990 & E1111 & $88.50-88.40$ & Biface \\
\hline QQ48-22 & N0990.83 & E1111.44 & $88.80-88.70$ & Dawson dart point \\
\hline OO48-22 & N0990 & E1111 & $89.10-89.00$ & Point Fragment \\
\hline OQ49-1 & N0989 & E1110 & $88.80-88.70$ & Gary dart point \\
\hline QQ49-1 & N0989 & E1110 & $89.00-88.90$ & Perdiz arrow point \\
\hline QQ49-1 & N0989.67 & E1110.05 & 89.34 & Perdiz arrow point \\
\hline OQ49-1 & N0989 & E1110 & $89.00-88.90$ & untypeable point \\
\hline OO49-1 & N0989.20 & E1110.35 & 88.84 & untypeable point \\
\hline OQ49-2 & N0989 & E1111 & $88.80-88.70$ & Andice \\
\hline QQ49-2 & N0989 & E1111 & $89.4-89.3$ & Biface \\
\hline QQ49-2 & N0989 & E1111 & $88.20-88.10$ & Biface \\
\hline OQ49-2 & N0989 & E1111 & $88.00-87.90$ & Biface \\
\hline QQ49-2 & N0989 & E1111 & $87.90-87.80$ & Core \\
\hline QQ49-2 & N0989 & E1111 & $88.70-88.60$ & Gary preform \\
\hline OQ49-2 & N0989 & E1111 & $88.60-88.50$ & Gary preform \\
\hline QQ49-2 & N0989.41 & E1111.07 & 89.12 & $\begin{array}{l}\text { untyped poss. } \\
\text { Perdiz/Catahoula }\end{array}$ \\
\hline
\end{tabular}

relation to the other dates from this block excavation. The AMS dates from QQ48-12, Level 266 are within the range of recent dates often assigned to Gary points. There is no reason to suspect contamination or sedimentary time transgression that would create anomalously young dates from this level (an additional date on Level 266 in QQ48-19 is consistent with the two dates from QQ48-12). The other two dates shown in Table 5-5 are from levels in excavation units that did not contain diagnostic points. Although these are not directly associated with any points they are from adjacent units, from levels that did contain points (Levels 264 and 266), and can bracket the temporal distribution of these tools.

The two points from the Y47 block were recovered in apparent temporal sequence. The Perdiz point (Figure $5-9 \mathrm{~m}$ ) was collected a maximum of $40 \mathrm{~cm}$ above the Dawson point (Figure 5-8b). No charcoal samples were collected from the Y47 block that could be dated and compared with these diagnostic points. There are no dates for any of the NN-OO excavation units. Charcoal samples were collected from an apparent feature that was later determined to be a modern roasting pit.

\section{Bifaces}

A total of 16 bifaces were collected from controlled excavations. Of these, nine are quartzite, ( 7 fine-grained; 2 coarse-grained), four are chert, and three are of petrified wood. Fragments of six bifaces appear to represent pieces of finished or nearly finished projectile points. Two of the six are arrow point distal fragments, two others are dart point barbs, and the remaining two are dart point stem fragments that probably belonged to Gary or Dawson points.

One large biface fragment represents a well-finished blade of a relatively long and broad knife (Figure 5-9u). This piece is made on very high quality chert and is unique in the assemblage for the workmanship, form, and the relative rarity of large pieces of good raw material. One side of each edge of this knife is carefully pressure flaked with only a few pressure flakes apparent on the opposite face. This results in slightly alternately beveled edges. This piece has been broken from a snap fracture that is likely due to use. 


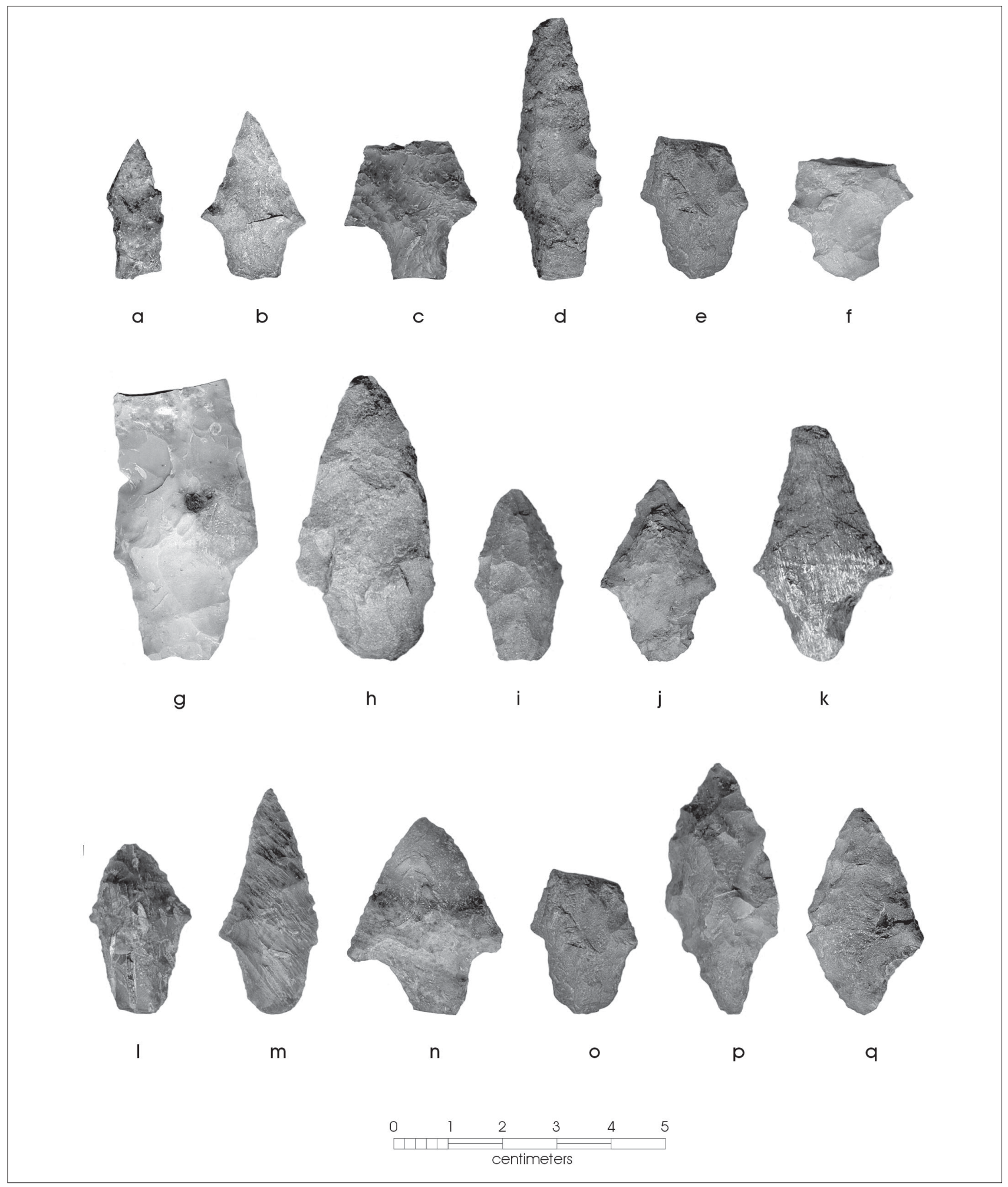

Figure 5-8. Projectile points and bifaces recovered from 41WA47: (a) Andice/Bell; (b-d) Dawson; (e-h) Dawson preform; (i-o) Gary; (p-q) Gary preform. 


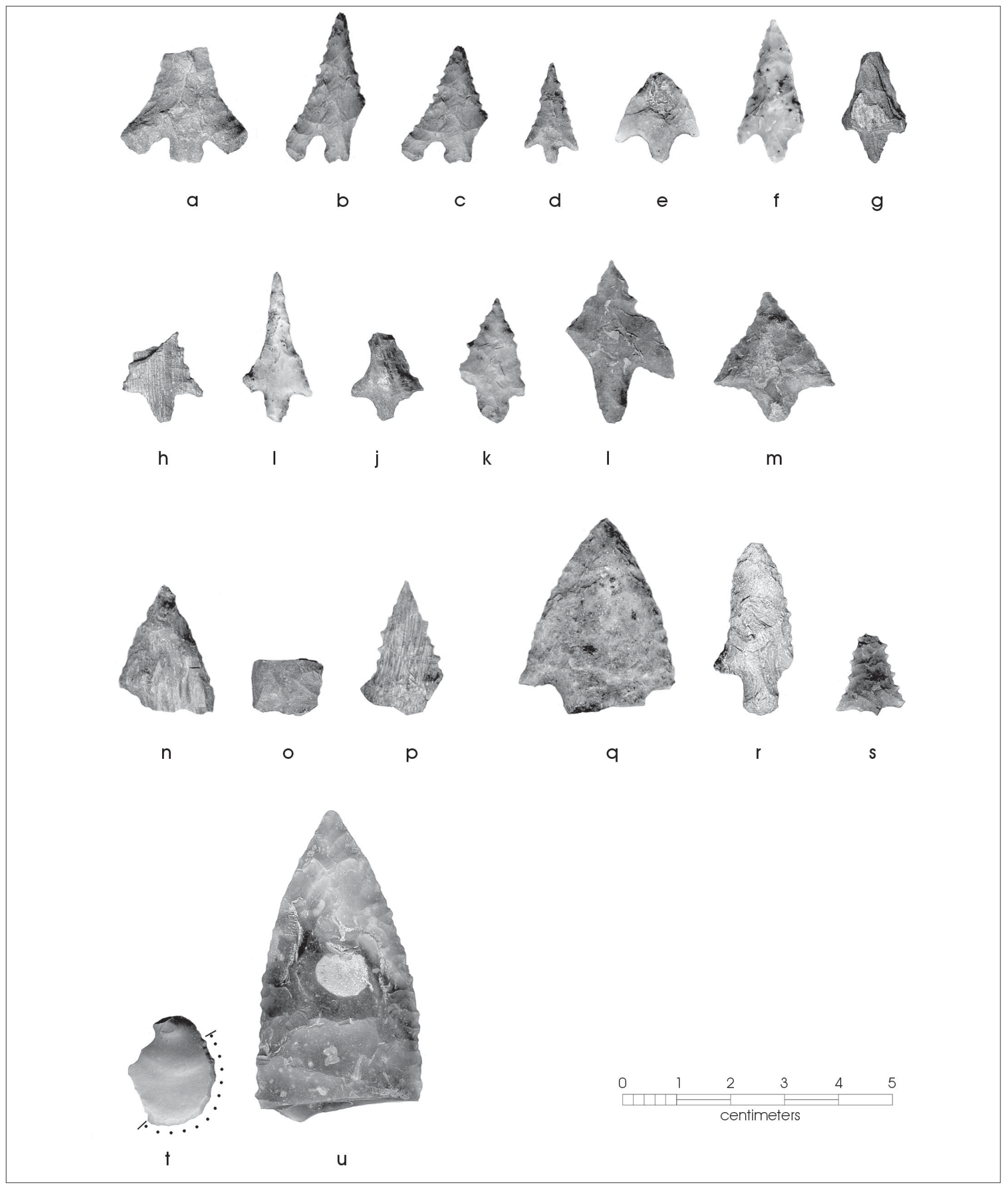

Figure 5-9. Projectile points, knife fragment, and flake tool recovered from 41WA47: (a-c) Catahoula; (d-m) Perdiz; (n-s) untyped; ( $t$ flake tool; $(u)$ knife fragment. 
Table 5-10. Provenience of all diagnostic projectile points form $41 \mathrm{WA} 47$

\begin{tabular}{|c|c|c|c|c|c|c|c|c|}
\hline \multirow[b]{2}{*}{ Northing } & \multirow[b]{2}{*}{ Easting } & \multicolumn{2}{|r|}{ Type: } & \multicolumn{3}{|c|}{ Dart points } & \multicolumn{2}{|c|}{ Arrow points } \\
\hline & & Provenience & Level & Andice/Bell & Dawson & Gary & Perdiz & Catahoula \\
\hline & & BHT1 & surface & & 1 preform & & & \\
\hline & & & & & & & & \\
\hline N0976 & E1099 & NN51-16 & $257(89.30-89.20)$ & & & & 1 & \\
\hline N0976 & E1099 & NN51-16 & $260(89.00-88.90)$ & & & & 1 & \\
\hline & & & & & & & & \\
\hline N0976 & E1098 & NN51-17 & $258(89.20-89.10)$ & & & 1 & & \\
\hline & & & & & & & & \\
\hline N0975 & E1098 & NN51-24 & $259(89.10-89.00)$ & & & 1 & 1 & \\
\hline & & & & & & & & \\
\hline N0975.45 & E1100.16 & OO51-21 & $260(89.00-88.90)$ & & & & & 1 \\
\hline & & & & & & & & \\
\hline N0989 & E1109 & PP49-5 & $255(89.50-89.40)$ & & & & 2 & \\
\hline N0989 & E1109 & PP49-5 & $260(89.00-88.90)$ & & & & 1 & \\
\hline N0989.30 & E1109.56 & PP49-5 & $261(88.90-88.80)$ & & 1 preform & & & \\
\hline N0989 & E1109 & PP49-5 & $264(88.60-88.50)$ & & 1 preform & & & \\
\hline & & & & & & & & \\
\hline N0992 & E1111 & $0048-12$ & $257(88.70)$ & & & & 1 & \\
\hline N0992 & E1111 & OQ48-12 & $262(88.80-88.70)$ & & 1 & 1 & & \\
\hline N0992 & E1111 & OQ48-12 & $263(88.70-88.60)$ & & & & & 1 \\
\hline N0992 & E1111 & OQ48-12 & $265(88.50-88.40)$ & & & 1 & & \\
\hline N0992 & E1111 & Q048-12 & $266(88.40-88.30)$ & & & 1 & & \\
\hline No991 & F1111 & $0048-19$ & $260(8910-8900)$ & & & & 1 & 1 \\
\hline N0991 & E1111 & QQ48-19 & $269(88.10-88.00)$ & & & 1 & & \\
\hline & & & & & & & & \\
\hline N0990.83 & E1111.44 & QQ48-22 & $262(88.80-88.70)$ & & 1 & & & \\
\hline & & & & & & & & \\
\hline N0989.67 & E1110.05 & QO49-1 & $255(89.34)$ & & & & 1 & \\
\hline N0989 & E1110 & QQ49-1 & $260(89.00-88.90)$ & & & & 1 & \\
\hline N0989 & E1110 & QQ49-1 & $262(88.80-88.70)$ & & & 1 & & \\
\hline & & & & & & & & \\
\hline N0989 & E1111 & QQ49-2 & $263(88.70-88.60)$ & & & 1 preform & & \\
\hline N0989 & E1111 & QQ49-2 & $264(88.60-88.50)$ & & & 1 preform & & \\
\hline N0989 & E1111 & QQ49-2 & $272(87.80-87.70)$ & 1 & & & & \\
\hline $\mathrm{N} 1100$ & E1140 & ST N1100 E1140 & $6(50-60)$ & & 1 preform & & & \\
\hline & & & & & & & & \\
\hline N0999 & E1020 & Y47-1 & $218(93.37-93.10)$ & & & & 1 & \\
\hline & & & & & & & & \\
\hline N0999 & E1021 & Y47-2 & $221(92.90-92.80)$ & & 1 & & & \\
\hline
\end{tabular}


Table 5-11. Vertical distribution of projectile points from the NN-OO and PP-QQ blocks from 41WA47

\begin{tabular}{|c|c|c|c|c|c|}
\hline \multirow{2}{*}{ Type } & \multicolumn{3}{|c|}{ Dart points } & \multicolumn{2}{|c|}{ Arrow points } \\
\hline & Andice & Dawson & Gary & Perdiz & Catahoula \\
\hline $255(89.50-89.40)$ & & & & 3 & \\
\hline $257(89.30-89.20)$ & & & & 2 & \\
\hline $258989.20-89.10)$ & & & 1 & & \\
\hline $259(89.10-89.00)$ & & & 1 & 1 & \\
\hline $260(89.00-88.90)$ & & & & 4 & $\underline{2}$ \\
\hline $261(88.90-88.80)$ & & 1 preform & 1 & & \\
\hline $262(88.80-88.70)$ & & 2 & 1 & & \\
\hline $263(88.70-88.60)$ & & & 1 preform & & 1 \\
\hline $264(88.60-88.50)$ & & 1 preform & 1 preform & & \\
\hline $265(88.50-88.40)$ & & & 1 & & \\
\hline $266(88.40-88.30)$ & & & 1 & & \\
\hline $269(88.10-88.00)$ & & & 1 & & \\
\hline $272(87.80-87.70)$ & 1 barb & & & & \\
\hline **Totals: & 1 & 4 & 9 & 10 & 3 \\
\hline
\end{tabular}

* Unit provenience data is presented in Table 5-10.

** Four specimens are excluded from the table: one Dawson preform from ST N1000-E1140; two points (Dawson, Perdiz) from block Y47; and one Dawson preform found on surface.

Nine other bifaces were identified from the excavated assemblage. Three of these are illustrated in Figure 510. The illustrated examples all suggest dart point preforms abandoned due to flaking problems encountered during reduction. Two are complete (Figure $5-10 \mathrm{a}, \mathrm{c})$ and have thick areas on one face that have not been successfully thinned. Numerous step fractures indicate failed attempts to finish thinning these pieces. The third biface (Figure 5-10b) is relatively thin, but appears to have been broken during thinning. Two complete pieces were discarded at a relatively early stage of reduction. Very poor flaking quality exhibited by these bifaces suggests they were abandoned because of the intractability of the raw materials. The final four bifaces are early to middle reduction stage fragments broken in manufacture.

\section{Cores}

Cores or tested cobbles were uncommon $(n=6)$ from the excavation of 41WA47. Three of the cores are petrified wood, two are chert, and one is a fine-grained quartzite.
Four examples are illustrated in Figure 5-11. None exhibit formal characteristics of investment in economical reduction or preparation of particular core morphology. Although here classified as cores, they all appear to represent pieces that have poor flaking qualities and suggest discard of unpromising tested cobbles. Three large pieces of petrified wood all exhibit minimal flaking (Figure 5-11a-c). Unlike the chert and quartzite at 41WA47, this petrified wood does not have a cortex indicating an origin as river gravels. These pieces have a readily identifiable cortex and some rounding of portions of the exterior, but have not been subject to the same alluvial transport as indicated in the morphology of the cherts and quartzites. These are the largest clasts identified within these sediments. All three pieces have few removals with planar fractures and poor flake control. Because of the poor flaking, it is possible that two of them exhibit natural breaks. Their size and angularity strongly suggest they are manuports. The frequency of petrified wood as a raw material in this assemblage also suggests that they are discarded cores or tested pieces. In contrast to the petrified wood, the 


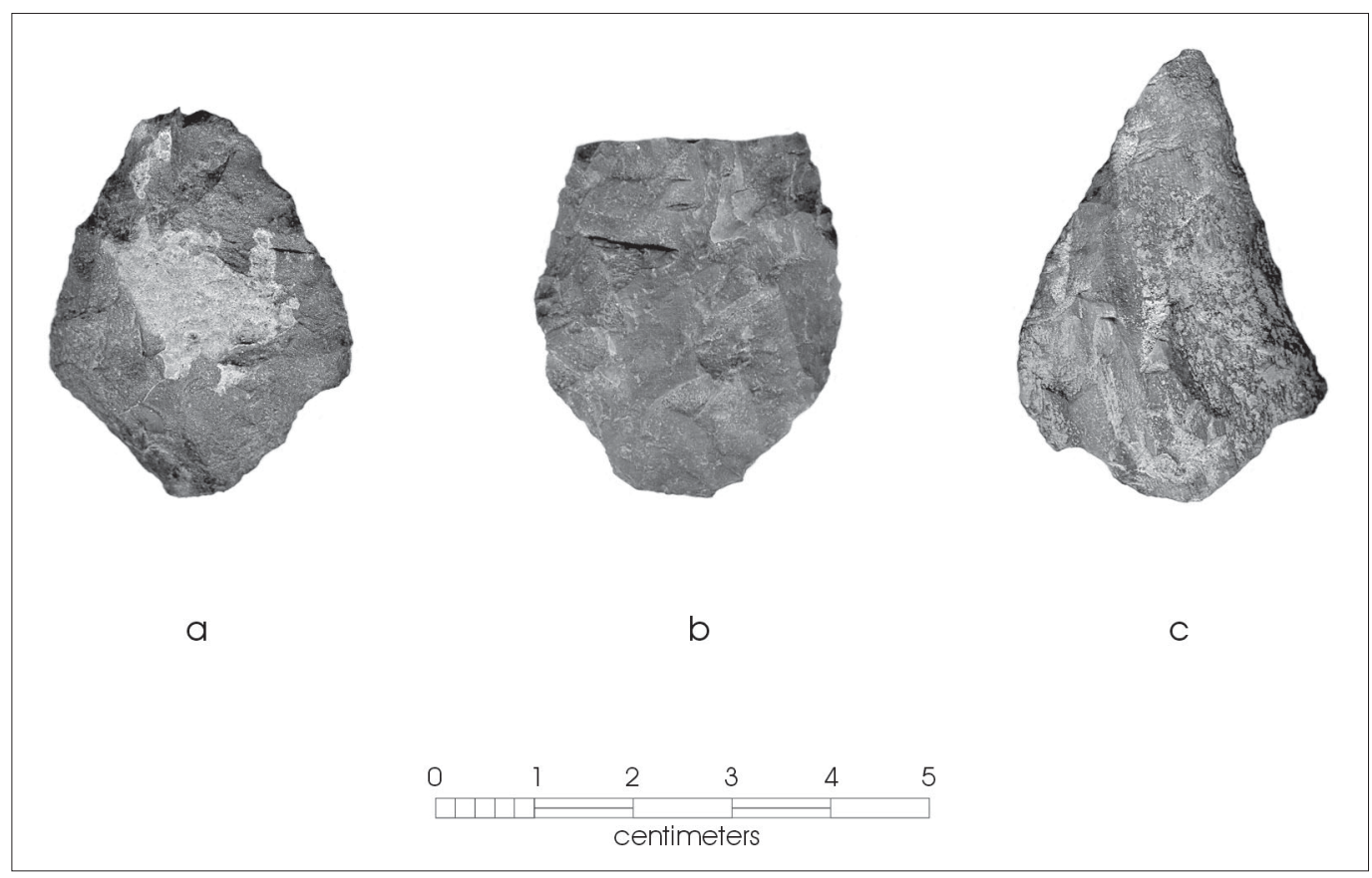

Figure 5-10. Bifaces recovered from 41 WA47.

other three cores are small gravels. The pieces classified as cores all have few flake scars. The example illustrated in Figure 5-11d is a quartzite cobble with eight broad flake scars retaining a significant amount of cortex. The flake scars indicate poorly controllable flake removals. The two other chert cores show more minimal flaking, cortex, and very poor fracturing characteristics.

\section{Hammerstones}

Three quartzite pebbles that are probably hammerstones were recovered from the controlled excavations at 41WA47. Two are illustrated in Figure 5-12. The two illustrated examples show significant pecking damage. The hammerstone in Figure 5-12a has battering on one end (the left end in the figure) and breakage of the opposite end. There is no abrasion of the lateral margins of this pebble. Figure 5-12b shows a pebble with breakage on one end and battering damage along one margin (the superior margin in the illustration). The opposite edge has no damage. The isolated damage on both of these rocks suggests cultural modification rather than alluvial or colluvial damage. One other quartzite pebble may represent a minimally used hammerstone. This piece exhibits a very small amount of battering on one end. All of these pieces were collected along with the natural clasts reserved from screening and were not identified during fieldwork. Examination of several other large clasts returned for laboratory analysis demonstrated lack of any battering or abrasive damage, or damage along all keeled edges from alluvial entrainment.

\section{Flake Tool}

The single flake tool identified within the assemblage is made on a small flake of good quality chert (Figure 5$9 t)$. There are four dorsal scars on this piece. Slight lipping on the platform suggests that it may be a bifacial thinning flake. Most of the edge from $7 \mathrm{~mm}$ distal of the platform and extending to all of the intact distal margin shows edge retouch and possible use wear. The occurrence of retouch at the juncture with the broken margin suggests that at least part of the missing portion also had been retouched. All edge flaking has been done on the ventral face. Retouch does not extend more than $1.5 \mathrm{~mm}$ into the flake. There are abundant small, 


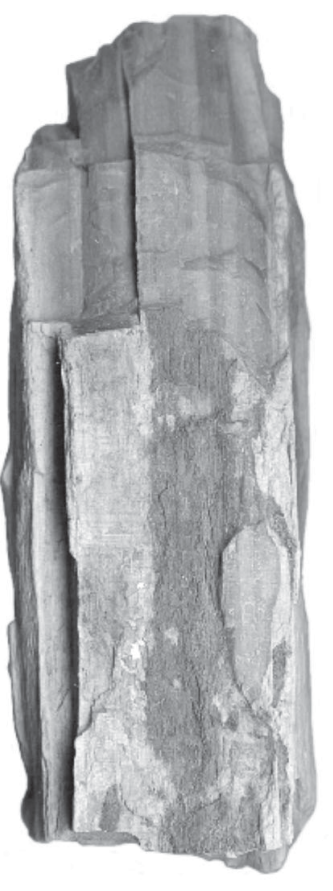

a

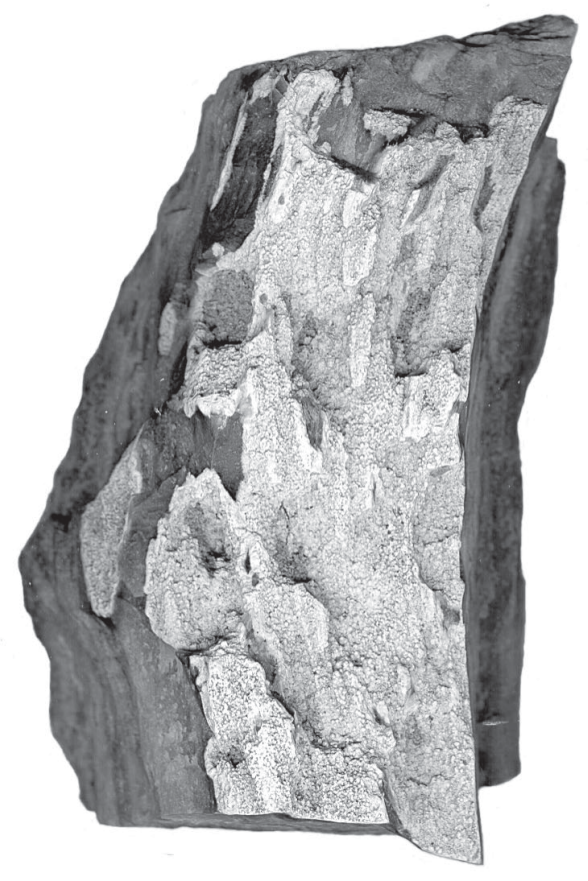

b

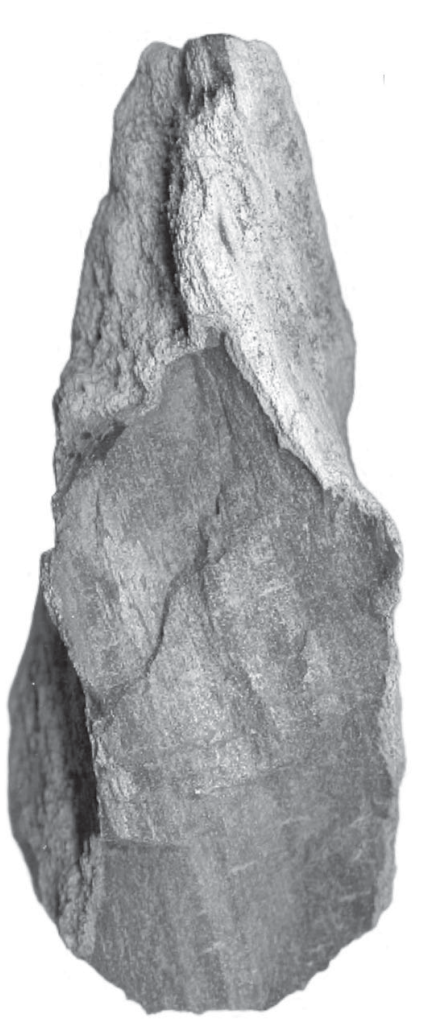

c

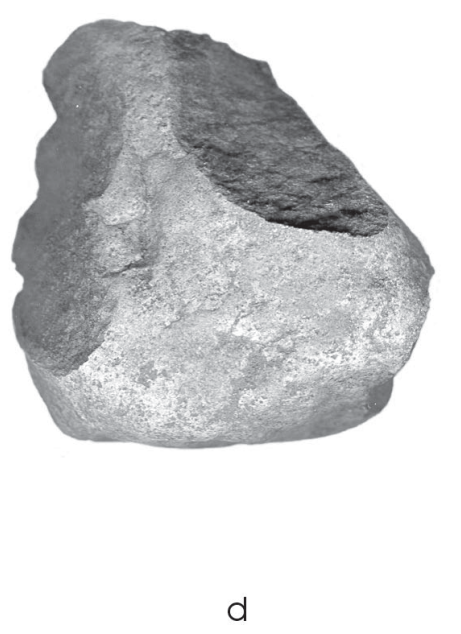

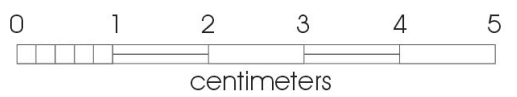

Figure 5-11. Cores recovered from 41 WA47. 


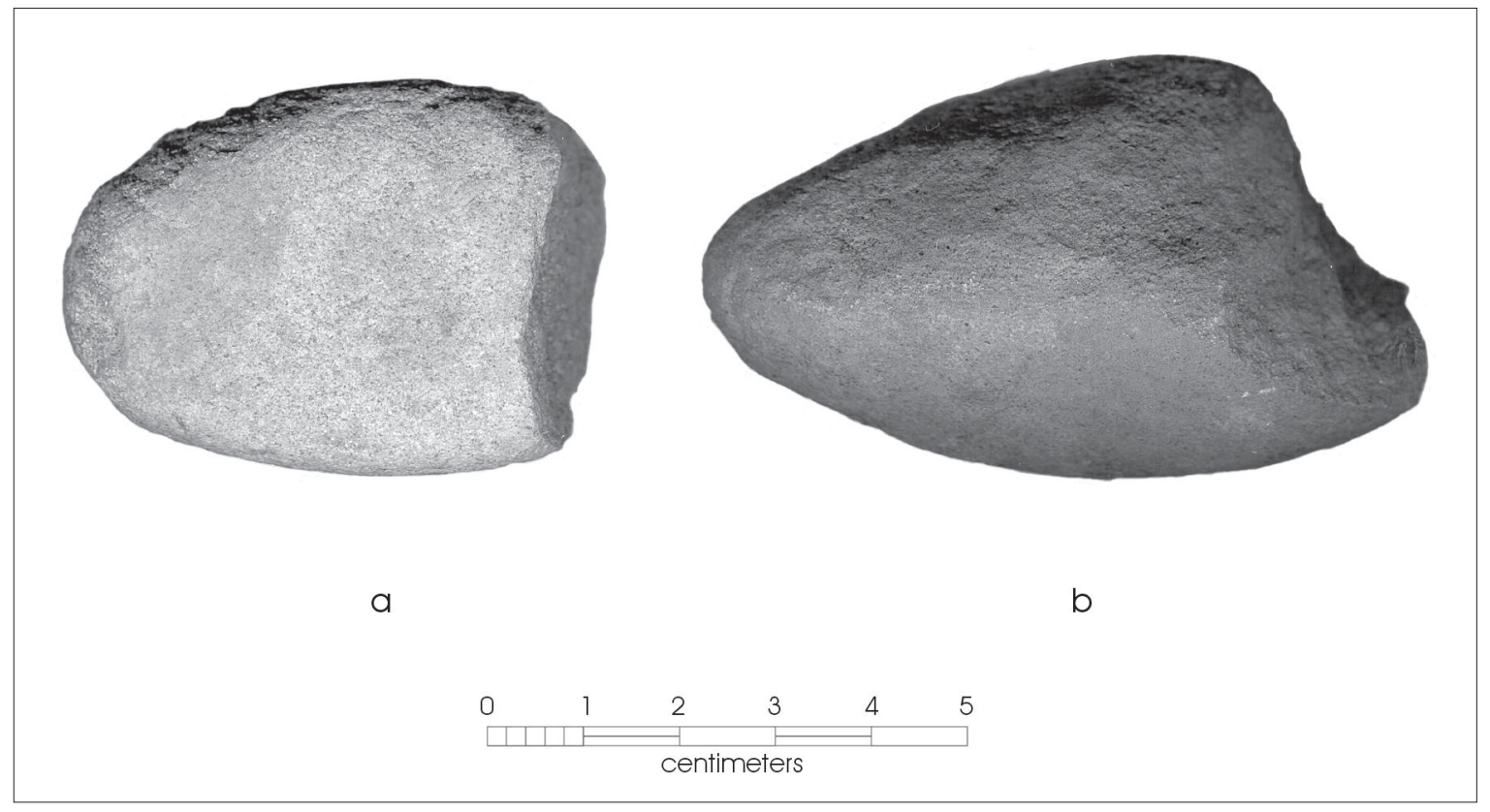

Figure 5-12. Hammerstones recovered from 41 WA47.

overlapping step fractures along most of the margin, especially the distal edge and the most distal portion of the flake.

It is notable that the lithic tool assemblage is dominated by projectile points. Complete and fragmentary points represent 59 percent of the total tool sample (62\% of the chipped stone tools if hammerstones are not included). Bases were not more common than relatively complete points and preforms. An additional six fragments probably represent portions of projectile points. There is comparatively little evidence of early stage reduction. Early stage bifaces and failed bifaces are relatively uncommon $(n=9)$, as are cores $(n=6)$. The poor quality of the raw materials, lack of very local gravel sources, and dearth of early stage reduction all are consistent with use of this location as a habitation area provisioned with extra local lithics.

\section{Ceramic Analysis}

\section{by Marybeth S. F. Tomka}

The cultural materials from the current excavations at 41WA47 resulted in the recovery of 471 ceramic sherds and 201 pieces of burned clay. Of the 471 sherds, 205 (43\%) are ceramic vessel fragments less than $20 \mathrm{~mm}$ in maximum dimension. Metric data was collected on all 471 sherds. Additional observational data was collected on the 266 larger specimens. When possible, the surfaces and cores of the 205 small specimens were also examined and recorded. Therefore, the following discussion will refer to two distinct sample sizes and each attribute presentation will present the sample size to allow for meaningful interpretations. 


\section{Methods}

The following attributes were recorded for all sherds greater than $20 \mathrm{~mm}$ in maximum dimension: vessel type (jar, bowl, unknown), vessel portion (body, rim, neck, base), rim form (includes both profile view and lip form, e.g., everted rim, square lip), rim thickness, rim diameter (the short horizontal lengths of the rims hampered accurate data and length of the rim section was also noted), base form, maximum dimension, maximum thickness (several measurements were taken to account for vagaries in vessel wall thickness and the maximum was then recorded), weight, firing atmosphere at core (interior and exterior surface colors were noted, but elaboration and interpretations were recorded in comments), surface treatment (interior and exterior), and surface decoration (interior and exterior). For the purposes of this analysis, polishing is considered both as a surface treatment and a possible decoration. Although polishing has functional implications, it cannot be precluded as a decorative technique. The final two attributes are related to each other and will be discussed in concert. The paste, temper, probable type/similar type, and comments were also recorded where appropriate. The determination of vessel type was made by considering a number of sherd characteristics including the curvature of the vessel (i.e., inward and outward), the finish of the interior and exterior surfaces, and obvious indicators of function, such as the presence/ absence of a lip.

\section{Results}

Bowls make up the majority of vessel types present at 56 percent; however, 35 percent of all sherds could not reliably be put into a category. Not surprisingly, due to the small overall size of the sherds, the vast majority of sherds $(85 \%)$ are attributed to the main body of vessels. The thickness of the sherds was sampled before recording a maximum size to discern a change in the vessel shape not observable with the naked eye. Also of no surprise is that a higher proportion of rim and neck sherds can be attributed to jars since the essential constriction of the vessel opening begins at the neck of the vessel. Two of the largest sherds (maximum dimension of $109.98 \mathrm{~mm}$ and $92.69 \mathrm{~mm}$, respectively) are high body or near neck sherds and come from the same vessel.
Vessel portion could only be determined on 247 (93\%) of the 266 sherds larger than $20 \mathrm{~mm}$ in maximum dimension. Thirty, or 13 percent, of 247 sherds, are rims. Forty-three percent of the rim sherds have straight rim profiles supporting the fact that most of the vessels are bowls, or at least straight side opening jars or bottles. The lip forms are almost equally split among those that could not be classified (33\%), rounded lips (33\%), and squared lips (27\%). In addition, one sherd has a pointed lip profile and one sherd has a scalloped edge that is more indicative of a decorative technique than a functional attribute. Rim thickness ranges from the smallest of $2 \mathrm{~mm}$ in size to almost $9 \mathrm{~mm}$ with an average thickness of $4 \mathrm{~mm}$. Thirty-seven percent of the rims have thicknesses between 3 and $4 \mathrm{~mm}$. Rim sherds preserve only small sections of rim. The average length of rim preserved on sherds is $20 \mathrm{~mm}$, with 41 percent of the rims falling between $10-20 \mathrm{~mm}$ and 32 percent falling between $20-30 \mathrm{~mm}$ in length. Of note is the fact that had the rim lengths been the maximum dimensions of the sherd, the specimen would not have been fully analyzed.

Only three base fragments were recorded. All of these sherds indicate that the coils of the vessel were built upon a disk of clay. The bases are $7 \mathrm{~mm}, 9.5 \mathrm{~mm}$, and $12 \mathrm{~mm}$ in thickness and are larger than the average sherds in overall size. Two of the three sherds are over $45 \mathrm{~mm}$, whereas the majority $(36 \%)$ of the specimens fall between $16-25 \mathrm{~mm}$ in maximum dimension. The average size is $29 \mathrm{~mm}$ and the median is $25.5 \mathrm{~mm}$ making the interpretation of vessel shape and rim diameter very difficult. The majority of sherds (71\%) fall between 11 $\mathrm{mm}$ and $40 \mathrm{~mm}$ in maximum dimension with the highest peak between 16 and $20 \mathrm{~mm}$ in maximum dimension.

The examination of sherd cores and surfaces allows the analyst to surmise the method used for firing the vessels -fired in an oxygen-rich fire or one that restricts oxygen. Unfortunately the use of ceramic vessels for cooking occasionally allows post-firing events to obliterate the evidence of initial firing. In this group of sherds, the surfaces were more suggestive of initial firing conditions than the cores that are traditionally used by analysts. Many of the surfaces are brown to red in color with orange at one end of the spectrum and black at the other end. The black sherds can occasionally be attributed to the intentional smudging of the surfaces for functional 
effect. However, many of the cores show evidence of multiple or incomplete firings. Either of these can be attributed to using the vessels as cooking pots. Many uses of the vessel can lead to multiple zones of color in the core of vessels, however, in the Huntsville State Park collection the color zones are not only unclear but appear to be randomly distributed. It is not known whether the clays used or the tempering agents affect the way heat is transferred to allow color change.

Data on firing atmosphere was collected on 179 sherds $(67 \%)$ of the total of 266 . The reduced sample is the result of many sherds being too small for fresh breakage and the exposure of a clean core. The majority (34\%) of the sherds are indicative of an oxygen-rich atmosphere, but 25 percent of 179 sherds are reduced. Another 19 percent of the specimens are either incompletely reduced or oxidized. Twenty-two percent of the specimens also suggest multiple firings by exhibiting multiple zones of color in their cores.

Surface treatment and surface decoration are both indicative of functional use and technique of manufacture. A large percentage $(45 \%, \mathrm{n}=120)$ of the sherds larger than $20 \mathrm{~mm}$ in maximum dimension $(n=266)$ have at least one surface that has been smoothed during manufacture. Four sherds from the PP-QQ block have scraping marks on their interiors and of these three are thought to be from jars. Two of these are definitely from the same vessel. Seventy-nine sherds have evidence of interior surface decoration. The majority is polished (89\%); however, the other 11 percent of the sherds have been smudged. Smudged vessels are those that have polished interiors and were fired in reducing atmospheres. It is thought the smudging prevents the transmission of liquid or other foodstuffs into the clay body (Shephard 1963). The polished, blackened surfaces are thought to be a manufacture technique. Blackening through use is more apt to take the form of soot deposition that tends to rub off. Evidence of sooting was found on two sherds from the same jar recovered from Unit QQ492, Level 258. On the exterior surfaces of sherds, polishing is present on 79 percent of the sherds $(n=210)$. Two sherds have been polished to the point that the polishing has floated the clay particles into forming a self-slip and sealing the exterior surface. This technique is commonly called either floating or burnishing. An additional sherd appears to have a smudged exterior but this may have been a function of the use of the vessel for cooking. Two of the largest sherds from a single vessel actually have material adhering to their surfaces that may be soot. Care was taken not to remove this material.

The sample of sherds from $41 \mathrm{WA} 47$ contains examples of engraved, incised, and notched decoration techniques (Figure 5-13; Table 5-12). One sherd has been brushed and another has been excised or engraved, all common techniques on Caddoan pottery found to the north of the Walker County area in which Huntsville State Park is located. The engraved sherd has a sandy paste. Ten sherds have been incised. Five of the ten incised sherds contain materials other than sand as temper. Three sherds have bone and sand, one sherd has shell and bone, and another has shell, bone, and sand. With a sample size this small it is impossible to know if the tempering differences are related to functional or stylistic motives. The presence of common Caddoan decorative techniques in an assemblage that also contains vessels with less common coastal tempering agents is highly suggestive of an interaction with groups outside the general Walker County area. The notched rim, however, is a common Goose Creek ceramic series decorative technique.

The ceramic sherds are of a paste with high sand content that was recorded as fine-, medium-, or coarse-grained. In several instances the size of the sand grain was large enough to warrant that in addition to the sandy paste, sand was added to the clay body as temper (e.g., $5 \mathrm{~mm}$ sized-grain in specimen 352-1-2). In all other cases where sand was seen in the clay body, the size distribution is more indicative of naturally occurring sand. In addition to sand tempering, bone, grog, and shell were also seen in various combinations. One sherd may well represent a Baytown variety vessel, as it contains grog temper in an otherwise very sandy-pasted matrix.

Of the 266 sherds for which temper type could be established, 259 (97\%) are sand tempered. The majority (52\%) of the sandy-paste sherds are medium-grained and roughly one-third (32\%) of the sherds are coarse-grained. Viewed at a fresh break, coarse-textured sherds exhibit tightly packed sand grains, where as the fine textured ones allow more of the clay body to show through. There does not seem to be a relationship between temper and thickness of the sherds. Only seven sherds have material other than sand added as tempering (see Table 5-12). 


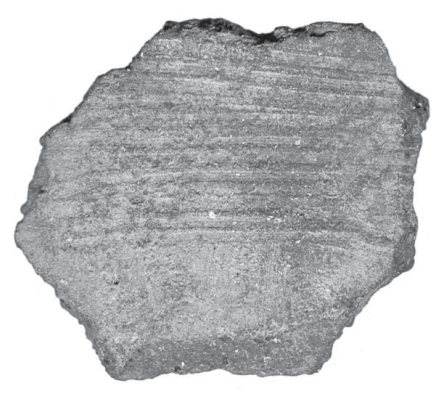

$122-2$

(a)

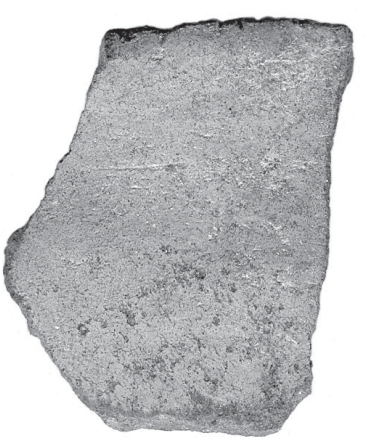

214-1-1

(b)

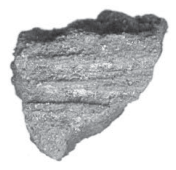

215-3-1

(g)

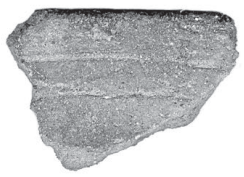

76-2-1

(k)

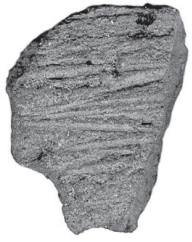

379-1-1

(j)

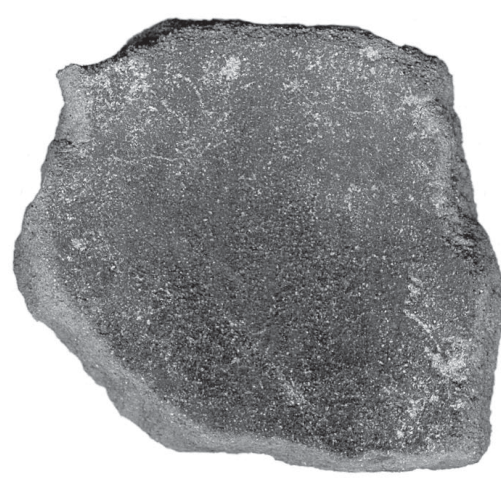

182-4-2

(c)

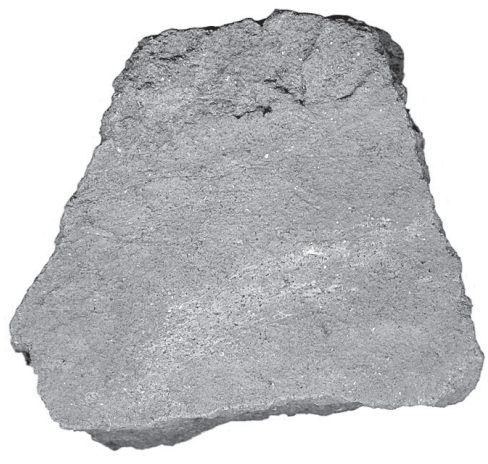

232-1

(h)

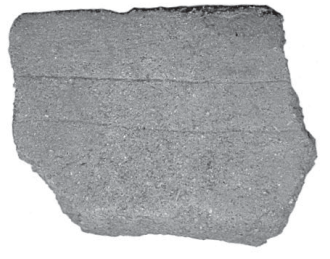

346-1-3

(i)

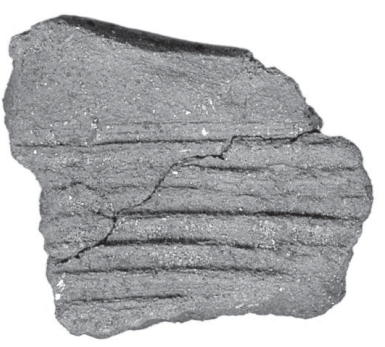

77-2-2

(I)

\begin{tabular}{|c|c|c|c|c|}
\hline 0 & 1 & 2 & 3 & 4 \\
\hline \begin{tabular}{l|l|l|} 
& & \\
\end{tabular} & ⺊ & - & F & - \\
\hline
\end{tabular}

Figure 5-13. Decorated ceramics from 41WA47: (a) 122-2 - incised; (b) 214-1-1 - notched rim; (c) 182-4-2 - interior smudged; (d) 145-2-3 - incised; (e) 177-2-3 - eroded incised lines; $(f)$ 211-5 - engraved with scalloped rim; $(g)$ 215-3-1 - incised; (h) 232-1 - incised; (i) 346-1-3 - incised; (j) 379-1-1 - incised; (k) 76-2-1 - incised; (l) 77-2-2 - incised. 


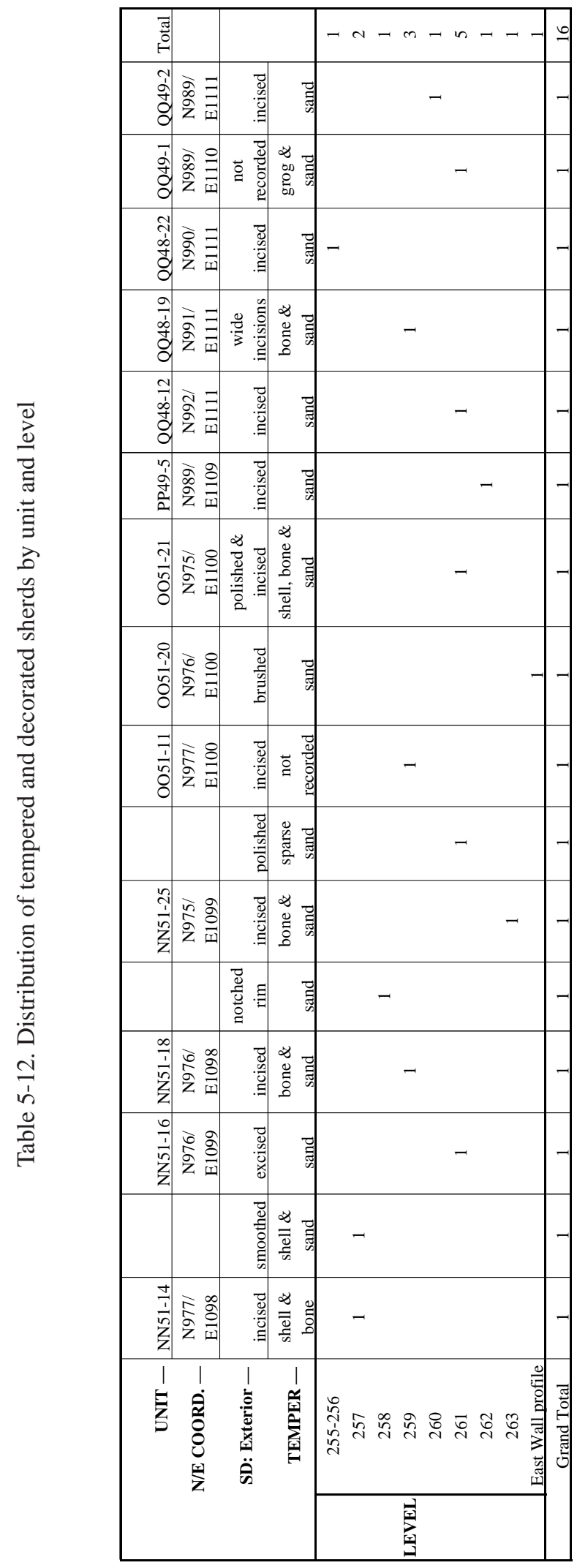


Shell tempering is present in three specimens, bone is present in five pieces, and grog is part of tempering in a single sherd.

The vast majority ( $\mathrm{n}=261 ; 98 \%$ ) of the 266 sherds can be classified as the Goose Creek series of ceramics. Only five sherds, containing a mixture of bone and shell or sand temper would not be considered Goose Creek. Five of the Goose Creek series sherds can be classified as Goose Creek Incised, variety unspecified, and one sherd as Baytown Plain variety San Jacinto (QQ49-1, cat \# 250). All but one of the typed sherds is from the PP-QQ block and range from the joined Level 255-256 to Level 261. One of the Goose Creek sherds is from the NN-OO block, Level 259.

As indicated above, few $(n=12)$ of the sherds have design elements and the design elements are much too small to confidently assign type names to these specimens. Therefore the temporal affiliation of the site cannot be determined based on the relative proportion of types in the collection. However, using Aten's (1983:Figure 14.1) ceramic seriation the dating of site 41WA47 would cover the entire ceramic period. However, if we take into account the five bone tempered specimens, the ceramics point to the post Mayes Island period.

\section{Burned Clay}

Two hundred and one pieces of hardened clay were recovered in the controlled excavations. These were excluded from the ceramic analysis because they are incompletely fired and show no evidence of tempering or vessel wall morphology. These burned clay pieces may represent daub. However, close examination of these specimens revealed no stick or grass impressions on any of the pieces. On the other hand, they may represent burned clay from hearths dug into the Bt horizon. Most were not identified in the field. They were recognized during laboratory processing and ceramic analysis as not representing gravels, peds, or sherds. If all materials from the dry screens had not been reserved and returned to the laboratory, it is unlikely that more than ten examples would have been returned for laboratory examination.

\section{Other Archaeological Remains}

\author{
by Russell D. Greaves \& Steve A. Tomka
}

\section{Macrobotanical Analysis}

A sequence of nine macrobotanical samples from the QQ49-2 unit (N989-E1111) were processed at the CAR laboratory and analyzed by Dr. J. Philip Dering, Texas A\&M University. The samples were chosen from unit QQ49-2 because this unit had the most complete column of sediments from the same provenience. Samples were processed from every other $10-\mathrm{cm}$ level for analysis (Levels 255, 257, 259 (258), 261, 263, 265, 267, 269, and 271). The sample from Level 259 was lost during processing and the Level 258 sample was substituted. Evidence of relatively abundant charcoal and carbonized nutshell fragments was noted during excavation. It was expected that analysis of materials from this unit would provide the largest sample for paleobotanical recovery and analysis within 41 WA47. The results of the macrobotanical analysis are presented in Appendix A, a brief summary is provided below.

Few macrobotanical remains were preserved in the samples examined. The diversity of species represented also is very low. Results of paleobotanical analyses indicate that no remains of cultigens were recovered. Carbonized hickory (Carya sp.) endocarps were the only possible food residue recovered from these samples. Only a small amount of wood charcoal was identified. Charcoal that could be identified to genus indicated oak and willow/cottonwood. Given the low recovery of macrobotanical remains, it is difficult to distinguish whether these are likely cultural or natural background contributions of charred plant parts. Dering (Appendix A) indicates the likely uses of such plants if they can be inferred to represent cultural remains. Resolution of some of this ambiguity could be approached through two changes in sampling methods in future investigations. Larger samples could be collected to improve recovery of macrobotanical remains. Designation of particular units for the recovery of up to seven liters of sediments from each $10-\mathrm{cm}$ level could dramatically improve representation of plant remains. More horizontally 
extensive block excavations could provide spatial data on charred plant macrofossils indicating whether associations and patterning suggest cultural origins for any of these residues. Currently, it is uncertain whether these remains are due to past human activities or natural fires.

\section{Phytolith Analysis}

A single phytolith sample from QQ49-2 (N989-E1111) Level 269 (88.20-88.00 m) was submitted to Dr. Susan Mulholland of the Interdisciplinary Archaeology Studies Laboratory, University of Minnesota Duluth. This is the same excavation unit as the macrobotanical samples submitted for analysis. Because of the evidence for translocation of materials within this profile (i.e, lamellae in BHT-1), a single test sample was submitted for initial investigation. Analysis results from this sample were evaluated to determine whether potentially useful information could be obtained from processing additional phytolith samples. Phytolith analysis also was used to determine if there was utility in examining sediment samples for pollen remains. The high soil acidity and evidence of particle movement (i.e., the movement of clay particles as indicated by lamellae in BHT-1) suggested that pollen recovery was probably less likely to provide an adequate numeric sample than opal phytoliths.

A qualitative quick-scan phytolith analysis was performed on this one sample to determine phytolith abundance and condition. Results indicate the presence of relatively abundant phytoliths (Appendix B). Most are extremely weathered and identification of phytolith forms was not possible for the majority of observed opal phytoliths. Although the amount of weathering may have preferentially destroyed smaller grass phytoliths, it appears that no grass phytoliths are represented in the sample.

Evidence did strongly suggest mechanical weathering is the dominant process obliterating the architecture of phytoliths. Mulholland also identified the presence of illuviated mineral particles. There is a strong chance that the relative abundance of heavily weathered phytoliths is partly due to translocation from higher within the profile. A full description of the results of this analysis and its taphonomic implications are provided in Appendix B. Even if identifications are problematic, analysis of additional samples could determine the likely amount of eluviation from superior elevations in the profile to lower positions such as that examined. This could provide important taphonomic data on particle movement within these sediments.

Samples were not submitted for pollen analyses because of the anticipated problems of acidity, mechanical weathering, and illuviation. The high acidity of these soils and sediments suggests a strong likelihood that many pollen grains that were present have been destroyed. The evidence of translocation (i.e., lamellae, mechanical weathering of phytolith grains) through these massive to weakly structured sands indicates that pollen has likely been redeposited low in the profile. This would compress and further obscure any vertical information about vegetation and climate change. Phytoliths are more resistant to such weathering and that is why they were selected for preliminary analysis. Quick-scan examination did indicate that weathering and illuviation are apparent in the sample submitted for phytolith examination. Given the difficulty in identifying the more robust phytoliths, these processes are likely to have obliterated most pollen from the samples.

\section{Faunal Remains}

Analysis of faunal remains was performed by Barbara A. Meissner (CAR) and is presented in Appendix C. A total of 1,264 bones were recovered from the controlled excavations of 41WA47. A single deer-sized bone fragment was recovered from shovel testing of 41WA228. Much of the bone is highly fragmented. Only 33 bones were identified to genus. Most of the identified bone suggests a dominance of deer (Odocoileus virginianus) or deer-sized ungulates (Table C-1). Very few elements $(n=28)$ were identified (Table C-2). Distal limb segments were the most commonly represented bones. This small sample of identified elements strongly suggests that survivorship of bones may be due to bone density. Table C-2 presents identified elements in relation to their meat utility. Although the inference from these data is that the pattern represents evidence for human butchering (Appendix C), it is unclear whether degradation in these highly acidic soils may not also have 
resulted in the preferential destruction of bones such as ribs and vertebrae. Taphonomic loss of such low-density bones is not uncommon, and has been noted to mimic human processing of high utility elements (Lyman 1994:258-263; Kreutzer 1996:116-117).

\section{Spatial Analyses}

\section{by Russell D. Greaves \& Jason D. Weston Distribution of Lithic Artifacts}

There are some spatial data available for the lithics from controlled excavations at 41WA47. Vertical relationships between artifact frequencies can be evaluated from this sample, and the piece-plotted artifacts from the controlled excavations offer clues to the taphonomic history of this site. The vertical distribution of projectile points has already been compared to absolute dates. Lithics from shovel tests on the site $(n=45)$ are excluded from consideration in the examination of vertical artifact distribution for two reasons. The small size of shovel tests makes assurance that recovered artifacts are from the excavation level they were identified in problematic. Especially below approximately $30 \mathrm{~cm}$, shovel test excavation frequently includes soil and sediment from the overlying arbitrary levels. When the number of recovered lithics in shovel tests is low, confidence that level tallies are comparable to controlled excavation units is poor. The other difficulty in comparing vertical distributions between shovel tests and controlled $1 \times 1-\mathrm{m}$ units is that the precision of vertical control is quite different. The depth of shovel test excavation levels was determined by measuring from the ground surface to the encountered artifact or base of the arbitrary excavation level. Controlled excavation units measured depths from established datum references with known elevations. Although the surface elevation of many of the shovel tests on $41 \mathrm{WA} 47$ were measured using the total station, the subsequent measurement methods are not readily compatible. The small number of lithics from shovel tests that are excluded from the analysis of vertical provenience is only 1.2 percent of the recovered sample from $41 \mathrm{WA} 47$.

Vertical distributions were compared within each of the excavation block areas. Evaluations between blocks are not appropriate because the sediment depths above the older Pleistocene Bt horizon are highly variable. The controlled excavation areas are not contiguous and each block potentially represents a different geomorphic setting and set of taphonomic events. The shallow depth of artifact bearing sediment above the Bt horizon in the M59 block (57 cm bgs) and the Y47 block ( $63 \mathrm{~cm} \mathrm{bgs)}$ is associated with single peaks of subsurface distribution within one $10-\mathrm{cm}$ excavation level and lower abundance in the levels above and below that bulge (Figures 5-14 and 5-15). A total of 26 lithics were recovered in the M59 1 x 2-m block and 283 from the two units in the Y47 block. These represent either accumulations on a relatively stable surface or concentration of artifacts on a deflated surface. The NN-OO block is a contiguous $3 \times 3-m$ excavation area. The upper boundary of the $\mathrm{Bt}$ horizon is highly variable and was encountered between $52-99 \mathrm{~cm}$ bgs. There is a concentration of artifacts between approximately $10-50 \mathrm{~cm}$ bgs (Figure 5-16).

The PP-QQ block offers the most significant information about subsurface deposits at 41WA47. These six 1 x 1-m units were excavated between 1.04-1.91 m below the current ground surface. The plot may be indicative of either a single peak in artifact density between 89.40 $88.30 \mathrm{~m}$ or two peaks, one from $89.4-88.80 \mathrm{~m}$ and a deeper one from 88.80-88.60 m relative to datum (Figure 5-17). The density of artifacts within each of the levels spanning this $1.1 \mathrm{~m}$ is comparable to that of the levels in the single density bulges of the other controlled excavation blocks.

\section{Piece-Plotted Artifacts}

Orientation and inclination data on piece-plotted artifacts allow determination of post-depositional processes. They can suggest the potential for cultural patterning in artifact spatial distribution. Preferential orientation of artifacts is a common indicator of alluvial and colluvial modifications. Post-depositional movement may not completely demolish the potential for culturally significant spatial patterning or associational integrity. Minimal modification of certain portions of archaeological deposits can be considered indicative of the amount of spatial integrity of other portions of the deposits. Random orientation is not an unambiguous signal of cultural deposition, but it is part of any reasoned argument that the materials are more likely to represent 


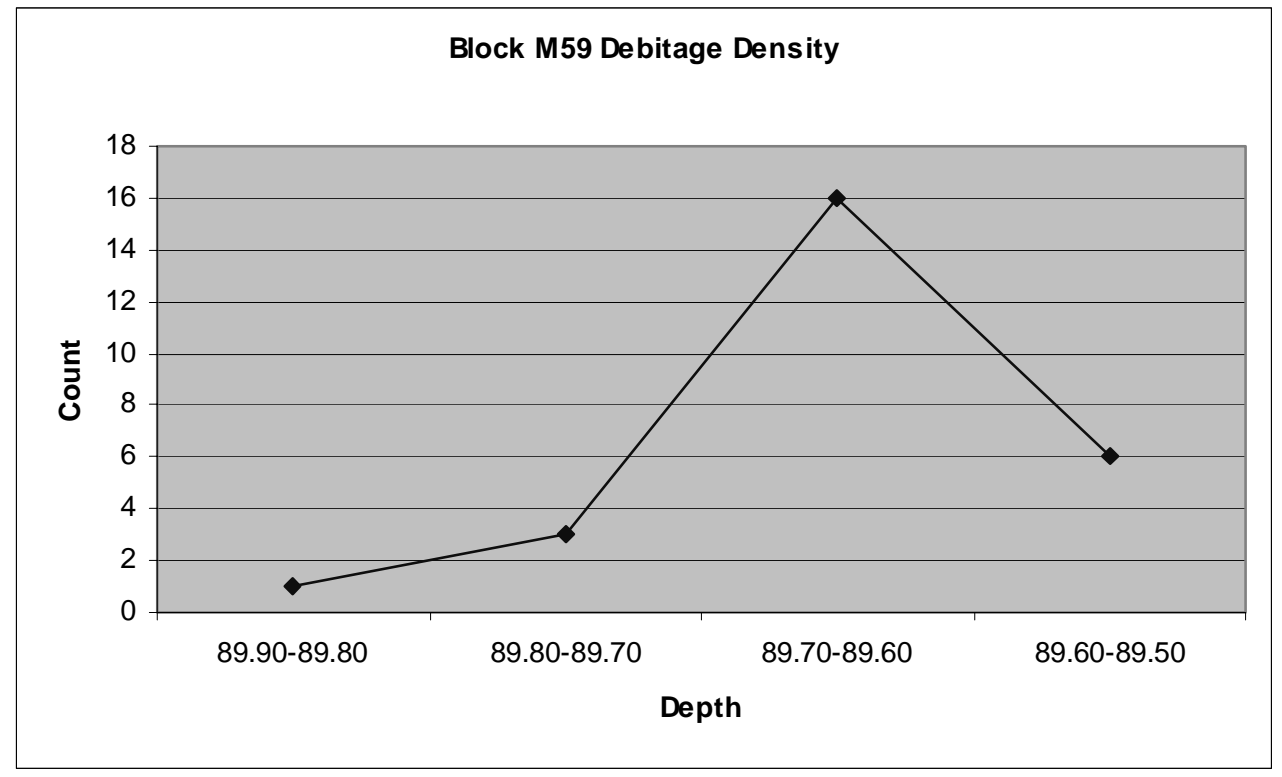

Figure 5-14. Vertical distribution of debitage from M59 Excavation Block, 41 WA47.

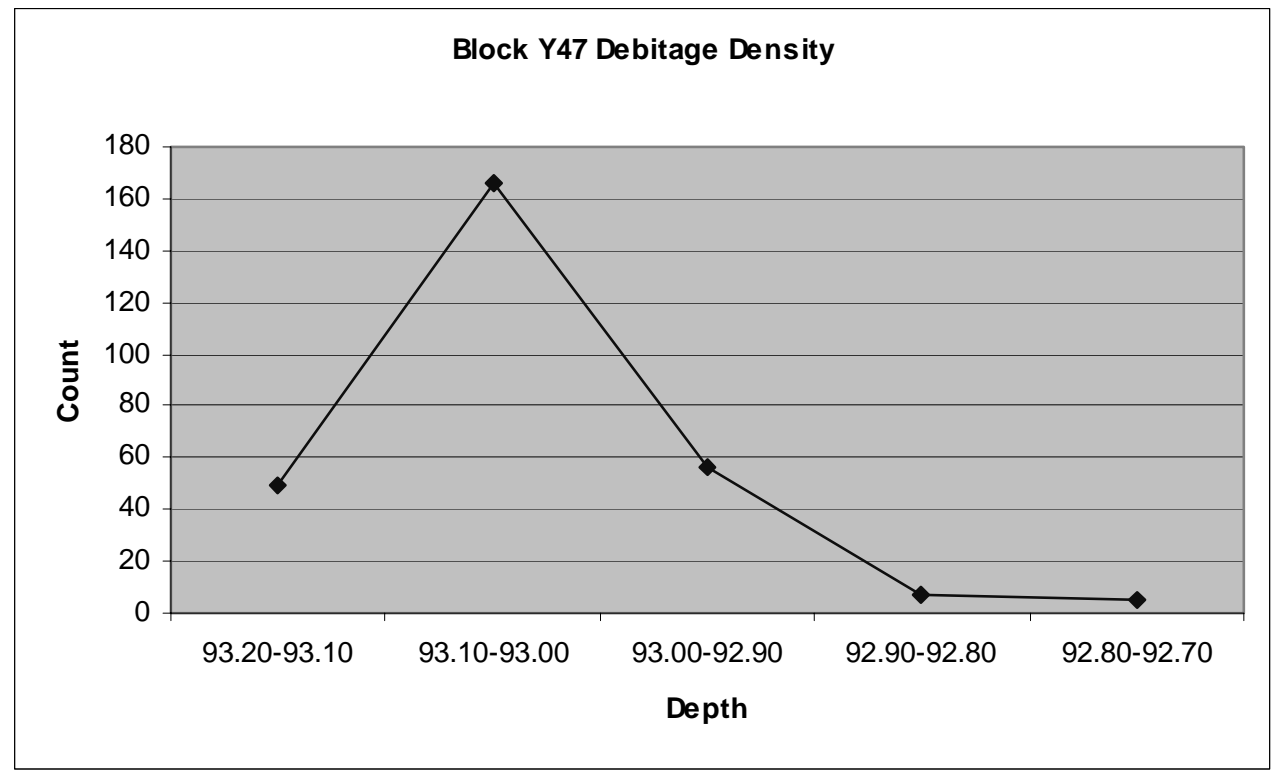

Figure 5-15. Vertical distribution of debitage from Y47 Excavation Block, 41 WA47. 


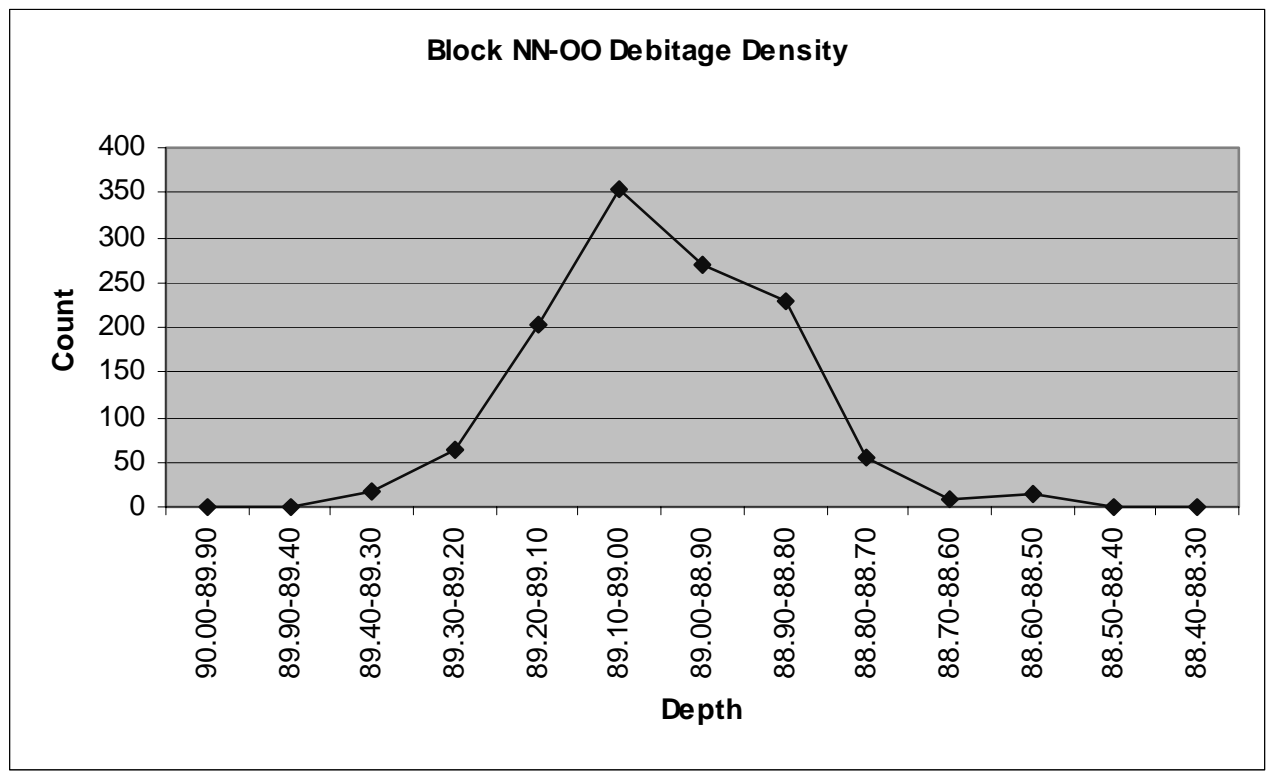

Figure 5-16. Vertical distribution of debitage from NN-OO51 Excavation Block, 41 WA47.

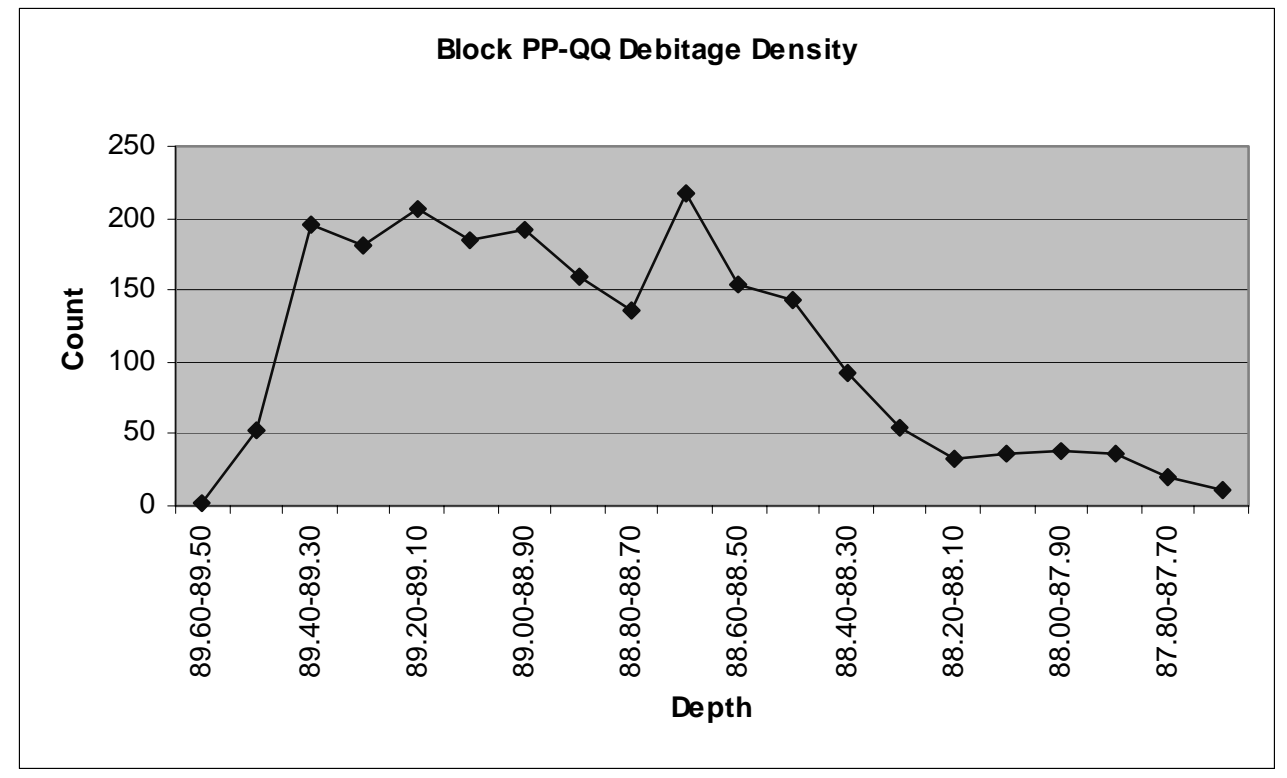

Figure 5-17. Vertical distribution of debitage from PP49/QQ48-49 Excavation Block, 41 WA47. 
relatively undisturbed human discard. As with assessment of alluvial and slope redeposition, the elimination of one set of patterning agencies still demands explanations for the existing patterning. Examination of the orientation and inclination do not unambiguously indicate the origin of deposits containing artifacts, but in concert with other classes of information they are critical data about site formation.

A total of 124 artifacts were piece-plotted. Seventy-three of these items had their orientation and inclination measured, the others were too small for precise orientation measurements. These include lithics, ceramics, bone, and larger natural clasts. There was a bias toward recognition of larger artifacts during shovel skimming that were found in situ and could have their dip and strike recorded. The orientation data permit assessment of the extent of post-depositional movement of these artifacts as sediment clasts. Preferential orientation of artifacts is a common indicator of alluvial and colluvial modifications. High angle inclination often is an indicator of trampling, sediment movement, or clast movements within sediments. These data allow evaluation of post-depositional processes and permit determination of the potential for the preservation of cultural patterning in artifact spatial distribution. This also is pertinent to more limited spatial orientation. Although the excavations at 41WA47 do not permit extensive analysis of horizontal spatial patterns, these assessments of the likely integrity of the deposits do allow evaluation of the association of artifacts as behavioral assemblages.

Data on orientation and inclination of 73 of the 124 pieceplotted artifacts suggests minimal post-depositional movement. There is no preferred orientation to any of the large flakes, ceramics, points, or bones that were measured. The inclination of these artifacts shows that most are relatively flat lying. The mean inclination is $13^{\circ}$ for all measured artifacts. Sixty-three of the 73 artifacts fall between $2-35^{\circ}$, seven rested between 40 $60^{\circ}$, and only three artifacts were inclined $70^{\circ}$ or more. The sharp condition of lithic edges also indicates insignificant post-depositional damage to these flakes and tools. The lack of weathering on the faunal material recovered indicates that burial was rapid. The taphonomy of lithics, ceramics, sherds, and bones all suggest that the artifacts have not been subject to significant postdepositional movement and were buried by relatively rapidly deposited, low energy sediments.

\section{Distribution of Ceramics and Burned Clay}

The distribution of ceramics indicates that the highest numbers of ceramics per unit occur in three units (QQ492, QQ48-12, and PP49-5; Table 5-13). All three of these units are found in the smaller block (PP-QQ) nearest the backhoe trench. Smaller numbers per unit are found in three additional units in the PP-QQ block (QQ49-1; QQ48-19; and QQ48-22) and in one unit in the NN-OO block (NN51-24). Block M59, located at the extreme southwest end of the site produced no ceramics and block Y47, the in the west-central part of the site, produced only five ceramics from Levels 2 and 3 . Since the number of levels excavated within each unit varies, a more accurate measure is the mean number of ceramics per level. Since sample size is strongly influenced by the number of levels excavated per unit, the mean density of ceramics per level (last line of Table 5-13) parallels the pattern noted above, with the exception that unit NN51-24 has the fourth highest ceramic density across the site. Nonetheless, four of the five highest ceramic densities are found in block PP-QQ.

As evident from the distribution of ceramics by level within each unit, ceramics tend to be found relatively high in the units and continue to occur throughout the unit until the penultimate level excavated within each unit. Within each unit, the last level was normally dug into the Bt horizon that predates human occupation of the site. It is difficult to compare the vertical distribution of ceramics across the site since the nine units with ceramics in block NN-OO, on average, only contained seven levels. On the other hand, the six units with ceramics from the PP-QQ block contained an average of 13.8 excavated levels per unit. Although, overall the vertical distribution of the 452 sherds appears to be unimodal (see total column in Table 5-13), four of the PP-QQ units (PP45-5, QQ48-12, QQ48-19, and QQ49-1) suggest that there may be two distinct components at the site; one occurring above Level 259 and the other peaking in Level 260 (see QQ49-1) or below. This general pattern agrees in broad terms with 


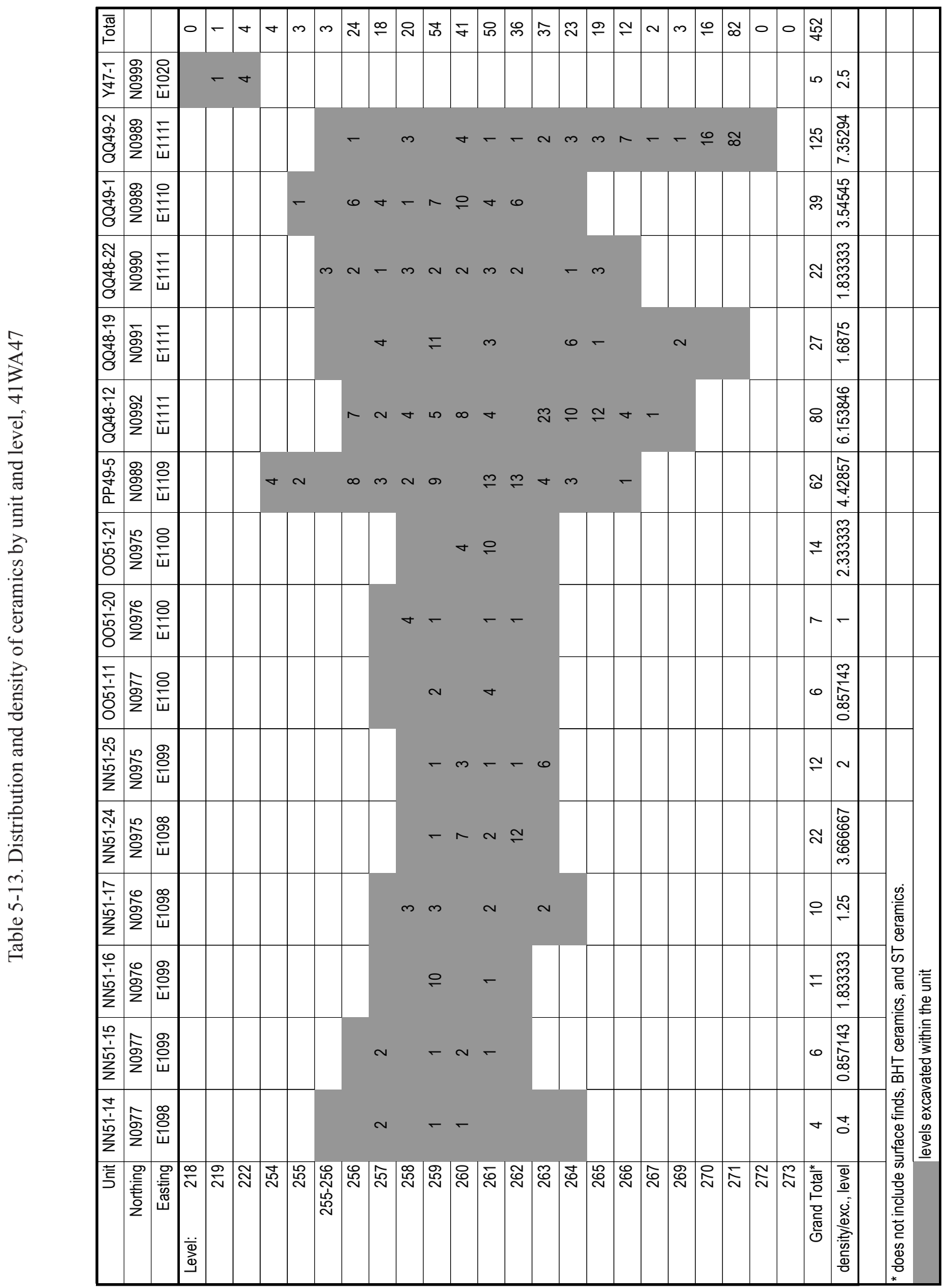


the trend that arrow points are present in Level 257 and above, and dart points are present in Level 264 and below. The in-between levels represent a zone of arrow and dart point co-occurrence, suggesting either contemporaneity or perhaps a mixing of components at the contact surface of two cultural components.

Because the hardened clay specimens can fragment into greater numbers during storage, weight by unit and level is a more consistent way of tracking the quantity of hardened clay from the site. Table 5-14 shows the horizontal and vertical distribution of hardened clay recovered from the site. A total of nine excavation units contained hardened clay. Four of these units have only a small quantity limited to a single level. On the other hand, the remaining five units (N989-E1109, N992-E1111, N991-E1111, N989-E1110, and N989-E1111) have between 38.8-158.8 grams of hardened clay distributed across a number of successive levels. No features of any type were identified during excavation in these units and the hardened clay did not occur as a localized concentration within these units but rather as hardened clay balls recovered in the screen.

With one exception (N989-E1110), the vertical distribution of hardened clay has a unimodal distribution peaking at various depths within each unit (i.e., Level 261 in N989-E1109; Level 266 in N992-E1111). In N989-E1110 two peaks are evident in hardened clay distribution; one occurs between Levels 256-259 and the second in Level 262.

\section{Magnetic Sediment Susceptibility}

The two sediment column samples acquired for magnetic susceptibility studies from the backhoe trench are from roughly the northern and southern ends of the trench. The first column cut through the southern end of a dark organic stained zone while the second column was $11 \mathrm{~m}$ to the south and about $30 \mathrm{~cm}$ south of a second organically stained area near the opposite end of the

Table 5-14. Weight (grams) of hardened clay by unit and level, 41WA47

\begin{tabular}{|c|c|c|c|c|c|c|c|c|c|c|}
\hline \multicolumn{11}{|c|}{ Unit } \\
\hline Level & $\begin{array}{c}\text { NN51-16 } \\
\text { (N976/ } \\
\text { E1099) }\end{array}$ & $\begin{array}{c}\text { NN51-18 } \\
\text { (N976/ } \\
\text { E1098 } \\
\end{array}$ & $\begin{array}{c}\mathrm{NN} 51-25 \\
\text { (N975/ } \\
\mathrm{E} 1099)\end{array}$ & $\begin{array}{l}\text { PP49-5 } \\
\text { (N989/ } \\
\text { E1109) } \\
\end{array}$ & $\begin{array}{c}\text { QQ48-12 } \\
\text { (N992/ } \\
\text { E1111) }\end{array}$ & $\begin{array}{c}\text { QQ48-19 } \\
\text { (N991/ } \\
\text { E1111) }\end{array}$ & $\begin{array}{c}\text { QQ48-22 } \\
\text { (N990/ } \\
\text { E1111) }\end{array}$ & $\begin{array}{l}\text { QQ49-1 } \\
\text { (N989/ } \\
\text { E1110) }\end{array}$ & $\begin{array}{l}\text { QQ49-2 } \\
\text { (N989/ } \\
\text { E1111) }\end{array}$ & Total \\
\hline 255 & \multirow{18}{*}{1.7} & \multirow{18}{*}{0.4} & \multirow{18}{*}{5.7} & & & & \multirow{18}{*}{2.91} & 0.43 & & 0.43 \\
\hline 256 & & & & 0.7 & & & & 8.75 & & 9.45 \\
\hline 257 & & & & 3.4 & & & & 7.74 & 0.27 & 11.41 \\
\hline 258 & & & & 1.8 & & & & & 2.57 & 4.37 \\
\hline 259 & & & & 5.9 & & & & 7.82 & & 18.73 \\
\hline 260 & & & & & & & & 2.46 & & 8.16 \\
\hline 261 & & & & 14.6 & & & & & 2.49 & 17.09 \\
\hline 262 & & & & 5 & & & & 23.65 & 8.79 & 37.44 \\
\hline 263 & & & & & 1.17 & & & & & 1.17 \\
\hline 264 & & & & 7 & 3.92 & 10.5 & & 8.55 & & 29.97 \\
\hline 265 & & & & 0.4 & 1.95 & 9.09 & & & 30.7 & 42.14 \\
\hline 266 & & & & & 104.24 & & & & & 104.24 \\
\hline 267 & & & & & 1.83 & 10.02 & & & & 11.85 \\
\hline 268 & & & & & 0.47 & 9.13 & & & & 9.6 \\
\hline 269 & & & & & & 25.17 & & & & 25.17 \\
\hline 270 & & & & & & 35.78 & & & & 35.78 \\
\hline 271 & & & & & & 24.42 & & & & 24.42 \\
\hline 272 & & & & & & 34.39 & & & & 34.39 \\
\hline Total & 1.7 & 0.4 & 5.7 & 38.8 & 113.58 & 158.5 & 2.91 & 59.4 & 44.82 & 425.8 \\
\hline
\end{tabular}


trench. Figure 5-18a shows the magnetic susceptibility of the sediments in Column 1 while Figure 5-18b shows the same values for Column 2. Within Column 1, there are three peaks in magnetic susceptibility, one occurs between $12.5-18 \mathrm{~cm}$ bgs, the second between $28-32.5$ $\mathrm{cm}$ bgs, and the third between $88-92.5 \mathrm{~cm}$ bgs. The first of the peaks coincides well with the boundary between the $\mathrm{A} 1$ and $\mathrm{A} 3$ horizons. The second peak also falls on the boundary between the $\mathrm{A} 3$ and $\mathrm{C} 1$ horizons, while the third peak falls about $12 \mathrm{~cm}$ below the boundary between the $\mathrm{C} 1$ and $\mathrm{C} 2$ horizons and at about the same distance below the base of the organically stained zone. Within Column 2, there are only two peaks in magnetic susceptibility, one occurs between $42.5-48 \mathrm{~cm}$ bgs, the second between $58-62.5 \mathrm{~cm}$ bgs. The first of these peaks is roughly in the middle of the $\mathrm{C} 1$ horizon. The second peak, however, coincides with the boundary between the $\mathrm{C} 1$ and $\mathrm{C} 2$ horizons. The results of the magnetic susceptibility analysis of the two column samples suggest that there are correspondences between sediment magnetic susceptibility and depositional units recognized in the field. These depositional units may or may not correspond with occupation surfaces.

To discern whether there are any relationships between occupation surfaces, as represented by artifact density distributions, the magnetic susceptibility of sediments from unit N989-E1111 (QQ49-2) was standardized and compared with the standardized scores for the number of debitage recovered from the same unit (Figure 5-19). The magnetic susceptibility scores show that although some oscillations do occur within them, there are two broad peaks in values, one between $89.18-88.93 \mathrm{~cm} \mathrm{bgs}$, and the other between $88.78-88.53 \mathrm{~cm}$ bgs (Figure 5-19 bottom). The standard scores for the number of debitage by level from N989-E1111 also contains two broad peaks, one between $89.35-88.90 \mathrm{~cm}$ bgs, and the other between $88.70-88.60 \mathrm{~cm}$ bgs (Figure 5-19 top). There is strong correspondence between magnetic susceptibility and debitage abundance in unit N989-E1111, suggesting that the organic enrichments detected by the magnetic susceptibility analysis may actually correspond with occupation surfaces upon which relatively high numbers of debitage were discarded.

Unfortunately, no ${ }^{14} \mathrm{C}$ dates are available from this unit. Nonetheless, five projectile points have been recovered from the unit. Two of them are identified as Gary preforms, one is an Andice barb, and two are untypeable/ untyped arrow points. The two arrow points are from $89.12-89.00 \mathrm{~cm}$ bgs and fall squarely within the upper peak of magnetic susceptibility. The Andice is from $88.80-88.70 \mathrm{~cm}$ bgs and appears to be out of place considering that the two Gary dart points are from 88.70$88.50 \mathrm{~cm}$ bgs and fit well within the second peak in magnetic susceptibility. These patterns suggest very good correspondence between the magnetic susceptibility of sediments, debitage abundance, and projectile point distributions within the unit.

The analysis of magnetic susceptibility values for the column sample from unit N975-E1100 produced a relatively flat line without major relief suggesting a lack of organic enrichment across this unit.

\section{Overall Distribution Patterns}

The previous analyses that combined information on sediment magnetic susceptibility with debitage frequencies and the distribution of projectile points does indicate the possibility that at least two or perhaps three components may be present and discernible in the deeper deposits of the site (i.e., in block PP-QQ). It is possible that these components may be present even in the shallower portions of the site, although homogenized to such a degree as to be nondiscernible (i.e., block NN$\mathrm{OO})$. The analyses suggest that if there are three distinct components, these may simply be divided into an upper arrow point component with Perdiz and Catahoula points, a lower dart point component containing Dawson and Gary points, and perhaps what is equivalent to a middle component or perhaps a mixed deposit of early and later materials containing both arrow and dart points.

Once the materials from the principal excavation blocks are combined, the vertical distribution of ceramics and debitage, while interesting, tends to blur any unique patterns that may have been notable at the level of individual units. Figure 5-20 shows the distribution of standardized values for debitage and ceramic sherds within the units of the two principal excavation blocks (NN-OO and PP-QQ) at 41WA47. The raw data for this plot is provided in Table 5-15. It is significant that both the plot of standardized values for ceramics and debitage exhibit a single peak and that the peaks for the two classes 


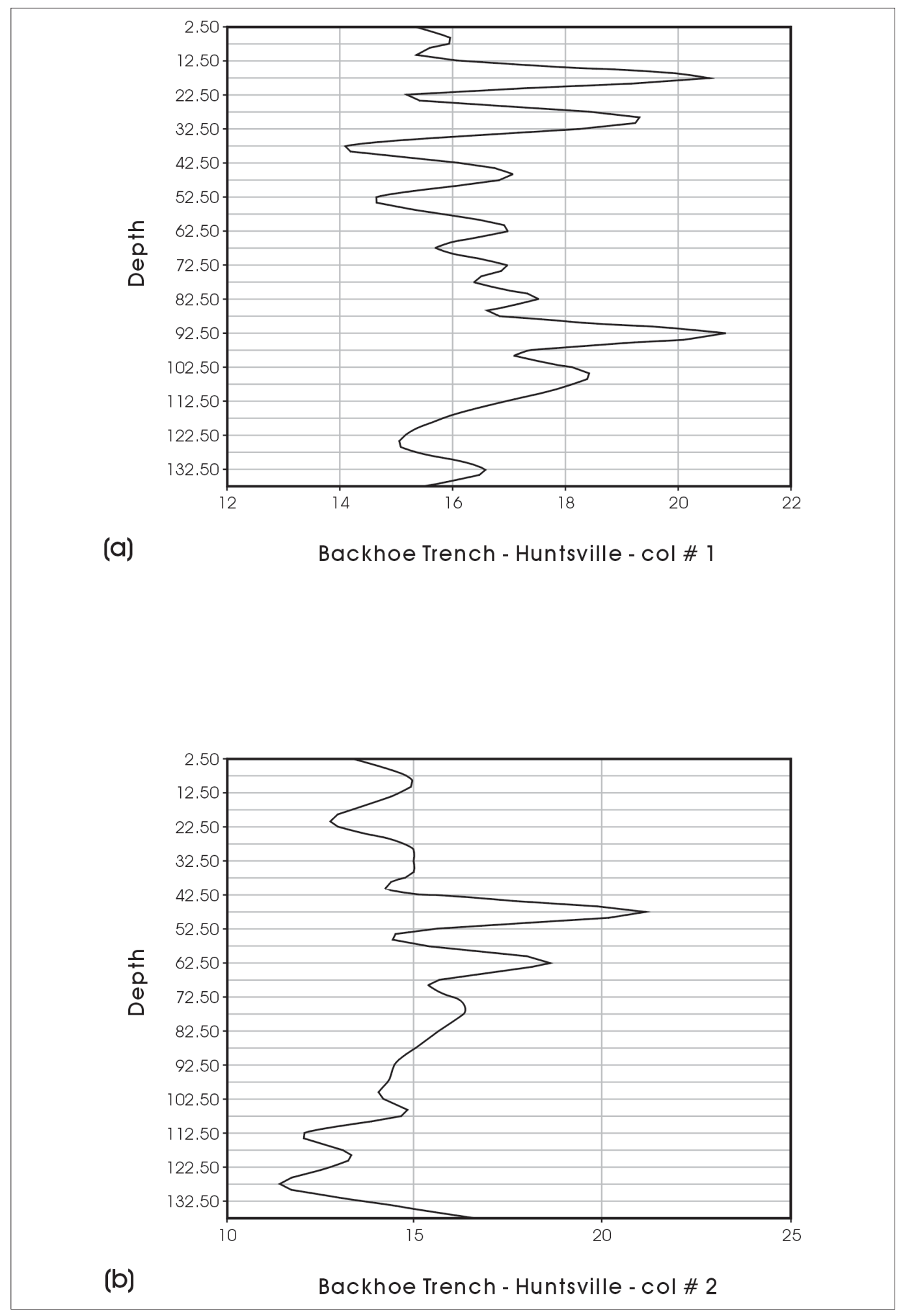

Figure 5-18. Magnetic sediment susceptibility values in BHT-1: (a) sediment sample Column 1; (b) sediment sample Column 2. 


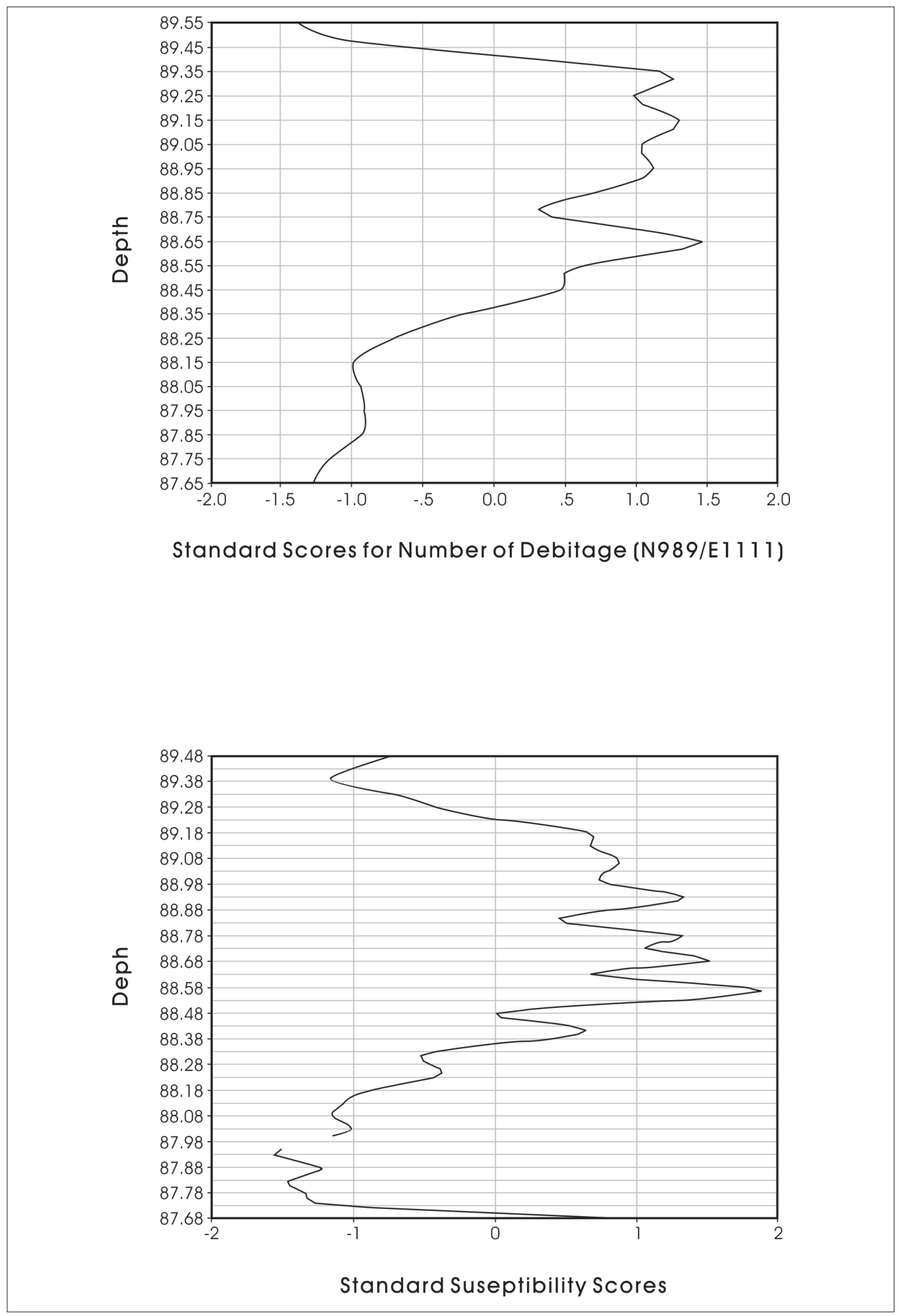

Figure 5-19. Standardized magnetic susceptibility scores and debitage count scores in Unit N989-E1111. 
of material overlap so dramatically. The peaks center on Level 259 and seem to encompass Levels 256-265. A smaller secondary peak may be present in the upper levels of the blocks, centered on Levels 219 and 220.

Based on a combination of ${ }^{14} \mathrm{C}$ dates, the temporal diagnostic projectile points, and the age range of the ceramic assemblage, it can be concluded that the archaeological deposits at 41WA47 range from the later part of the Late Archaic (i.e., 1920 вP) through the Late Ceramic period (i.e., 510 вP). Gary and Dawson points are representative of the earliest component at the site, while Perdiz and Catahoula points represent the latest period. The large number of ceramics may span the entire Early to Late Ceramic Periods.

\section{Summary and Recommendations by Russell D. Greaves}

Site 41 WA47 is a stratified, multiple occupation site that is considered to be a significant cultural resource. The site has already been officially designated a State Archeological Landmark. The current investigations provided data strongly suggestive that relatively discrete occupational events or archaeological components may be preserved within the deeper sediments remaining at this site (i.e., in the vicinity of BHT-1 and excavation block PP-QQ).

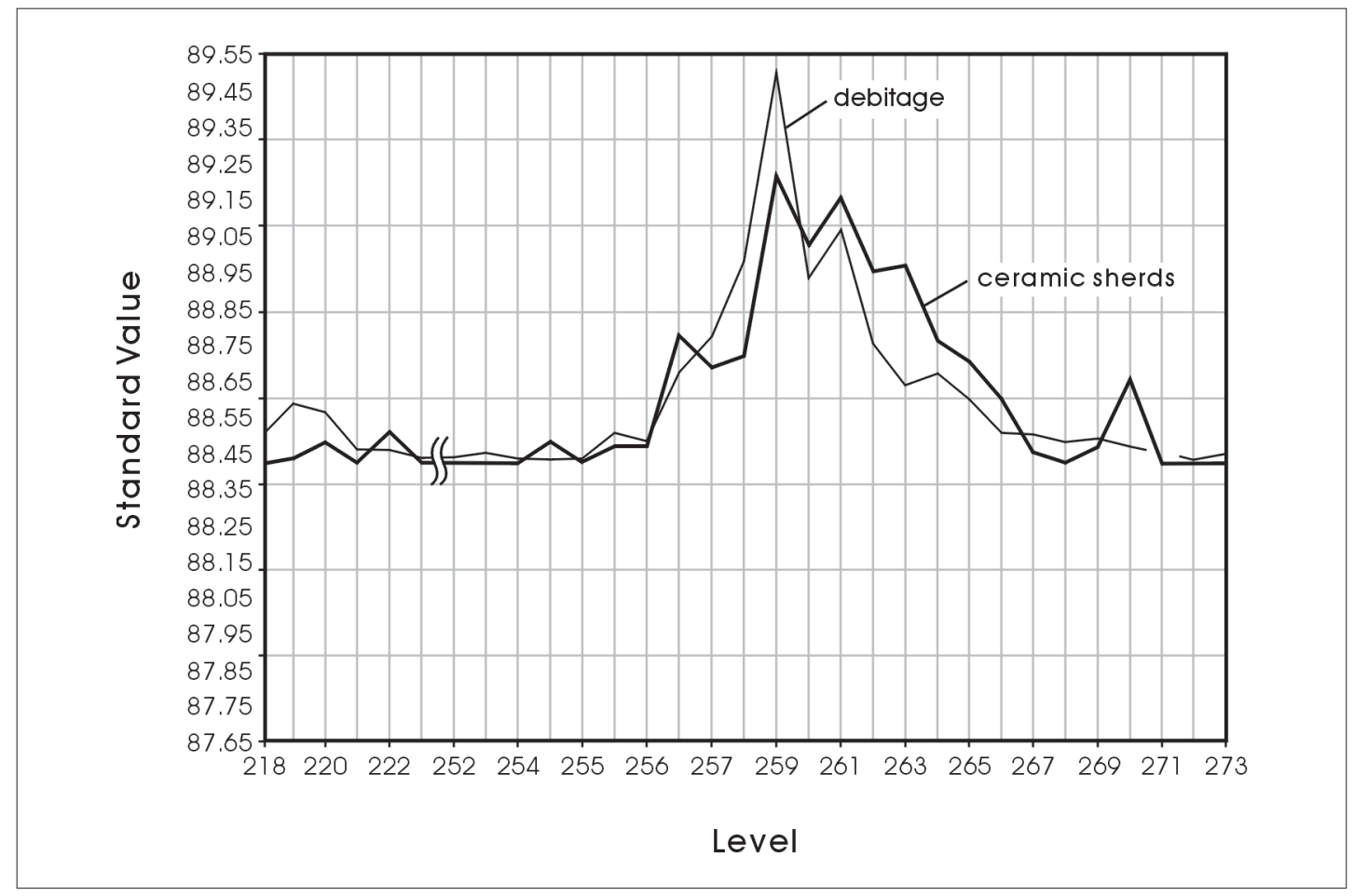

Figure 5-20. Distribution of standardized values for ceramic sherds and lithic debitage, excavation blocks $N N-O O$ and $P P-Q Q$ combined. 
Table 5-15. Count of ceramic sherds and unmodified debitage by level, 41WA47

\begin{tabular}{|c|c|c|}
\hline Level & $\begin{array}{c}\text { Ceramic } \\
\text { Sherds }\end{array}$ & Debitage \\
\hline 218 & 0 & 49 \\
\hline 219 & 1 & 110 \\
\hline 220 & 4 & 93 \\
\hline 221 & 0 & 19 \\
\hline 222 & 6 & 20 \\
\hline 250 & 0 & 2 \\
\hline 252 & 0 & 6 \\
\hline 253 & 0 & 14 \\
\hline 254 & 0 & 3 \\
\hline 254 & 4 & 1 \\
\hline 255 & 0 & 1 \\
\hline 255 & 3 & 53 \\
\hline 256 & 3 & 34 \\
\hline 256 & 24 & 173 \\
\hline 257 & 18 & 241 \\
\hline 258 & 20 & 391 \\
\hline 259 & 54 & 748 \\
\hline 260 & 41 & 353 \\
\hline 261 & 50 & 446 \\
\hline 262 & 36 & 222 \\
\hline 263 & 37 & 144 \\
\hline 264 & 23 & 170 \\
\hline 265 & 19 & 117 \\
\hline 266 & 12 & 52 \\
\hline 267 & 2 & 51 \\
\hline 268 & 0 & 34 \\
\hline 269 & 3 & 42 \\
\hline 270 & 16 & 26 \\
\hline $271 *$ & 0 & 56 \\
\hline 272 & 0 & 0 \\
\hline 273 & 0 & 11 \\
\hline
\end{tabular}

* eighty-two sherdlets were excluded from sample
Normal visitation and use of the park is associated with areas of extreme erosion and loss of archaeological sediments at 41WA47. Erosion has severely impacted many portions of the site. In addition to the large area noted on Figure 5-1, where the sandy layer is relatively thin, some areas within the identified site boundary have been eroded down to the older, argillic Bt horizon. These relatively narrow and sometimes linear zones are relatively common in front of RV pullouts and in areas of steep natural gradient where sheet wash has severely eroded sediments. Shovel testing and controlled excavation indicate that the depth of the overlying archaeological sediments is highly variable. Archaeological deposits are relatively thin in the southwestern and northeastern portions of the site. The deepest deposits are found in the vicinity of BHT- 1 and excavation block PP-QQ. One portion of the site containing deposits approximately $180-200 \mathrm{~cm}$ deep was tested through a backhoe trench and two controlled excavation blocks of 1 x 1-m units. Abundant artifacts were encountered within these deep sediments, especially lithics, ceramics, and bone. This area of the site represents roughly 20 percent of the total site area or about $10,500 \mathrm{~m}^{2}$.

Good preservation conditions are indicated by the presence and condition of bone within these excavations, although differential preservation may have destroyed some low meat utility elements. Nonetheless, the quantity of faunal remains recovered as well as their good preservation conditions suggest the abundant availability of at least this data type for investigations of subsistence practices over time. Macrobotanical remains were not recovered in large numbers and can contribute little to the reconstruction of prehistoric diet and other aspects of life. The presence of phytoliths in relatively large numbers in the 41WA47 sample is encouraging, although the phytolith grains have been subject to mechanical erosion. Evidence of translocation of sediments and phytolith grains may, however, limit the utility of an extensive phytolith analysis effort. Pieces of burned clay may be indicative of the possibility that architectural elements may be preserved within some of the remaining archaeological deposits. However, the hardened clay fragments may also be indicative of disturbed hearth features. Piece plotting strongly suggests minimal spatial reorientation of artifacts subsequent to burial. A series of six AMS dates bracket the occupation of 41WA47 
between approximately 1700-1900 BP (AD 50-250) and 300-500 BP (AD 1450-1650). Although one date within this chronosequence appears to be anomalous, the other five dates indicate that charcoal within these soils and sediments are likely to provide good temporal control for interpreting site taphonomy and human use of this location. This site clearly contains significant potential to provide important information about use and reoccupation events at this location.

This work is the first detailed characterization of 41WA47 since its initial identification in 1978. Controlled $1 \times 1-m$ test units demonstrated that this site has been subject to significant erosion and loss of some archaeological deposits. Normal park activities are likely to result in additional destruction of this site unless efforts are made to stabilize the existing soils and protect this resource. This investigation has demonstrated the location of deep and significant archaeological remains in the southcentral portion of the site.

The following actions are recommended to protect the significant cultural deposits of the site particularly in the area of deep deposits:

1) Remove campground pullouts 63,64 , and 65 from camping use and return those areas to a natural state;

2) Prevent the digging of temporary barbecue pits by park visitors and restrict ash and charcoal disposal to designated areas; and,

3) Identify erosion control measures for the site to stabilize the ground surface and prevent impact to buried deposits. 


\title{
Chapter 6: $\quad$ Summary \& Recommendations
}

\author{
Russell D. Greaves
}

\section{Archaeological Survey Summary And RECOMMENDATIONS}

During the archaeological survey of the six parcels within Huntsville State Park three previously unidentified archaeological sites (41WA264, 41WA265, 41WA266) were encountered. Two of those sites (41WA264 and 41WA265) were found within Area E (Figure 2-2). The other site (41WA266) was identified in Area F (Figure 2-3). All three are small, low-density archaeological sites. They contain lithics, but no other classes of artifacts were recovered during shovel testing of these three sites. There are no indications of archaeological features or obvious, intact paleosols associated with the buried artifacts. Shovel testing also identified a much larger area of 41WA228 than previously delineated.

Two of the previously unidentified archaeological sites (41WA264 and 41WA266) are in highly disturbed contexts within the existing campgrounds and contain very few artifacts. Both are situated along campground roads, and are associated with improved tent platforms, picnic tables, parking pullouts, and other campground facilities. 41WA264 has an especially low density of artifacts. Shovel tests on this site also contained significant evidence of recent subsurface disturbance. It is apparent that these two sites have been subject to repeated episodes of modification from heavy equipment. Both 41WA264 and 41WA266 are considered to be ineligible as SAL or NRHP properties. No additional archaeological characterization is considered necessary and no additional testing is being recommended for these highly disturbed archaeological sites.

Site 41WA265 in Area E (Figure 2-2) is a very small concentration of lithics. A relatively abundant amount of material (one biface and five flakes) was recovered in two shovel tests from depths between $30-60 \mathrm{~cm}$ bgs. Six additional shovel tests placed closely around the two containing artifacts produced no cultural materials. No other nearby shovel tests indicated any contiguous archaeological deposits. These shovel tests are at the most north-central periphery of survey Area E. There is a utility line trench that has disturbed the area directly east of these shovel tests. Although the proximity of any previous archaeological investigations along that utility line and the 41WA265 location are unknown, no evidence of artifacts has been reported from examination of any areas nearby to this trench. Although no larger site was identified, there is a strong possibility that the subsurface artifacts could represent the margin of an unidentified site located to the east of this portion of Area E. Previous work in the park, has recorded a site not far to the east of 41WA265 (McNatt et al. 2000:45-48, 64). On the basis of the site investigations performed under the current survey, this site does not appear to merit official SAL designation or NRHP listing. No additional archaeological testing is considered necessary at this location. However, any future impacts outside of the currently delineated site area, or this portion of survey Area E, should carefully determine whether a larger archaeological site could be present.

Shovel testing of portions of Area F near two shovel tests that previously defined 41WA228 indicated the presence of a significantly larger archaeological site than was previously recorded. Archaeological materials within the shovel tests defining this site were moderately abundant and several contained artifacts to the basal depths of testing ( $\sim 60 \mathrm{~cm} \mathrm{bgs})$. Some portions of this site are within areas disturbed by campground roads, facilities, and the park superintendent's house. Shovel testing was useful in defining new boundaries for 41WA228, but is not the ideal technique for providing a more detailed view of the sedimentary context or better controls on artifact sampling. This site may have several areas with a low density of artifacts. At least a portion of the existing cultural materials on-site have been severely impacted by previous road construction and park facilities improvements.

Given the increased site size, the eligibility status of 41WA228 for official SAL designation or NRHP listing remains unknown. While the proposed road improvements will impact the cultural deposits falling in the immediate vicinity of the road, TPW Cultural 
Resource Coordinator, Art Black, will monitor construction within the impact area and will halt work if and when cultural deposits and features are encountered -to evaluate the significance of the deposits in consultation with the Texas Historical Commission.

\section{4IWA47 SUMMARY AND RECOMMENDATIONS}

Site 41WA47 is a significant cultural resource. It was officially designated as an SAL in 1983. This excavation represents the first detailed investigation of the site. 41WA47 has been demonstrated to contain localized pockets of deep and potentially stratified archaeological deposits. The areas adjacent to BHT-1 and the PP-QQ excavation blocks contained the deepest and most intact deposits, extending almost $2 \mathrm{~m}$ below the current ground surface.

Based on the shovel test data and the depth of the Bt horizon in some block excavation units, it appears that the portion worthy of preservation is located in the southcentral section of the site. This section, appears to constitute approximately 15-20 percent of the overall site, or roughly an area of 7,819-10,500 $\mathrm{m}^{2}$. The remaining $80-85$ percent of the site area has been impacted by either current park usage, construction associated with park improvements, natural forces of erosion, or a combination of the three.

Nineteen controlled 1 x 1-m excavation units within four excavation blocks recovered significant information about 41WA47. Profiling provided important information about site formation. Excavation data strongly suggest that artifacts may not have been subject to significant post-depositional movement.

There is a good chronosequence of deposits provided by six AMS dates (Table 5-5). These dates indicate occupation of 41WA47 between approximately 19001700 вP and 500-300 вP. Abundant lithics $(n=3,717)$ were found in the $1 \mathrm{x} 1-\mathrm{m}$ units in the controlled excavation areas. A relatively large number of diagnostic projectile points $(n=36)$ were recovered throughout the deposits. Ceramics also were relatively abundant $(n=471)$. A large amount of highly fractured bone $(n=1,264)$ was collected that offers important taphonomic information and possibly can provide additional data on human subsistence. Some of the burned clay from the site may represent evidence of daub $(n=201)$, although it may also represent the remains of hearths. Paleobotanical recovery identified charcoal and carbonized hickory nutshell fragments that provide paleoenvironmental information and may indicate some aspects of human diet or wood use. Preliminary phytolith analyses provided provocative information about the paleoenvironment and taphonomic processes at 41WA47. The site has been officially designated a State Archeological Landmark. Results from this investigation indicate that this site has a very significant potential for research on site formation, multiple occupation dynamics, technology, and subsistence. Based on a combination of ${ }^{14} \mathrm{C}$ dates, the temporal diagnostic projectile points, and the age range of the ceramic assemblage, it can be concluded that the archaeological deposits at 41WA47 range from the later part of the Late Archaic (i.e., 1920 вP) through the Late Ceramic period (i.e., 510 вр). Gary and Dawson points are representative of the earliest component at the site, while Perdiz and Catahoula points represent the latest period. The large number of ceramics may span the entire Early to Late Ceramic periods. The occupation at 41WA47 spans the time period from the later part of the Late Archaic through the Late Ceramic time periods when a variety of technological innovations and horticultural adaptations become evident within the archaeological record of east Texas. Several exciting research questions generated from this work could readily be addressed through additional data collection at 41WA47.

The proposed road construction will affect several portions of 41WA47. Conditions at this site indicate that park facility construction, maintenance, and erosion from these park improvements have already degraded many portions of the site. The depths of deposits range from approximately $2 \mathrm{~m}$ to completely absent across areas that demonstrably are part of the site. The deepest archaeological deposits with the best research potential are found in the south-central portion of the site.

Visitation of this park is quite heavy. Fire pit excavation, charcoal dumping, and especially erosion initiated around parking areas, picnic tables, tent pads, and fire rings have adversely affected many visitor use areas on the site. The natural slope of this campground area makes erosion control in association with such intense use 
problematic. There is a very high probability that this site will continue to be degraded unless some stabilization efforts are established. That also is highly problematic because the site is entirely situated within a very popular improved campground facility. $41 \mathrm{WA} 47$ appears to be threatened with ongoing destruction of the archaeological deposits and loss of significant information about occupational history in this part of Walker County.

The following actions are recommended to protect the significant cultural deposits of the site:

1) Remove campground pullouts 63,64 , and 65 from camping use and return those areas to a natural state;

2) Prevent the digging of temporary barbecue pits by park visitors and restrict ash and charcoal disposal to designated areas; and,

3) Identify erosion control measures for the site to stabilize the ground surface and prevent impact to buried deposits.

If short- and medium-term measures are found to be insufficient to reduce the loss of this resource either due to continued erosion or impact from campground use, further mitigation efforts may be necessary to fully take advantage of the wealth of data and research potential of 41WA47. Expanded horizontal block excavations contiguous with the PP49/QQ48-49 block excavations would augment the chronological and contextual data recovered from this deeply stratified site. 


\section{References Cited}

Aronow, S.

1979 Geology. In Soil Survey of Walker County, Texas, by W. R. McClintock, J. J. Castille, M. Stewart, and L. E. Andrew, pp. 52-55. United States Department of Agriculture, Soil Conservation Service and Forest Service, Texas Agricultural Experiment Station. U.S. Government Printer, Washington, D.C.

Aten, L. E.

1983 Indians of the Upper Texas Coast. Academic Press, New York.

Barnard, H. D.

1939 Early History of Research in Texas Archeology by the Department of Anthropology and History of the Anthropology Museum of the University of Texas. Unpublished Master's thesis, Department of Anthropology, University of Texas, Austin.

Binford, L. R.

2001 Constructing Frames of Reference: An Analytical Method for Archaeological Theory Building Using Ethnographic and Environmental Data Sets. University of California Press, Berkeley.

Blair, W. F.

1950 The Biotic Provinces of Texas. The Texas Journal of Science 2(1):93-117.

Bomar, G. W.

1995 Texas Weather. Second Edition. University of Texas Press, Austin.

Boes, T. C.

1992 Archeological Testing and Monitoring at Huntsville State Park, Walker County, Texas. Letter Report No. 14. Texas Parks and Wildlife Department, Public Land Division, Cultural Resources Program, Austin.

Bousman, C. B.

1998 Paleoenvironmental Change in Central Texas: The Palynological Evidence. Plains Anthropologist 43(164):201-219.

Brown, A. G.

1997 Alluvial Geoarchaeology: Floodplain Archaeology and Environmental Change. Cambridge Manuals in Archaeology. Cambridge University Press, Cambridge.

Collins, M. B.

1995 Forty Years of Archeology in Central Texas. Bulletin of the Texas Archeological Society 66:361-400.

Collins, M. B., W. A. Gose, and S. Shaw

1994 Preliminary Geomorphological Findings at Dust and Nearby Caves. Journal of Alabama Archaeology 40:35-56. 
Crawford, C. A., and L. C. Nordt

2001 Chapter 5: Geoarchaeology. In Camp Maxey III: Archaeological Testing of 23 Prehistoric Sites, Lamar County, Texas, by R. B. Mahoney, pp. 12-18. Archaeological Survey Report, No. 314. Center for Archaeological Research, The University of Texas at San Antonio.

Davis, M. W., J. Guy, M. S. F. Tomka, and D. J. Crouch

1994 Archaeological Investigations at Huntsville Fish Hatchery, Walker County, Texas. Texas Parks and Wildlife Department, Cultural Resources Program, Austin.

Denton, J. T.

1984 Archeological Testing of Site 41PK69, Polk County, Texas. State Department of Highways and Public Transportation, Austin.

Dillehay, T. D.

1974 Late Quaternary Bison Population Changes on the Southern Plains. Plains Anthropologist 19(65):180-196.

Duffen, W. A., R. K. Harris, P. Newell, A. T. Jackson, A. D. Krieger, and F. H. Watt

1940 Recent field work in Texas. Texas Archaeological News, an Occasional Report Issued by the Council of Texas Archaeologists 2:1-26.

Ensor, H. B., and D. L. Carlson

1988 The Crawford Site, 41PK69, Central Trinity River Uplands, Polk County, Texas. Contract Reports in Archaeology series, Report No. 4. State Department of Highways and Public Transportation.

Ferring, C. R.

1992 Alluvial Pedology and Geoarchaeological Research. In Soils in Archaeology: Landscape Evolution and Human Occupation, edited by V. T. Holliday, pp. 1-39. Smithsonian Institution Press, Washington, D.C.

Fields, R. C.

1995 The Archeology of the Post Oak Savannah of East Central Texas. Bulletin of the Texas Archeological Society 66:301-330.

Gadus, E. F., and R. C. Fields

1997 Test Excavations at 41WA185, Walker County, Texas. Technical Reports, No. 25. Prewitt and Associates, Inc., Austin.

Girard, J. S.

2000 National Register testing at the Conly Site (16BI19). In Regional Archaeology Program, Management Unit 1, Eleventh Annual Report, pp. 11-64. Louisiana Regional Archaeology Program, Natchitoches.

Greaves, R. D.

2001 "Thirty days in the work house: geoarchaeology of stratified ceramic deposits in the sandy mantle of Huntsville State Park." Paper presented at the 72nd Annual Meeting of the Texas Archeological Society, Corpus Christi, Texas. 
Greaves, R. D., and J. D. Weston

2001 Huntsville State Park Archaeological Survey and Limited Mitigation of 41WA47, Interim Report. Submitted to Texas Parks and Wildlife Department. Manuscript on file at Center for Archaeological Research, The University of Texas at San Antonio.

Hahn, T. H. G., III, R. B. Mahoney, T. M. Bond, C. Coxe, and W. Coco

1994 Highway 61 Visited, Cultural Resources Survey and Testing of the LA-US 61 Four Lane Project Corridor between Bains and Thompson Creek, West Feliciana Parish, Louisiana. Coastal Environments, Inc., Baton Rouge.

Jodry, M. A., and D. J. Stanford

1992 Stewart's Cattle Guard Site. In Ice Age Hunters of the Rockies, edited by D. J. Stanford and J. S. Day, pp. 101-168. Denver Museum of Natural History, University Press of Colorado, Denver.

Johnson, L.

1989 Great Plains Interlopers in the Eastern Woodlands during Late Paleo-Indian Times. Office of the State Archeologist, Report 36. Texas Historical Commission, Austin.

1995 Past Cultures and Climates at Jonas Terrace: 41ME29, Medina County, Texas. Office of the State Archeologist, Report 40. Texas Historical Commission, Austin.

Johnson, L., and G. T. Goode

1994 A new try at dating and characterizing Holocene climates, as well as archeological periods, on the eastern Edward's Plateau. Bulletin of the Texas Archeological Society 65:1-51.

Kenmotsu, N. A., and T. K. Perttula (editors)

1993 Archeology in the Eastern Planning Region, Texas: A Planning Document. Cultural Resource Management Report No. 3. Department of Antiquities Protection, Texas Historical Commission, Austin.

Kuehn, D. D.

1996 Results of Geoarchaeological Investigations. In Report on the 1995 Archaeological and Historical Investigations at Washington-on-the-Brazos State Historical Park (41WT5), Washington County, Texas, edited by D. D. Kuehn, pp. 33-46. Technical Report No. 2. Center for Environmental Archaeology, Texas A\&M University, College Station.

Kreutzer, L. A.

1996 Taphonomy of the Mill Iron Site Bison Bonebed. In The Mill Iron Site, edited G. C. Frison, pp. 101-143. University of New Mexico Press, Albuquerque.

Lyman, R. L.

1994 Vertebrate Taphonomy. Cambridge Manuals in Archaeology. Cambridge University Press, Cambridge.

McClean, R. G., and W. F. Kean

1993 Contributions of Wood Ash Magnetism to Archeomagnetic Properties of Fire Pits and Hearths. Earth and Planetary Science Letters 119:387-394. 
McClintock, W. R., J. J. Castille, M. Stewart, and L. E. Andrew

1979 Soil Survey of Walker County, Texas. United States Department of Agriculture, Soil Conservation Service and Forest Service, Texas Agricultural Experiment Station. U.S. Government Printer, Washington, D.C.

McClurkan, B. B.

1968 Livingston Reservoir, 1965-1966: Late Archaic and Neo-American Occupations. Texas Archeological Salvage Project Papers, No. 12. The University of Texas at Austin.

Mahoney, R. B., and S. A. Tomka

2001 National Register Eligibility Testing of 41MM340 and 41MM341, along Little River, Milam County, Texas. Archeological Studies Program, Report No. 30, Texas Department of Transportation, Environmental Affairs Division, Austin; Archaeological Survey Report, No. 303, Center for Archaeological Research, The University of Texas at San Antonio.

McNatt, L. D.

1978 Archeological Investigations at the Kaygal Recreation Area Site (41WA82), Walker County, Texas. Anthropology Research Laboratory, Report No. 44. Texas A\&M University, College Station.

McNatt, L., A. Ringstaff, and P. Schuchert

2000 Huntsville State Park: Intensive survey of proposed wastewater system improvement project. In 1998 Annual Report to the Texas Historical Commission, Antiquities Permit No. 1935, pp. 45-75. Cultural Resources Program, Texas Parks and Wildlife Department, Austin.

McNatt, L., C. G. Ward, P. Schuchert, A. Ringstaff, and M. Howard

2001 Archeological Survey and History of Huntsville State Park, Walker County, Texas. Cultural Resources Program, Texas Parks and Wildlife Department, Austin.

Nordt, L. C., and C. B. Bousman

1998 Fluvial Geomorphology and Geoarchaeology of Visor Creek. In Archaeological Survey of Southwest Block and Selected Roads and Firebreaks at Camp Maxey, Lamar County, Texas, edited by D. L. Nickels, L. C. Nordt, T. K. Perttula, C. B. Bousman, and K. Miller, pp. 9-15. Archaeological Survey Report No. 290. Center for Archaeological Research, The University of Texas at San Antonio.

Nunley, J. P.

1963 Appraisal of the Archeological Resources of Livingston Reservoir, Polk, San Jacinto, Trinity, and Walker Counties, Texas. Texas Archeological Salvage Project, University of Texas at Austin.

Perttula, T. K.

1993 Regional Preservation Plan for Archeological Resources, Southeast Texas Archeological Region. In Archeology in the Eastern Planning Region, Texas: A Planning Document, edited by N. A. Kenmotsu and T. K. Perttula, pp. 205-213. Cultural Resource Management Report No. 3. Department of Antiquities Protection, Texas Historical Commission, Austin.

Perttula, T. K. (editor)

1999 The Hurricane Hill Site (41HP106): The Archaeology of a Late Archaic/Early Ceramic and Early-Middle Caddoan Settlement in Northeast Texas. 2 Vols. Special Publication No. 4. Friends of Northeast Texas Archaeology, Pittsburgh and Austin. 
Prewitt, E. R.

1981 Cultural Chronology in Central Texas. Bulletin of the Texas Archeological Society 52:65-89.

1985 From Circleville to Toyah: Comments on Central Texas Chronology. Bulletin of the Texas Archeological Society 54:201-238.

Ralph, R.

1978 Texas Parks and Wildlife Department Archeological Site Record for 41WA47. Unpublished document on file at the Center for Archaeological Research, The University of Texas at San Antonio.

Reynolds, R. L., and J. W. King

1995 Magnetic Records of Climate Change. U.S. National Report to I.U.G.G., 1991-1994. American Geophysical Union. <http://www.ang.org/revgeophys/reyno100/reyno100.html> Accessed April 2001.

Schambach, F. F.

1998 Pre-Caddoan Cultures of the Trans-Mississippi South. Research Series No. 53. Arkansas Archeological Survey, Fayetteville.

Shafer, H. J.

1965 Archeological Surveys of Honea, Pat Mayse, and Halsell Reservoirs, Texas. Survey Report No. 1. Texas Archeological Salvage Project. The University of Texas at Austin.

1968 Archeological Investigations in the San Jacinto River Basin, Montgomery County, Texas. Survey Report No. 2. Texas Archeological Salvage Project. The University of Texas at Austin.

1974 Archeology and Indians of Southeast Texas. In The Big Thicket: Participants Handbook for the Contemporary Science Seminar, Spring 1974. Houston Museum of Natural Science and the University of Houston.

Shafer, H. J., E. P. Baxter, T. B. Stearns, and J. P. Dering

1975 An Archeological Assessment of the Big Thicket National Preserve. Report No. 19. Anthropology Research Laboratory, Texas A\&M University, College Station.

Shafer, H. J., and E. P. Baxter

1975 An Archeological Survey of Scott's Ridge and Kaygal Recreation Sites, Sam Houston National Forest. Report No. 15. Anthropology Research Laboratory. Texas A\&M University, College Station.

Shafer, H. J., and T. B. Stearns

1975 Archeological Investigations at the Scott's Ridge Site (41MQ41), Montgomery County, Texas. Report No. 17. Anthropology Research Laboratory, Texas A\&M University, College Station.

Shepard, A. O.

1963 Ceramics for the Archaeologist. Carnegie Institution of Washington, Publication 609, Washington, D.C.

Singer, M. J., and P. Fine

1989 Pedogenic Factors Affecting Magnetic Susceptibility of Northern California Soils. Soil Science Society of America Journal 53:1119-1127. 


\section{Soil Survey Staff}

1975 Soil Taxonomy: A Basic System of Classification for Making and Interpreting Soil Surveys. Agricultural Handbook No. 436, Soil Conservation Service, U.S. Department of Agriculture. U.S. Government Printing Office, Washington, D.C.

1993 Soil Survey Manual. U.S. Department of Agriculture Handbook No. 18. Government Printing Office, Washington, D.C.

Stein, J. K.

1992 Organic Matter in Archaeological Contexts. In Soils in Archaeology: Landscape Evolution and Human Occupation, edited by V. T. Holliday, pp. 193-216. Smithsonian Institution Press, Washington, D.C.

Story, D. A.

1990 Culture History of the Native Americans. In The Archeology and Bioarcheology of the Gulf Coastal Plain: Vol. 1, edited by D. A. Story, J. A. Guy, B. A. Burnett, M. Doty Freeman, J. C. Rose, D. G. Steele, B. W. Olive, and K. J. Reinhard, pp. 163-366. Research Series No. 38. Arkansas Archeological Survey, Fayetteville.

Stuvier, M., and P. J. Reimer

1993 Extended ${ }^{14} \mathrm{C}$ Database and Revised CALIB Radiocarbon Calibration Program. Radiocarbon 35:215-230.

Texas Parks and Wildlife Department (TPW)

2002 State Parks and Historic Sites Huntsville State Park. <http://www.tpwd.state.tx.us/park/huntsvil/> Accessed May 2002.

Ward, C. G., and L. McNatt

1996 State of Texas Archeological Site Data Form for 41WA47. Unpublished document on file at the Center for Archaeological Research, The University of Texas at San Antonio.

Waters, M. R.

1992 Principles of Geoarchaeology: A North American Perspective. The University of Arizona Press, Tucson.

Weinstein, R. A.

1986 Tchefuncte Occupation in the Lower Mississippi Delta and Adjacent Coastal Zone. In The Tchula Period in the Mid-South and Lower Mississippi Valley: Proceedings of the 1982 Mid-South Archaeological Conference, edited by D. H. Dye and R. C. Brister, pp. 102-127. Archaeological Report No. 17. Mississippi Department of Archives and History, Jackson.

Weinstein, R. A., T. H. G. Hahn III, M. S. Henson, D. B. Kelley, and J. P. Whelan, Jr. 1989 Archeological Testing and Mitigation at Cedar Hill Park, Wallisville Lake Project, Chambers County, Texas. Coastal Environments, Inc., Baton Rouge.

Wyckoff, D. G.

1984 The Foragers: Eastern Oklahoma. In Prehistory of Oklahoma, edited by R. E. Bell, pp. 119-160. Academic Press, New York. 



\section{Appendix A}

\section{Plant Remains from 41WA47}

by

\section{J. Philip Dering}

\section{Center for Ecological Archaeology}

Texas A\&M University 


\section{Appendix A: $\quad$ Plant Remains from 41WA47}

\section{J. Philip Dering}

The purpose of this study is to describe macrobotanical remains from site 41WA47, located in Hunstville State Park. To this end, the Center for Archaeological Research (CAR) at The University of Texas at San Antonio submitted nine flotation samples and three macrobotanical (charcoal) samples to the Archaeobotanical Laboratory at the Center for Ecological Archaeology, Texas A\&M University, for analysis. This appendix presents the results of the botanical analysis of these samples. The data will contribute information regarding local environment and land use practices at the site.

The archaeobotanical analysis will address three specific research questions pertinent to regional subsistence and the recovery of subsistence remains from sites in the study area. These questions have been formulated to assess the nature of the archaeobotanical record at the site, and to address issues of land use during the period the site was occupied.

1) What is the frequency and abundance of the primary plant resources in the flotation samples?

2) How do the data reflect the importance of these plant resources in regional subsistence?

3) What do the data tell us about local vegetation in the region?

\section{Methods}

\section{Samples}

Standard archaeobotanical laboratory protocol was followed for the botanical analysis of the flotation and screen samples. Flotation samples consist of archaeological sediments that have been floated in water to separate lighter charred plant remains from heavier material, or clays/silts that can be suspended in water and rinsed out of the sample. The samples were floated by personnel from CAR, and the light and heavy fractions were submitted to Phil Dering for analysis. In addition, some macroplant samples, labeled as screen samples, were submitted for identification. Screen samples often included plant material collected from archaeological screens, recovered in situ during excavation, or picked from sieve screens during laboratory analysis. For the sake of simplification, all of these have been subsumed under the single term "macroplant sample."

Due to the poor preservation encountered at most open sites, only carbonized plant remains were considered for inclusion in the archaeological assemblage. Some uncarbonized plant material was noted in order to aid in understanding the post-depositional formation processes occurring at the site. Uncarbonized material was not included in any counts of macrobotanical remains.

\section{Sorting and Identification}

The analysis followed standard archaeobotanical laboratory procedures. Each flotation sample is passed through a set of nested screens of $4 \mathrm{~mm}, 2 \mathrm{~mm}$, and 0.450 $\mathrm{mm}$ mesh and examined for charred material, separated for identification. Charred wood caught on the $4 \mathrm{~mm}$ and $2 \mathrm{~mm}$ mesh screens is separated for weighing, counting, and identification. The carbonized macrobotanical (charcoal) samples collected from excavation screens were sorted and identified. Identification of carbonized wood was accomplished by using the snap technique, examining them at 8 to 45 magnifications with a hand lens or a binocular dissecting microscope, and comparing them to samples in the archaeobotanical herbarium. All seed identifications were made using seed manuals and reference collections at Texas A\&M University.

\section{Taxonomic Categories}

Identification of seed or nut fragments is usually taken to the genus level, however, the anatomy of some woods is so similar that it is very difficult to identify a sample to the genus level. In other cases, genera within a plant family are usually distinguishable, but some of the archaeological material is often too fragmented or 
deteriorated to allow identification to the genus level. For these reasons, some taxa are combined into wood types. All identifications in the "type" category represent identifications to the taxon level indicated by the name of the type. In the current report two wood types are used, Willow/Cottonwood and Indeterminate Hardwood. The Willow/Cottonwood (Salicaceae) type, as the name implies, includes both willow and cottonwood, woods which are difficult to distinguish when carbonized and broken into small fragments. The Indeterminate Hardwood type refers to any woody seed-bearing plant; not a cone-bearing tree such as pine, cypress, or juniper.

\section{Results}

Results of the analysis are presented in Tables A-1 and A-2. The nine flotation samples contained hickory nut, oak wood, and willow/cottonwood charcoal. The three macrobotanical (charcoal) samples contained willow/ cottonwood charcoal, hickory nut fragments, and burned bone. No evidence of cultivated plants was recovered.

The plant assemblage from flotation and macrobotanical samples was relatively small both in terms of quantity and in terms of species abundance. The plant assemblage consists of 66 nut fragments weighing 1.1 grams and 17 wood charcoal fragments weighing 0.8 grams. The three woody taxa identified in the samples are oak, willow/ cottonwood, and indeterminate hardwood. Hickory nut was the only seed or nut taxon noted in the samples. In addition to the plant materials, three bone fragments were noted in the samples.

Hickory nut fragments are by far the most commonly occurring of all plant resources at most archaeological sites in eastern Texas. Throughout the oak-hickory forests of southeastern North America, Native Americans utilized forest mast for rendering vegetable oil. Although the abundance of nut fragments in the 41WA47 samples suggests that nut processing was an important activity at the site, these remains are admittedly often overrepresented in the botanical assemblage. Nut fragments are well-preserved at most archaeological sites because so much of the processing involves fire, which results in accidental charring. In addition, hickory nuts are thick, dense, and resistant to decay.
Hickory nuts must be collected and processed in large quantities in order to render a sufficient amount of oil. Often prior to temporary storage, hickory nuts were parched on hot coals to kill insect egg cases. Hickory nuts were pounded into fragments and boiled in water to dissolve the nut meat. The resulting oily mass was strained from the thick nut fragments. The discarded nut fragments, which do not disintegrate when they are boiled, were often recycled as a fuel, another reason why charred nut fragments are quite abundant at archaeological sites located within the oak-hickory forests (Munson et al. 1971:417; Talalay et al. 1984:352).

Oak and willow/cottonwood were used as structural materials. Oak was used for house posts at many sites in the Caddoan region (Dering 1999, 2000). Cheatham (1992) utilized oak and reeds in a reconstruction of a Caddoan house. Swanton (1942) provides detailed descriptions of Caddoan houses and storage facilities based on ethnohistoric accounts, but these accounts do not name the types of wood that were used for construction. Houses were cone-shaped and built on a series of "thigh thick" wooden poles around which reed mats were woven. Beds were composed of upright poles and were raised off the ground and covered with reed mats.

The wood type willow/cottonwood includes two trees with excellent structural qualities. Because it is not often possible to separate these two wood types and both taxa grow in the study area, they are both included in the ethnobotanical overview. Cottonwood and willow were both utilized for fuel, tools, upright poles, and roofing elements throughout their distribution (Bohrer 1962; Vestal 1952; Vestal and Schultes 1939). Although neither tree is mentioned in the ethnohistoric observations of the Caddo, the willow/cottonwood charcoal type has been identified at several Caddoan sites and was presumably often used as a structural material and as a fuel (Dering 1999, 2000). Its use as an element in house roofs, storage bins, and other structures is well-documented in southwestern North America (cf. Curtin 1949; Russell 1908). The inner bark of willow is an effective pain reliever and anti-inflammatory agent, and willow is also an excellent raw material for tools and furnishings (Moerman 1998:508). 
Table A-1. Flotation samples from 41WA47, Unit QQ49-2, N989-E1111

\begin{tabular}{|c|c|c|c|c|c|c|c|}
\hline Level & FS & Lot & Identification & Common Name & Part & Count & Weight (gm) \\
\hline \multirow[t]{2}{*}{255} & \multirow[t]{2}{*}{600} & \multirow[t]{2}{*}{190} & Salicaceae & Willow/Cottonwood & Wood & 3 & 0.2 \\
\hline & & & Indeterminate & & $\begin{array}{c}\text { Twig } \\
\text { w/pith }\end{array}$ & 1 & 0.1 \\
\hline \multirow[t]{2}{*}{257} & \multirow[t]{2}{*}{660} & \multirow[t]{2}{*}{191} & Carya sp. & Hickory & Nut & 2 & 0.1 \\
\hline & & & Indeterminate & & Wood & 2 & 0.1 \\
\hline 258 & 663 & 208 & Carya sp. & Hickory & Nut & 4 & 0.1 \\
\hline 261 & 711 & 192 & Carya sp. & Hickory & Nut & 10 & 0.1 \\
\hline \multirow[t]{2}{*}{263} & \multirow[t]{2}{*}{717} & \multirow[t]{2}{*}{189} & Carya sp. & Hickory & Nut & 11 & 0.1 \\
\hline & & & Indeterminate & & Wood & 3 & 0.1 \\
\hline \multirow[t]{2}{*}{265} & \multirow[t]{2}{*}{723} & \multirow[t]{2}{*}{193} & Quercus sp. & Oak & Wood & 5 & 0.1 \\
\hline & & & Carya sp. & Hickory & Nut & 8 & 0.1 \\
\hline 267 & 729 & 194 & Carya sp. & Hickory & Nut & 6 & 0.1 \\
\hline \multirow[t]{2}{*}{269} & \multirow[t]{2}{*}{771} & \multirow[t]{2}{*}{195} & Carya sp. & Hickory & Nut & 9 & 0.1 \\
\hline & & & Indeterminate & & Wood & 2 & 0.1 \\
\hline 271 & 777 & 196 & Carya sp. & Hickory & Nut & 2 & 0.1 \\
\hline
\end{tabular}

Table A-2. Macrobotanical (charcoal) samples from 41WA47, Unit QQ49-2, N989-E1111

\begin{tabular}{|c|c|c|c|c|c|c|c|}
\hline Level & FS & Lot & Identification & Common Name & Part & Count & Weight (gm) \\
\hline 255 & 600 & 190 & Indeterminate & & Burned bone & 3 & 0.4 \\
\cline { 4 - 7 } & & & Carya sp. & Hickory & Nut & 12 & 0.2 \\
\hline 257 & 660 & 191 & Carya sp. & Hickory & Nut & 2 & 0.1 \\
\cline { 4 - 7 } & & Salicaceae & Willow/Cottonwood & Wood & 1 & 0.1 \\
\hline 261 & 711 & 192 & Charcoal flecks & & & na. & na. \\
\hline
\end{tabular}

\section{Summary and Conclusions}

The plant assemblage from $41 \mathrm{WA} 47$ is composed of charred wood and nut fragments. The assemblage as a whole is small in quantity, totaling $1.9 \mathrm{~g}$, and limited in species abundance, with only three taxa represented. The botanical assemblage indicates an oak-hickory woodland similar to that encountered in the region today. Pine, however, is missing from the samples, suggesting that at the time of occupation it may have not grown in the vicinity of the site.
Wood fragments were recovered in relatively small quantities. Two types, willow/cottonwood and oak, were identified. These woods have multiple uses as fuel, as structural material, as material for fashioning tools, and as a medicine. In addition to wood, hickory nut fragments were recovered from eight of the nine flotation samples and two of the three macroplant samples. The presence of hickory nut fragments suggests that the site was utilized for nut processing. 


\section{References Cited}

Bohrer, V. L.

1962 Nature and Interpretation of Ethnobotanical Materials from Tonto National Monument. In Archeological Studies at Tonto National Monument, Arizona, edited by L. R. Caywood, pp. 79-114. Technical Series, vol. 2. Southwestern Monuments Association.

Cheatham, S.

1992 The Caddo House Reconstruction. Primitive Technology 1:22-23.

Curtin, L. S. M.

1949 By the Prophet of the Earth. San Vicente Foundation, Santa Fe.

Dering, P.

1999 Plant Remains from the Oak Hill Site, 41RK214. Submitted to PBS\&J Environmental. Manuscript on file at the Center for Ecological Archaeology, Texas A\&M University, College Station, Texas.

2000 Plant Remains from three Caddoan sites in Camp County, 41CP304 (Pilgrim Site), 41CP316, and 41CP71. Submitted to T. K. Perttula. Manuscript on file at the Center for Ecological Archaeology, Texas A\&M University, College Station, Texas.

Moerman, D. E.

1998 Native American Ethnobotany. Timber Press, Inc., Portland, Oregon.

Munson, P. J., P. W. Parmalee, and R. A. Yarnell

1971 Subsistence Ecology of Scovill, A Terminal Middle Woodland Village. American Antiquity 36(4):410-431.

Russell, F.

1908 The Pima Indians. Bureau of American Ethnology, Annual Report, 26. Washington, D.C.

Swanton, J. R.

1942 Source Material on the History and Ethnology of the Caddo Indians. Bureau of American Ethnology, Bulletin 132. Smithsonian Institution, Washington, D.C.

Talalay, L., D. R. Keller, and P. J. Munson,

1984 Hickory Nuts, Walnuts, Butternuts, and Hazelnuts: Observations and Experiments Relevant to Their Aboriginal Exploitation in Eastern North America. In Experiments and Observations on Aboriginal Wild Plant Food Utilization in Eastern North America, edited by P. J. Munson, pp. 338-359. Prehistory Research Series 6(2). Indiana Historical Society, Indianapolis, Indiana.

Vestal, P. A.

1952 Ethnobotany of the Ramah Navajo. Reports of the Ramah Project, Number 4. Papers of the Peabody Museum of American Archaeology and Ethnology, Volume XL, Harvard University. Cambridge, Massachusetts.

Vestal, P. A., and R. E. Schultes

1939 The Economic Botany of the Kiowa Indians. Botanical Museum of Harvard University. Cambridge, Massachusetts. 



\title{
Appendix B
}

\section{Scan of Phytoliths from 41WA47}

by

\author{
Susan C. Mulholland
}

Interdisciplinary Archaeology Studies

University of Minnesota, Duluth 


\title{
Appendix B: $\quad$ Scan of Phytoliths from 41WA47
}

\author{
Susan C. Mulholland
}

\section{Introduction}

Phytoliths, mineral deposits that form in and between plant cells, are botanical microfossils that can provide information not available from analysis of other types of fossil material (Rovner 1983). Although many other minerals may form deposits, this analysis has focused on opaline silica since it generally exhibits good preservation in sediments. In addition, relatively wellknown comparative collections of silica phytoliths are available. Known silica-rich families include the Gramineae (grasses), Cyperaceae (sedges), and Equisetaceae (horsetails). Other families vary in amount of silicification from rare (Labiatae-mint) to abundant (Ulmaceae-elm); even families with relatively abundant production often contain species with low to absent phytolith production (Piperno 1985, 1988). All plant parts may produce phytoliths: leaf, stem, and root as well as inflorescence. Most parts used by humans, therefore, have the potential to be recorded in sediments, although roots fluctuate greatly in amount of phytolith production.

Silica can be preserved under sediment conditions that destroy organic microfossils. Phytoliths tend to be deposited at the site of production (Dimbleby 1978:129; Rovner 1988:158). Deposition normally occurs through surface or near-surface decomposition of plants; thus phytoliths are incorporated directly into sediments. Fire or strong wind erosion, however, can and do expose phytoliths to wind transport. Phytoliths have been recorded in atmospheric dust (Folger et al. 1967; Twiss et al. 1969), indicating transport over considerable distances. The question of water transport has not yet been addressed.

Phytolith studies have been applied to various archaeological and paleoecological problems (Piperno 1988). Identification of crops in sediments has been attempted for maize (Bozarth 1993; Pearsall 1978; Piperno 1984), rice (Fujiwara 1982), and various Old World cereals (Helbaek 1961; Rosen 1987). The study of farming practices includes identification of field surfaces (Pearsall and Trimble 1984), canals (Turner and Harrison 1981), and use of irrigation (Rosen 1987). Food residues (charred organics on ceramics) also often contain phytoliths (Jones 1993; Thompson 1986; Thompson and Mulholland 1994).

Environmental reconstruction has also been attempted using phytoliths. Carbone (1977) interpreted past environments, mostly forests, by comparison to modern soil A horizons; Lewis $(1981,1987)$ and MacDonald (1974) investigated changing types of prairie from Paleoindian to recent times. Studies comparing phytolith and pollen data indicate that phytolith data complement those obtained from pollen grains; in some cases (i.e., grasslands), more information is available from phytoliths (Kurmann 1985). Pollen grains are much more diverse for forests (Piperno 1985), however, even in such environments phytoliths provide independent support for environmental interpretation (Bozarth 1992; SchreveBrinkman 1978).

Most phytolith research to date has focused on identification of the original plant source by particle morphology. The ultimate goal is to identify plant taxa in order to reconstruct plant use and/or vegetation at sites (Piperno 1988; Rovner 1988). Recently, chemical and physical techniques have been applied to obtain other types of information from phytoliths. Dating of occluded carbon was first accomplished on sediments from a river terrace in Ohio (Wilding 1967). The process started with $45 \mathrm{~kg}$ of sediment and yielded $0.75 \mathrm{~g}$ of carbon; the date obtained was $13,300 \pm 450$ BP. AMS dating has greatly reduced the amount of phytolith material needed (Mulholland and Prior 1993). Another application involves thermoluminescence dating of phytoliths from hearths in Ecuadorian sites (Rowlett and Pearsall 1993). Environmental reconstruction has made use of oxygen, hydrogen, and carbon stable isotope ratios for a direct indication of paleotemperature (Bombin and Muehlenbachs 1980; Fredlund 1993; Kelly et al. 1991). 


\section{Methods and Materials}

One sample from site 41WA47 in Huntsville State Park, Walker County, Texas was processed (Table B-1). The sample is from 150-160 cm below the modern surface and $70-80 \mathrm{~cm}$ below the basal solum. The project objective was to assess qualitative phytolith abundance and degree of preservation within the samples (quickscan). Identifiable phytoliths are those that can be identified to established phytolith types, usually a reflection of plant anatomical elements. Some types are identifiable to various plant taxa, such as grass silicacells (to family and subfamily). Others are not yet related to specific plant taxa. However, differences in amounts of phytolith types between samples can be interpreted in terms of patterns of plant or vegetation types. Comparative samples from natural or nonfeature proveniences are essential.

Table B-1. Provenience of Sediment Sample, 41WA47

$$
\begin{aligned}
& \text { \# Unit Level Other Provenience } \\
& 1 \text { QQ49-2 } 269 \quad \text { N989 E1111 }
\end{aligned}
$$

Separation of phytoliths from the sediment matrix is based on both particle size and specific gravity. Sands were removed by screening at 90 microns; clays were removed by settling for one hour (separation at 5-10 microns). Particles with a specific gravity between 2.3 and 1.5 were then extracted using a heavy liquid solution of zinc bromide and water. To increase phytolith recovery, the extraction step was repeated. Slides for light microscopic examination are prepared with Permount (index of refraction $=1.54$ ) and examined with a Zeiss Universal petrographic microscope equipped with a Nomarski Differential Interference Contrast (DIC) condenser system. The Nomarski DIC increases contrast in transparent particles, including phytoliths, by introducing a shadow effect.

The objective of the quick-scan study was to assess phytolith abundance and preservation. Quick-scan analysis provides qualitative information from a scan at $320 X$. Abundance is assessed on the amount of recognizable phytoliths seen in a haphazard scan of a slide: "abundant" refers to many phytoliths in good preservation; "frequent" is a significant amount of identifiable phytoliths; "common" is a lesser amount of phytoliths; "scattered" is identifiable phytoliths that are not very numerous; and "rare" is occasional phytoliths found in an otherwise empty slide. Basic analysis provides quantitative data on the phytolith assemblage -the types and relative percentages of phytoliths present in a sample. A count is made across the slide, with different types tabulated (see below for a description of types). Comparisons between samples are made on percentages of each type.

Interpretation of plant contributors usually relies on comparison of phytolith assemblages from the unknown samples to those from reference plant specimens. The relative amounts of various phytolith types is often the best indicator of plant contributor. In sediments, the likelihood of several (or numerous) plants mixing together complicates plant identification enormously. However, artifacts provide a restricted context that may represent one or a few plants and provide a simpler problem.

The use of phytolith assemblages (as opposed to unique shapes) requires extensive comparative material. Although it is not proven that phytolith shape is genetically controlled and therefore absolutely consistent in a taxon across environments, shape morphology at least intuitively appears more stable than type frequency. In addition, all quantitative data is subject to statistical variation, requiring information on error factors or confidence intervals. Therefore, it is doubly important to obtain comparative phytolith data from the regional vegetation.

\section{Phytolith Classification}

Classification of individual phytoliths is initially to shape type. Without a regional comparative collection, only some phytolith types can be confidently assigned to a plant taxon. However, differences in phytolith assemblages between closely spaced samples can be interpreted in terms of patterns of plant groups or vegetation types. The classification scheme is based on the type of cell that becomes silicified (Mulholland 1987; Mulholland and Rapp 1992). Table B-2 lists the most common types observed to date; most cannot be assigned to a specific plant taxon. Category 7, however, is definitely an indicator of grasses. Grasses contain 
Table B-2. Phytolith Categories (Mulholland and Rapp 1992)

1. Trichomes - Hairs and papillae. Spherical to ovoid with a conical top.

2. Stomata - Guard and/or subsidiary cells. The entire complex is ovoid in shape. Guard cells are shaped like a telephone receiver. Subsidiary cells are ovoid to trianguloid.

3. Bulliform cells - Enlarged thin-walled epidermal cells. Keystone shapes.

4. Epidermal groundmass cells - Unspecialized epidermal cells. Various thin rectangular box shapes with interlocking edges.

5. Rods - Fibers, sclereids, xylem cells, and other cylindrical shaped cells.

6. Rectangles/Squares - Large blocky cells. Cube to rectangular box. Thicker than groundmass cells or silicacells.

7. Silica-bodies - Phytoliths from specialized silica accumulating cells. Truncated to beveled pyramids, cones, rectangular boxes, and cylinders. At least one broad face (base) is present. Note that although silica-bodies are equated with short cells in botanical texts, some very long bodies are included here with the shorter ones. The long bodies are consistently silicified and resemble the other silica-bodies in surface texture (unlike groundmass cells that become silicified). For these reasons, the longer cells are included here.

specialized silica-cells that function to collect silica (Esau 1977:85), as well as other anatomical elements that may become silicified. Every grass species examined to date has phytoliths from grass silica cells; no other plant taxon produces phytoliths with these shapes. Distinctive silicabodies have been the subject of much taxonomic research (Brown 1984; Metcalfe 1960; Mulholland 1989; Twiss et al. 1969). This study uses general morphological subdivisions of grass silica-body types (Table B-3).

Grass silica-bodies exhibit both multiplicity and redundancy (Rovner 1971). Multiplicity is the production of many types by a taxon; redundancy is the occurrence of one type in many taxa. These factors complicate identification of grasses by phytoliths. Most efforts to correlate grass silica-bodies to grass taxa either focus on identification of certain important species by unique morphological characteristics (Pearsall 1978; Piperno 1984) or correlate general shape types to subfamilies and tribes (Brown 1984; Mulholland 1989; Twiss et al. 1969). The unique species identifiers are as yet few in number; correlations of more general shapes to grass subfamilies are more widely applicable, although not without exceptions (Mulholland 1989). While extensive studies of local taxa are necessary to verify hypotheses of phytolith patterns developed in other regions, analysis of sediments can be based on some general correlations.

Based on North American reference material (Mulholland 1989), grass silica-bodies are identified to Gramineae subfamilies as follows: sinuates and rectangles (Figure B-1a) indicate the tribes Poeae, Triticeae, Aveneae, and Phalarideae of the Pooideae; rondels (Figure B-1b) are found in most of the subfamilies, particularly from inflorescence material -although most abundant in the Pooideae, rondels cannot be used as indicators of these taxa without consideration of other subfamilies; saddles (Figure B-1c) indicate Chloridoideae, although they also occur in some species of the Arundinoideae (Ollendorf et al. 1988) and Pooideae (low amounts); and dumbbells (Figure B-1d) are produced by the Panicoideae, Aristideae (Arundinoideae), Chloridoideae, and Stipeae (Pooideae). Some tentative distinctions may be made between dumbbells from these taxa. Stipeae tend to produce dumbbells with tops smaller than the base; dumbbells with saddle-like tops are characteristic of the Chloridoideae. The Aristideae produce large quantities of dumbbells with long shafts. In the absence of these special types, dumbbells may generally be taken to indicate the Panicoideae. 
I. Body is a rectangular box to truncated or beveled pyramid; cross section of base approximately rectangular to square or other polygon (base may have lobes but general outline is a polygon); top is a flat to slightly concave or convex face or elevated ridge(s).

A. Nonlobate: sides of base lack definite lobes

1. Base has 3 sides

TRIANGLE

2. Base has 4 sides

RECTANGLE

3. Base has 5 sides

PENTAGON

B. Lobate: sides of base have definite lobes

1. Minimal base diameters approx. equal

CROSS

2. Minimal base diameters unequal

a. Bilobate: Maximum of 2 lobes per side

1. Shaft/lobe ratio $>2 / 3$

2. Shaft/lobe ratio $<2 / 3$

b. Polylobate: More than 2 lobes per side

1. Shaft/lobe ratio $>2 / 3$

2. Shaft/lobe ratio $<2 / 3$
SINUATE

DUMBBELL

SINUATE

DUMBBELL

II. Body is a short cylinder to truncated or beveled cone; cross section of base approximately oval to circular or other curved shape (base may have concave or flat segments but general outline is curved shape); top is a flat to slightly concave or convex face or elevated ridge(s).

A. Entire: edges of base all convex

RONDEL

B. Flattened: some edges of base straight

RONDEL

C. Indented: some edges of base concave

RONDEL

III. Body is saddle-like; cross section of top (or both top and base) has two opposite convex edges that flare outward from the face surface and two opposite lower edges that are usually concave; top is concave.
A. Tabular: top and base same size and shape
B. Plateau: top smaller than or different shape
C. Ridge: top is a ridge

SADDLE

SADDLE

SADDLE

Other phytolith types are generally not as well identified to specific plant taxa. Silicified bulliform cells are considered indicative of the Gramineae. The other phytolith types (nos. 1, 2, and 4-6 from Table B-2) may be produced by both grasses and other plant taxa (forbs, shrubs, and trees). Subdivisions of these types need to be identified based on morphological differences between taxa. Trichomes, in particular, are silicified in numerous taxa, exhibiting considerable morphological variation. A study of some North Dakota species indicates differences in size and shape of trichomes and trichome bases (Mulholland 1987). Piperno (1988) identifies some 

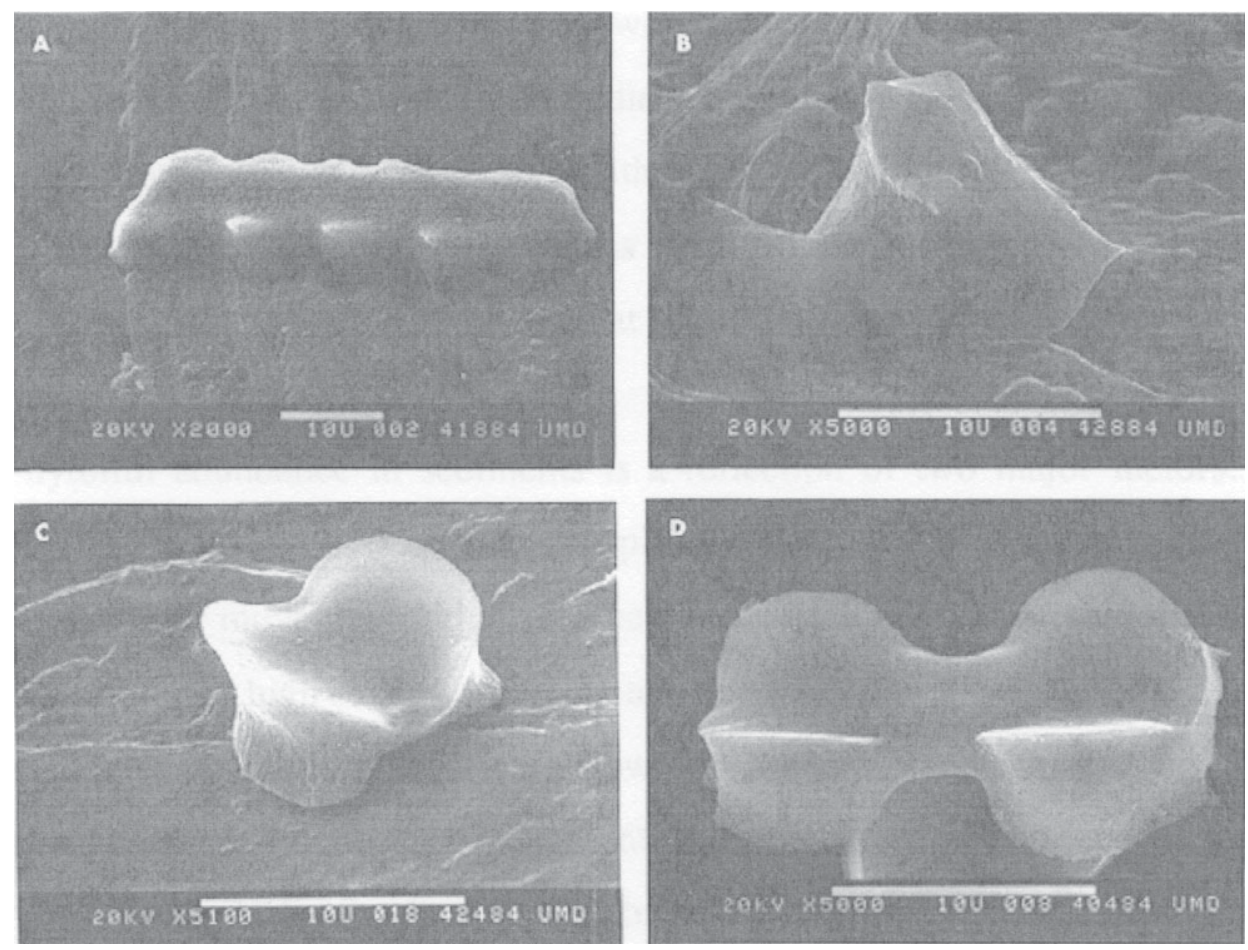

Figure B-1. Types of silica-bodies. a) sinuate, Phleum pratense; b) rondel, Dactylis glomerata; c) saddle, Bouteloua cultipendula; d) dumbbell, Panicum capillare. Bar is 10 micrometers.

shapes (trichomes and other types) that may be unique to particular species in tropical regions. Patterns of phytolith production in plant families (Piperno 1988:2137) provide information on possible contributors that must be checked against local reference material.

\section{Phytolith Abundance (Quick-Scan)}

The abundance of silica phytoliths was fairly high in the sample, with abundant silica-bodies seen in the scan. However, the bodies were mostly weathered to such a degree that no identification could be made as to phytolith type. One bulliform cell and a trichome were observed as well as a few rods. No grass silica-bodies were observed during the scan. In addition, black particles were present in great quantities throughout the slide. These probably are organic matter rather than minerals.

Phytolith abundance in sediments is a reflection of two major factors: 1) the amount of original phytolith deposition from decaying plant material; and 2) subsequent sedimentary processes that can degrade or move phytoliths. The relatively high amount of phytoliths observed in the sample indicates both high original plant content and lack of post-depositional degradation strong enough to remove phytoliths completely. However, the weathered nature of most of the phytoliths indicates that some post-depositional degradation has occurred. Postdepositional degradation is not unknown, particularly in sediments with basic $\mathrm{pH}$ conditions (Mason 1966) or sandy sediment texture. Given the acidic nature of this sediment (Russell Greaves, personal communication 2001), physical weathering within the sandy sediment column is the probable source (as opposed to chemical dissolution).

The high amount of black particles (unidentifiable to type) suggests some additional processes in the sediment formation. These particles may represent an accumulation of organics in the sediment layer, which is characterized as an illuviated layer showing extensive signs of mineral translocation. Given the probable illuvial nature of the layer, the origin of the phytoliths is also suspect. 


\section{Conclusions}

The sediment sample did not yield sufficient phytoliths for a basic scan and analysis. Only a few phytoliths were identifiable to type. Abundance of the phytoliths is generally good, more so than expected given the sandy nature of the sediments. No grass silica-bodies, which are unique to grasses, were observed. The only identifiable phytoliths are rods, trichomes, and a bulliform cell. However, grass silica-bodies are generally smaller than other types and may have become weathered (and unidentifiable) to a greater degree than non-grass types.

Intense post-depositional weathering is suggested to explain the phytolith condition. Weathered types are dominant in the sample. These are usually solid, amorphous bodies with extremely rough surfaces. Chemical processes, particularly $\mathrm{pH}$ values of 8 or higher, can affect phytoliths. Prolonged or intense exposure to high $\mathrm{pH}$ values often obscures the shape and surface texture of silica phytoliths. Mechanical breakage also occurs, most often in coarse (sandy) sediments.

Mechanical breakage and weathering is suggested as the cause of the weathered bodies in this sample. The sediment is reported to be acidic, which does not degrade phytoliths chemically. The sediment is a very fine sand to sandy loam, which is conducive to mechanical abrasion. In addition, the sediment is considered an illuvial layer with indications of mineral translocation (Russell Greaves, personal communication 2001). The sample was taken from the zone of maximum illuvial accumulation. The phytoliths could have translocated from higher layers and received mechanical abrasion during the process. Alternatively, the phytoliths could represent in situ decomposition of plant material and weathering in place.

Phytoliths are abundant in the sediment sample from 41WA47, more so than expected. However, severely weathered forms are the vast majority of the items observed. The extensive weathering, suggested as a result of mechanical abrasion in the sandy sediments, renders the phytolith assemblage insufficient for a basic count. It is unknown whether other layers with less indications of particle translocation contain a more intact assemblage. Given the unexpected amount of phytoliths additional examination of higher and/or less active layers may be warranted. 


\section{References Cited}

Bombin, M., and K. Muehlenbachs

1980 Potential of 18O/16O ratios in opaline plant silica as a continental paleoclimatic tool. Paper, American Quaternary Association, 6th Biennial Meeting. Abstracts and Program, pp. 43-44.

Bozarth, S. R.

1992 Classification of opal phytoliths formed in selected dicotyledons native to the Great Plains. In Phytolith Systematics: Emerging Issues, edited by G. Rapp, Jr. and S.C. Mulholland, pp. 193-214. Advances in Archaeological and Museum Science, volume 1, Plenum Press.

1993 Maize (Zea mays) cob phytoliths from a central Kansas Great Bend aspect archaeological site. Plains Anthropologist 38(6):279-286.

Brown, D. A.

1984 Prospects and limits of a phytolith key for grasses in the Central Plains. Journal of Archaeological Science 11:345-368.

Carbone, V. A.

1977 Phytoliths as Paleoecological Indicators. In Amerinds and Their Paleoenvironments in Northeastern North America, edited by W. Newman and B. Salwin, pp. 194-205. Annals of the New York Academy of Sciences, vol. 288.

Dimbleby, G.

1978 Plants and Archaeology. Humanities Press, Inc., Atlantic Highlands, New Jersey.

Esau, K.

1977 Anatomy of Seed Plants. Second edition, Wiley and Sons, New York.

Folger, D. W., L. H. Burckle, and B. C. Heezen

1967 Opal phytoliths in a North Atlantic dust fall. Science 155:1243-1244.

Fredlund, G.

1993 Paleoenvironmental interpretations of stable carbon, hydrogen, and oxygen isotopes from opal phytoliths, Eustis Ash Pit, Nebraska. In Current Research in Phytolith Analysis: Applications in Archaeology and Paleoecology, edited by D. M. Pearsall and D. R. Piperno, pp. 37-46. MASCA Research Papers in Science and Archaeology, Vol. 10.

Fujiwara, H.

1982 Detection of plant opals contained in pottery walls of the Jomon period in Kumamotu prefecture. Archaeology and Natural Science 4:55-66.

Helbaek, H.

1961 Studying the Diet of Ancient Man. Archaeology 14:95-101. 
Jones, J. G.

1993 Analysis of pollen and phytoliths in residue from a Colonial period ceramic vessel. In Current Research in Phytolith Analysis: Applications in Archaeology and Paleoecology, edited by D. M. Pearsall and D. R. Piperno, pp. 31-35. MASCA Research Papers in Science and Archaeology, Vol. 10.

Kelly, E. F., R. G. Amundson, B. D. Marino, and M. J. DeNiro

1991 Stable isotope ratios of carbon in phytoliths as a quantitative method of monitoring vegetation and climate change. Quaternary Research 35:222-233.

Kurmann, M. H.

1985 An opal phytolith and palynomorph study of extant and fossil soils in Kansas (U.S.A.). Palaeogeography, Palaeoclimatology, Palaeoecology 49:217-235.

Lewis, R. O.

1981 Use of Opal Phytoliths in Paleoenvironmental Reconstruction. Journal of Ethnobiology 1:175-181.

1987 Opal Phytolith Studies from the Horner Site, Wyoming, Appendix 5. In The Horner Site, edited by G. C. Frison and L. C. Todd, pp. 451-459. Academic Press.

MacDonald, L. L.

1974 Opal Phytoliths as Indicators of Plant Succession in North-Central Wyoming. M.S. thesis, University of Wyoming.

Mason, B.

1966 Principles of Geochemistry. Third edition, Wiley and Sons, New York.

Metcalfe, C. R.

1960 Anatomy of the Monocotyledons. I: Gramineae. Clarendon Press, Oxford.

Mulholland, S. C.

1987 Phytolith Studies at Big Hidatsa, North Dakota. Ph.D. dissertation, University of Minnesota.

1989 Phytolith shape frequencies in North Dakota grasses: A comparison to general patterns. Journal of Archaeological Science 16:489-511.

Mulholland, S. C., and C. Prior

1993 AMS radiocarbon dating of phytoliths. In Current Research in Phytolith Analysis: Applications in Archaeology and Paleoecology, edited by D. M. Pearsall and D. R. Piperno, pp. 21-23. MASCA Research Papers in Science and Archaeology, Vol. 10.

Mulholland, S. C., and G. Rapp, Jr.

1992 A morphological classification of grass silica-bodies. In Phytolith Systematics: Emerging Issues, edited by G. Rapp, Jr. and S. C. Mulholland, pp. 65-89. Advances in Archaeological and Museum Science, vol. 1, Plenum Press.

Ollendorf, A. L., S. C. Mulholland, and G. Rapp, Jr.

1988 Phytolith analysis as a means of plant identification: Arundo donax and Phragmites communis. Annals of Botany 61:209-214. 
Pearsall, D. M.

1978 Phytolith analysis of archaeological soils: Evidence for maize cultivation in Formative Ecuador. Science 199:177-178.

Pearsall, D. M., and M. K. Trimble

1984 Identifying past agricultural activity through soil phytolith analysis: A case study from the Hawaiian Islands. Journal of Archaeological Science 11:119-133.

Piperno, D. R.

1984 A comparison and differentiation of phytoliths from maize and wild grasses: Use of morphological criteria. American Antiquity 49:361-383.

1985 Phytolith analysis and tropical paleoecology: Production and taxonomic significance of siliceous forms in New World plant domesticates and wild species. Review of Palaeobotany and Palynology 45:185-228.

1988 Phytolith Analysis: An Archaeological and Geological Perspective. Academic Press, New York.

Rosen, A. M.

1987 Phytolith studies at Shiqmim. In Shiqmim I, edited by T. E. Levy, pp. 243-249. BAR International Series 356.

Rovner, I.

1971 Potential of opal phytoliths for use in paleoecological reconstruction. Quaternary Research 1:343-359.

1983 Plant opal phytolith analysis: Major advances in archaeobotanical research. In Advances in Archaeological Method and Theory, edited by M. Schiffer, vol. 6, pp. 225-266. Academic Press, New York.

1988 Macro- and micro-ecological reconstruction using plant opal phytolith data from archaeological sediments. Geoarchaeology 3:155-163.

Rowlett, R. M., and D. M. Pearsall

1993 Archaeological age determination derived from opal phytoliths by thermoluminescence. In Current Research in Phytolith Analysis: Applications in Archaeology and Paleoecology, edited by D. M. Pearsall and D. R. Piperno, pp. 25-29. MASCA Research Papers in Science and Archaeology, Vol. 10.

Schreve-Brinkman, E. J.

1978 A palynological study of the Upper Quaternary sequence in the El Abra Corridor and rock shelters (Colombia). Palaeogeography, Palaeoclimatology, Palaeoecology 25:1-109.

Thompson, R. G.

1986 The recovery of opal phytoliths from ceramics and Plains anthropological studies. Paper, 44th Annual Plains Conference, Nov. 19-23, Lincoln, Nebraska. Program and Abstracts, p. 58.

Thompson, R. G., and S. C. Mulholland, S.C.

1994 Identification of corn in food residues on utilized ceramics at the Shea site (32CS101). Phytolitharien Newsletter 8(2):7-11.

Turner, B. L., III, and P. D. Harrison

1981 Prehistoric raised-field agriculture in the Maya lowlands. Science 213:299-405. 
Twiss, P. C., E. Suess, and R. M. Smith

1969 Morphological classification of grass phytoliths. Soil Science Society of America Proceedings 33:109115 .

Wilding, L. P.

1967 Radiocarbon Dating of Biogenetic Opal. Science 156:66-67. 



\title{
Appendix C
}

\section{Vertebrate Faunal Remains}

by

\author{
Barbara A. Meissner
}




\title{
Appendix C: $\quad$ Vertebrate Faunal Remains
}

\author{
Barbara A. Meissner
}

A total of 1,265 vertebrate faunal remains, weighing $475.41 \mathrm{~g}$, was recovered from two sites during the project. The bone was recovered by screening sediments through $0.64 \mathrm{~cm}(1 / 4 ")$ screens. All bone was washed in tap water and air-dried. The bone was identified to the most specific taxon possible using the comparative collection at CAR, as well as several reference texts (Cohen and Serjeantson 1996; Gilbert 1990; Hildebrand 1955; Olsen 1964). Identifications were conservative, however, otherwise unidentifiable, cow-sized bone that was machine-sawed was identified as Bos taurus. All bone was weighed. Evidence of exposure to heat was noted on all bone. Element, portion of element, evidence of immaturity, butcher marks, and pathologies were noted on bone identified to the order taxonomic level. When bone could be identified only to class (e.g., mammal, bird, etc.) an estimate of the size of the animal was made when possible.
After the analysis, the bone was bagged by unit and level Bone identified to at least the order taxonomic level was bagged separately and included in the unit-level bags with unidentified bone. With the exception of one bone, all bone was recovered from site 41WA47. A single bone of a deer-sized mammal (weighing $0.28 \mathrm{~g}$ ) was recovered from 41WA228. Table C-1 is a list of the count and weight of all bone by taxon from 41WA47. A complete provenienced list of all faunal data is listed in table form at the end of this appendix.

Much of the bone is in very fragmented condition, with the average bone weight only $0.37 \mathrm{~g}$. Only 33 bones (2.6\%) could be identified to the genus taxonomic level. Only three genera were identified, of which one, Bos, consisted entirely of machine saw-cut bone $(n=8)$. These eight bones were recovered within $20 \mathrm{~cm}$ of the modern ground surface and are twentieth-century in origin. A

Table C-1. Identified Taxa from 41WA47

\begin{tabular}{|c|c|c|c|}
\hline Taxa & Common Name & Count & Weight (g) \\
\hline Mammalia & Mammals & & \\
\hline Artiodactyla & Deer, sheep, goats & 22 & 91.60 \\
\hline Bos taurus & Cattle & 8 & 14.81 \\
\hline Lepus californicus & Blacktailed jackrabbit & 1 & 0.56 \\
\hline Odocoileus virginianus & White-tailed deer & 24 & 65.18 \\
\hline Rodentia & Rodents & 2 & 0.24 \\
\hline Mammal--large & Deer, sheep-sized & 197 & 173.29 \\
\hline Mammal--very large & Cattle, bison, horse-sized & 6 & 11.78 \\
\hline \multirow[t]{2}{*}{ Mammal } & Size indeterminate & 991 & 110.35 \\
\hline & \begin{tabular}{|r|} 
Total Mammals \\
\end{tabular} & 1,251 & 467.81 \\
\hline Aves & Birds & & \\
\hline Cathartidae & Vultures & 1 & 2.33 \\
\hline \multirow[t]{2}{*}{ Aves } & Size indeterminate & 10 & 4.40 \\
\hline & Total Birds & 11 & 6.73 \\
\hline Reptilia & Reptiles & & \\
\hline \multirow[t]{2}{*}{ Testudines } & Turtles & 2 & 0.59 \\
\hline & Total Reptiles & 2 & 0.59 \\
\hline & Overall Totals & 1,264 & 475.13 \\
\hline
\end{tabular}


single calcaneus of a blacktailed jackrabbit (Lepus californicus) was identified. All other identified bone was white-tailed deer (Odocoileus virginianus), representing at least two individuals.

Elements identified from white-tailed deer and bone identified as artiodactyl (excluding teeth) are listed in Table C-2, divided according to meat utility. Note that there are no ribs and only a few vertebrae identified. The majority of the elements are from bones that carry very small amounts of meat.

Evidence of exposure to heat can indicate whether bone was routinely thrown into the fire as a disposal method. Under normal cooking conditions bone may become smoke-stained or charred, but a long period of heating at high temperatures is needed to calcine bone, circumstances normally seen only when bone is deliberately burned (David 1990:75). A total of 449 bones in the collection (35.5 percent of the total) showed evidence of heat alteration (Table C-3).

The unit with the most burned bone was NN51-16, with 151 burned specimens from a total of 205 bones (see Table C-4). These burned bones were 33.6 percent of the total recovered burned bone. However, this unit is the known location of a modern fire pit feature (see Chapter 5, discussion of controlled excavation). It is not possible to separate modern burned bone from prehistoric burned bone, and indeed, it is likely that at least some of the burned bone from this unit was modern in origin.

\section{Discussion}

In addition to the identified deer, 22 bones were identified as Artiodactyla (Table C-1). Although they were too fragmentary to be certain, these are probably also whitetailed deer. Most, if not all, of the bone identified only as "Large Mammal" are also probably white-tailed deer. The overall impression, then, is that the meat diet of the prehistoric people inhabiting 41WA47 consisted almost entirely of deer, with a few birds (most of which were probably ducks) also utilized.

It is interesting that most of the artiodactyl elements identified are those that do not carry a great deal of meat. The bones of the thoracic spine and ribs are absent, and only three lumbar vertebrae and one scapula fragment were identified. This suggests one of three possibilities: 1) that only partial deer carcasses were brought to the site; 2 ) that most bones that carry large quantities of meat had been heavily processed, for instance for rendering bone grease, and that this processing left them “analytically absent" (Lyman and O'Brien 1987); or 3) that the units excavated in this project encountered only butchering refuse areas and did not encounter areas

Table C-2. Artiodactyl Elements Identified (excluding teeth)

\begin{tabular}{|c|c|c|}
\hline Element & Ct. & $\begin{array}{c}\% \text { of } \\
\text { Elements } \\
\text { Identified } \\
\end{array}$ \\
\hline \multicolumn{2}{|l|}{ High meat utility } & \multirow{3}{*}{$14.3 \%$} \\
\hline Lumbar vertebra & 3 & \\
\hline Scapula & 1 & \\
\hline \multicolumn{2}{|l|}{ Moderate meat utility } & \multirow{4}{*}{$21.4 \%$} \\
\hline Humerus & 1 & \\
\hline Tibia & 4 & \\
\hline Mandible & 1 & \\
\hline \multicolumn{2}{|l|}{ Low meat utility } & \multirow{4}{*}{$64.3 \%$} \\
\hline Metapodial & 7 & \\
\hline Carpal/Tarsal & 9 & \\
\hline Phalange & 2 & \\
\hline Total Identified Elements & 28 & \\
\hline
\end{tabular}

Table C-3. Burned Bone

\begin{tabular}{|c|c|c|}
\hline Degree of Heat Alteration & Ct. & $\%$ \\
\hline Smoke-stained & 2 & $0.4 \%$ \\
\hline Charred & 73 & $16.3 \%$ \\
\hline Partially calcined & 81 & $18.0 \%$ \\
\hline Calcined & 293 & $65.3 \%$ \\
\hline Total & 449 & $100.0 \%$ \\
\hline
\end{tabular}


where food remains were discarded. The first possibility seems the least likely, as white-tailed deer are small enough to carry intact some distance. The second possibility may have had some impact on the identifiability of the bone, however, if extensive processing of the bone for bone grease extraction was practiced, one would expect much more highly fragmented bone and fewer ends of long bones than was present (Vehik 1977). It is likely, therefore, that most of the bones recovered were from butchering discard areas.

Very little information about butchering practices could be gathered from this collection. It should be noted, however, that every long bone large enough to identify to the order taxonomic level showed evidence of having been broken while the bone was fresh. The deer humerus was both broken near the distal end and had a distinct impact scar. All of the metapodials had also apparently been broken. Thus, though for the most part the artiodactyl collection seems to reflect butchering discard, even these bones were processed to extract marrow.

No fish and only two fragments of small turtle shells were identified. Part of the reason for this apparent lack of riverine species may be attributed to the use of $1 / 4 "$ screens. Bones from small fish would be frequently lost in such circumstances. Meissner et al. (2001) noted that careful examination of the heavy fraction of floatation samples from a site near a creek in Bexar County (41BX126) resulted in the identification of 760 fish otoliths. A representative sample of 118 of these was identified as all belonging to small fish of the minnow family (Cyprinidae), which do not exceed two inches, even as adults (Meissner et al. 2001:202). Although only five fish vertebrae were identified in the matrix screened through 1/4" screens (Meissner et al. 2001:195-196), at least 380 much smaller fish were present. This may also have been the case at 41WA47. However, if the inhabitants of 41WA47 were utilizing riverine resources to any extent, one would expect at least more riverine turtle carapace fragments to have been recovered.

At least eight bones were machine sawed and are modern in origin. At least some of the burned bone may be modern in origin, as well. However, the fact that only eight bones could be attributed to domestic species suggests that the majority of the bone is prehistoric in age. In addition, all the long bones identified to at least the order taxonomic level were broken while the bone was fresh, strongly suggesting prehistoric marrow extraction practices. 


\section{References Cited}

Cohen, A., and D. Serjeantson

1996 A Manual for the Identification of Bird Bones from Archaeological Sites. Revised edition. Archetype Publications, London.

David, B.

1990 How was this bone burnt? In Problem Solving in Taphonomy, edited by S. Solomon, I. Davidson, and D. Watson, pp. 65-79. Tempus, St. Lucia, Queensland.

Gilbert, B. M.

1990 Mammalian Osteology. Missouri Archaeological Society, Columbia.

Hildebrand, M.

1955 Skeletal Differences Between Deer, Sheep, and Goats. California Fish and Game 41:327-346.

Lyman, R. L., and M. J. O'Brien

1987 Plow-Zone Zooarchaeology: Fragmentation and Identifiability. Journal of Archaeological Science 16:293317.

Meissner, B. A., D. A. Cargill, and D. L. Nickels

2001 Vertebrate Faunal Remains and Fish Otoliths. In Test Excavations at the Culebra Creek Site, 41BX126, Bexar County, Texas, by D. L. Nickels, C. B. Bousman, J. D. Leach, and D. A. Cargill, pp. 195-203. Archeology Studies Program Report No. 3, Environmental Affairs Division, Texas Department of Transportation and Archaeological Survey Report No. 265, Center for Archaeological Research, the University of Texas at San Antonio.

Olsen, S. J.

1964 Mammal Remains from Archaeological Sites Part I; Southeastern and Southwestern United States. Peabody Museum, Cambridge.

Vehik, S. C.

1977 Bone Fragments and Bone Grease Manufacturing: A Review of Their Archaeological Use and Potential. Plains Anthropologist 22:169-182. 


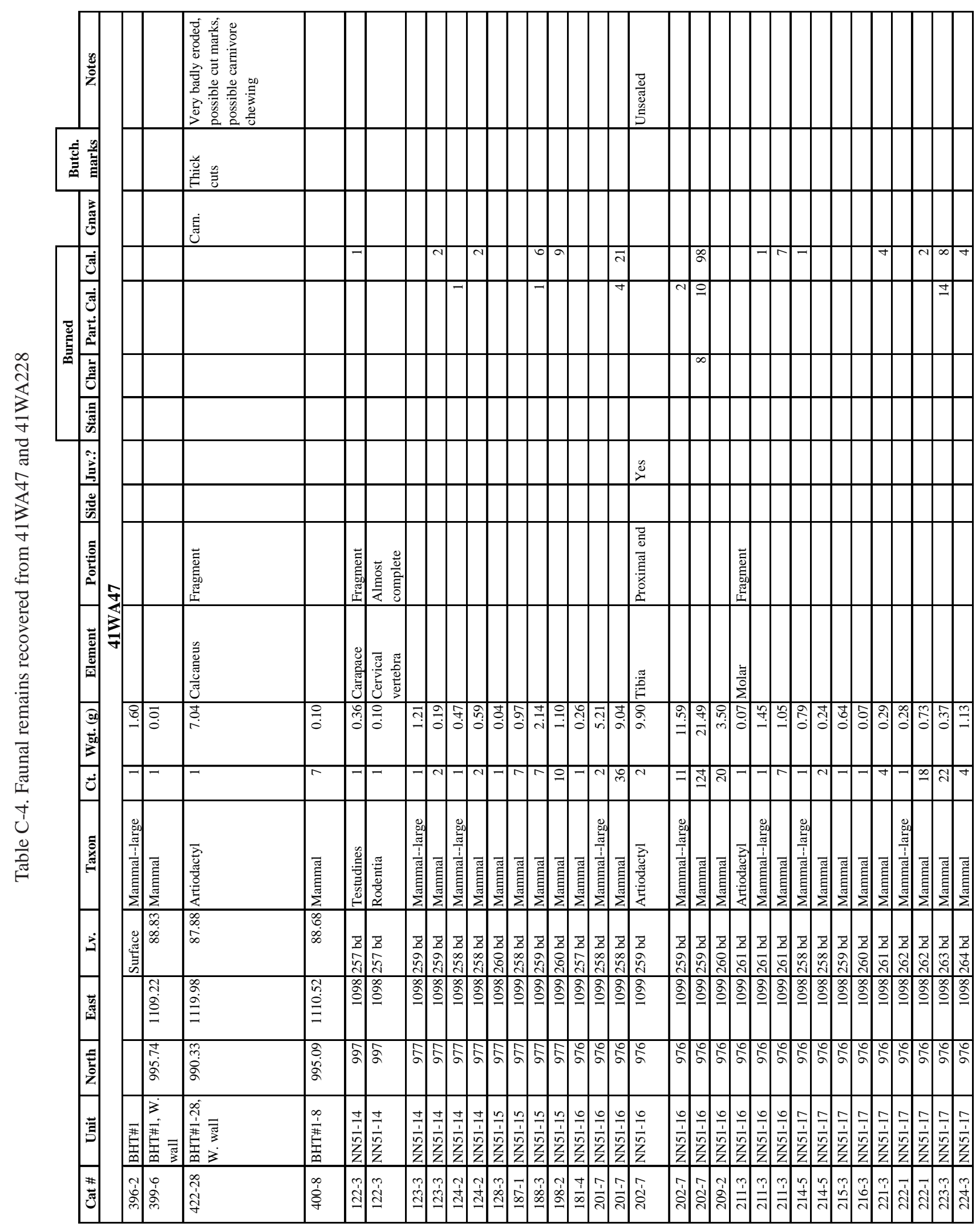




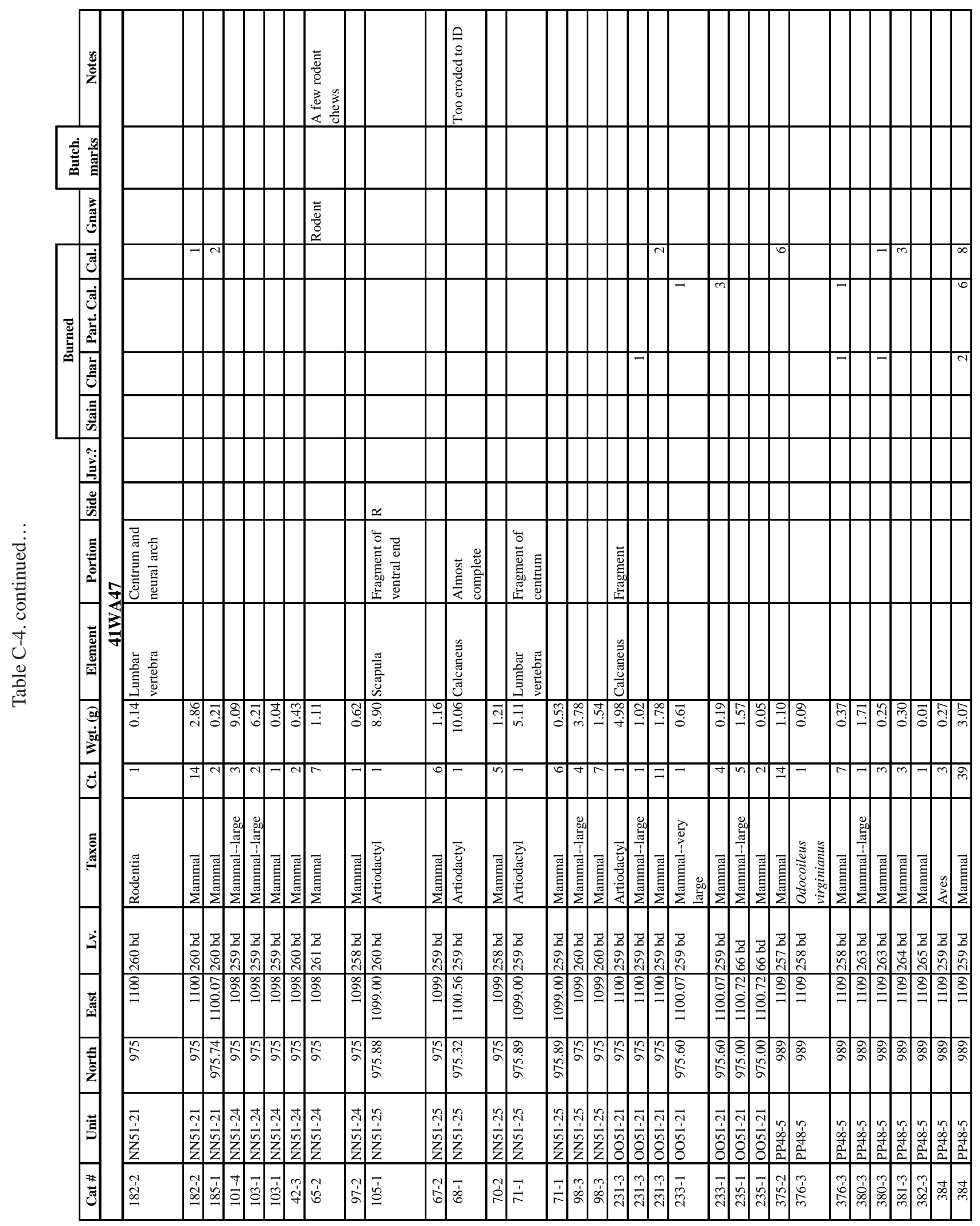




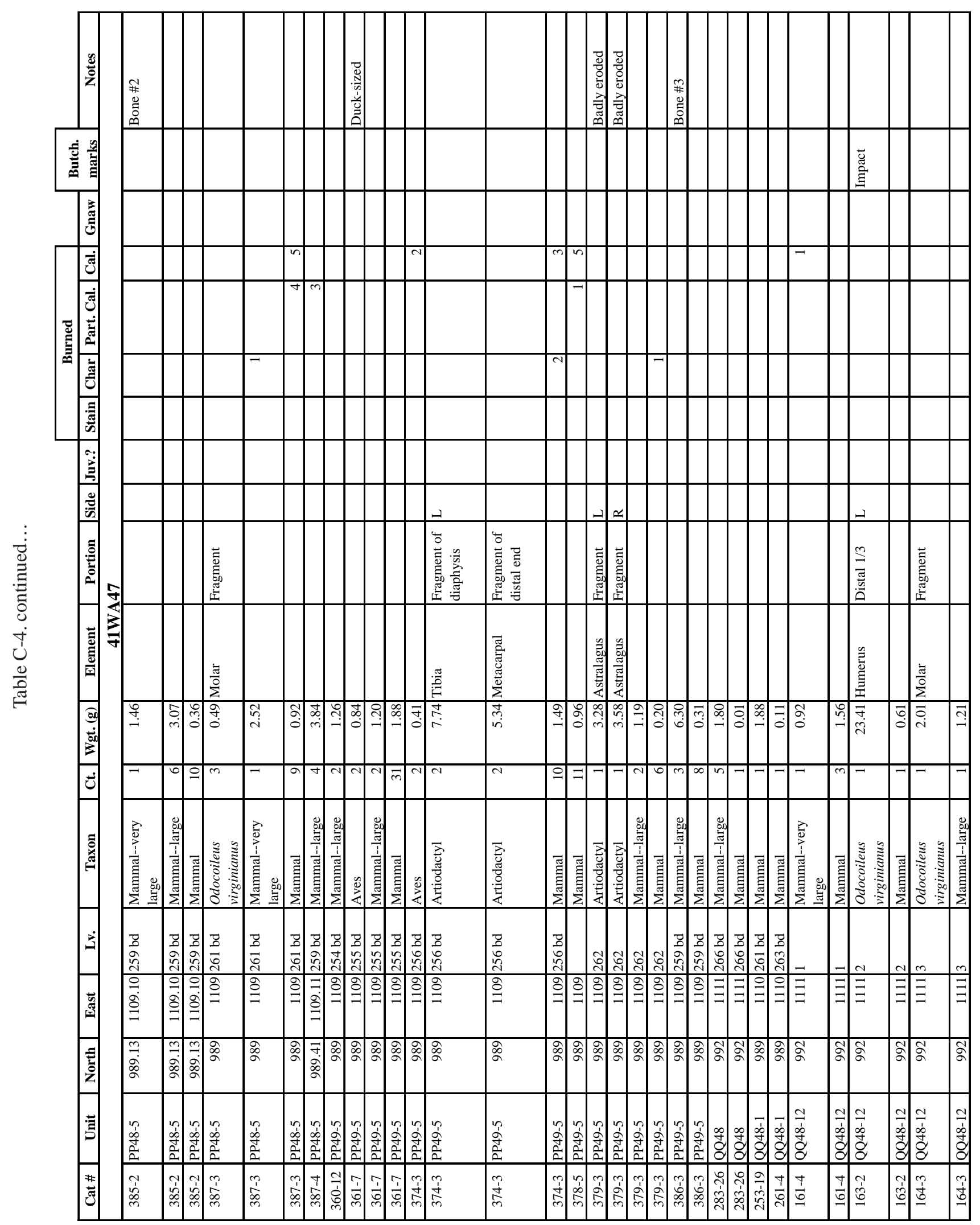




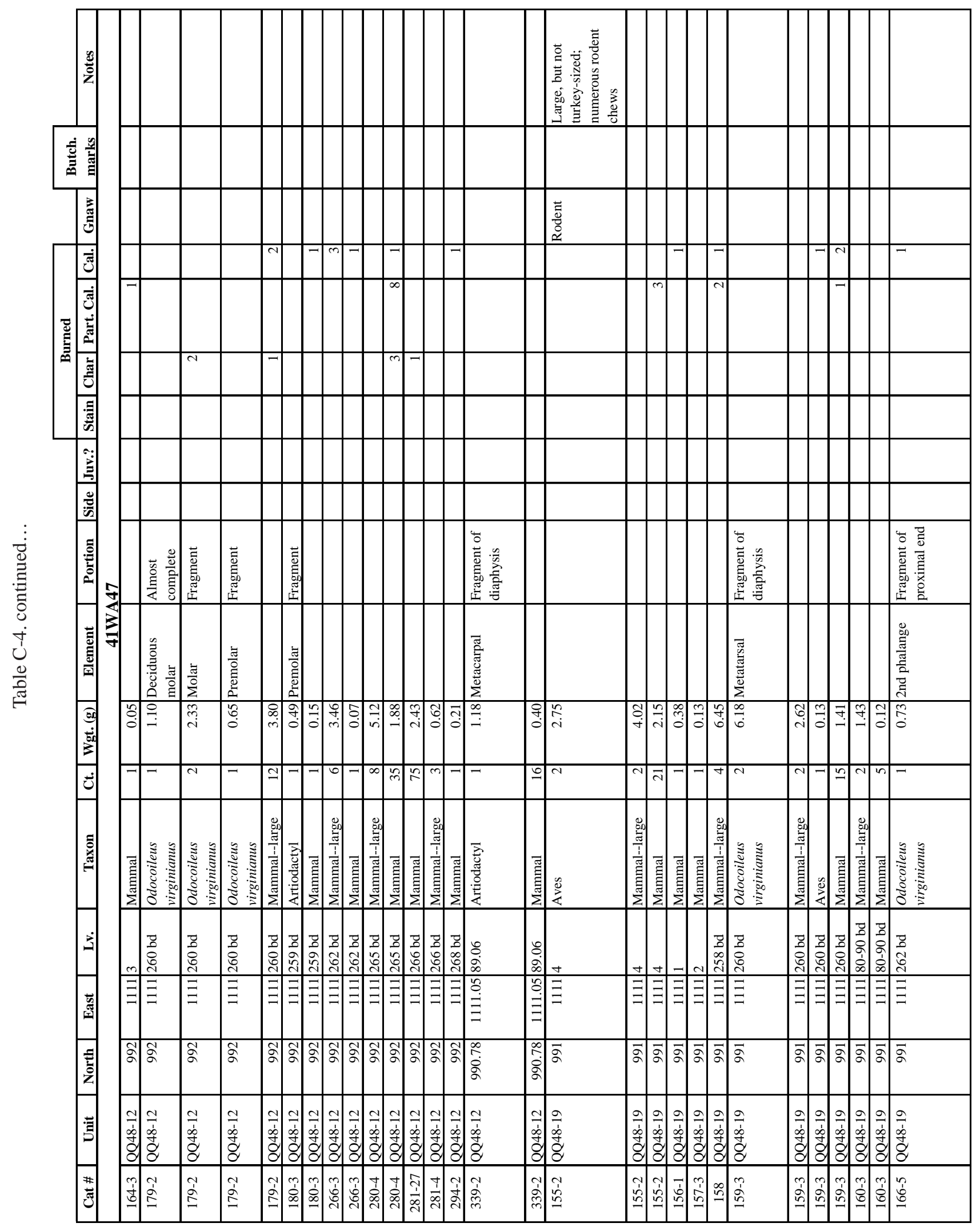




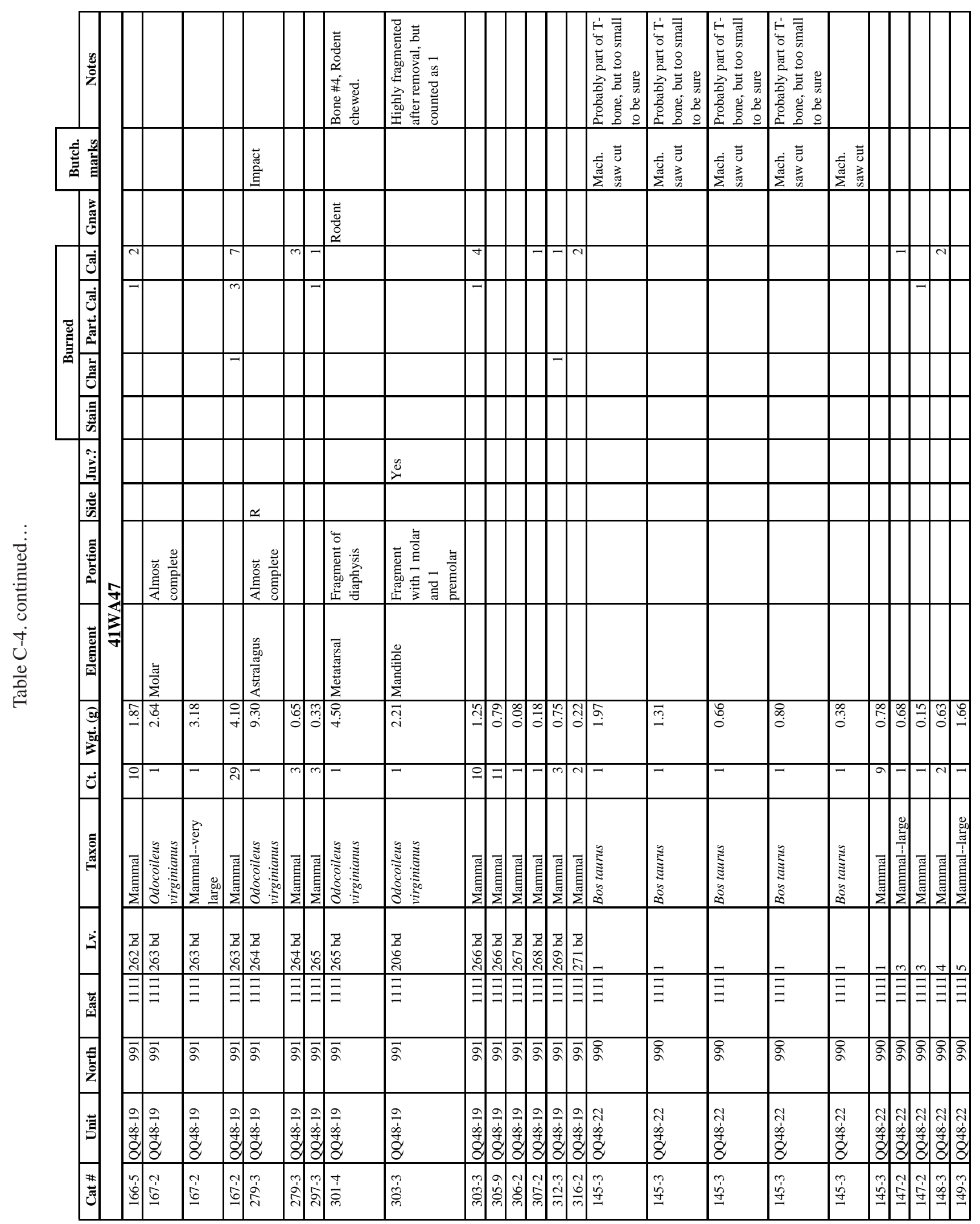




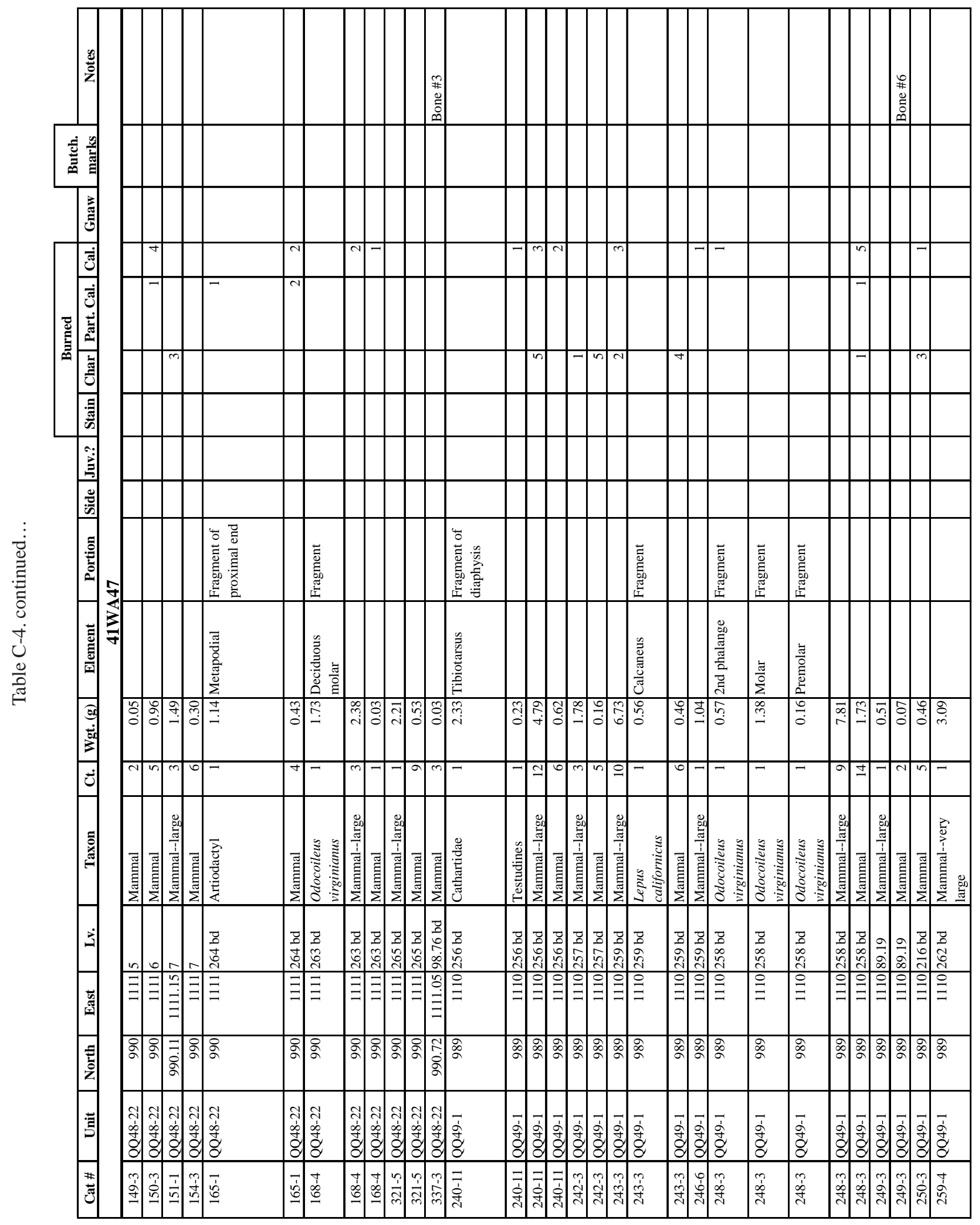




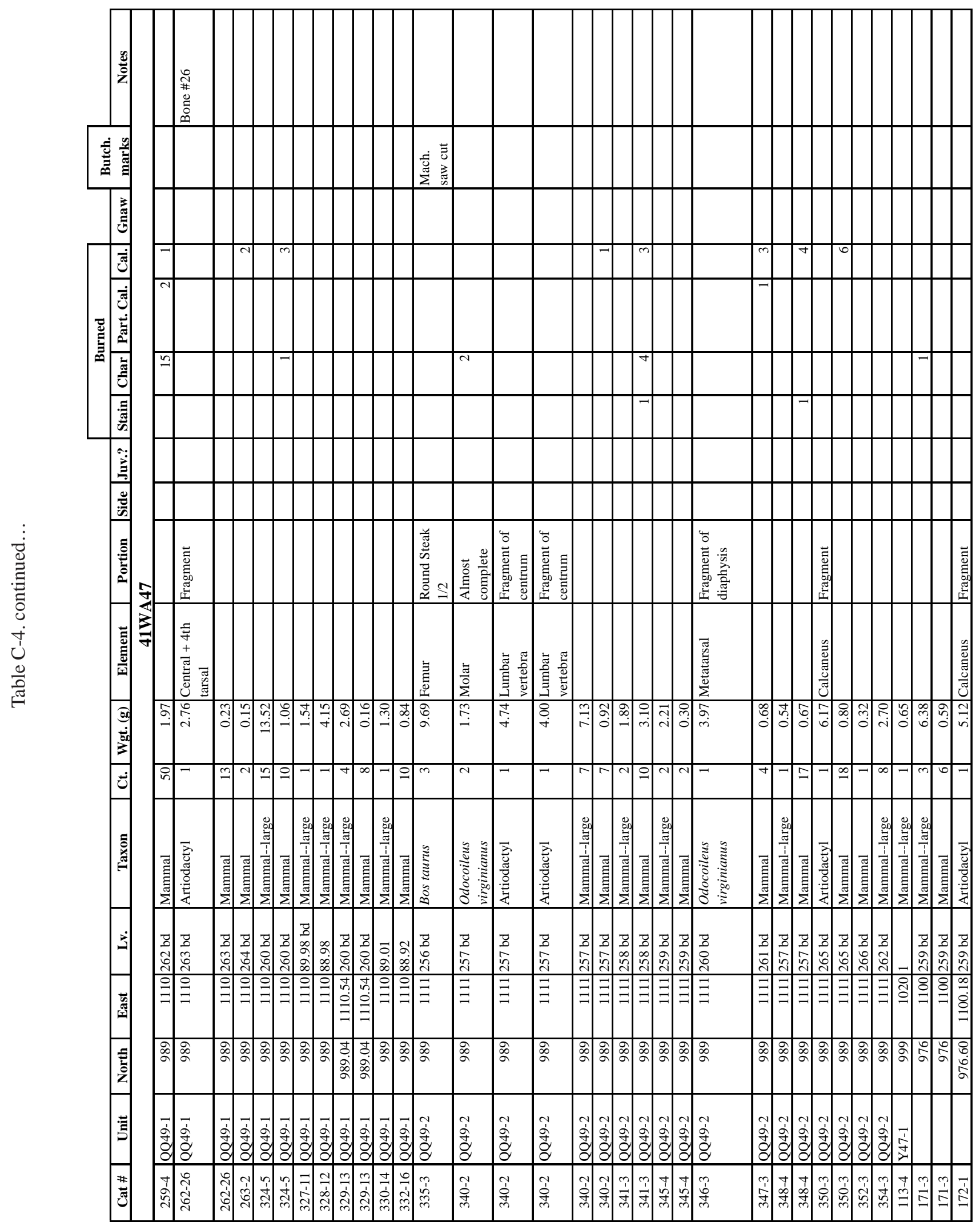




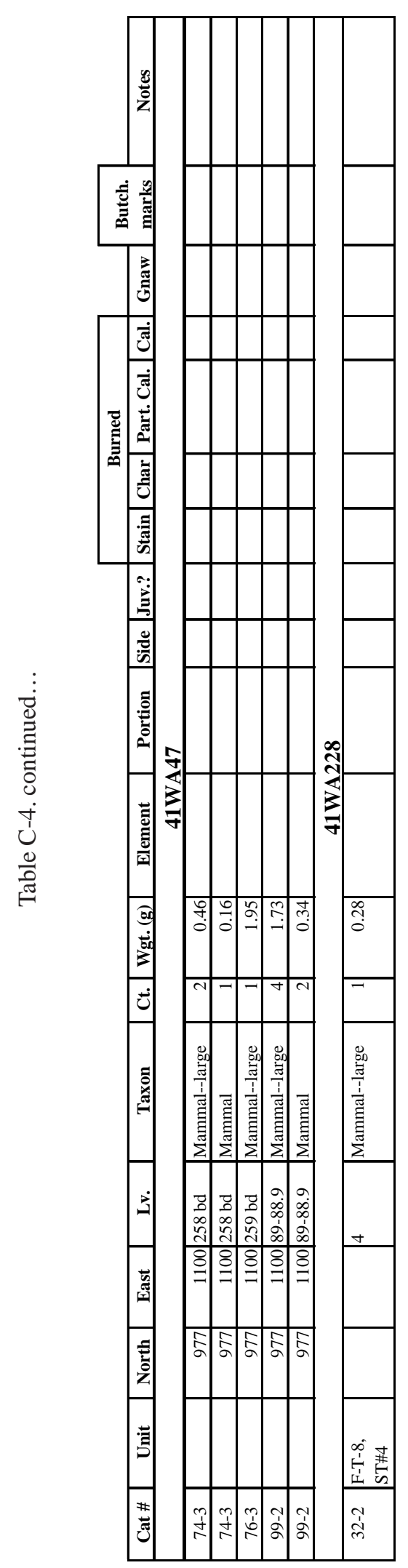





\section{Appendix D}

\section{Radiocarbon Laboratory Analysis}

by

Russell D. Greaves 


\title{
Appendix D: Radiocarbon Laboratory Analyses
}

\author{
Russell D. Greaves
}

\section{Sample Environment}

Six charcoal samples were submitted to Beta Analytic, Inc. for radiocarbon analysis. All samples are from controlled $1 \times 1-\mathrm{m}$ excavation units at site 41WA47 in Huntsville State Park, Walker County, Texas. All samples are from a group of adjacent excavation units (QQ48-49 or N989-992 E1111) and represent a sequence through the soil profile. All of the above samples are charcoal, collected by trowel, placed in aluminum foil inside of 4 mil polyethylene bags.

\section{Site 4IWA47}

Sample Beta 157965

QQ48-12-13

N992-E1111 Level $264(88.60-88.50 \mathrm{~m})$

Sample depth: $107 \mathrm{~cm}$ bgs* $(88.50 \mathrm{~m} * *)$

collected 7/1/01

This sample was collected from the lower portion of the $\mathrm{C} 1$ horizon. Compared with the provenience of sample QQ48-22\#1, this portion of $\mathrm{C} 1$ contains relatively robust illuvial clay lamellae. Relatively abundant cultural artifacts were collected from this excavation level.

\section{Site 41 WA47}

Sample Beta 157966

QQ48-12-24

N992-E1111 Level 266 (88.40-88.30 m)

Sample depth: $117 \mathrm{~cm}$ bgs $(88.40 \mathrm{~m})$

collected 7/1/01

This charcoal sample was collected from the upper portion of the $\mathrm{C} 2$ horizon. This horizon contains the most abundant and robust evidence of illuvial clay lamellae in this soil profile. Cultural artifacts were relatively abundant in this level, including one distal fragment of a Gary dart point.

\footnotetext{
$*=\mathrm{cm}$ below ground surface

$* *=\mathrm{m}$ in relation to arbitrary datum elevation of 100.00
}

\author{
Site 41WA47 \\ Sample Beta 157967 \\ QQ48-12-32 \\ N992-E1111 Level 266 (88.40-88.30 m) \\ Sample depth: $125 \mathrm{~cm}$ bgs $(88.32 \mathrm{~m})$ \\ collected $7 / 1 / 01$
}

This sample was collected from the middle of the $\mathrm{C} 2$ horizon, a massive-very weakly developed fine, wellsorted sand with abundant illuvial lamellae. As noted, artifacts were abundant in this excavation level.

\section{Site 41WA47 \\ Sample Beta 157968 \\ QQ48-19-8 \\ N991-E1111 Level 266 (88.40-88.30 m) \\ Sample depth: $118 \mathrm{~cm}$ bgs $(88.33 \mathrm{~m})$ \\ collected 7/2/01}

This sample comes from the middle of the $\mathrm{C} 2$ horizon. This unit is a massive-very weakly developed fine, wellsorted sand deposit. There are many robust, continuous illuvial clay lamellae in this sedimentary unit. These accumulations of illuvial clay contain very small amounts of total clay enrichment. Lamellae may be forming at the stratigraphic breaks within these massive sands that are difficult to identify without micromorphological examination of the sediments. Relatively abundant artifacts and bone were recovered from this excavation level.

\section{Site 41WA47}

\section{Sample Beta 157969}

QQ48-22-1 N990-E1111 Level 262 (88.80-88.70 m)

Sample depth: $74 \mathrm{~cm}$ bgs $(88.76 \mathrm{~m})$

collected 6/29/01

This sample was collected from the upper portion of the $\mathrm{C} 1$ horizon. This is a massive-weakly developed fine, well-sorted sand deposit. This portion of the $\mathrm{C} 1$ sediment contains few, discontinuous illuvial clay lamellae. Roots in this horizon are few, fine-medium. Root bioturbation 
of all of the $\mathrm{C}$ horizon deposits is minimal. Clear indications of krotovina or invertebrate bioturbation were not identified within the $\mathrm{C} 1-\mathrm{C} 3$ horizons. There is a moderate amount of cultural material in this excavation level and two complete projectile points (one was identified as a Dawson dart point) were piece-plotted at $102 \mathrm{~cm}$ bgs $(88.70 \mathrm{~m})$.

\section{Site 41WA47}

Sample Beta 157970

QQ49-1-10

N989-E1110 Level 260 (89.00-88.90 m)

Sample depth: $68 \mathrm{~cm}$ bgs $(88.96 \mathrm{~m})$

collected $7 / 4 / 01$

This sample is from a weakly developed $\mathrm{Bh}$ or $\mathrm{Bw}$ horizon at the base of the modern soil development. This is a fine, well-sorted sand with very few clasts. Roots in this horizon are few, fine-medium. There is minimalmoderate root bioturbation within this horizon. There are abundant cultural artifacts within this horizon. This sample comes from an excavation level that contained a complete Perdiz arrow point. 


\section{CALIBRATION OF RADIOCARBON AGE TO CALENDAR YEARS}

(V ariables: C $13 / \mathrm{C} 12=-24.8:$ lab. $\mathrm{mult}=1$ )

\section{Laboratory number: Beta-157965}

Conventional radiocarbon age: $1000 \pm 40 \mathrm{BP}$

2 Sigm a calibrated results: Cal AD 980 to 1060 (Cal BP 970 to 890) and (95\% probability) Cal AD 1080 to 1150 (Cal BP 860 to 800)

Intercept data

Intercept of radiocarbon age with calibration curve:

1 Sigma calibrated result: Cal AD 1000 to 1030 (Cal BP 950 to 920) (68\% probability)

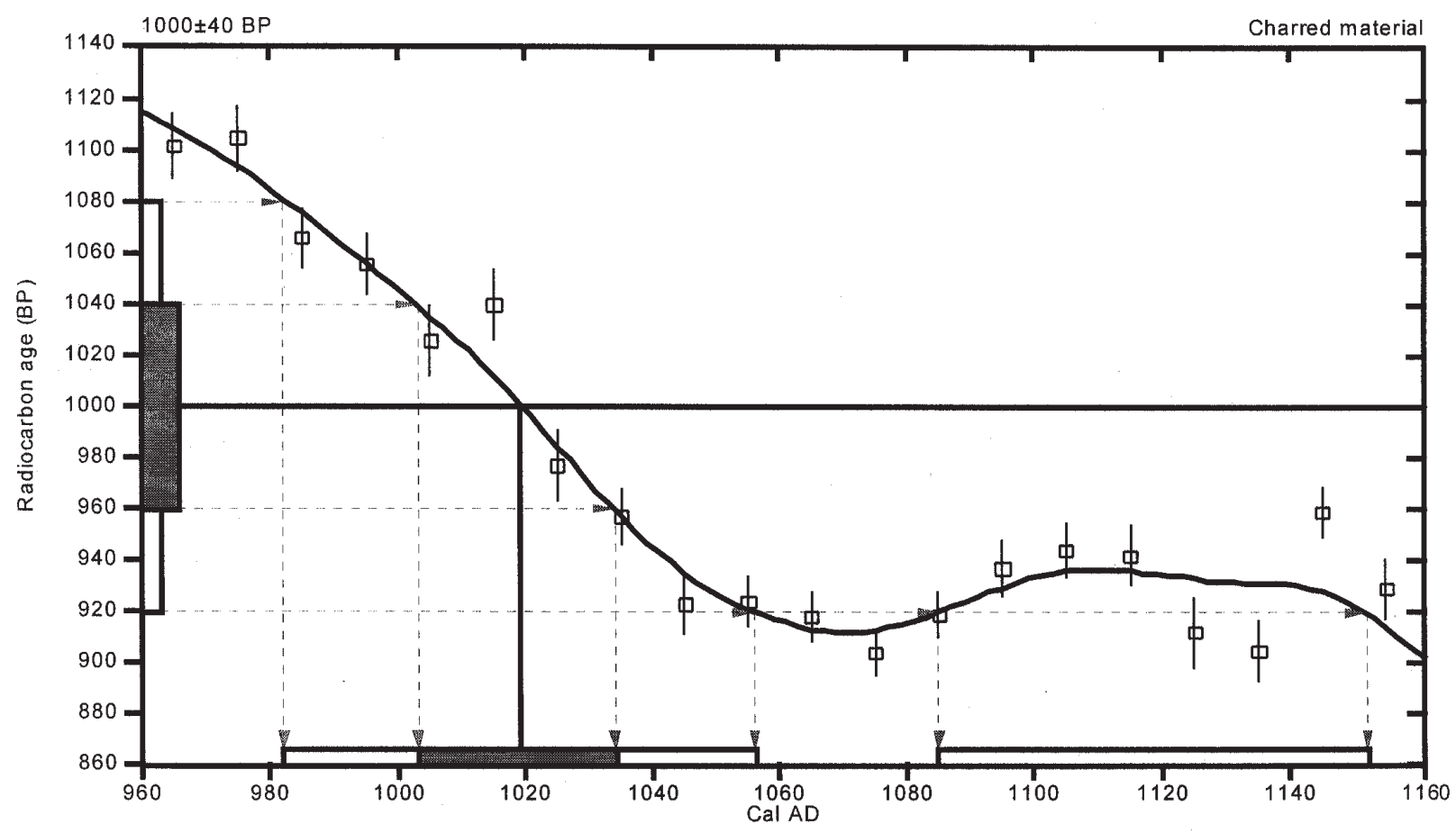

References:

Database used

Calibration Database

Editorial Comment

Stuiver, M., van der Plicht, H., 1998, Radiocarbon 40(3), pxii-xiii

INTCAL98 Radiocarbon Age Calibration

Stuiver, M., et. al., I998, Radiocarbon 40(3), p1041-1083

$M$ ath ematics

A Simplified Approach to Calibrating C14 Dates

Talma, A. S., Vogel, J. C., 1993, Radiocarbon 35(2), p317-322

\section{Beta Analytic Inc.}

4985 SW 74 Court, Miami, Florida 33155 USA Tel: (305) $6675167 \cdot$ Fax: (305) $6630964 \cdot$ E-Mail: beta@radiocarbon.com 


\section{CALIBRATION OF RADIOCARBON AGE TO CALENDAR YEARS}

\section{(Variables: $\mathrm{C} 13 / \mathrm{C} 12=-27.4$ :lab. $\mathrm{mult}=1$ )}

\section{Labo ratory number: Beta-157966}

\section{Conventional radiocarbon age: $1280 \pm 40 \mathrm{BP}$}

2 Sigm a calibrated results: Cal AD 660 to 810 (Cal BP 1280 to 1140) and ( $95 \%$ probability) Cal AD 840 to 860 (Cal BP 1110 to 1100)

Intercept data

Intercept of radiocarbon age with calibration curve:

1 Sigma calibrated result: Cal AD 680 to 780 (Cal BP 1270 to 1170 )

(68\% probability)

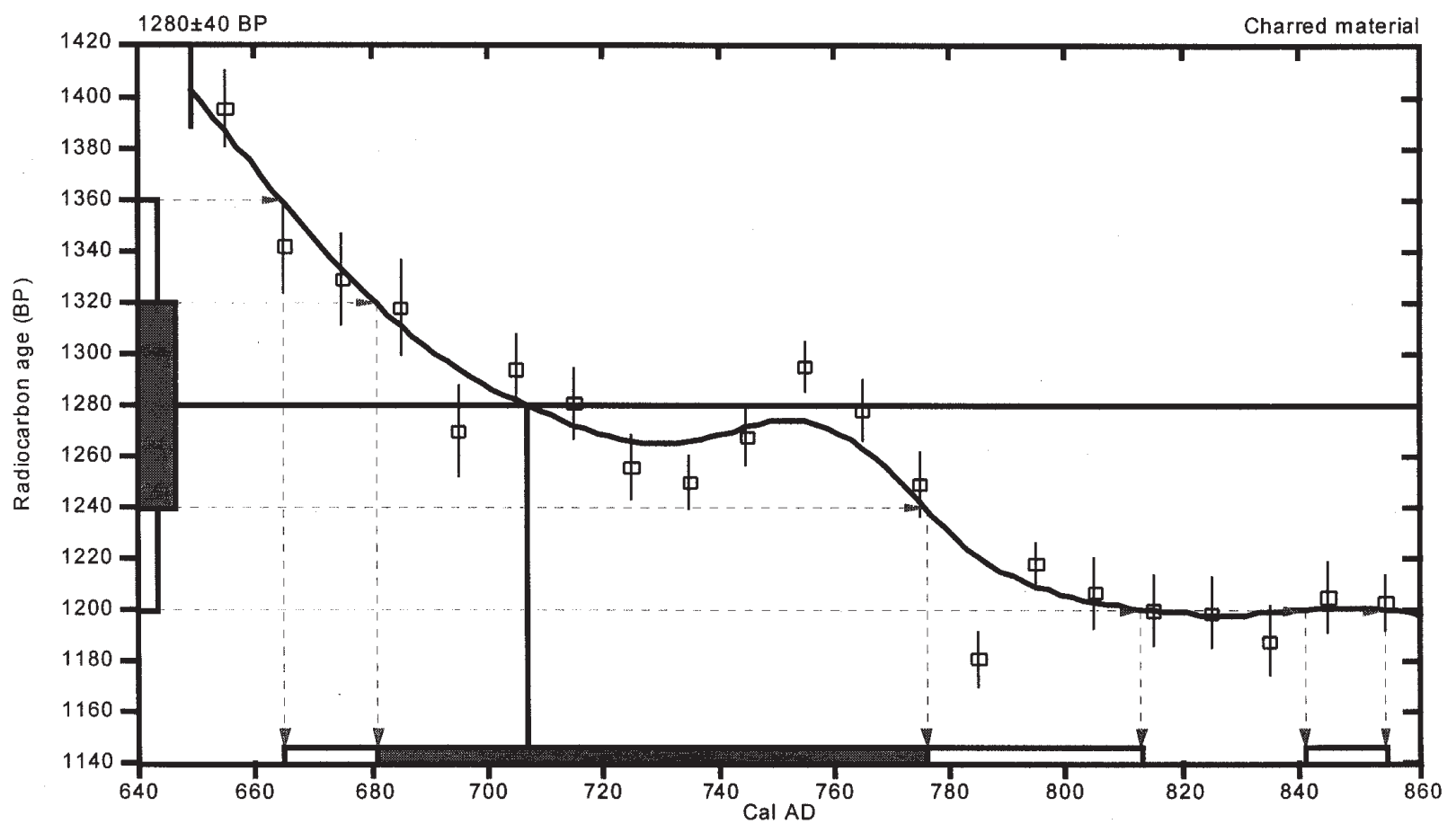

References:

Database used

Calibration Database

Editorial Comment

Stuiver, M., van der Plicht, $H_{\text {. }}$ 1998, Radiocarbon 40(3), pxii-xiii

INTCAL98 Radiocarbon Age Calibration

Stuiver, M., et. al., 1998, Radiocarbon 40(3), p1041-1083

$M$ ath ematics

A Simplified Approach to Calibrating C14 Dates

Talma, A. S., Vogel, J. C., 1993, Radiocarbon 35(2), p317-322

\section{Beta Analytic Inc.}

4985 SW 74 Court, Miami, Florida 33155 USA -Tel: (305) $6675167 \cdot$ Fax: (305)6630964·E-Mail: beta@radiocarbon.com 


\section{CALIBRATION OF RADIOCARBON AGE TO CALENDAR YEARS}

(V ariables: C13/C 12=-24.7:lab. $\mathrm{mult}=1$ )

Laboratory number: Beta-157967

Conventional radiocarbon age: $1900 \pm 40 \mathrm{BP}$

2 Sigm a calibrated result: Cal AD 30 to 220 (Cal BP 1920 to 1730) (95\% probability)

Intercept data

Intercept of radiocarbon age with calibration curve:

1 Sigma calibrated result: Cal AD 70 to 130 (Cal BP 1880 to 1820 )

(68\% probability)

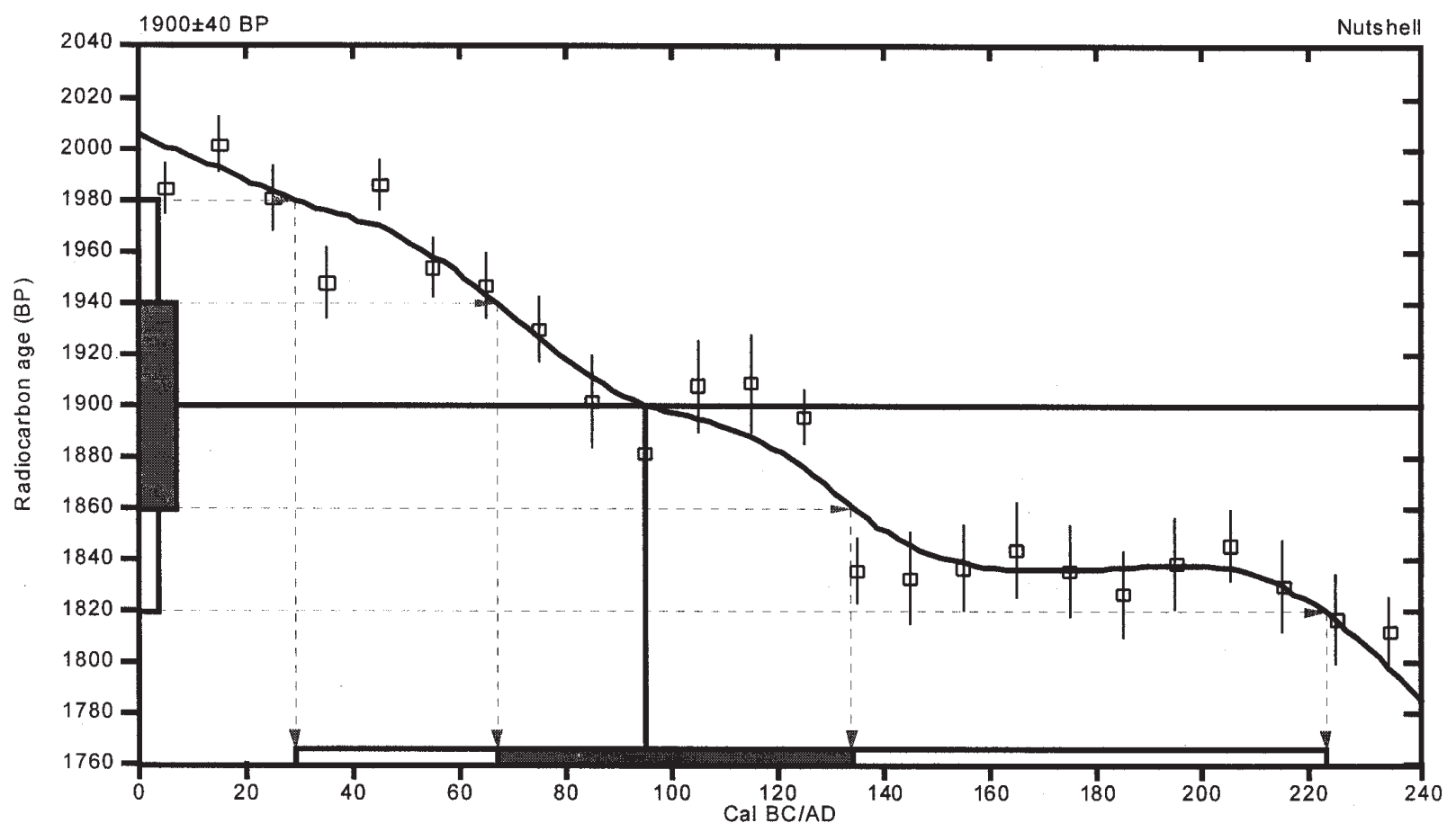

References:

Da tabase used

Calibration Database

Editorial Comment

Stuiver, M., van der Plicht, $H ., 1998$, Radiocarbon 40(3), pxii-xiii

INTCAL98 Radiocarbon Age Calibration

Stuiver, M., et. al., 1998, Radiocarbon 40(3), p1041-1083

Math ematics

A Simplified Approach to Calibrating C14 Dates

Talma, A. S., Vogel, J. C., 1993, Radiocarbon 35(2), p317-322

\section{Beta Analytic Inc.}

4985 SW 74 Court, Miami, Florida 33155 USA -Tel: (305) $6675167 \cdot$ Fax: (305) $6630964 \cdot$ E-Mail: beta@radiocarbon.com 


\section{CALIBRATION OF RADIOCARBON AGE TO CALENDAR YEARS}

(Variables: $\mathrm{C} 13 / \mathrm{C} 12=-27.5$ :lab. $\mathrm{mult}=1$ )

\section{Labo ratory nu mber: Beta-157968}

Conventional radiocarbon age: $1170 \pm 40 \mathrm{BP}$

2 Sigm a calibrated result: Cal AD 770 to 980 (Cal BP 1180 to 970) (95\% probability)

Intercept data

Intercept of radiocarbon age with calibration curve:

1 Sigm a calibrated result: (68\% probability)

Cal AD 880 (Cal BP 1070)

Cal AD 790 to 900 (Cal BP 1160 to 1050 )

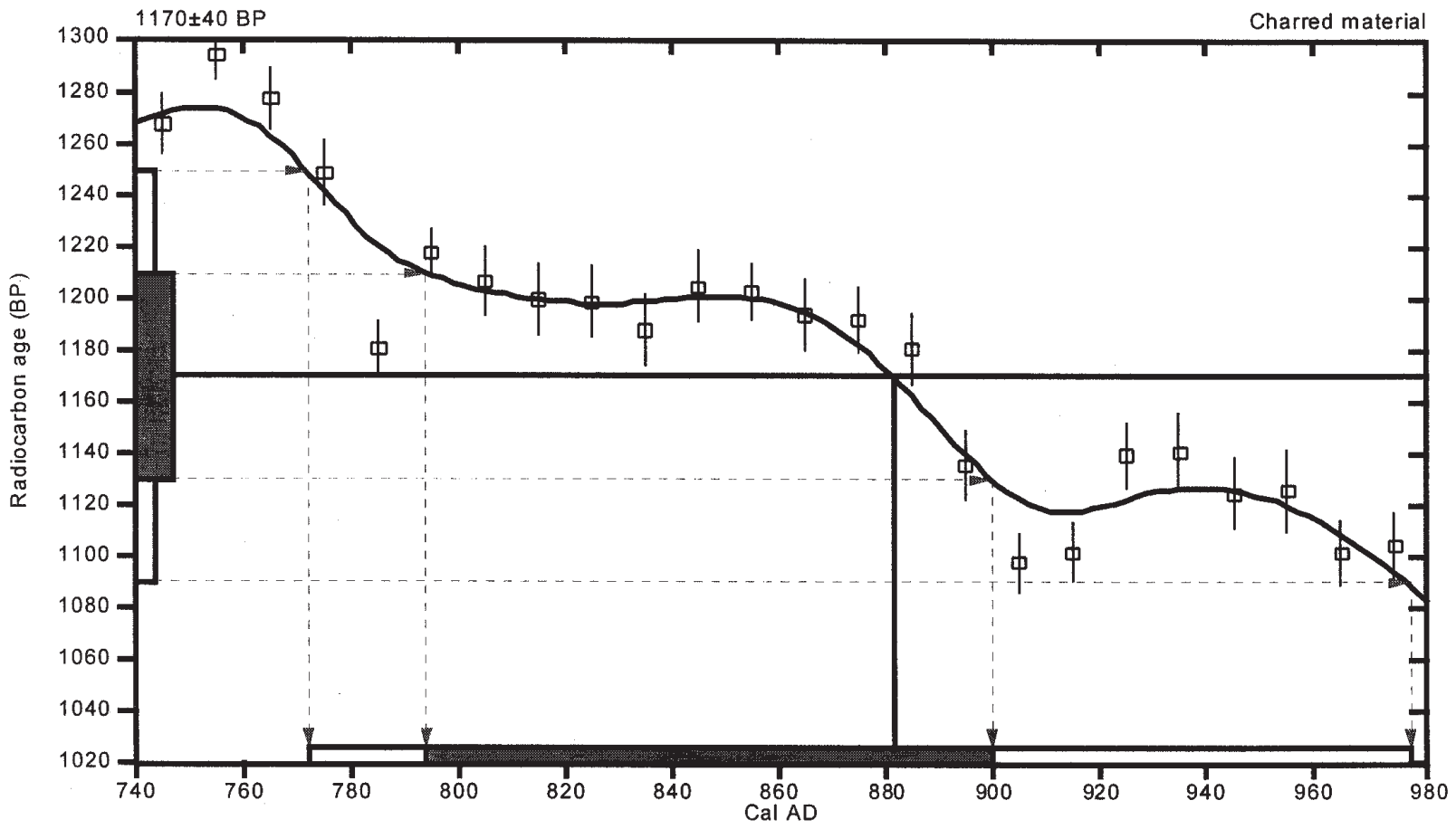

References:

Database used

Calibration Database

Editorial Comment

Stuiver, M., van der Plicht, H., 1998, Radiocarbon 40(3), pxii-xiii

INTCAL98 Radiocarbon Age Calibration

Stuiver, M., et. al., 1998, Radiocarbon 40(3), p1041-1083

Mathematics

A Simplified Approach to Calibrating C14 Dates

Talma, A.S., Vogel, J. C., 1993, Radiocarbon 35(2), p317-322

\section{Beta Analy tic Inc.}

4985 SW 74 Court, Miami, Florida 33155 USA Tel: (305) $6675167 \cdot$ Fax: (305) $6630964 \cdot$ E-Mail: beta@radiocarbon.com 


\section{CALIBRATION OF RADIOCARBON AGE TO CALENDAR YEARS}

(Variables: C 13/C 12=-25.3:lab. mult $=1$ )

Laboratory number: Beta-157969

Conventional radiocarbon age: $1600 \pm 40 \mathrm{BP}$

2 Sigm a calibrated result: Cal AD 390 to 550 (Cal BP 1560 to 1400)

(95\% probability)

Intercept data

Intercept of radiocarbon age

with calibration curve: Cal AD 430 (Cal B P 1520)

1 Sigm a calibrated result: Cal AD 410 to 530 (Cal BP 1540 to 1420)

(68\% probability)

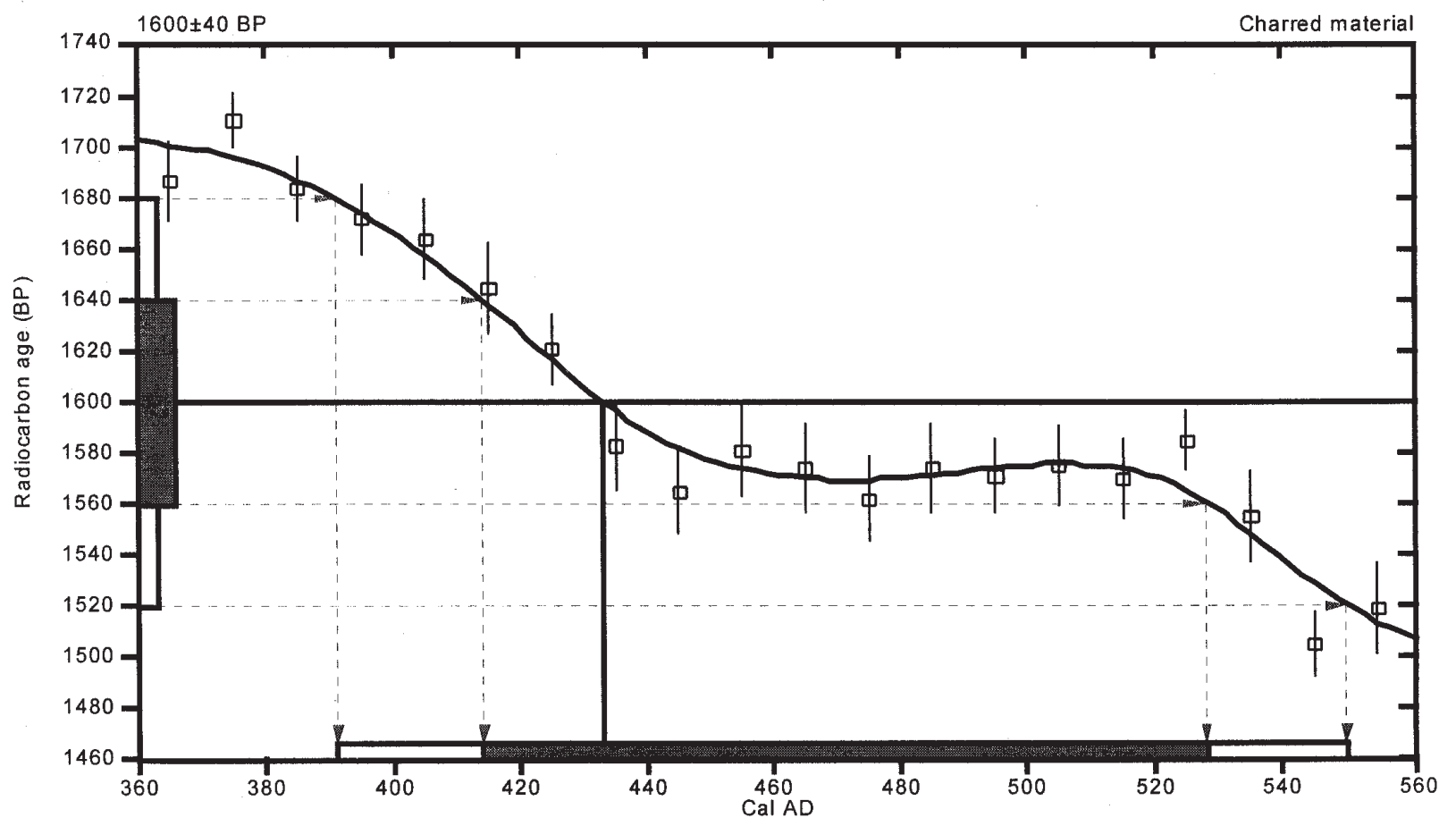

References:

Database used

Calibration Database

Editorial Comment

Stuiver, M., van der Plicht, H., 1998, Radioca rbon 40(3), pxil-xili

INTCAL98 Radiocarbon Age Calibration

Stuiver, M., et. al., 1998, Radiocarbon 40(3), p1041-1083

$M$ ath ematics

A Simplified Approach to Calibrating C14 Dates

Talma, A. S., Vogel, J. C., 1993, Radiocarbon 35(2), p317-322

\section{Beta Analy tic Inc.}

4985 SW 74 Court, Miami, Florida 33155 USA Tel: (305) $6675167 \cdot$ Fax: (305) $6630964 \cdot$ E-Mail: beta@radiocarbon.com 


\section{CALIBRATION OF RADIOCARBON AGE TO CALENDAR YEARS}

(V ariables: C 13/C 12 $=-27.1$ :lab. $\mathrm{mult}=1$ )

Laboratory number: Beta-157970

Conventional radiocarbon age: $370 \pm 40 \mathrm{BP}$

2 Sigm a calibrated result: Cal AD 1440 to 1640 (Cal BP 510 to 310) (95\% probability)

Intercept data

Intercept of radiocarbon age with calibration curve:

1 Sigma calibrated results: Cal AD 1460 to 1520 (Cal BP 490 to 430 ) and

(68\% probability) Cal AD 1580 to 1630 (Cal B P 380 to 320 )

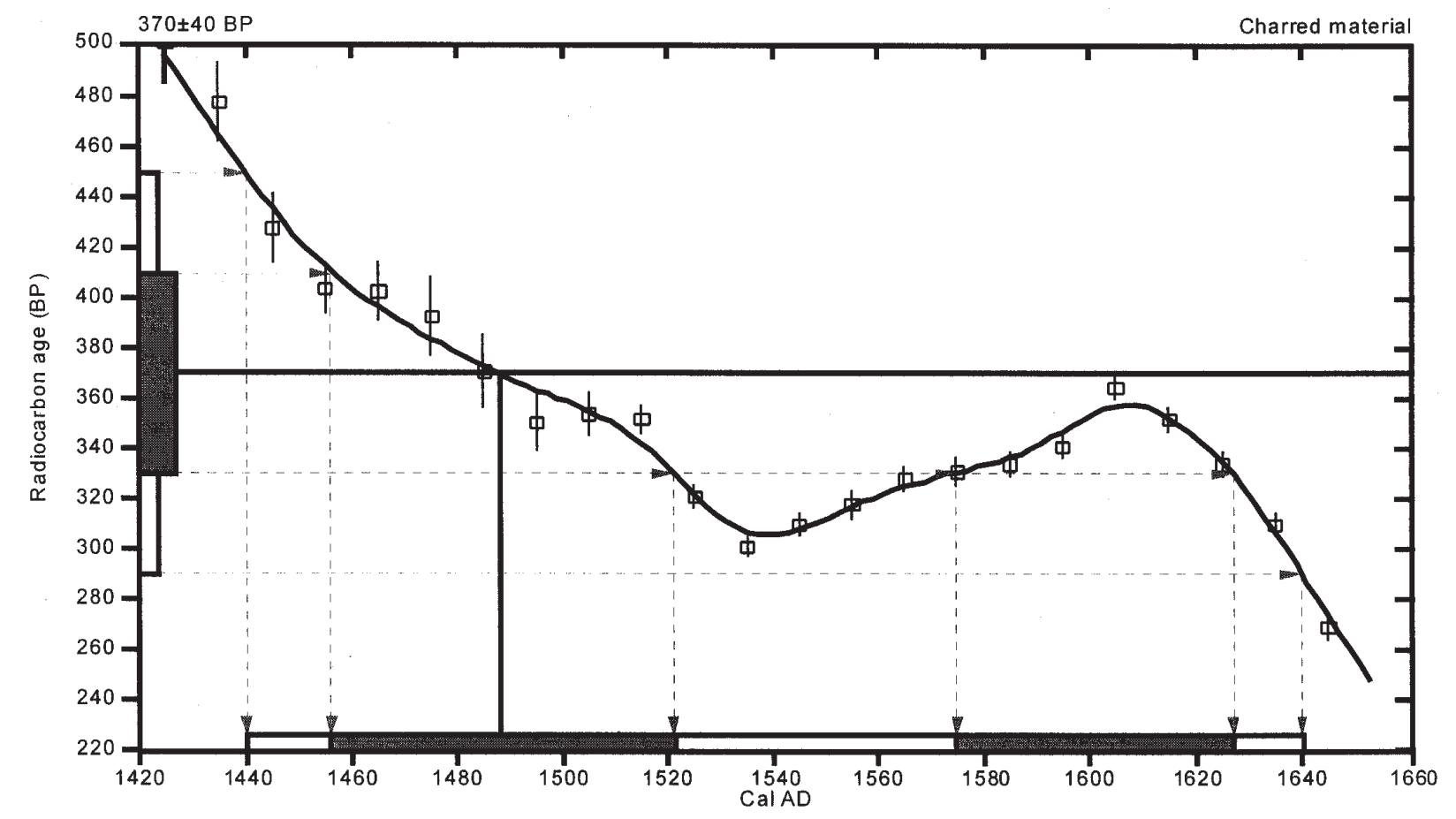

References:

Database used

Calibration Database

Editorial Comment

Stuiver, M., van der Plicht, H., 1998, Radiocarbon 40(3), pxi i-xiii

INTCAL98 Radiocarbon Age Calibration

Stuiver, M., et. al., 1998, Radiocarbon 40(3), p1041-1083

Math ematics

A Simplified Approach to Calibrating C14 Dates

Talma, A. S., Vogel, J. C., I993, Radiocarbon 35(2), p317-322

\section{Beta Analytic Inc.}

4985 SW 74 Court, Miami, Florida 33155 USA Tel: (305) $6675167 \cdot$ Fax: (305) $6630964 \cdot$ E-Mail; beta@radiocarbon.com 



\section{Appendix E}

Shovel Test Data: Areas A, B, C, and D 
Table E-1. Shovel Test data, Areas A, B, C, and D

\begin{tabular}{|c|c|c|c|c|c|c|}
\hline Area & Transect & $\begin{array}{c}\text { Shovel } \\
\text { Test }\end{array}$ & $\begin{array}{c}\text { Maximum } \\
\text { depth } \\
\text { (cm bs) }\end{array}$ & $\begin{array}{c}\text { Depth of } \\
\text { Bt soil } \\
\text { (cm bs) }\end{array}$ & $\begin{array}{c}\text { Levels with } \\
\text { Artifacts } \\
(\mathrm{cm} \text { bs })\end{array}$ & Artifacts (\# and Kind) \\
\hline A & 1 & 1 & 60 & $* \mathrm{NC}$ & 0 & 0 \\
\hline $\mathrm{A}$ & 1 & 2 & 60 & $\mathrm{NC}$ & 0 & 0 \\
\hline $\mathrm{A}$ & 1 & 3 & 70 & $\mathrm{NC}$ & 0 & 0 \\
\hline A & 1 & 4 & 60 & $\mathrm{NC}$ & 0 & 0 \\
\hline $\mathrm{A}$ & 1 & 5 & 60 & $\mathrm{NC}$ & 0 & 0 \\
\hline $\mathrm{A}$ & 1 & 6 & 60 & $\mathrm{NC}$ & 0 & 0 \\
\hline A & 1 & 7 & 60 & $\mathrm{NC}$ & 0 & 0 \\
\hline A & 1 & 8 & 60 & $\mathrm{NC}$ & 0 & 0 \\
\hline $\mathrm{A}$ & 1 & 9 & 60 & $\mathrm{NC}$ & 0 & 0 \\
\hline $\mathrm{A}$ & 1 & 10 & 60 & $\mathrm{NC}$ & 0 & 0 \\
\hline $\mathrm{A}$ & 1 & 11 & 60 & $\mathrm{NC}$ & 0 & 0 \\
\hline $\mathrm{A}$ & 1 & 12 & 60 & $\mathrm{NC}$ & 0 & 0 \\
\hline $\mathrm{A}$ & 2 & 1 & 60 & $\mathrm{NC}$ & 0 & 0 \\
\hline $\mathrm{A}$ & 2 & 2 & 50 & 41 & 0 & 0 \\
\hline $\mathrm{A}$ & 2 & 3 & 60 & $\mathrm{NC}$ & 0 & 0 \\
\hline $\mathrm{A}$ & 2 & 4 & 60 & $\mathrm{NC}$ & 0 & 0 \\
\hline A & 3 & 1 & 60 & 55 & 0 & 0 \\
\hline $\mathrm{A}$ & 3 & 2 & 60 & $\mathrm{NC}$ & 0 & 0 \\
\hline A & 3 & 3 & 60 & 55 & 0 & 0 \\
\hline A & 3 & 4 & 50 & 30 & 0 & 0 \\
\hline B & 1 & 1 & 60 & 50 & 0 & 0 \\
\hline $\mathrm{B}$ & 1 & 2 & 60 & $\mathrm{NC}$ & 0 & 0 \\
\hline $\mathrm{B}$ & 1 & 3 & 60 & 45 & 0 & 0 \\
\hline B & 1 & 4 & 40 & 23 & 0 & 0 \\
\hline $\mathrm{B}$ & 1 & 6 & 60 & $\mathrm{NC}$ & 0 & 0 \\
\hline $\mathrm{B}$ & 1 & 7 & 70 & $\mathrm{NC}$ & 0 & 0 \\
\hline $\mathrm{B}$ & 2 & 1 & 60 & $\mathrm{NC}$ & 0 & 0 \\
\hline $\mathrm{B}$ & 2 & 2 & 60 & 50 & 0 & 0 \\
\hline B & 2 & 3 & 60 & $\mathrm{NC}$ & 0 & 0 \\
\hline $\mathrm{B}$ & 2 & 4 & 60 & $\mathrm{NC}$ & 0 & 0 \\
\hline B & 2 & 5 & 70 & $\mathrm{NC}$ & 0 & 0 \\
\hline B & 2 & 6 & 60 & $\mathrm{NC}$ & 0 & 0 \\
\hline $\mathrm{B}$ & 3 & 1 & 60 & $\mathrm{NC}$ & 0 & base of excavation =closer to $\mathrm{Bt}$ contact \\
\hline $\mathrm{B}$ & 3 & 2 & 60 & $\mathrm{NC}$ & 0 & 0 \\
\hline $\mathrm{C}$ & 1 & 1 & 60 & $\mathrm{NC}$ & 0 & 0 \\
\hline $\mathrm{C}$ & 1 & 2 & 70 & $\mathrm{NC}$ & $3(20-30)$ & 1 lithic \\
\hline $\mathrm{D}$ & 1 & 1 & 20 & 10 & 0 & 0 \\
\hline $\mathrm{D}$ & 1 & 2 & 60 & $\mathrm{NC}$ & 0 & 0 \\
\hline
\end{tabular}

$* \mathrm{NC}=$ no contact with $\mathrm{Bt}$ soil 


\section{Appendix $\mathbf{F}$}

\section{Shovel Test Data: Area E}


Table F-1. Shovel Test data, Area E

(Does not include shovel tests on 41WA47 - see Appendix H)

\begin{tabular}{|c|c|c|c|c|c|c|c|}
\hline Area & Transect & Shovel Test & Site & $\begin{array}{c}\text { Maximum } \\
\text { depth } \\
(\mathrm{cm} \text { bs })\end{array}$ & $\begin{array}{l}\text { Depth of Bt } \\
\text { soil (cm bs) }\end{array}$ & $\begin{array}{l}\text { Levels with } \\
\text { artifacts } \\
\text { (cm bs) }\end{array}$ & Artifacts (\# and Kind) \\
\hline $\mathrm{E}$ & 1 & 1 & & 40 & $* \mathrm{NC}$ & 0 & 0 \\
\hline $\mathrm{E}$ & 1 & 2 & & 30 & $\mathrm{NC}$ & 0 & 0 \\
\hline $\mathrm{E}$ & 1 & 3 & & 50 & 37 & 0 & 0 \\
\hline $\mathrm{E}$ & 1 & 4 & & 50 & 37 & $1(0-10)$ & 1 glass \\
\hline $\mathrm{E}$ & 1 & 5 & & 60 & 48 & 0 & 0 \\
\hline $\mathrm{E}$ & 1 & 6 & & 60 & $\mathrm{NC}$ & 0 & 0 \\
\hline $\mathrm{E}$ & 1 & 7 & & 38 & $\mathrm{NC}$ & 0 & 0 \\
\hline $\mathrm{E}$ & 1 & 8 & & 34 & $\mathrm{NC}$ & 0 & 0 \\
\hline $\mathrm{E}$ & 1 & 9 & & 50 & $\mathrm{NC}$ & $1(0-10)$ & 1 pull tab \\
\hline $\mathrm{E}$ & 2 & 1 & & 60 & $\mathrm{NC}$ & 0 & 0 \\
\hline $\mathrm{E}$ & 2 & 2 & 41WA264 & 60 & $\mathrm{NC}$ & $6(50-60)$ & 1 carbonized nutshell \\
\hline $\mathrm{E}$ & 2 & 3 & & 60 & $\mathrm{NC}$ & 0 & 0 \\
\hline $\mathrm{E}$ & 2 & 4 & & 30 & 30 & 0 & 0 \\
\hline $\mathrm{E}$ & 2 & 5 & & 50 & 35 & 0 & 0 \\
\hline $\mathrm{E}$ & 2 & 6 & & 40 & 30 & 0 & 0 \\
\hline $\mathrm{E}$ & 2 & 7 & & 50 & 40 & 0 & 0 \\
\hline $\mathrm{E}$ & 2 & 8 & & 60 & $\mathrm{NC}$ & $1(0-10)$ & 1 pull tab; 1 crown cap \\
\hline $\mathrm{E}$ & 2 & 9 & & 60 & $\mathrm{NC}$ & 0 & 0 \\
\hline $\mathrm{E}$ & 2 & 17 & & 60 & $\mathrm{NC}$ & 0 & 0 \\
\hline $\mathrm{E}$ & 2 & 18 & & 60 & $\mathrm{NC}$ & 0 & 0 \\
\hline $\mathrm{E}$ & 3 & 1 & & 60 & $\mathrm{NC}$ & 0 & 0 \\
\hline $\mathrm{E}$ & 3 & 2 & 41WA264 & 60 & $\mathrm{NC}$ & 0 & 0 \\
\hline $\mathrm{E}$ & 3 & 3 & 41WA264 & 60 & $\mathrm{NC}$ & 0 & 0 \\
\hline $\mathrm{E}$ & 3 & 4 & 41WA264 & 60 & $\mathrm{NC}$ & 0 & 0 \\
\hline $\mathrm{E}$ & 3 & 5 & & 60 & $\mathrm{NC}$ & 0 & 0 \\
\hline $\mathrm{E}$ & 3 & 6 & 41WA264 & 40 & 32 & 0 & 0 \\
\hline $\mathrm{E}$ & 3 & 7 & & 40 & 32 & 0 & 0 \\
\hline $\mathrm{E}$ & 3 & 8 & & 60 & $\mathrm{NC}$ & 0 & 0 \\
\hline $\mathrm{E}$ & 3 & 9 & & 60 & $\mathrm{NC}$ & 0 & 0 \\
\hline E & 3 & 10 & & 32 & 32 & 0 & 0 \\
\hline $\mathrm{E}$ & 3 & 11 & & 30 & fill & $2(10-20)$ & 1 glass \\
\hline $\mathrm{E}$ & 3 & 12 & & 20 & 11 & 0 & 0 \\
\hline $\mathrm{E}$ & 3 & 13 & & 50 & 45 & 0 & 0 \\
\hline $\mathrm{E}$ & 3 & 14 & & 30 & 2 & 0 & 0 \\
\hline $\mathrm{E}$ & 3 & 15 & & 30 & 10 & $1(0-10)$ & 1 wire \\
\hline $\mathrm{E}$ & 3 & 16 & & 50 & 40 & 0 & 0 \\
\hline $\mathrm{E}$ & 3 & 17 & & 70 & $\mathrm{NC}$ & 0 & 0 \\
\hline $\mathrm{E}$ & 3 & 18 & & 50 & 45 & 0 & 0 \\
\hline $\mathrm{E}$ & 3 & 19 & & 50 & 32 & 0 & 0 \\
\hline $\mathrm{E}$ & 4 & 1 & & 60 & $\mathrm{NC}$ & 0 & 0 \\
\hline $\mathrm{E}$ & 4 & 2 & 41WA264 & 70 & $\mathrm{NC}$ & $4(30-40)$ & 1 lithic \\
\hline $\mathrm{E}$ & 4 & 3 & 41WA264 & 61 & $\mathrm{NC}$ & 0 & 0 \\
\hline $\mathrm{E}$ & 4 & 4 & 41WA264 & 60 & $\mathrm{NC}$ & 0 & 0 \\
\hline $\mathrm{E}$ & 4 & 5 & 41WA264 & 60 & 57 & $2(10-20)$ & 1 pull tab \\
\hline $\mathrm{E}$ & 4 & 6 & 41WA264 & 60 & $\mathrm{NC}$ & 0 & 0 \\
\hline
\end{tabular}


Table F-1. Continued...

\begin{tabular}{|c|c|c|c|c|c|c|c|}
\hline Area & Transect & Shovel Test & Site & $\begin{array}{c}\text { Maximum } \\
\text { depth } \\
(\mathrm{cm} \mathrm{bs})\end{array}$ & $\begin{array}{l}\text { Depth of Bt } \\
\text { soil (cm bs) }\end{array}$ & $\begin{array}{c}\text { Levels with } \\
\text { artifacts } \\
(\mathbf{c m} \text { bs })\end{array}$ & Artifacts (\# and Kind) \\
\hline \multirow[t]{4}{*}{$\mathrm{E}$} & \multirow[t]{4}{*}{4} & \multirow[t]{4}{*}{7} & \multirow[t]{4}{*}{ 41WA264 } & \multirow[t]{4}{*}{60} & \multirow[t]{4}{*}{46} & $1(0-10)$ & electrical tape \\
\hline & & & & & & $3(20-30)$ & 1 lithic \\
\hline & & & & & & $4(30-40)$ & 1 lithic \\
\hline & & & & & & $6(50-60)$ & 1 lithic \\
\hline E & 4 & 8 & 41WA264 & 40 & 39 & $2(10-20)$ & 1 lithic \\
\hline E & 4 & 9 & & 40 & 44 & $1(0-10)$ & 1 glass \\
\hline $\mathrm{E}$ & 4 & 10 & & 21 & 12 & 0 & 0 \\
\hline $\mathrm{E}$ & 4 & 11 & & 20 & 13 & 0 & 0 \\
\hline E & 4 & 12 & & 20 & 10 & 0 & 0 \\
\hline E & 4 & 13 & & 30 & 20 & 0 & 0 \\
\hline E & 4 & 14 & & 30 & 6 & $2(10-20)$ & 1 lithic \\
\hline E & 4 & 15 & & 50 & 32 & 0 & 0 \\
\hline $\mathrm{E}$ & 4 & 16 & & 70 & $\mathrm{NC}$ & 0 & 0 \\
\hline $\mathrm{E}$ & 4 & 17 & & 60 & $\mathrm{NC}$ & 0 & 0 \\
\hline $\mathrm{E}$ & 4 & 18 & & 50 & 40 & 0 & 0 \\
\hline $\mathrm{E}$ & 7 & 1 & & 40 & 40 & 0 & 0 \\
\hline $\mathrm{E}$ & 7 & 2 & 41WA264 & 60 & $\mathrm{NC}$ & 0 & 0 \\
\hline E & 7 & 3 & 41WA264 & 60 & $\mathrm{NC}$ & 0 & 0 \\
\hline $\mathrm{E}$ & 7 & 4 & 41WA264 & 60 & $\mathrm{NC}$ & 0 & 0 \\
\hline $\mathrm{E}$ & 7 & 5 & 41WA264 & 60 & $\mathrm{NC}$ & 0 & 0 \\
\hline $\mathrm{E}$ & 7 & 6 & 41WA264 & 50 & $\mathrm{NC}$ & $4(30-40)$ & 1 concrete frag. \\
\hline $\mathrm{E}$ & 7 & 7 & & 60 & $\mathrm{NC}$ & 0 & 0 \\
\hline $\mathrm{E}$ & 7 & 8 & & 60 & $\mathrm{NC}$ & $2(10-20)$ & 1 metal D-ring \\
\hline $\mathrm{E}$ & 7 & 9 & & 60 & $\mathrm{NC}$ & 0 & 0 \\
\hline E & 8 & 1 & & 50 & 40 & 0 & 0 \\
\hline $\mathrm{E}$ & 8 & 2 & 41WA264 & 60 & $\mathrm{NC}$ & $4(30-40)$ & 1 lithic \\
\hline $\mathrm{E}$ & 8 & 3 & 41WA264 & 60 & $\mathrm{NC}$ & $1(0-10)$ & 1 bottle top \\
\hline $\mathrm{E}$ & 8 & 4 & 41WA264 & 60 & $\mathrm{NC}$ & $2(10-20)$ & 1 plastic \\
\hline $\mathrm{E}$ & 8 & 5 & & 60 & $\mathrm{NC}$ & 0 & 0 \\
\hline E & 8 & 6 & & 20 & 10 & 0 & 0 \\
\hline $\mathrm{E}$ & 8 & 7 & & 60 & 50 & 0 & 0 \\
\hline $\mathrm{E}$ & 8 & 8 & & 60 & 60 & 0 & 0 \\
\hline $\mathrm{E}$ & 9 & 1 & & 60 & 60 & 0 & 0 \\
\hline E & 9 & 2 & 41WA264 & 60 & $\mathrm{NC}$ & $4(30-40)$ & 1 biface \\
\hline $\mathrm{E}$ & 9 & 3 & 41WA264 & 60 & $\mathrm{NC}$ & 0 & 0 \\
\hline $\mathrm{E}$ & 9 & 4 & & 60 & $\mathrm{NC}$ & 0 & 0 \\
\hline E & 9 & 5 & & 60 & $\mathrm{NC}$ & 0 & 0 \\
\hline $\mathrm{E}$ & 9 & 6 & & 60 & $\mathrm{NC}$ & 0 & 0 \\
\hline $\mathrm{E}$ & 10 & 1 & 41WA264 & 62 & $\mathrm{NC}$ & 0 & 0 \\
\hline E & 10 & 2 & 41WA264 & 60 & $\mathrm{NC}$ & $4(30-40)$ & 1 lithic \\
\hline E & 10 & 3 & 41WA264 & 32 & 30 & 0 & 0 \\
\hline $\mathrm{E}$ & 10 & 4 & 41WA264 & 70 & $\mathrm{NC}$ & $6(50-60)$ & 1 lithic \\
\hline $\mathrm{E}$ & 10 & 5 & & 60 & $\mathrm{NC}$ & 0 & 0 \\
\hline E & 11 & 1 & & 50 & $\mathrm{NC}$ & 0 & 0 \\
\hline $\mathrm{E}$ & 11 & 2 & & 50 & 47 & $1(0-10)$ & 1 FCR(?) \\
\hline $\mathrm{E}$ & 11 & 3 & & 40 & $\mathrm{NC}$ & 0 & 0 \\
\hline E & 11 & 4 & & 15 & 13 & 0 & 0 \\
\hline
\end{tabular}


Table F-1. Continued...

\begin{tabular}{|c|c|c|c|c|c|c|c|}
\hline Area & Transect & Shovel Test & Site & $\begin{array}{c}\text { Maximum } \\
\text { depth } \\
(\mathrm{cm} \mathrm{bs})\end{array}$ & $\begin{array}{l}\text { Depth of Bt } \\
\text { soil (cm bs) }\end{array}$ & $\begin{array}{c}\text { Levels with } \\
\text { artifacts } \\
(\mathrm{cm} \text { bs })\end{array}$ & Artifacts (\# and Kind) \\
\hline $\mathrm{E}$ & 11 & 5 & & 60 & $\mathrm{NC}$ & 0 & 0 \\
\hline $\mathrm{E}$ & 11 & 6 & & 50 & $\mathrm{NC}$ & 0 & 0 \\
\hline $\mathrm{E}$ & 11 & 7 & & 60 & $\mathrm{NC}$ & 0 & 0 \\
\hline $\mathrm{E}$ & 11 & 8 & & 40 & $\mathrm{NC}$ & 0 & 0 \\
\hline $\mathrm{E}$ & 11 & 9 & & 20 & $\mathrm{NC}$ & $1(0-10)$ & 1 lithic \\
\hline $\mathrm{E}$ & 11 & 10 & & 20 & $\mathrm{NC}$ & 0 & 0 \\
\hline $\mathrm{E}$ & 11 & 11 & & 60 & $\mathrm{NC}$ & 0 & 0 \\
\hline $\mathrm{E}$ & 11 & 12 & & 60 & $\mathrm{NC}$ & 0 & 0 \\
\hline $\mathrm{E}$ & 11 & 13 & & 60 & $\mathrm{NC}$ & 0 & 0 \\
\hline $\mathrm{E}$ & 11 & 14 & & 60 & $\mathrm{NC}$ & 0 & 0 \\
\hline $\mathrm{E}$ & 12 & 1 & & 60 & $\mathrm{NC}$ & 0 & 0 \\
\hline $\mathrm{E}$ & 12 & 2 & & 60 & $\mathrm{NC}$ & 0 & 0 \\
\hline $\mathrm{E}$ & 12 & 3 & & 60 & $\mathrm{NC}$ & $1(0-10)$ & 1 brick frag. \\
\hline $\mathrm{E}$ & 12 & 4 & & 50 & $\mathrm{NC}$ & 0 & 0 \\
\hline $\mathrm{E}$ & 12 & 5 & & 30 & 30 & 0 & 0 \\
\hline $\mathrm{E}$ & 12 & 6 & & 30 & $\mathrm{NC}$ & 0 & 0 \\
\hline $\mathrm{E}$ & 12 & 7 & & 20 & $\mathrm{NC}$ & 0 & 0 \\
\hline $\mathrm{E}$ & 12 & 8 & & 20 & $\mathrm{NC}$ & 0 & 0 \\
\hline $\mathrm{E}$ & 12 & 9 & & 30 & $\mathrm{NC}$ & 0 & 0 \\
\hline $\mathrm{E}$ & 12 & 10 & & 30 & $\mathrm{NC}$ & 0 & 0 \\
\hline $\mathrm{E}$ & 12 & 11 & & 30 & $\mathrm{NC}$ & 0 & 0 \\
\hline $\mathrm{E}$ & 12 & 12 & & 60 & $\mathrm{NC}$ & 0 & 0 \\
\hline $\mathrm{E}$ & 12 & 13 & & 60 & $\mathrm{NC}$ & 0 & 0 \\
\hline $\mathrm{E}$ & 12 & 14 & & 60 & $\mathrm{NC}$ & 0 & 0 \\
\hline $\mathrm{E}$ & 12 & 15 & & 70 & $\mathrm{NC}$ & 0 & 3 lithics \\
\hline $\mathrm{E}$ & 12 & 16 & & 60 & $\mathrm{NC}$ & $1(0-10)$ & 1 rifle shell \\
\hline $\mathrm{E}$ & 13 & 3 & & 70 & $\mathrm{NC}$ & 0 & 0 \\
\hline $\mathrm{E}$ & 13 & 4 & & 60 & $\mathrm{NC}$ & $1(0-10)$ & 1 plastic; 1 FCR(?) \\
\hline $\mathrm{E}$ & 13 & 5 & & 60 & $\mathrm{NC}$ & $1(0-10)$ & 1 glass \\
\hline $\mathrm{E}$ & 13 & 6 & & 60 & $\mathrm{NC}$ & 0 & 0 \\
\hline $\mathrm{E}$ & 13 & 7 & & 60 & 60 & 0 & 0 \\
\hline $\mathrm{E}$ & 13 & 8 & & 60 & $\mathrm{NC}$ & 0 & 0 \\
\hline $\mathrm{E}$ & 13 & 9 & & 60 & $\mathrm{NC}$ & 0 & 0 \\
\hline $\mathrm{E}$ & 14 & 3 & & 60 & 60 & $4(30-40)$ & 1 lithic \\
\hline $\mathrm{E}$ & 14 & 4 & & 30 & $\mathrm{NC}$ & $2(10-20)$ & 1 pull tab \\
\hline $\mathrm{E}$ & 14 & 5 & & 45 & $\mathrm{NC}$ & 0 & 0 \\
\hline $\mathrm{E}$ & 14 & 6 & & 30 & 29 & 0 & 0 \\
\hline $\mathrm{E}$ & 14 & 7 & & 60 & $\mathrm{NC}$ & 0 & 0 \\
\hline $\mathrm{E}$ & 14 & 8 & & 60 & $\mathrm{NC}$ & 0 & 0 \\
\hline $\mathrm{E}$ & 14 & 9 & & 40 & 38 & 0 & 0 \\
\hline $\mathrm{E}$ & 14 & 10 & & 47 & 47 & $1(0-10)$ & 2 glass \\
\hline $\mathrm{E}$ & 14 & 11 & & 37 & 37 & 0 & 0 \\
\hline $\mathrm{E}$ & 14 & 12 & & 30 & $\mathrm{NC}$ & 0 & 0 \\
\hline $\mathrm{E}$ & 14 & 14 & & 30 & 28 & 0 & 0 \\
\hline $\mathrm{E}$ & 14 & 15 & & 10 & $\mathrm{NC}$ & 0 & 0 \\
\hline $\mathrm{E}$ & 14 & 16 & & 20 & 16 & 0 & 0 \\
\hline$E$ & 14 & 17 & & 10 & $\mathrm{NC}$ & 0 & 0 \\
\hline
\end{tabular}


Table F-1. Continued...

\begin{tabular}{|c|c|c|c|c|c|c|c|}
\hline Area & Transect & Shovel Test & Site & $\begin{array}{c}\text { Maximum } \\
\text { depth } \\
(\mathrm{cm} \text { bs) } \\
\end{array}$ & $\begin{array}{l}\text { Depth of Bt } \\
\text { soil (cm bs) }\end{array}$ & $\begin{array}{l}\text { Levels with } \\
\text { artifacts } \\
\text { (cm bs) }\end{array}$ & Artifacts (\# and Kind) \\
\hline $\mathrm{E}$ & 14 & 18 & & 20 & \begin{tabular}{|l|}
$\mathrm{NC}$ \\
\end{tabular} & $1(0-10)$ & 1 lithic \\
\hline E & 14 & 19 & & 20 & $\mathrm{NC}$ & 0 & 0 \\
\hline E & 14 & 20 & & 40 & $\mathrm{NC}$ & 0 & 0 \\
\hline $\mathrm{E}$ & 14 & 21 & & 60 & $\mathrm{NC}$ & 0 & 0 \\
\hline E & 14 & 22 & & 40 & $\mathrm{NC}$ & 0 & 0 \\
\hline $\mathrm{E}$ & 15 & 1 & & 60 & $\mathrm{NC}$ & 0 & 0 \\
\hline E & 15 & 2 & & 60 & $\mathrm{NC}$ & 0 & 0 \\
\hline $\mathrm{E}$ & 15 & 3 & & 60 & $\mathrm{NC}$ & 0 & 0 \\
\hline E & 15 & 4 & & 50 & $\mathrm{NC}$ & 0 & 0 \\
\hline $\mathrm{E}$ & 15 & 5 & & 60 & $\mathrm{NC}$ & 0 & 0 \\
\hline E & 15 & 6 & & 41 & 41 & 0 & 0 \\
\hline $\mathrm{E}$ & 15 & 7 & & 40 & $\mathrm{NC}$ & 0 & 0 \\
\hline $\mathrm{E}$ & 15 & 8 & & 60 & $\mathrm{NC}$ & 0 & 0 \\
\hline $\mathrm{E}$ & 15 & 9 & & 30 & $\mathrm{NC}$ & 0 & 0 \\
\hline $\mathrm{E}$ & 15 & 10 & & 40 & $\mathrm{NC}$ & 0 & 0 \\
\hline $\mathrm{E}$ & 15 & 11 & & 20 & 12 & 0 & 0 \\
\hline $\mathrm{E}$ & 15 & 13 & & 60 & $\mathrm{NC}$ & 0 & 0 \\
\hline $\mathrm{E}$ & 15 & 14 & & 18 & $\mathrm{NC}$ & 0 & 0 \\
\hline E & 15 & 15 & & 20 & $\mathrm{NC}$ & 0 & 0 \\
\hline $\mathrm{E}$ & 15 & 16 & & 30 & 23 & 0 & 0 \\
\hline E & 16 & 1 & & 40 & $\mathrm{NC}$ & $3(20-30)$ & 1 lithic \\
\hline $\mathrm{E}$ & 16 & 2 & & 37 & 37 & 0 & 0 \\
\hline $\mathrm{E}$ & 16 & 3 & & 60 & $\mathrm{NC}$ & $4(30-40)$ & 1 lithic \\
\hline $\mathrm{E}$ & 16 & 4 & & 48 & 43 & 0 & 0 \\
\hline $\mathrm{E}$ & 16 & 5 & & 51 & $\mathrm{NC}$ & 0 & 0 \\
\hline E & 16 & 7 & & 50 & $\mathrm{NC}$ & 0 & 0 \\
\hline $\mathrm{E}$ & 16 & 8 & & 60 & $\mathrm{NC}$ & 0 & 0 \\
\hline E & 16 & 9 & & 50 & $\mathrm{NC}$ & 0 & 0 \\
\hline $\mathrm{E}$ & 16 & 11 & & 30 & 30 & 0 & 0 \\
\hline E & 16 & 12 & & 16 & 16 & 0 & 0 \\
\hline $\mathrm{E}$ & 17 & 1 & & 30 & $\mathrm{NC}$ & 0 & 0 \\
\hline E & 17 & 2 & & 56 & 56 & 0 & 0 \\
\hline $\mathrm{E}$ & 17 & 3 & & 50 & 43 & 0 & 0 \\
\hline E & 17 & 6 & & 60 & $\mathrm{NC}$ & 0 & 0 \\
\hline $\mathrm{E}$ & 17 & 7 & & 60 & $\mathrm{NC}$ & 0 & 0 \\
\hline \multirow[t]{3}{*}{ E } & \multirow[t]{3}{*}{18} & \multirow[t]{3}{*}{1} & \multirow[t]{3}{*}{ 41WA265 } & \multirow[t]{3}{*}{80} & \multirow[t]{3}{*}{$\mathrm{NC}$} & $4(30-40)$ & 1 lithic \\
\hline & & & & & & $5(40-50)$ & 2 lithics \\
\hline & & & & & & $6(50-60)$ & 1 biface frag. \\
\hline E & 18 & 1 -N1 & 41WA265 & 60 & $\mathrm{NC}$ & $3(20-30)$ & 2 lithics \\
\hline E & 18 & $1-\mathrm{N} 2$ & 41WA265 & 50 & 30 & 0 & 0 \\
\hline $\mathrm{E}$ & 18 & 1-S1 & 41WA265 & 60 & $\mathrm{NC}$ & 0 & 0 \\
\hline E & 18 & 1-E1 & 41WA265 & 60 & $\mathrm{NC}$ & 0 & 0 \\
\hline $\mathrm{E}$ & 18 & 1-W1 & 41WA265 & 60 & $\mathrm{NC}$ & 0 & 0 \\
\hline E & 18 & 1-NE1 & 41WA265 & 60 & $\mathrm{NC}$ & 0 & 0 \\
\hline $\mathrm{E}$ & 18 & 1-NW1 & 41WA265 & 60 & $\mathrm{NC}$ & 0 & 0 \\
\hline E & 19 & 1 & & 38 & 38 & 0 & 0 \\
\hline $\mathrm{E}$ & 19 & 2 & & 60 & $\mathrm{NC}$ & 0 & 0 \\
\hline
\end{tabular}





\title{
Appendix G
}

\author{
Shovel Test Data: Area F
}


Table G-1. Shovel Test data, Area F

\begin{tabular}{|c|c|c|c|c|c|c|c|}
\hline Area & Transect & Shovel Test & Site & $\begin{array}{c}\text { Maximum } \\
\text { depth } \\
(\mathrm{cm} \mathrm{bs})\end{array}$ & $\begin{array}{l}\text { Depth of Bt } \\
\text { soil (cm bs) }\end{array}$ & $\begin{array}{c}\text { Levels with } \\
\text { artifacts } \\
(\mathrm{cm} \mathrm{bs})\end{array}$ & Artifacts (\# and Kind) \\
\hline $\mathrm{F}$ & 1 & 1 & & 60 & $* \mathrm{NC}$ & 0 & 0 \\
\hline $\mathrm{F}$ & 1 & 2 & & 60 & $\mathrm{NC}$ & 0 & 0 \\
\hline $\mathrm{F}$ & 1 & 3 & & 60 & $\mathrm{NC}$ & 0 & 0 \\
\hline $\mathrm{F}$ & 1 & 4 & & 40 & 38 & 0 & 0 \\
\hline $\mathrm{F}$ & 1 & 5 & 41WA228 & 60 & $\mathrm{NC}$ & 0 & 0 \\
\hline $\mathrm{F}$ & 1 & 6 & 41WA228 & 60 & $\mathrm{NC}$ & 0 & 0 \\
\hline $\mathrm{F}$ & 1 & 7 & 41WA228 & 60 & $\mathrm{NC}$ & $5(40-50)$ & 1 lithic \\
\hline $\mathrm{F}$ & 1 & 8 & 41WA228 & 60 & $\mathrm{NC}$ & 0 & 0 \\
\hline $\mathrm{F}$ & 1 & 10 & 41WA228 & 60 & $\mathrm{NC}$ & $2(10-20)$ & 1 lithic \\
\hline $\mathrm{F}$ & 1 & 11 & & 50 & $\mathrm{NC}$ & 0 & 0 \\
\hline $\mathrm{F}$ & 1 & 12 & & 40 & $\mathrm{NC}$ & 0 & 0 \\
\hline $\mathrm{F}$ & 2 & 1 & & 60 & $\mathrm{NC}$ & 0 & 0 \\
\hline $\mathrm{F}$ & 2 & 2 & & 60 & $\mathrm{NC}$ & 0 & 0 \\
\hline $\mathrm{F}$ & 2 & 3 & & 60 & $\mathrm{NC}$ & 0 & 0 \\
\hline $\mathrm{F}$ & 2 & 4 & 41WA228 & 70 & $\mathrm{NC}$ & $6(50-60)$ & 2 lithics; 1 ceramic \\
\hline $\mathrm{F}$ & 2 & 5 & 41WA228 & 60 & $\mathrm{NC}$ & $3(20-30)$ & 2 lithics \\
\hline $\mathrm{F}$ & 2 & 6 & 41WA228 & 60 & $\mathrm{NC}$ & $2(10-20)$ & 1 lithic \\
\hline $\mathrm{F}$ & 2 & 7 & 41WA228 & 60 & $\mathrm{NC}$ & 0 & 0 \\
\hline $\mathrm{F}$ & 2 & 9 & 41WA228 & 30 & 30 & 0 & 0 \\
\hline $\mathrm{F}$ & 2 & 10 & 41WA228 & 60 & $\mathrm{NC}$ & $2(10-20)$ & $1 \mathrm{FCR}$ \\
\hline $\mathrm{F}$ & 2 & 11 & 41WA228 & 50 & 20 & 0 & 0 \\
\hline $\mathrm{F}$ & 2 & 12 & 41WA228 & 60 & $\mathrm{NC}$ & $2(10-20)$ & 1 lithic \\
\hline $\mathrm{F}$ & 2 & 13 & 41WA228 & 60 & $\mathrm{NC}$ & 0 & 0 \\
\hline $\mathrm{F}$ & 2 & 14 & 41WA228 & 40 & $\mathrm{NC}$ & 0 & 0 \\
\hline $\mathrm{F}$ & 3 & 1 & & 30 & $\mathrm{NC}$ & 0 & 0 \\
\hline $\mathrm{F}$ & 3 & 2 & & 60 & $\mathrm{NC}$ & 0 & 0 \\
\hline $\mathrm{F}$ & 3 & 3 & & 60 & $\mathrm{NC}$ & 0 & 0 \\
\hline $\mathrm{F}$ & 3 & 4 & & 50 & 50 & 0 & 0 \\
\hline $\mathrm{F}$ & 3 & 5 & & 30 & 27 & 0 & 0 \\
\hline $\mathrm{F}$ & 3 & 6 & & 40 & $\mathrm{NC}$ & 0 & 0 \\
\hline $\mathrm{F}$ & 3 & 7 & & 60 & $\mathrm{NC}$ & 0 & 0 \\
\hline $\mathrm{F}$ & 3 & 8 & & 60 & $\mathrm{NC}$ & 0 & 0 \\
\hline $\mathrm{F}$ & 3 & 9 & 41WA228 & 47 & $\mathrm{NC}$ & 0 & 0 \\
\hline $\mathrm{F}$ & 3 & 10 & 41WA228 & 60 & $\mathrm{NC}$ & 0 & 0 \\
\hline \multirow[t]{2}{*}{$\mathrm{F}$} & \multirow[t]{2}{*}{3} & \multirow[t]{2}{*}{11} & \multirow[t]{2}{*}{ 41WA228 } & \multirow[t]{2}{*}{60} & \multirow[t]{2}{*}{$\mathrm{NC}$} & $5(40-50)$ & 2 lithics \\
\hline & & & & & & $6(50-60)$ & 2 lithics \\
\hline $\mathrm{F}$ & 3 & 12 & 41WA228 & 60 & $\mathrm{NC}$ & 0 & 0 \\
\hline $\mathrm{F}$ & 3 & 13 & 41WA228 & 30 & $\mathrm{NC}$ & $2(10-20)$ & 1 lithics \\
\hline $\mathrm{F}$ & 3 & 14 & 41WA228 & 60 & $\mathrm{NC}$ & 0 & 0 \\
\hline $\mathrm{F}$ & 3 & 15 & 41WA228 & 30 & $\mathrm{NC}$ & 0 & 0 \\
\hline $\mathrm{F}$ & 3 & 16 & & 60 & $\mathrm{NC}$ & 0 & 0 \\
\hline $\mathrm{F}$ & 4 & 1 & & 30 & $\mathrm{NC}$ & 0 & 0 \\
\hline $\mathrm{F}$ & 4 & 2 & & 60 & $\mathrm{NC}$ & 0 & 0 \\
\hline $\mathrm{F}$ & 4 & 3 & & 61 & $\mathrm{NC}$ & 0 & 0 \\
\hline $\mathrm{F}$ & 4 & 4 & & 61 & $\mathrm{NC}$ & 0 & 0 \\
\hline $\mathrm{F}$ & 4 & 5 & & 61 & $\mathrm{NC}$ & 0 & 0 \\
\hline $\mathrm{F}$ & 4 & 6 & & 61 & $\mathrm{NC}$ & 0 & 0 \\
\hline
\end{tabular}

$* \mathrm{NC}=$ no contact with Bt soil 
Table G-1. Continued...

\begin{tabular}{|c|c|c|c|c|c|c|c|}
\hline Area & Transect & Shovel Test & Site & $\begin{array}{c}\text { Maximum } \\
\text { depth } \\
(\mathrm{cm} \text { bs })\end{array}$ & $\begin{array}{l}\text { Depth of Bt } \\
\text { soil (cm bs) }\end{array}$ & $\begin{array}{c}\text { Levels with } \\
\text { artifacts } \\
\text { (cm bs) }\end{array}$ & Artifacts (\# and Kind) \\
\hline $\mathrm{F}$ & 4 & 7 & & 61 & $\mathrm{NC}$ & 0 & 0 \\
\hline $\mathrm{F}$ & 4 & 8 & & 60 & $\mathrm{NC}$ & 0 & 0 \\
\hline $\mathrm{F}$ & 4 & 9 & & 60 & $\mathrm{NC}$ & 0 & 0 \\
\hline $\mathrm{F}$ & 4 & 10 & 41WA228 & 56 & 56 & 0 & 0 \\
\hline $\mathrm{F}$ & 4 & 11 & 41WA228 & 50 & $\mathrm{NC}$ & 0 & 0 \\
\hline \multirow[t]{2}{*}{$\bar{F}$} & \multirow[t]{2}{*}{4} & \multirow[t]{2}{*}{12} & \multirow[t]{2}{*}{ 41WA228 } & \multirow[t]{2}{*}{61} & \multirow[t]{2}{*}{$\mathrm{NC}$} & $4(30-40)$ & 1 lithic \\
\hline & & & & & & $5(40-50)$ & 2 lithics \\
\hline $\mathrm{F}$ & 4 & 13 & 41WA228 & 50 & $\mathrm{NC}$ & 0 & 0 \\
\hline $\mathrm{F}$ & 4 & 14 & 41WA228 & 60 & $\mathrm{NC}$ & 0 & 0 \\
\hline $\mathrm{F}$ & 4 & 15 & 41WA228 & 40 & $\mathrm{NC}$ & 0 & 0 \\
\hline $\mathrm{F}$ & 4 & 16 & 41WA228 & 60 & $\mathrm{NC}$ & 0 & 0 \\
\hline $\mathrm{F}$ & 4 & 17 & & 60 & $\mathrm{NC}$ & 0 & 0 \\
\hline $\mathrm{F}$ & 5 & 1 & & 60 & $\mathrm{NC}$ & 0 & 0 \\
\hline $\mathrm{F}$ & 5 & 2 & 41WA228 & 60 & $\mathrm{NC}$ & $5(40-50)$ & 1 lithic \\
\hline $\mathrm{F}$ & 5 & 3 & 41WA228 & 60 & $\mathrm{NC}$ & 0 & 0 \\
\hline $\mathrm{F}$ & 5 & 4 & 41WA228 & 60 & $\mathrm{NC}$ & 0 & 0 \\
\hline $\mathrm{F}$ & 5 & 5 & 41WA228 & 60 & $\mathrm{NC}$ & 0 & 0 \\
\hline $\mathrm{F}$ & 5 & 6 & 41WA228 & 60 & $\mathrm{NC}$ & $3(20-30)$ & 1 lithic \\
\hline $\mathrm{F}$ & 5 & 7 & 41WA228 & 60 & $\mathrm{NC}$ & $3(20-30)$ & 1 lithic \\
\hline $\mathrm{F}$ & 5 & 8 & 41WA228 & 60 & $\mathrm{NC}$ & 0 & 0 \\
\hline $\mathrm{F}$ & 5 & 9 & & 60 & $\mathrm{NC}$ & 0 & 0 \\
\hline $\mathrm{F}$ & 5 & 10 & & 60 & $\mathrm{NC}$ & 0 & 0 \\
\hline $\mathrm{F}$ & 5 & 11 & & 60 & $\mathrm{NC}$ & 0 & 0 \\
\hline $\mathrm{F}$ & 5 & 12 & & 60 & $\mathrm{NC}$ & 0 & 0 \\
\hline $\mathrm{F}$ & 5 & 13 & & 60 & $\mathrm{NC}$ & 0 & 0 \\
\hline $\mathrm{F}$ & 5 & 14 & & 60 & $\mathrm{NC}$ & 0 & 0 \\
\hline $\mathrm{F}$ & 5 & 15 & & 60 & $\mathrm{NC}$ & 0 & 0 \\
\hline $\mathrm{F}$ & 6 & 1 & & 60 & $\mathrm{NC}$ & 0 & 0 \\
\hline $\mathrm{F}$ & 6 & 2 & 41WA228 & 62 & $\mathrm{NC}$ & 0 & 0 \\
\hline $\mathrm{F}$ & 6 & 3 & 41WA228 & 62 & $\mathrm{NC}$ & $2(10-20)$ & 1 lithic \\
\hline $\mathrm{F}$ & 6 & 4 & 41WA228 & 60 & $\mathrm{NC}$ & 0 & 0 \\
\hline $\mathrm{F}$ & 6 & 5 & 41WA228 & 60 & $\mathrm{NC}$ & 0 & 0 \\
\hline $\mathrm{F}$ & 6 & 6 & 41WA228 & 52 & $\mathrm{NC}$ & 0 & 0 \\
\hline $\mathrm{F}$ & 6 & 7 & 41WA228 & 38 & 38 & $3(20-30)$ & 2 lithics \\
\hline $\mathrm{F}$ & 6 & 8 & 41WA228 & 62 & $\mathrm{NC}$ & 0 & 0 \\
\hline $\mathrm{F}$ & 6 & 9 & & 61 & $\mathrm{NC}$ & 0 & 0 \\
\hline $\mathrm{F}$ & 6 & 11 & & 60 & $\mathrm{NC}$ & 0 & 0 \\
\hline $\mathrm{F}$ & 6 & 12 & & 40 & $\mathrm{NC}$ & 0 & 0 \\
\hline $\mathrm{F}$ & 6 & 13 & & 61 & $\mathrm{NC}$ & 0 & 0 \\
\hline $\mathrm{F}$ & 6 & 14 & & 60 & $\mathrm{NC}$ & 0 & 0 \\
\hline $\mathrm{F}$ & 6 & 15 & & 60 & $\mathrm{NC}$ & 0 & 0 \\
\hline $\mathrm{F}$ & 6 & 16 & & 50 & $\mathrm{NC}$ & 0 & 0 \\
\hline $\mathrm{F}$ & 7 & 1 & & 60 & $\mathrm{NC}$ & 0 & 0 \\
\hline $\mathrm{F}$ & 7 & 2 & & 60 & $\mathrm{NC}$ & 0 & 0 \\
\hline $\mathrm{F}$ & 7 & 3 & 41WA228 & 60 & $\mathrm{NC}$ & 0 & 0 \\
\hline $\mathrm{F}$ & 7 & 4 & 41WA228 & 60 & $\mathrm{NC}$ & 0 & 0 \\
\hline $\mathrm{F}$ & 7 & 5 & 41WA228 & 60 & $\mathrm{NC}$ & 0 & 0 \\
\hline $\mathrm{F}$ & 7 & 6 & 41WA228 & 60 & $\mathrm{NC}$ & 0 & 0 \\
\hline
\end{tabular}


Table G-1. Continued...

\begin{tabular}{|c|c|c|c|c|c|c|c|}
\hline Area & Transect & Shovel Test & Site & $\begin{array}{c}\text { Maximum } \\
\text { depth } \\
\text { (cm bs) }\end{array}$ & $\begin{array}{l}\text { Depth of Bt } \\
\text { soil (cm bs) }\end{array}$ & $\begin{array}{c}\text { Levels with } \\
\text { artifacts } \\
(\mathrm{cm} \text { bs })\end{array}$ & Artifacts (\# and Kind) \\
\hline $\mathrm{F}$ & 7 & 7 & 41WA228 & 60 & $\mathrm{NC}$ & 0 & 0 \\
\hline $\mathrm{F}$ & 7 & 8 & & 60 & $\mathrm{NC}$ & 0 & 0 \\
\hline $\mathrm{F}$ & 7 & 9 & & 60 & $\mathrm{NC}$ & 0 & 0 \\
\hline $\mathrm{F}$ & 7 & 10 & & 60 & $\mathrm{NC}$ & 0 & 0 \\
\hline $\mathrm{F}$ & 7 & 12 & & 60 & $\mathrm{NC}$ & 0 & 0 \\
\hline $\mathrm{F}$ & 7 & 13 & & 50 & $\mathrm{NC}$ & 0 & 0 \\
\hline $\mathrm{F}$ & 7 & 14 & & 50 & $\mathrm{NC}$ & 0 & 0 \\
\hline $\mathrm{F}$ & 7 & 15 & & 80 & $\mathrm{NC}$ & 0 & 0 \\
\hline $\mathrm{F}$ & 8 & 1 & & 60 & $\mathrm{NC}$ & $1(0-10)$ & 1 crown cap \\
\hline$F$ & 8 & 2 & & 60 & $\mathrm{NC}$ & $2(10-20)$ & 2 lithics \\
\hline $\mathrm{F}$ & 8 & 3 & & 60 & $\mathrm{NC}$ & 0 & 0 \\
\hline $\mathrm{F}$ & 8 & 4 & 41WA228 & 60 & $\mathrm{NC}$ & $4(30-40)$ & 2 lithics; 1 bone; charcoal \\
\hline $\mathrm{F}$ & 8 & 5 & 41WA228 & 60 & $\mathrm{NC}$ & $5(40-50)$ & charcoal \\
\hline \multirow[t]{2}{*}{$\mathrm{F}$} & \multirow[t]{2}{*}{8} & \multirow[t]{2}{*}{6} & \multirow[t]{2}{*}{ 41WA228 } & \multirow[t]{2}{*}{60} & \multirow[t]{2}{*}{$\mathrm{NC}$} & $2(10-20)$ & 1 can lid \\
\hline & & & & & & $4(30-40)$ & 1 lithic \\
\hline $\mathrm{F}$ & 8 & 7 & 41WA228 & 60 & $\mathrm{NC}$ & 0 & 0 \\
\hline $\mathrm{F}$ & 8 & 8 & 41WA228 & 60 & $\mathrm{NC}$ & $5(40-50)$ & 1 lithic \\
\hline $\mathrm{F}$ & 8 & 9 & 41WA228 & 60 & $\mathrm{NC}$ & $3(20-30)$ & 0 \\
\hline F & 8 & 10 & 41WA228 & 60 & $\mathrm{NC}$ & $4(30-40)$ & 1 lithic \\
\hline $\mathrm{F}$ & 8 & 11 & & 60 & $\mathrm{NC}$ & 0 & 0 \\
\hline $\mathrm{F}$ & 8 & 12 & & 60 & $\mathrm{NC}$ & $1(0-10)$ & 1 broken cup, modern \\
\hline $\mathrm{F}$ & 8 & 13 & & 6 & $\mathrm{NC}$ & 0 & 0 \\
\hline F & 8 & 14 & & 60 & $\mathrm{NC}$ & 0 & 0 \\
\hline $\mathrm{F}$ & 8 & 15 & & 60 & $\mathrm{NC}$ & 0 & 0 \\
\hline$F$ & 8 & 16 & & 60 & $\mathrm{NC}$ & 0 & 0 \\
\hline$F$ & 8 & 17 & & 60 & $\mathrm{NC}$ & 0 & 0 \\
\hline F & 8 & 18 & & 60 & $\mathrm{NC}$ & 0 & 0 \\
\hline $\mathrm{F}$ & 8 & 19 & & 60 & $\mathrm{NC}$ & 0 & 0 \\
\hline $\mathrm{F}$ & 8 & 20 & & 60 & $\mathrm{NC}$ & 0 & 0 \\
\hline F & 9 & 1 & & 40 & $\mathrm{NC}$ & 0 & 0 \\
\hline $\mathrm{F}$ & 9 & 2 & 41WA266 & 50 & $\mathrm{NC}$ & $3(20-30)$ & 1 crown cap \\
\hline $\mathrm{F}$ & 9 & 6 & & 60 & $\mathrm{NC}$ & 0 & 0 \\
\hline$F$ & 9 & 8 & & 60 & $\mathrm{NC}$ & 0 & 0 \\
\hline F & 9 & 10 & & 60 & $\mathrm{NC}$ & 0 & 0 \\
\hline $\mathrm{F}$ & 9 & 12 & & 60 & $\mathrm{NC}$ & 0 & 0 \\
\hline $\mathrm{F}$ & 9 & 13 & & 60 & $\mathrm{NC}$ & 0 & 0 \\
\hline$F$ & 10 & 1 & & 60 & $\mathrm{NC}$ & 0 & 0 \\
\hline$F$ & 10 & 2 & 41WA266 & 60 & $\mathrm{NC}$ & 0 & 0 \\
\hline $\mathrm{F}$ & 10 & 3 & 41WA266 & 40 & $\mathrm{NC}$ & $3(20-30)$ & 1 lithic \\
\hline $\mathrm{F}$ & 10 & 4 & 41WA266 & 40 & 38 & $2(10-20)$ & 1 lithic \\
\hline \multirow[t]{2}{*}{$\bar{F}$} & \multirow[t]{2}{*}{10} & \multirow[t]{2}{*}{5} & \multirow[t]{2}{*}{ 41WA266 } & \multirow[t]{2}{*}{60} & \multirow[t]{2}{*}{$\mathrm{NC}$} & $3(20-30)$ & 1 lithic \\
\hline & & & & & & $4(30-40)$ & 1 lithic \\
\hline$F$ & 10 & 8 & & 60 & $\mathrm{NC}$ & 0 & 0 \\
\hline$F$ & 10 & 9 & & 60 & $\mathrm{NC}$ & 0 & 0 \\
\hline $\mathrm{F}$ & 10 & 10 & & 60 & $\mathrm{NC}$ & 0 & 0 \\
\hline $\mathrm{F}$ & 10 & 12 & & 10 & 10 & 0 & 0 \\
\hline$F$ & 10 & 14 & & 60 & $\mathrm{NC}$ & 0 & 0 \\
\hline
\end{tabular}


Table G-1. Continued...

\begin{tabular}{|c|c|c|c|c|c|c|c|}
\hline Area & Transect & Shovel Test & Site & $\begin{array}{c}\text { Maximum } \\
\text { depth } \\
(\mathrm{cm} \mathrm{bs})\end{array}$ & $\begin{array}{l}\text { Depth of Bt } \\
\text { soil (cm bs) }\end{array}$ & $\begin{array}{c}\text { Levels with } \\
\text { artifacts } \\
(\mathrm{cm} \mathrm{bs})\end{array}$ & Artifacts (\# and Kind) \\
\hline $\mathrm{F}$ & 11 & 1 & 41WA266 & 61 & NC & 0 & 0 \\
\hline $\mathrm{F}$ & 11 & 2 & 41WA266 & 33 & 20 & $3(20-30)$ & 1 lithic \\
\hline $\mathrm{F}$ & 11 & 3 & 41WA266 & 50 & $\mathrm{NC}$ & $3(20-30)$ & 1 lithic \\
\hline $\mathrm{F}$ & 11 & 4 & 41WA266 & 40 & $\mathrm{NC}$ & 0 & 0 \\
\hline $\mathrm{F}$ & 11 & 5 & & 30 & $\mathrm{NC}$ & 0 & 0 \\
\hline $\mathrm{F}$ & 11 & 6 & & 60 & $\mathrm{NC}$ & 0 & 0 \\
\hline $\mathrm{F}$ & 11 & 7 & & 60 & $\mathrm{NC}$ & 0 & 0 \\
\hline $\mathrm{F}$ & 11 & 8 & & 60 & $\mathrm{NC}$ & 0 & 0 \\
\hline $\mathrm{F}$ & 11 & 9 & & 20 & 20 & $2(10-20)$ & 1 glass \\
\hline $\mathrm{F}$ & 11 & 11 & & 60 & $\mathrm{NC}$ & 0 & 0 \\
\hline $\mathrm{F}$ & 11 & 13 & & 60 & $\mathrm{NC}$ & $4(30-40)$ & 1 metal fuel can \\
\hline $\mathrm{F}$ & 12 & 1 & & 50 & $\mathrm{NC}$ & $1(0-10)$ & 1 wire \\
\hline $\mathrm{F}$ & 12 & 2 & 41WA266 & 50 & $\mathrm{NC}$ & 0 & 0 \\
\hline $\mathrm{F}$ & 12 & 3 & & 60 & $\mathrm{NC}$ & 0 & 0 \\
\hline $\mathrm{F}$ & 13 & 1 & & 60 & $\mathrm{NC}$ & 0 & 0 \\
\hline $\mathrm{F}$ & 13 & 3 & & 40 & $\mathrm{NC}$ & 0 & 0 \\
\hline $\mathrm{F}$ & 14 & 1 & & 60 & $\mathrm{NC}$ & 0 & 0 \\
\hline $\mathrm{F}$ & 15 & 2 & & 50 & 50 & 0 & 0 \\
\hline $\mathrm{F}$ & 15 & 3 & & 60 & $\mathrm{NC}$ & 0 & 0 \\
\hline$F$ & 15 & 4 & & 60 & $\mathrm{NC}$ & 0 & 0 \\
\hline $\mathrm{F}$ & 15 & 5 & & 60 & $\mathrm{NC}$ & 0 & 0 \\
\hline $\mathrm{F}$ & 15 & 6 & & 60 & $\mathrm{NC}$ & 0 & 0 \\
\hline $\mathrm{F}$ & 16 & 1 & & 60 & $\mathrm{NC}$ & 0 & 0 \\
\hline $\mathrm{F}$ & 16 & 2 & & 10 & 10 & 0 & 0 \\
\hline $\mathrm{F}$ & 16 & 4 & & 60 & $\mathrm{NC}$ & $1(0-10)$ & 1 glass \\
\hline $\mathrm{F}$ & 16 & 5 & & 60 & $\mathrm{NC}$ & 0 & 0 \\
\hline $\mathrm{F}$ & 16 & 7 & & 60 & $\mathrm{NC}$ & 0 & 0 \\
\hline $\mathrm{F}$ & 16 & 8 & & 60 & $\mathrm{NC}$ & 0 & 0 \\
\hline $\mathrm{F}$ & 16 & 9 & & 60 & $\mathrm{NC}$ & 0 & 0 \\
\hline $\mathrm{F}$ & 16 & 11 & & 60 & $\mathrm{NC}$ & 0 & 0 \\
\hline $\mathrm{F}$ & 16 & 13 & & 60 & $\mathrm{NC}$ & $4(30-40)$ & 1 lithic \\
\hline $\mathrm{F}$ & 17 & 1 & & 50 & 46 & 0 & 0 \\
\hline $\mathrm{F}$ & 17 & 2 & & 40 & 40 & 0 & 0 \\
\hline $\mathrm{F}$ & 17 & 3 & & 30 & 24 & 0 & 0 \\
\hline $\mathrm{F}$ & 17 & 4 & & 50 & $\mathrm{NC}$ & 0 & 0 \\
\hline$F$ & 17 & 5 & & 60 & $\mathrm{NC}$ & $1(0-10)$ & 1 biface frag. \\
\hline $\mathrm{F}$ & 17 & 6 & & 60 & $\mathrm{NC}$ & 0 & 0 \\
\hline $\mathrm{F}$ & 17 & 7 & & 60 & $\mathrm{NC}$ & $6(50-60)$ & 1 lithic \\
\hline $\mathrm{F}$ & 17 & 8 & & 60 & $\mathrm{NC}$ & $1(0-10)$ & 1 metal frag. \\
\hline $\mathrm{F}$ & 18 & 1 & & 60 & $\mathrm{NC}$ & 0 & 0 \\
\hline $\mathrm{F}$ & 18 & 2 & & 60 & $\mathrm{NC}$ & 0 & 0 \\
\hline $\mathrm{F}$ & 19 & 1 & & 60 & $\mathrm{NC}$ & 0 & 0 \\
\hline$F$ & 19 & 2 & & 60 & $\mathrm{NC}$ & 0 & 0 \\
\hline $\mathrm{F}$ & 19 & 3 & & 60 & $\mathrm{NC}$ & 0 & 0 \\
\hline $\mathrm{F}$ & 19 & 4 & & 35 & 35 & 0 & 0 \\
\hline $\mathrm{F}$ & 19 & 5 & & 60 & $\mathrm{NC}$ & 0 & 0 \\
\hline $\mathrm{F}$ & 20 & 1 & & 60 & $\mathrm{NC}$ & 0 & 0 \\
\hline
\end{tabular}


Table G-1. Continued...

\begin{tabular}{|c|c|c|c|c|c|c|c|}
\hline Area & Transect & Shovel Test & Site & $\begin{array}{c}\text { Maximum } \\
\text { depth } \\
(\mathrm{cm} \mathrm{bs})\end{array}$ & $\begin{array}{l}\text { Depth of Bt } \\
\text { soil (cm bs) }\end{array}$ & $\begin{array}{c}\text { Levels with } \\
\text { artifacts } \\
(\mathrm{cm} \text { bs }) \\
\end{array}$ & Artifacts (\# and Kind) \\
\hline $\mathrm{F}$ & 20 & 2 & & 20 & 18 & 0 & 0 \\
\hline $\mathrm{F}$ & 20 & 3 & & 60 & $\mathrm{NC}$ & $3(20-30)$ & 1 pull tab \\
\hline $\mathrm{F}$ & 20 & 4 & & 60 & $\mathrm{NC}$ & 0 & 0 \\
\hline $\mathrm{F}$ & 20 & 5 & & 60 & $\mathrm{NC}$ & 0 & 0 \\
\hline $\mathrm{F}$ & 21 & 1 & & 60 & $\mathrm{NC}$ & 0 & 0 \\
\hline $\mathrm{F}$ & 21 & 2 & & 60 & $\mathrm{NC}$ & 0 & 0 \\
\hline $\mathrm{F}$ & 21 & 3 & & 60 & $\mathrm{NC}$ & 0 & 0 \\
\hline $\mathrm{F}$ & 22 & 1 & & 60 & $\mathrm{NC}$ & 0 & 0 \\
\hline $\mathrm{F}$ & 22 & 2 & & 60 & $\mathrm{NC}$ & 0 & 0 \\
\hline $\mathrm{F}$ & 22 & 3 & & 70 & $\mathrm{NC}$ & $6(50-60)$ & 1 lithic \\
\hline $\mathrm{F}$ & 23 & 1 & & 60 & $\mathrm{NC}$ & 0 & 0 \\
\hline $\mathrm{F}$ & 23 & 2 & & 60 & $\mathrm{NC}$ & 0 & 0 \\
\hline $\mathrm{F}$ & 23 & 3 & & 60 & $\mathrm{NC}$ & 0 & 0 \\
\hline $\mathrm{F}$ & 24 & 1 & & 60 & $\mathrm{NC}$ & 0 & 0 \\
\hline $\mathrm{F}$ & 24 & 2 & & 60 & $\mathrm{NC}$ & 0 & 0 \\
\hline $\mathrm{F}$ & 25 & 1 & & 60 & $\mathrm{NC}$ & 0 & 0 \\
\hline $\mathrm{F}$ & 26 & 1 & & 60 & $\mathrm{NC}$ & 0 & 0 \\
\hline $\mathrm{F}$ & 26 & 2 & & 60 & $\mathrm{NC}$ & 0 & 0 \\
\hline $\mathrm{F}$ & 26 & 3 & & 60 & $\mathrm{NC}$ & 0 & 0 \\
\hline $\mathrm{F}$ & 26 & 4 & & 60 & $\mathrm{NC}$ & 0 & 0 \\
\hline $\mathrm{F}$ & 26 & 5 & & 60 & $\mathrm{NC}$ & 0 & 0 \\
\hline $\mathrm{F}$ & 26 & 6 & & 60 & $\mathrm{NC}$ & 0 & 0 \\
\hline $\mathrm{F}$ & 26 & 7 & & 60 & $\mathrm{NC}$ & $3(20-30)$ & 1 lithic \\
\hline $\mathrm{F}$ & 26 & 8 & & 30 & 30 & 0 & 0 \\
\hline $\mathrm{F}$ & 26 & 9 & & 60 & $\mathrm{NC}$ & 0 & 0 \\
\hline $\mathrm{F}$ & 26 & 10 & & 60 & $\mathrm{NC}$ & 0 & 0 \\
\hline $\mathrm{F}$ & 26 & 11 & & 60 & $\mathrm{NC}$ & 0 & 0 \\
\hline
\end{tabular}




\section{Appendix $\mathbf{H}$}

\section{Shovel Test Results: 41WA47}


Table H-1. Shovel Test results, 41WA47

\begin{tabular}{|c|c|c|c|c|c|c|c|}
\hline Transect & $\begin{array}{c}\text { Shovel } \\
\text { Test }\end{array}$ & Northing & Easting & $\begin{array}{c}\text { Maximum } \\
\text { depth } \\
(\mathrm{cm} \mathrm{bs})\end{array}$ & $\begin{array}{l}\text { Depth of Bt } \\
\text { soil (cm bs) }\end{array}$ & $\begin{array}{c}\text { Levels with } \\
\text { artifacts } \\
(\mathrm{cm} \text { bs })\end{array}$ & Artifacts (\# and Kind) \\
\hline & & 1000 & 940 & $61 \mathrm{~cm}$ & $\mathrm{NC}$ & $4(30-40)$ & 1 lithic \\
\hline & & 1040 & 940 & $60 \mathrm{~cm}$ & $60 \mathrm{~cm}$ & $5(40-50)$ & 1 lithic \\
\hline & & \multirow[t]{4}{*}{920} & \multirow[t]{4}{*}{$960^{*}$} & \multirow[t]{4}{*}{$80 \mathrm{~cm}$} & \multirow[t]{4}{*}{$\mathrm{NC}$} & $3(20-30)$ & 2 lithics \\
\hline & & & & & & $4(30-40)$ & 2 lithics \\
\hline & & & & & & $5(40-50)$ & 2 lithics \\
\hline & & & & & & $7(60-70)$ & 1 lithic \\
\hline & & 960 & $960 \div$ & $27 \mathrm{~cm}$ & $27 \mathrm{~cm}$ & 0 & 0 \\
\hline & & 1040 & 980 & $80 \mathrm{~cm}$ & $78 \mathrm{~cm}$ & $6(50-60)$ & 1 ceramic \\
\hline & & \multirow[t]{3}{*}{1000} & \multirow[t]{3}{*}{985} & \multirow[t]{3}{*}{$39 \mathrm{~cm}$} & \multirow[t]{3}{*}{$39 \mathrm{~cm}$} & $2(10-20)$ & 1 lithic \\
\hline & & & & & & $3(20-30)$ & 3 lithics \\
\hline & & & & & & $4(30-40)$ & $1 \mathrm{FCR}$ \\
\hline & & 980 & 999 & $30 \mathrm{~cm}$ & $30 \mathrm{~cm}$ & $3(20-30)$ & 1 lithic \\
\hline & & \multirow[t]{2}{*}{943} & \multirow[t]{2}{*}{1000} & \multirow[t]{2}{*}{$36 \mathrm{~cm}$} & \multirow[t]{2}{*}{$30-36 \mathrm{~cm}$} & $2(10-20)$ & 1 lithic \\
\hline & & & & & & $3(20-30)$ & $1 \mathrm{FCR}$ \\
\hline & & 920 & 1019末 & $20 \mathrm{~cm}$ & $20 \mathrm{~cm}$ & 0 & \begin{tabular}{|l|}
0 \\
\end{tabular} \\
\hline & & \multirow[t]{2}{*}{1000} & \multirow[t]{2}{*}{1019} & \multirow[t]{2}{*}{$50 \mathrm{~cm}$} & \multirow[t]{2}{*}{$50 \mathrm{~cm}$} & $3(20-30)$ & 2 lithics \\
\hline & & & & & & $4(30-40)$ & 1 lithic \\
\hline & & 960 & 1019 & $20 \mathrm{~cm}$ & $20 \mathrm{~cm}$ & $2(10-20)$ & 2 lithics \\
\hline & & 1010 & 1020 & $40 \mathrm{~cm}$ & $39 \mathrm{~cm}$ & $3(20-30)$ & 1 lithic \\
\hline & & 940 & 1060 & $60 \mathrm{~cm}$ & $\mathrm{NC}$ & 0 & 0 \\
\hline & & \multirow[t]{2}{*}{1022} & \multirow[t]{2}{*}{$1060 * *$} & \multirow[t]{2}{*}{$40 \mathrm{~cm}$} & \multirow[t]{2}{*}{$\mathrm{NC}$} & $2(10-20)$ & 3 lithics \\
\hline & & & & & & $4(30-40)$ & 1 lithic \\
\hline & & 960 & 1061 & $60 \mathrm{~cm}$ & $\mathrm{NC}$ & $4(30-40)$ & 1 lithic \\
\hline & & \multirow[t]{4}{*}{980} & 1100 & $70 \mathrm{~cm}$ & $\mathrm{NC}$ & $3(20-30)$ & 1 lithic \\
\hline & & & & & & $5(40-50)$ & 1 lithic \\
\hline & & & & & & $6(50-60)$ & 2 lithics; 4 charcoal \\
\hline & & & & & & $7(60-70)$ & 1 nut endocarp; 3 charcoal \\
\hline & & 1020 & 1100 & $70 \mathrm{~cm}$ & $\mathrm{NC}$ & $6(50-60)$ & 1 lithic \\
\hline & & & & & $\mathrm{NC}$ & $7(60-70)$ & 1 poss. flake \\
\hline & & 1060 & 1115 & $60 \mathrm{~cm}$ & $\mathrm{NC}$ & $5(40-50)$ & 1 lithic \\
\hline & & 1020 & $1140 \pm * * *$ & $60 \mathrm{~cm}$ & $\mathrm{NC}$ & $5(40-50)$ & 1 poss. flake \\
\hline & & 1040 & 1140 & $60 \mathrm{~cm}$ & $\mathrm{NC}$ & 0 & 0 \\
\hline & & 1060 & 1140 & $70 \mathrm{~cm}$ & $\mathrm{NC}$ & $6(50-60)$ & 2 lithics \\
\hline & & & & & $\mathrm{NC}$ & $7(60-70)$ & $1 \mathrm{FCR}$ \\
\hline & & 1100 & 1140 & $77 \mathrm{~cm}$ & $72-77 \mathrm{~cm}$ & $6(50-60)$ & 1 projectile point \\
\hline & & 1060 & 1180 & $60 \mathrm{~cm}$ & $56-60 \mathrm{~cm}$ & $4(30-40)$ & 1 lithic \\
\hline & & & & & & $6(50-60)$ & 2 lithics; 1 core \\
\hline & & 1080 & 1220 末 & $50 \mathrm{~cm}$ & $48-50 \mathrm{~cm}$ & 0 & 0 \\
\hline & & 1120 & 1220 & $9 \mathrm{~cm}$ & $9 \mathrm{~cm}$ & 0 & 0 \\
\hline 1 & 10 & & & 70 & $\mathrm{NC}$ & $5(40-50)$ & 1 lithic \\
\hline & & & & & & $6(50-60)$ & 1 lithic \\
\hline & & & & & & $7(60-70)$ & 1 lithic \\
\hline 1 & 11 & & & 60 & 60 & $1(0-10)$ & 1 glass \\
\hline & & & & & & $3(20-30)$ & 2 lithics; charcoal \\
\hline & & & & & & $4(30-40)$ & 2 lithics \\
\hline & & & & & & $5(40-50)$ & 2 lithics; 1 FCR(?) \\
\hline & & & & & & $6(50-60)$ & charcoal \\
\hline
\end{tabular}


Table H-1. Continued...

\begin{tabular}{|c|c|c|c|c|c|c|c|}
\hline Transect & $\begin{array}{c}\text { Shovel } \\
\text { Test }\end{array}$ & Northing & Easting & $\begin{array}{c}\text { Maximum } \\
\text { depth } \\
(\mathrm{cm} \mathrm{bs})\end{array}$ & $\begin{array}{l}\text { Depth of Bt } \\
\text { soil (cm bs) }\end{array}$ & $\begin{array}{c}\text { Levels with } \\
\text { artifacts } \\
(\mathbf{c m} \text { bs })\end{array}$ & Artifacts (\# and Kind) \\
\hline \multirow[t]{2}{*}{1} & \multirow[t]{2}{*}{12} & & & \multirow[t]{2}{*}{60} & \multirow[t]{2}{*}{60} & $1(0-10)$ & 1 glass \\
\hline & & & & & & $3(20-30)$ & 1 plastic \\
\hline \multirow[t]{2}{*}{1} & \multirow[t]{2}{*}{13} & & & \multirow[t]{2}{*}{60} & \multirow[t]{2}{*}{59} & $2(10-20)$ & 1 glass \\
\hline & & & & & & $3(20-30)$ & $1 \mathrm{FCR}(?)$ \\
\hline \multirow[t]{2}{*}{1} & \multirow[t]{2}{*}{14} & & & \multirow[t]{2}{*}{60} & \multirow[t]{2}{*}{50} & $1(0-10)$ & 1 tent peg; 1 crown cap; 1 plastic; 1 glass \\
\hline & & & & & & $4(30-40)$ & 1 lithic \\
\hline 1 & 15 & & & 60 & $\mathrm{NC}$ & 0 & 0 \\
\hline 1 & 16 & & & 40 & 40 & 0 & 0 \\
\hline 2 & 10 & & & 30 & 15 & 0 & 0 \\
\hline 2 & 11 & & & 30 & 15 & $1(0-10)$ & 1 tent peg \\
\hline 2 & 12 & & & 30 & 15 & $1(0-10)$ & 1 FCR(?) \\
\hline 2 & 13 & & & 30 & 18 & 0 & 0 \\
\hline 2 & 14 & & & 40 & 28 & 0 & 0 \\
\hline 2 & 15 & & & 70 & 59 & 0 & 0 \\
\hline 2 & 16 & & & 30 & 15 & 0 & 0 \\
\hline 5 & 1 & & & 60 & $\mathrm{NC}$ & 0 & 0 \\
\hline 6 & 1 & & & 60 & $\mathrm{NC}$ & $2(10-20)$ & 2 lithics \\
\hline \multirow[t]{2}{*}{6} & \multirow[t]{2}{*}{2} & & & \multirow[t]{2}{*}{60} & \multirow[t]{2}{*}{$\mathrm{NC}$} & $3(20-30)$ & 1 lithic \\
\hline & & & & & & $4(30-40)$ & 1 lithic \\
\hline 13 & 1 & & & 60 & $\mathrm{NC}$ & 0 & 0 \\
\hline 13 & 2 & & & 31 & 30 & 0 & 0 \\
\hline 14 & 1 & & & 60 & 60 & 0 & 0 \\
\hline 14 & 2 & & & 60 & $\mathrm{NC}$ & 0 & 0 \\
\hline
\end{tabular}

$\mathrm{NC}=$ no contact with Bt soil

*=point bar formation

$* *=$ disturbed fill, water pipeline at $39 \mathrm{~cm}$

$* * *=$ orange mottling in level $6=$ close to clay

$\$=$ disturbed context 



\section{Appendix I}

\section{Excavation Data: Blocks Y47 and M59}


Table I-1. Excavation data, Blocks Y47 and M59

\begin{tabular}{|c|c|c|c|c|c|c|}
\hline $\begin{array}{c}\text { Block \& } \\
\text { Unit }\end{array}$ & $\begin{array}{l}\text { Northing } \\
\text { and } \\
\text { Easting }\end{array}$ & $\begin{array}{l}\text { maximum } \\
\text { depth } \\
\text { (cmbs) }\end{array}$ & Levels \# (m*) & $\begin{array}{l}\text { screen artifacts } \\
\quad(\# \& \text { kind })\end{array}$ & $\begin{array}{l}\text { piece plotted artifacts } \\
\text { (\# \& kind) }\end{array}$ & $\begin{array}{c}\text { depth of } \\
\text { Bt soil } \\
\text { (cmbs) }\end{array}$ \\
\hline \multirow[t]{5}{*}{ Y47-1 } & \multirow[t]{5}{*}{$\begin{array}{l}\text { N } 0999 \\
\text { E } 1020\end{array}$} & \multirow[t]{5}{*}{$\begin{array}{c}57 \\
(92.70)\end{array}$} & $218(93.20-93.10)$ & $\begin{array}{l}1 \text { pull tab; } 1 \text { glass; } 1 \text { proj } \\
\text { point; } 30 \text { lithics }\end{array}$ & 0 & \multirow[t]{5}{*}{$\begin{array}{c}35 \\
(92.90)\end{array}$} \\
\hline & & & $219(93.10-93.00)$ & $\begin{array}{l}\text { aluminum foil; glass; } \\
41 \text { lithics; } 2 \text { petrified wood; } \\
1 \text { ceramic }\end{array}$ & 0 & \\
\hline & & & $220(93.00-92.90)$ & 45 lithics & 0 & \\
\hline & & & $221(92.90-92.80)$ & 2 lithics & 0 & \\
\hline & & & $222(92.80-92.70)$ & 0 & 0 & \\
\hline \multirow[t]{5}{*}{ Y47-2 } & \multirow{5}{*}{$\begin{array}{l}\text { N } 0999 \\
\text { E } 1021\end{array}$} & \multirow{5}{*}{$\begin{array}{c}57 \\
(92.70)\end{array}$} & $218(93.20-93.10)$ & 14 Lithics; 1 FCR(?) & 0 & \multirow{5}{*}{$\begin{array}{c}52 \\
(92.75)\end{array}$} \\
\hline & & & $219(93.10-93.00)$ & 62 lithics & 0 & \\
\hline & & & $220(93.00-92.90)$ & 51 Lithics; 2 FCR(?) & 0 & \\
\hline & & & $221(92.90-92.80)$ & 1 proi point; 10 lithics & 0 & \\
\hline & & & $222(92.80-92.70)$ & 3 lithics & 0 & \\
\hline \multirow[t]{4}{*}{ M59-1 } & \multirow[t]{4}{*}{$\begin{array}{l}\text { N } 0939 \\
\text { E } 0960\end{array}$} & \multirow[t]{4}{*}{$\begin{array}{c}63 \\
(89.30)\end{array}$} & $\begin{array}{c}251-252 \\
(89.90-89.75) \\
\end{array}$ & $\begin{array}{l}1 \text { wire; } 1 \text { tent stake; } \\
1 \text { pull tab }\end{array}$ & 0 & \multirow[t]{4}{*}{$\begin{array}{c}50 \\
(89.43)\end{array}$} \\
\hline & & & $\begin{array}{c}252-253 \\
(89.75-89.65) \\
\end{array}$ & misc modern; 3 lithics & 0 & \\
\hline & & & $\begin{array}{c}253-254 \\
(89.65-89.55) \\
\end{array}$ & 1 lithic; 1 FCR(?) & 0 & \\
\hline & & & $\begin{array}{c}254-255 \\
(89.55-89.45) \\
\end{array}$ & 0 & 0 & \\
\hline \multirow[t]{3}{*}{ M59-2 } & \multirow[t]{3}{*}{$\begin{array}{l}\text { N } 0939 \\
\text { E } 0961\end{array}$} & \multirow[t]{3}{*}{$\begin{array}{c}43 \\
(89.55)\end{array}$} & $\begin{array}{c}250-252 \\
(90.10-89.75) \\
\end{array}$ & $\begin{array}{l}\text { misc modern; } 1 \text { mussel } \\
\text { shell frag.; charcoal }\end{array}$ & 0 & \multirow[t]{3}{*}{$\begin{array}{c}29 \\
(89.69)\end{array}$} \\
\hline & & & $\begin{array}{c}252-253 \\
(89.75-89.65) \\
\end{array}$ & 4 lithics; 1 petrified wood & 0 & \\
\hline & & & $\begin{array}{c}253-254 \\
(89.65-89.55) \\
\end{array}$ & 1 lithic; 1 FCR & 0 & \\
\hline
\end{tabular}

*all levels are referenced to survey datum on site - established as arbitrary $100.00 \mathrm{~m}$ elevation 


\section{Appendix J}

\section{Excavation Data: Block NN/OO}


Table J-1. Excavation data, Block NN/OO

\begin{tabular}{|c|c|c|c|c|c|c|}
\hline $\begin{array}{l}\text { Block \& } \\
\text { Unit }\end{array}$ & $\begin{array}{c}\text { Northing } \\
\text { and } \\
\text { Easting }\end{array}$ & $\begin{array}{c}\text { maximum } \\
\text { depth } \\
(\text { cmbs })\end{array}$ & Levels \# (m*) & $\begin{array}{l}\text { screen artifacts } \\
\quad(\# \& \text { kind) }\end{array}$ & $\begin{array}{l}\text { piece plotted artifacts } \\
\text { (\# \& kind) }\end{array}$ & $\begin{array}{c}\text { depth of } \\
\text { Bt soil } \\
\text { (cmbs) }\end{array}$ \\
\hline \multirow[t]{6}{*}{ NN51-24 } & \multirow[t]{6}{*}{$\begin{array}{l}\text { N } 0975 \\
\text { E } 1098\end{array}$} & \multirow[t]{6}{*}{$\begin{array}{c}64 \\
(88.61)\end{array}$} & $258(89.20-89.10)$ & $\begin{array}{l}1 \text { crown cap; } 2 \text { wires; } \\
11 \text { lithics; } 1 \text { bone }\end{array}$ & 0 & \multirow[t]{6}{*}{$\begin{array}{c}35 \\
(88.80)\end{array}$} \\
\hline & & & $259(89.10-89.00)$ & $\begin{array}{l}2 \text { proj points; } 48 \text { lithics; } \\
1 \text { ceramic; } 5 \text { bone frags.; } \\
1 \text { burnt nutshell; charcoal } \\
\end{array}$ & 1 proj point; 1 bone & \\
\hline & & & $260(89.00-88.90)$ & $\begin{array}{l}\text { 200 metal frags; } \\
37 \text { lithics; } 5 \text { ceramics; } \\
2 \text { bone frags.; } 1 \text { burned } \\
\text { nutshell; charcoal }\end{array}$ & 0 & \\
\hline & & & $261(88.90-88.80)$ & $\begin{array}{l}\text { 300 metal frags; } \\
50 \text { lithics; } 3 \text { FCR(?); } \\
2 \text { ceramics; } 4 \text { bone frags.; } \\
1 \text { burned nutshell }\end{array}$ & 0 & \\
\hline & & & $262(88.80-88.70)$ & $\begin{array}{l}26 \text { metal frags; } 21 \text { lithics; } \\
1 \text { ceramic; burned nutshell; } \\
\text { charcoal }\end{array}$ & 0 & \\
\hline & & & $263(88.70-88.60)$ & Lithics; burned nutshell & 0 & \\
\hline \multirow[t]{6}{*}{ NN51-25 } & \multirow{6}{*}{$\begin{array}{l}\text { N } 0975 \\
\text { E } 1099\end{array}$} & \multirow{6}{*}{$\begin{array}{c}52 \\
(88.70)\end{array}$} & $258(89.20-89.10)$ & 19 lithics; 19 ceramics & 1 lithic & \multirow{6}{*}{$\begin{array}{c}43 \\
(88.79)\end{array}$} \\
\hline & & & $259(89.10-89.00)$ & $\begin{array}{l}1 \text { pull tab; } 37 \text { lithics; } \\
6 \text { bone frags; charcoal }\end{array}$ & $\begin{array}{l}2 \text { bone frags.; } 1 \text { ceramic; } \\
1 \text { petrified wood }\end{array}$ & \\
\hline & & & $260(89.00-88.90)$ & $\begin{array}{l}41 \text { lithics; } 1 \text { ceramic; } \\
\text { charcoal }\end{array}$ & \begin{tabular}{|l|}
1 ceramic; 1 lithic; \\
1 bone \\
\end{tabular} & \\
\hline & & & $261(88.90-88.80)$ & $\begin{array}{l}31 \text { lithics; } 3 \text { ceramics; } \\
\text { charcoal }\end{array}$ & 0 & \\
\hline & & & $262(88.80-88.70)$ & 3 lithics; charcoal & 1 ceramic & \\
\hline & & & $263(88.70-88.60)$ & 1 lithic & 0 & \\
\hline \multirow[t]{6}{*}{ OO51-21 } & \multirow{6}{*}{$\begin{array}{l}\text { N } 0975 \\
\text { E } 1100\end{array}$} & \multirow{6}{*}{$\begin{array}{c}57 \\
(88.60)\end{array}$} & $258(89.20-89.10)$ & 0 & 0 & \multirow{6}{*}{$\begin{array}{c}40 \\
(88.77)\end{array}$} \\
\hline & & & $259(89.10-89.00)$ & $\begin{array}{l}54 \text { lithics; } 1 \text { ceramic; } \\
8 \text { bone frags. }\end{array}$ & 1 ceramic; 1 bone & \\
\hline & & & $260(89.00-88.90)$ & $\begin{array}{l}57 \text { lithics; } 3 \text { ceramics; } \\
13 \text { bone frags; charcoal }\end{array}$ & $\begin{array}{l}1 \text { proj point; } 1 \text { ceramic; } \\
1 \text { bone }\end{array}$ & \\
\hline & & & $261(88.90-88.80)$ & $\begin{array}{l}37 \text { lithics; } 2 \text { ceramics; } \\
3 \text { bone frags; charcoal }\end{array}$ & 1 bone & \\
\hline & & & $262(88.80-88.70)$ & 8 lithics; charcoal & 0 & \\
\hline & & & $263(88.70-88.60)$ & \begin{tabular}{|r|}
0 \\
\end{tabular} & 0 & \\
\hline \multirow[t]{8}{*}{ NN51-17 } & \multirow[t]{8}{*}{$\begin{array}{l}\text { N } 0976 \\
\text { E } 1098\end{array}$} & \multirow[t]{8}{*}{$\begin{array}{c}75 \\
(88.63)\end{array}$} & $257(89.30-89.20)$ & $\begin{array}{l}1 \text { glass; } 1 \text { plastic; } \\
4 \text { lithics }\end{array}$ & 0 & \multirow[t]{8}{*}{$\begin{array}{c}62 \\
(88.76)\end{array}$} \\
\hline & & & $258(89.20-89.10)$ & $\begin{array}{l}1 \text { proj point; } 23 \text { lithics; } \\
2 \text { ceramics; } 3 \text { bone frags. }\end{array}$ & 0 & \\
\hline & & & $259(89.10-89.00)$ & $\begin{array}{l}39 \text { flakes; } 3 \text { ceramics; } \\
1 \text { bone; charcoal }\end{array}$ & 0 & \\
\hline & & & $260(89.00-88.90)$ & $\begin{array}{l}18 \text { lithics; } 1 \text { bone frag.; } \\
\text { charcoal }\end{array}$ & 0 & \\
\hline & & & $261(88.90-88.80)$ & $\begin{array}{l}30 \text { lithics; } 2 \text { ceramics; } \\
1 \text { bone frag.; charcoal }\end{array}$ & 0 & \\
\hline & & & $262(88.80-88.70)$ & $\begin{array}{l}23 \text { lithics; } 5 \text { bone frags.; } \\
\text { charcoal }\end{array}$ & 0 & \\
\hline & & & $263(88.70-88.60)$ & $\begin{array}{l}5 \text { lithics; } 1 \text { bone frag.; } \\
\text { charcoal }\end{array}$ & 0 & \\
\hline & & & $264(88.60-88.50)$ & 3 lithics & 0 & \\
\hline
\end{tabular}

*all levels are referenced to survey datum on site - established as arbitrary $100.00 \mathrm{~m}$ elevation 
Table J-1. Continued...

\begin{tabular}{|c|c|c|c|c|c|c|}
\hline $\begin{array}{c}\text { Block \& } \\
\text { Unit }\end{array}$ & $\begin{array}{l}\text { Northing } \\
\text { and } \\
\text { Easting } \\
\end{array}$ & $\begin{array}{c}\text { maximum } \\
\text { depth } \\
(\text { cmbs })\end{array}$ & Levels \# (m*) & $\begin{array}{l}\text { screen artifacts } \\
\quad(\# \& \text { kind })\end{array}$ & $\begin{array}{l}\text { piece plotted artifacts } \\
\text { (\# \& kind) }\end{array}$ & $\begin{array}{c}\text { depth of } \\
\text { Bt soil } \\
\text { (cmbs) }\end{array}$ \\
\hline \multirow[t]{6}{*}{ NN51-16 } & \multirow[t]{6}{*}{$\begin{array}{l}\text { N } 0976 \\
\text { E } 1099\end{array}$} & \multirow[t]{6}{*}{$\begin{array}{c}64 \\
(88.70)\end{array}$} & $257(89.30-89.20)$ & $\begin{array}{l}\text { misc modern; } 1 \text { glass; } \\
1 \text { proj point; } 12 \text { lithics; } \\
1 \text { FCR(?) }\end{array}$ & 0 & \multirow[t]{6}{*}{$\begin{array}{c}54 \\
(88.80)\end{array}$} \\
\hline & & & $258(89.20-89.10)$ & $\begin{array}{l}1 \text { wire; } 1 \text { spent shotgun } \\
\text { shell; } 1 \text { concrete frag; } \\
36 \text { lithics; } 47 \text { bone frags.; } \\
2 \text { burned nutshells }\end{array}$ & 0 & \\
\hline & & & $259(89.10-89.00)$ & $\begin{array}{l}1 \text { hammerstone; } \\
35 \text { lithics; } 5 \text { ceramics; } \\
60 \text { bone frags.; } 1 \text { burned } \\
\text { nutshell; charcoal }\end{array}$ & 1 core; 4 charcoal samples & \\
\hline & & & $260(89.00-88.90)$ & $\begin{array}{l}1 \text { proj point; } 29 \text { lithics; } \\
\text { bone frags; charcoal }\end{array}$ & 0 & \\
\hline & & & $261(88.90-88.80)$ & $\begin{array}{l}1 \text { hammerstone; } \\
36 \text { lithics; } 1 \text { ceramic; } \\
9 \text { bone frags.; burned } \\
\text { nutshell frags; charcoal }\end{array}$ & 0 & \\
\hline & & & $262(88.80-88.70)$ & 6 lithics; charcoal & 0 & \\
\hline \multirow[t]{7}{*}{ O051-20 } & \multirow[t]{7}{*}{$\begin{array}{l}\text { N } 0976 \\
\text { E } 1100\end{array}$} & \multirow[t]{7}{*}{$\begin{array}{c}59 \\
(88.69)\end{array}$} & $257(89.30-89.20)$ & $\begin{array}{l}1 \text { glass; } 1 \text { metal frag; } \\
1 \text { lithic }\end{array}$ & 0 & \multirow[t]{7}{*}{$\begin{array}{c}48 \\
(88.80)\end{array}$} \\
\hline & & & $258(89.20-89.10)$ & $\begin{array}{l}1 \text { glass; } 25 \text { lithics; } \\
4 \text { ceramics }\end{array}$ & 1 ceramic & \\
\hline & & & $259(89.10-89.00)$ & $\begin{array}{l}33 \text { lithics; } 1 \text { ceramic; } \\
6 \text { bone frags. }\end{array}$ & 1 ceramic; 1 bone & \\
\hline & & & $260(89.00-88.90)$ & $\begin{array}{l}20 \text { lithics; } 1 \text { FCR(?); } \\
1 \text { ceramic; charcoal }\end{array}$ & 0 & \\
\hline & & & $261(88.90-88.80)$ & $\begin{array}{l}26 \text { lithics; } 2 \text { FCR(?); } \\
1 \text { ceramic; charcoal }\end{array}$ & 0 & \\
\hline & & & $262(88.80-88.70)$ & $\begin{array}{l}3 \text { lithics; } 1 \text { ceramic; } \\
\text { charcoal }\end{array}$ & $\begin{array}{l}1 \text { petrified wood; } \\
1 \text { cobble }\end{array}$ & \\
\hline & & & $263(88.70-88.60)$ & $\begin{array}{c}0 \\
\end{array}$ & $\begin{array}{r}0 \\
\end{array}$ & \\
\hline \multirow[t]{9}{*}{ NN51-14 } & \multirow[t]{9}{*}{$\begin{array}{l}\text { N } 0977 \\
\text { E } 1098\end{array}$} & \multirow[t]{9}{*}{$\begin{array}{c}99 \\
(88.49)\end{array}$} & $\begin{array}{c}255-256 \\
(89.50-89.30) \\
\end{array}$ & $>50$ glass; 12 lithics & 0 & \multirow[t]{9}{*}{$\begin{array}{c}78 \\
(88.70)\end{array}$} \\
\hline & & & $257(89.30-89.20)$ & $\begin{array}{l}10 \text { glass; } 22 \text { lithics; } \\
1 \text { ceramic; } 2 \text { bone frags }\end{array}$ & 1 ceramic & \\
\hline & & & $258(89.20-89.10)$ & $\begin{array}{l}1 \text { glass; } 5 \text { bone frags.; } \\
3 \text { burned nutshells }\end{array}$ & 0 & \\
\hline & & & $259(89.10-89.00)$ & $\begin{array}{l}1 \text { glass; } 12 \text { lithics; } \\
1 \text { ceramic; } 3 \text { bone frags; } \\
2 \text { burned nutshells }\end{array}$ & 0 & \\
\hline & & & $260(89.00-88.90)$ & $\begin{array}{l}15 \text { lithics; } 1 \text { ceramic; } \\
2 \text { bone frags. }\end{array}$ & 2 lithics & \\
\hline & & & $26188.90-88.80)$ & $\begin{array}{l}16 \text { lithics; } 5 \text { burned } \\
\text { nutshells }\end{array}$ & 0 & \\
\hline & & & $262(88.80-88.70)$ & $\begin{array}{l}16 \text { lithics; } 2 \text { burned } \\
\text { nutshells }\end{array}$ & 1 core & \\
\hline & & & $263(88.70-88.60)$ & 6 lithics & 1 core & \\
\hline & & & $264(88.60-88.50)$ & $\begin{array}{l}5 \text { lithics; } 1 \text { bone frag.; } \\
\text { charcoal }\end{array}$ & 0 & \\
\hline
\end{tabular}


Table J-1 . Continued...

\begin{tabular}{|c|c|c|c|c|c|c|}
\hline $\begin{array}{c}\text { Block \& } \\
\text { Unit }\end{array}$ & $\begin{array}{l}\text { Northing } \\
\text { and } \\
\text { Easting }\end{array}$ & $\begin{array}{c}\text { maximum } \\
\text { depth } \\
\text { (cmbs) }\end{array}$ & Levels \# (m*) & $\begin{array}{l}\text { screen artifacts } \\
\quad(\# \& \text { kind })\end{array}$ & $\begin{array}{l}\text { piece plotted artifacts } \\
\text { (\# \& kind) }\end{array}$ & $\begin{array}{l}\text { depth of } \\
\text { Bt soil } \\
\text { (cmbs) }\end{array}$ \\
\hline \multirow[t]{7}{*}{ NN51-15 } & \multirow[t]{7}{*}{$\begin{array}{l}\text { N } 0977 \\
\text { E } 1099\end{array}$} & \multirow[t]{7}{*}{$\begin{array}{c}70 \\
(88.73)\end{array}$} & $256(89.40-89.30)$ & $\begin{array}{l}2 \text { glass; } 1 \text { aluminum foil; } \\
3 \text { lithics }\end{array}$ & 0 & \multirow[t]{7}{*}{$\begin{array}{c}63 \\
(88.80)\end{array}$} \\
\hline & & & $257(89.30-89.20)$ & $\begin{array}{l}2 \text { concrete frags; } 1 \text { proj. } \\
\text { point frag.; } 12 \text { lithics; } \\
2 \text { ceramics }\end{array}$ & 0 & \\
\hline & & & $258(89.20-89.10)$ & $\begin{array}{l}25 \text { lithics; } 1 \text { sandstone; } \\
6 \text { bone frags.; } 1 \text { burned } \\
\text { nutshell }\end{array}$ & 0 & \\
\hline & & & $259(89.10-89.00)$ & $\begin{array}{l}25 \text { lithics; } 1 \text { ceramic; } \\
8 \text { bone frags.; } 10 \text { burned } \\
\text { nutshells }\end{array}$ & 0 & \\
\hline & & & $260(89.00-88.90)$ & $\begin{array}{l}17 \text { lithics; } 1 \text { ceramic; } \\
7 \text { bone frags.; } 4 \text { burned } \\
\text { nutshells }\end{array}$ & 1 lithic & \\
\hline & & & $26188.90-88.80)$ & $\begin{array}{l}4 \text { lithics; } 1 \text { ceramic; } \\
2 \text { burned nutshells }\end{array}$ & 0 & \\
\hline & & & $262(88.80-88.70)$ & \begin{tabular}{|c|}
0 \\
\end{tabular} & 0 & \\
\hline \multirow[t]{7}{*}{ OO51-11 } & \multirow{7}{*}{$\begin{array}{l}\text { N } 0977 \\
\text { E } 1100\end{array}$} & \multirow{7}{*}{$\begin{array}{c}75 \\
(88.60)\end{array}$} & $257(89.30-89.20)$ & 10 lithics & 0 & \multirow{7}{*}{$\begin{array}{c}65 \\
(88.70)\end{array}$} \\
\hline & & & $258(89.20-89.10)$ & $\begin{array}{l}25 \text { lithics; } 8 \text { ceramics; } \\
3 \text { bone frags. }\end{array}$ & 0 & \\
\hline & & & $259(89.10-89.00)$ & $\begin{array}{l}20 \text { lithics; } 1 \text { FCR(?); } \\
2 \text { ceramics; } 1 \text { bone } \\
\end{array}$ & 0 & \\
\hline & & & $260(89.00-88.90)$ & $\begin{array}{l}1 \text { hammerstone; } 1 \text { biface } \\
\text { frag.; } 24 \text { lithics; } 5 \text { bone } \\
\text { frags. }\end{array}$ & 0 & \\
\hline & & & $261(88.90-88.80)$ & $\begin{array}{l}1 \text { biface; } 18 \text { lithics; } \\
4 \text { ceramics }\end{array}$ & 0 & \\
\hline & & & $262(88.80-88.70)$ & $\begin{array}{c}0 \\
\end{array}$ & 0 & \\
\hline & & & $263(88.70-88.60)$ & 0 & 0 & \\
\hline
\end{tabular}




\section{Appendix K}

\section{Excavation Data: Block PP/QQ}


Table K-1. Excavation data, Block PP/QQ

\begin{tabular}{|c|c|c|c|c|c|c|}
\hline $\begin{array}{l}\text { Block \& } \\
\text { Unit }\end{array}$ & $\begin{array}{l}\text { Northing } \\
\text { and } \\
\text { Easting }\end{array}$ & $\begin{array}{c}\text { maximum } \\
\text { depth } \\
(\mathrm{cmbs}) \\
\end{array}$ & Levels \# (m*) & $\begin{array}{l}\text { screen artifacts } \\
\quad(\# \& \text { kind })\end{array}$ & $\begin{array}{l}\text { piece plotted artifacts } \\
\text { (\# \& kind) }\end{array}$ & $\begin{array}{l}\text { depth of Bt } \\
\text { soil (cmbs) }\end{array}$ \\
\hline \multirow[t]{13}{*}{ PP49-5 } & \multirow[t]{13}{*}{$\begin{array}{l}\text { N } 0989 \\
\text { E } 1109\end{array}$} & \multirow[t]{13}{*}{$\begin{array}{c}152 \\
(88.28)\end{array}$} & $254(89.60-89.50)$ & $\begin{array}{l}\text { misc modern; } \\
1 \text { lithic; } 5 \text { bone }\end{array}$ & 0 & \multirow[t]{13}{*}{$\begin{array}{c}150 \\
(88.30)\end{array}$} \\
\hline & & & $255(89.50-89.40)$ & $\begin{array}{l}\text { misc modern; } 2 \text { proj } \\
\text { points; } 1 \text { biface tip; } \\
51 \text { lithics; } 1 \text { FCR(?); } \\
2 \text { ceramics; } 11 \text { bone } \\
\text { frags. }\end{array}$ & 0 & \\
\hline & & & $256(89.40-89.30)$ & $\begin{array}{l}36 \text { lithics; } \\
8 \text { ceramics; } \\
22 \text { bone frags. }\end{array}$ & 0 & \\
\hline & & & $257(89.30-89.20)$ & $\begin{array}{l}30 \text { lithics; } 2 \text { FCR(?); } \\
13 \text { bone frags. }\end{array}$ & 0 & \\
\hline & & & $258(89.20-89.10)$ & $\begin{array}{l}28 \text { lithics; } \\
2 \text { ceramics; } 9 \text { bone } \\
\text { frags.; charcoal }\end{array}$ & 2 charcoal samples & \\
\hline & & & $259(89.10-89.00)$ & $\begin{array}{l}1 \text { concrete frag.; } \\
43 \text { lithics; } 4 \text { FCR(?); } \\
2 \text { ceramics; } 20 \text { bone } \\
\text { frags.; } 14 \text { burned } \\
\text { nutshell; charcoal }\end{array}$ & $\begin{array}{l}3 \text { ceramics; } 3 \text { bone } \\
\text { frags. }\end{array}$ & \\
\hline & & & $260(89.00-88.90)$ & $\begin{array}{l}1 \text { proj point } 1 \text { core; } 28 \\
\text { lithics; } 1 \text { petrified } \\
\text { wood; } 3 \text { FCR(?); } \\
2 \text { ceramics; } 10 \text { bone } \\
\text { frags.; charcoal }\end{array}$ & 0 & \\
\hline & & & $261(88.90-88.80)$ & $\begin{array}{l}52 \text { lithics; } \\
8 \text { ceramics; } 19 \text { bone } \\
\text { frags.; charcoal }\end{array}$ & $\begin{array}{l}1 \text { proj point; } 1 \text { lithic; } \\
1 \text { petrified wood; } \\
1 \text { charcoal sample } \\
\end{array}$ & \\
\hline & & & $262(88.80-88.70)$ & $\begin{array}{l}26 \text { lithics; } 1 \text { petrified } \\
\text { wood; } 5 \text { ceramics; } \\
9 \text { bone frags.; } \\
\text { charcoal }\end{array}$ & 0 & \\
\hline & & & $263988.70-88.60)$ & $\begin{array}{l}1 \text { aluminum; } \\
32 \text { lithics; } \\
3 \text { ceramics; } 6 \text { bone } \\
\text { frags.; charcoal }\end{array}$ & 0 & \\
\hline & & & $264(88.60-88.50)$ & $\begin{array}{l}1 \text { proj point; } \\
1 \text { flake; } 1 \text { bone; } \\
\text { charcoal }\end{array}$ & 0 & \\
\hline & & & $265(88.50-88.40)$ & $\begin{array}{l}12 \text { lithics; } 1 \text { bone; } \\
\text { charcoal }\end{array}$ & 0 & \\
\hline & & & $266(88.40-88.30)$ & 8 lithics; charcoal & 0 & \\
\hline
\end{tabular}

*all levels are referenced to survey datum on site - established as arbitrary $100.00 \mathrm{~m}$ elevation 
Table K-1. Continued...

\begin{tabular}{|c|c|c|c|c|c|c|}
\hline $\begin{array}{c}\text { Block \& } \\
\text { Unit }\end{array}$ & $\begin{array}{l}\begin{array}{c}\text { Northing } \\
\text { and } \\
\text { Easting }\end{array} \\
\end{array}$ & $\begin{array}{c}\text { maximum } \\
\text { depth } \\
(\mathrm{cmbs})\end{array}$ & Levels \# (m*) & $\begin{array}{l}\text { screen artifacts } \\
\quad \text { (\# \& kind) }\end{array}$ & $\begin{array}{l}\text { piece plotted artifacts } \\
\text { (\# \& kind) }\end{array}$ & $\begin{array}{l}\text { depth of } \\
\text { Bt soil } \\
\text { (cmbs) }\end{array}$ \\
\hline \multirow[t]{10}{*}{ QQ49-1 } & \multirow[t]{10}{*}{$\begin{array}{l}\text { N } 0989 \\
\text { E } 1110\end{array}$} & \multirow[t]{10}{*}{$\begin{array}{c}130 \\
(88.50)\end{array}$} & $255(89.50-89.40)$ & $\begin{array}{l}\text { misc modern; } \\
6 \text { lithics; } 1 \text { ceramic; } \\
\text { charcoal }\end{array}$ & 1 proj point & \multirow[t]{10}{*}{$* * \mathrm{NC}$} \\
\hline & & & $256(89.40-89.30)$ & $\begin{array}{l}4 \text { misc modern; } \\
52 \text { lithics; } \\
4 \text { ceramics; } \\
14 \text { bone frags. }\end{array}$ & $1 \mathrm{FCR}$ & \\
\hline & & & $257(89.30-89.20)$ & $\begin{array}{l}25 \text { lithics; } \\
3 \text { ceramics; } 4 \text { bone } \\
\text { frags. }\end{array}$ & 0 & \\
\hline & & & $258(89.20-89.10)$ & $\begin{array}{l}41 \text { lithics; } \\
2 \text { ceramics; } 24 \text { bone } \\
\text { frags.; charcoal }\end{array}$ & 1 bone & \\
\hline & & & $259(89.10-89.00)$ & $\begin{array}{l}38 \text { lithics; } \\
6 \text { ceramics; } \\
19 \text { bone frags. }\end{array}$ & $\begin{array}{l}2 \text { lithics; } 1 \text { ceramic; } \\
1 \text { bone }\end{array}$ & \\
\hline & & & $260(89.00-88.90)$ & $\begin{array}{l}1 \text { proj point; } \\
45 \text { lithics; } \\
4 \text { ceramics; } 20 \text { bone } \\
\text { frags.; } 2 \text { possible } \\
\text { daub; charcoal }\end{array}$ & $\begin{array}{l}1 \text { lithic; } 1 \text { ceramic; } \\
5 \text { bone frags.; } \\
2 \text { charcoal samples }\end{array}$ & \\
\hline & & & $261(88.90-88.80)$ & $\begin{array}{l}1 \text { concrete frag; } \\
29 \text { lithics; } \\
2 \text { ceramics; } \\
3 \text { bone frags. }\end{array}$ & $\begin{array}{l}1 \text { proj point; } 2 \text { lithics; } \\
1 \text { petrified wood; } \\
2 \text { ceramics; } 1 \text { bone } \\
\text { frag.; } 1 \text { charcoal sample }\end{array}$ & \\
\hline & & & $262(88.80-88.70)$ & $\begin{array}{l}1 \text { proj point; } \\
42 \text { lithics }\end{array}$ & 1 ceramic & \\
\hline & & & $263(88.70-88.60)$ & $\begin{array}{l}17 \text { lithics; } 1 \text { ceramic; } \\
4 \text { bone frags.; charcoal }\end{array}$ & 1 bone & \\
\hline & & & $264(88.60-88.50)$ & 1 bone & 2 lithics & \\
\hline
\end{tabular}

*all levels are referenced to survey datum on site - established as arbitrary $100.00 \mathrm{~m}$ elevation

** NC = no contact with Bt soil 
Table K-1. Continued...

\begin{tabular}{|c|c|c|c|c|c|c|}
\hline $\begin{array}{l}\text { Block \& } \\
\text { Unit }\end{array}$ & $\begin{array}{l}\text { Northing } \\
\text { and } \\
\text { Easting }\end{array}$ & $\begin{array}{c}\text { maximum } \\
\text { depth } \\
(\text { cmbs }) \\
\end{array}$ & Levels \# (m*) & $\begin{array}{l}\text { screen artifacts } \\
\quad(\# \& \text { kind })\end{array}$ & $\begin{array}{l}\text { piece plotted artifacts } \\
\text { (\# \& kind) }\end{array}$ & $\begin{array}{l}\text { depth of Bt } \\
\text { soil (cmbs) }\end{array}$ \\
\hline \multirow[t]{18}{*}{ QQ49-2 } & \multirow[t]{18}{*}{$\begin{array}{l}\text { N } 0989 \\
\text { E } 1111\end{array}$} & \multirow[t]{18}{*}{$\begin{array}{c}206 \\
(87.704)\end{array}$} & $255(89.50-89.40)$ & misc modern & 0 & \multirow[t]{18}{*}{$\begin{array}{c}201 \\
(87.79)\end{array}$} \\
\hline & & & $256(89.40-89.30)$ & $\begin{array}{l}1 \text { metal can; } 1 \text { pull } \\
\text { tab; } 13 \text { lithics; } \\
1 \text { ceramic; } 3 \text { bone } \\
\text { frags. }\end{array}$ & 1 ceramic & \\
\hline & & & $257(89.30-89.20)$ & $\begin{array}{l}26 \text { lithics; } \\
10 \text { bone frags. }\end{array}$ & 0 & \\
\hline & & & $258(89.20-89.10)$ & $\begin{array}{l}1 \text { proj point; } 1 \text { proj pt } \\
\text { frag; } 40 \text { lithics; } \\
3 \text { ceramics; } 13 \text { bone } \\
\text { frags. }\end{array}$ & $\begin{array}{l}1 \text { proj point; } \\
2 \text { ceramics }\end{array}$ & \\
\hline & & & $259(89.10-89.00)$ & $\begin{array}{l}1 \text { proj point; } \\
21 \text { lithics; } 1 \text { FCR(?); } \\
5 \text { bone frags. }\end{array}$ & 0 & \\
\hline & & & $260(89.00-88.90)$ & $\begin{array}{l}36 \text { lithics; } \\
3 \text { ceramics; } \\
1 \text { bone frag. }\end{array}$ & 0 & \\
\hline & & & $261(88.90-88.80)$ & $\begin{array}{l}38 \text { lithics; } 1 \text { FCR(?); } \\
1 \text { ceramic; } 1 \text { bone } \\
\text { frag.; charcoal }\end{array}$ & 0 & \\
\hline & & & $262(88.80-88.70)$ & $\begin{array}{l}9 \text { lithics; } 1 \text { ceramic; } \\
4 \text { bone frags. }\end{array}$ & 0 & \\
\hline & & & $263(88.70-88.60)$ & $\begin{array}{l}1 \text { biface; } 35 \text { lithics; } \\
2 \text { ceramics; } 4 \text { bone } \\
\text { frags.; charcoal }\end{array}$ & 0 & \\
\hline & & & $264(88.60-88.50)$ & $\begin{array}{l}1 \text { biface; } 29 \text { lithics; } \\
3 \text { ceramics; charcoal }\end{array}$ & 0 & \\
\hline & & & $265(88.50-88.40)$ & $\begin{array}{l}15 \text { lithics; } \\
4 \text { ceramics; } 5 \text { bone } \\
\text { frags; possible daub; } \\
\text { charcoal }\end{array}$ & 1 ceramic & \\
\hline & & & $266(88.40-88.30)$ & $\begin{array}{l}15 \text { lithics; } \\
2 \text { ceramics; } 1 \text { bone } \\
\text { frag.; charcoal }\end{array}$ & 0 & \\
\hline & & & $267(88.30-88.20)$ & $\begin{array}{l}4 \text { lithics; } 1 \text { ceramic; } \\
1 \text { possible daub; } \\
\text { charcoal }\end{array}$ & 0 & \\
\hline & & & $268(88.20-88.10)$ & 6 lithics & 0 & \\
\hline & & & $269(88.10-88.00)$ & 14 lithics; charcoal & 0 & \\
\hline & & & $270(88.00-87.90)$ & 19 lithics; charcoal & 1 biface tip & \\
\hline & & & $271(87.90-87.80)$ & $\begin{array}{l}25 \text { lithics; } 2 \text { FCR(?); } \\
\text { charcoal }\end{array}$ & 0 & \\
\hline & & & $272(87.80-87.70)$ & 21 lithics & 0 & \\
\hline
\end{tabular}

*all levels are referenced to survey datum on site - established as arbitrary $100.00 \mathrm{~m}$ elevation 
Table K-1. Continued...

\begin{tabular}{|c|c|c|c|c|c|c|}
\hline $\begin{array}{c}\text { Block \& } \\
\text { Unit }\end{array}$ & $\begin{array}{l}\text { Northing } \\
\text { and } \\
\text { Easting } \\
\end{array}$ & $\begin{array}{c}\text { maximum } \\
\text { depth } \\
(\text { cmbs }) \\
\end{array}$ & Levels \# (m*) & $\begin{array}{l}\text { screen artifacts } \\
\quad(\# \& \text { kind })\end{array}$ & $\begin{array}{c}\text { piece plotted artifacts } \\
\text { (\# \& kind) }\end{array}$ & $\begin{array}{l}\text { depth of Bt } \\
\text { soil (cmbs) }\end{array}$ \\
\hline \multirow[t]{10}{*}{ QQ48-22 } & \multirow[t]{10}{*}{$\begin{array}{l}\text { N } 0990 \\
\text { E } 1111\end{array}$} & \multirow[t]{10}{*}{$\begin{array}{c}140 \\
(88.40)\end{array}$} & $\begin{array}{c}255-256 \\
(89.50-89.30)\end{array}$ & $\begin{array}{l}\text { misc modern; } \\
20 \text { lithics; } 1 \text { FCR(?) } \\
3 \text { ceramics; } 1 \text { bone } \\
\end{array}$ & 0 & \multirow[t]{10}{*}{$* * \mathrm{NC}$} \\
\hline & & & $257(89.30-89.20)$ & $\begin{array}{l}1 \text { proj point frag.; } \\
28 \text { lithics; } 1 \text { ceramic }\end{array}$ & 0 & \\
\hline & & & $258(89.20-89.10)$ & $\begin{array}{l}24 \text { lithics; } 1 \text { bone; } \\
\text { charcoal }\end{array}$ & 0 & \\
\hline & & & $259(89.10-89.00)$ & $\begin{array}{l}15 \text { lithics; } 2 \text { ceramics; } \\
1 \text { bone frag.; charcoal }\end{array}$ & 0 & \\
\hline & & & $260(89.00-88.90)$ & $\begin{array}{l}18 \text { lithics; } 2 \text { ceramics; } \\
1 \text { bone }\end{array}$ & 0 & \\
\hline & & & $261(88.90-88.80)$ & $\begin{array}{l}20 \text { lithics; } 3 \text { ceramics; } \\
4 \text { bone frags.; charcoal } \\
\end{array}$ & 0 & \\
\hline & & & $262(88.80-88.70)$ & $\begin{array}{l}8 \text { lithics; } 15 \text { FCR(?); } \\
7 \text { ceramics; } 3 \text { bone } \\
\text { frags.; charcoal }\end{array}$ & $\begin{array}{l}1 \text { proj point; } 1 \text { bone } \\
\text { frag.; } 1 \text { charcoal } \\
\text { sample }\end{array}$ & \\
\hline & & & $263(88.70-88.60)$ & $\begin{array}{l}55 \text { lithics; } 6 \text { ceramics; } \\
6 \text { bone frags.; charcoal } \\
\end{array}$ & 0 & \\
\hline & & & $264(88.60-88.50)$ & $\begin{array}{l}20 \text { lithics; } 5 \text { ceramics; } \\
3 \text { bone frags }\end{array}$ & 0 & \\
\hline & & & $265(88.50-88.40)$ & \begin{tabular}{|c|}
0 \\
\end{tabular} & 0 & \\
\hline \multirow[t]{18}{*}{ QQ48-19 } & \multirow[t]{18}{*}{$\begin{array}{l}\text { N } 0991 \\
\text { E } 1111\end{array}$} & \multirow[t]{18}{*}{$\begin{array}{c}120 \\
(87.60)\end{array}$} & $\begin{array}{c}255-256 \\
(89.50-89.30)\end{array}$ & $\begin{array}{l}\text { misc modern; } 1 \text { proj } \\
\text { point; } 25 \text { lithics; } \\
\text { 2 FCR(?) } \\
\end{array}$ & 0 & \multirow[t]{18}{*}{$\begin{array}{c}111 \\
(87.69)\end{array}$} \\
\hline & & & $257(89.30-89.20)$ & $\begin{array}{l}1 \text { plastic cup; } \\
45 \text { lithics; } 4 \text { ceramics; } \\
1 \text { bone }\end{array}$ & 0 & \\
\hline & & & $258(89.20-89.10)$ & $\begin{array}{l}25 \text { lithics; } 1 \text { ceramic; } \\
4 \text { bone frags. } \\
\end{array}$ & 0 & \\
\hline & & & $259(89.10-89.00)$ & \begin{tabular}{|l|}
31 lithics; 1 tested \\
cobble; 2 ceramics; \\
14 bone frags. \\
\end{tabular} & 0 & \\
\hline & & & $260(89.00-88.90)$ & $\begin{array}{l}39 \text { lithics; } 4 \text { ceramics; } \\
7 \text { bone frags. }\end{array}$ & 1 proj point & \\
\hline & & & $261(88.90-88.80)$ & $\begin{array}{l}2 \text { lithics; } 2 \text { ceramics; } \\
1 \text { bone; charcoal } \\
\end{array}$ & 0 & \\
\hline & & & $262(88.80-88.70)$ & $\begin{array}{l}18 \text { lithics; } 6 \text { ceramics; } \\
1 \text { bone frag. }\end{array}$ & 0 & \\
\hline & & & $263(88.70-88.60)$ & $\begin{array}{l}44 \text { lithics; } 2 \text { ceramics; } \\
15 \text { bone frags; charcoal }\end{array}$ & 0 & \\
\hline & & & $26498.60-88.50)$ & $\begin{array}{l}34 \text { lithics; } 6 \text { ceramics; } \\
4 \text { bone frags. }\end{array}$ & 0 & \\
\hline & & & $265(88.50-88.40)$ & $\begin{array}{l}31 \text { lithics; } 1 \text { ceramic; } \\
4 \text { bone frags. }\end{array}$ & $\begin{array}{l}1 \text { lithic; } 1 \text { petrified } \\
\text { wood; } 1 \text { rock; } 1 \text { bone }\end{array}$ & \\
\hline & & & $266(88.40-88.30)$ & $\begin{array}{l}27 \text { lithics; } 1 \text { ceramic; } \\
17 \text { bone frags. }\end{array}$ & $\begin{array}{l}2 \text { bone; } 2 \text { charcoal } \\
\text { samples }\end{array}$ & \\
\hline & & & $267(88.30-88.20)$ & $\begin{array}{l}15 \text { flakes; } 1 \text { bone frag.; } \\
\text { charcoal }\end{array}$ & 0 & \\
\hline & & & $268(88.20-88.10)$ & 8 lithics; 1 bone & 3 lithics; 1 rock & \\
\hline & & & $269(88.10-88.00)$ & $\begin{array}{l}1 \text { proj point; } 25 \text { lithics; } \\
1 \text { ceramic; } 3 \text { bone } \\
\text { frags.; } 1 \text { possible daub }\end{array}$ & 1 core; 1 ceramic & \\
\hline & & & $270(88.00-87.90)$ & 9 lithics & 0 & \\
\hline & & & $271(87.90-87.80)$ & $\begin{array}{l}12 \text { lithics; } 2 \text { bone } \\
\text { frags.; charcoal }\end{array}$ & 0 & \\
\hline & & & $272(87.80-87.70)$ & 1 lithic & 0 & \\
\hline & & & $273(87.70-87.60)$ & 11 lithics; charcoal & 1 petrified wood & \\
\hline
\end{tabular}

*all levels are referenced to survey datum on site - established as arbitrary $100.00 \mathrm{~m}$ elevation

** NC $=$ no contact with Bt soil 
Table K-1. Continued...

\begin{tabular}{|c|c|c|c|c|c|c|}
\hline $\begin{array}{c}\text { Block \& } \\
\text { Unit }\end{array}$ & $\begin{array}{l}\text { Northing } \\
\text { and } \\
\text { Easting }\end{array}$ & $\begin{array}{c}\text { maximum } \\
\text { depth } \\
\text { (cmbs) }\end{array}$ & Levels \# (m*) & $\begin{array}{l}\text { screen artifacts } \\
\quad(\# \& \text { kind })\end{array}$ & $\begin{array}{l}\text { piece plotted artifacts } \\
\text { (\# \& kind) }\end{array}$ & $\begin{array}{l}\text { depth of } \\
\text { Bt soil } \\
\text { (cmbs) }\end{array}$ \\
\hline \multirow[t]{14}{*}{ QQ48-12 } & \multirow[t]{14}{*}{$\begin{array}{l}\text { N } 0992 \\
\text { E } 1111\end{array}$} & \multirow[t]{14}{*}{$\begin{array}{c}176 \\
(88.04)\end{array}$} & $256(89.40-89.30)$ & $\begin{array}{l}\text { misc modern; } \\
1 \text { biface frag; } \\
21 \text { lithics; } \\
1 \text { ceramic; } 1 \text { bone }\end{array}$ & 0 & \multirow[t]{14}{*}{$\begin{array}{c}173 \\
(88.070\end{array}$} \\
\hline & & & $257(89.30-89.20)$ & $\begin{array}{l}2 \text { proj points; } \\
28 \text { lithics }\end{array}$ & 0 & \\
\hline & & & $258(89.20-89.10)$ & $\begin{array}{l}48 \text { lithics; } \\
3 \text { ceramics; } \\
2 \text { bone frags. }\end{array}$ & 0 & \\
\hline & & & $259(89.10-89.00)$ & $\begin{array}{l}5 \text { ceramics; } \\
2 \text { bone frags. }\end{array}$ & 0 & \\
\hline & & & $260(89.00-88.90)$ & $\begin{array}{l}22 \text { lithics; } 3 \text { FCR(?); } \\
7 \text { ceramics; } 11 \text { bone } \\
\text { frags.: charcoal }\end{array}$ & 2 ceramics & \\
\hline & & & $261(88.90-88.80)$ & 1+lithics; ceramics & 1 ceramic & \\
\hline & & & $262(88.80-88.70)$ & $\begin{array}{l}24 \text { lithics; } \\
9 \text { ceramics; } \\
8 \text { bone frags. }\end{array}$ & $\begin{array}{l}1 \text { proj point; } 1 \text { proj } \\
\text { point frag.; } 1 \text { core frag; } \\
1 \text { petrified wood; } \\
2 \text { ceramics } \\
\end{array}$ & \\
\hline & & & $263(88.70-88.60)$ & $\begin{array}{l}1 \text { proj point; } 45 \text { lithics; } \\
7 \text { ceramics }\end{array}$ & 2 ceramics & \\
\hline & & & $264(88.60-88.50)$ & 42 lithics; 7 ceramics & 1 charcoal sample & \\
\hline & & & $265(88.50-88.40)$ & $\begin{array}{l}1 \text { proj point; } 3 \text { lithics; } \\
7 \text { ceramics; } 9 \text { bone } \\
\text { frags. }\end{array}$ & 4 lithics; 6 ceramics & \\
\hline & & & $266(88.40-88.30)$ & $\begin{array}{l}1 \text { proj point frag.; } \\
42 \text { lithics; } 5 \text { ceramics; } \\
3 \text { bone frags. }\end{array}$ & $\begin{array}{l}3 \text { lithics; } 3 \text { iron } \\
\text { concretions; } \\
1 \text { ceramic; } 2 \text { bone } \\
\text { frags.; } 1 \text { burned } \\
\text { nutshell; } 1 \text { charcoal } \\
\text { sample } \\
\end{array}$ & \\
\hline & & & $267(88.30-88.20)$ & 31 lithics; 1 ceramic & 2 lithics & \\
\hline & & & $268(88.20-88.10)$ & 18 lithics; 1 bone & 0 & \\
\hline & & & $269(88.10-88.00)$ & 1 lithic & 0 & \\
\hline
\end{tabular}

*all levels are referenced to survey datum on site - established as arbitrary $100.00 \mathrm{~m}$ elevation 